University of Louisville

ThinkIR: The University of Louisville's Institutional Repository

Electronic Theses and Dissertations

$12-2018$

\title{
Characterization of microreactor and analysis of carbonyl compounds in exhaled breath.
}

Qi Li

University of Louisville

Follow this and additional works at: https://ir.library.louisville.edu/etd

Part of the Chemical Engineering Commons

\section{Recommended Citation}

$\mathrm{Li}, \mathrm{Qi}$, "Characterization of microreactor and analysis of carbonyl compounds in exhaled breath." (2018). Electronic Theses and Dissertations. Paper 3088.

https://doi.org/10.18297/etd/3088

This Doctoral Dissertation is brought to you for free and open access by ThinkIR: The University of Louisville's Institutional Repository. It has been accepted for inclusion in Electronic Theses and Dissertations by an authorized administrator of ThinkIR: The University of Louisville's Institutional Repository. This title appears here courtesy of the author, who has retained all other copyrights. For more information, please contact thinkir@louisville.edu. 
CHARACTERIZATION OF MICROREACTOR AND ANALYSIS OF CARBONYL COMPOUNDS IN EXHALED BREATH

\author{
By \\ Qi Li \\ B.E., Tianjin University of Science \& Technology, 2013
}

\author{
A Dissertation \\ Submitted to the Faculty of the J. B. Speed School of Engineering \\ University of Louisville \\ in Partial Fulfillment of the Requirements \\ for the Degree of
}

Doctor of Philosophy in Chemical Engineering

\author{
Department of Chemical Engineering \\ University of Louisville \\ Louisville, KY
}

December 2018 



\title{
CHARACTERIZATION OF MICROREACTOR AND ANALYSIS OF CARBONYL COMPOUNDS IN EXHALED BREATH
}

\author{
By \\ Qi Li \\ B.E., Tianjin University of Science \& Technology, 2013
}

A Dissertation Approved On

November 19, 2018

by the Following Dissertation Committee:

Xiao-An Fu, Ph. D., Dissertation Director

Michael H. Nantz, Ph. D.

Eric R. Berson, Ph. D.

Gerold A. Willing, Ph. D. 


\section{ACKNOWLEDGMENTS}

I am profoundly grateful for my advisor Prof. Xiao-An Fu for his guidance, support, and encouragement during the course of my PhD. I also would like to thank him for giving me the chance to work on these interesting projects.

Special thanks to Prof. Michael H. Nantz, Prof. Eric R. Berson, Prof. Gerold A.Willing for serving as members of my dissertation committee and for all the fruitful and valuable discussions we had about this research. Special thanks to Dr. Michael Bousamra at Floyd Memorial Hospital, and Dr. Victor van Berkel at the James Graham Brown Cancer Center for recruiting patients to provide exhaled breath samples and their clinical guidance.

I would like to thank Dr. Ramakrishnam Raju Mandapati and Tirtha Sibakoti for supply of synthesized high-purity organic compounds throughout my project.

I would like to thank Dr. Pawel Lorkiewicz at the Center for Regulatory and Environmental Analytical Metabolomics (CREAM) for training me on FT-ICR-MS.

My thanks also go to Dr. Fu's current and former members especially Dr. Xinhua Sun, Dr. Mingxiao Li, Dr. Zhenzhen Xie, Dr. Yizheng Chen and Dr. Mumiye Ogunwale for their help during our stay together. 
I would also like to thank all the members and staff of the Micro/Nano Technology Center Dr. Julia Aebersold, Mr. Don Yeager, Mr. Michael Martin, and Mr. Curtis McKenna at the University of Louisville for their knowledgeable experience in microfabrication and tremendous source of support.

I am very grateful for the financial support from the Department of Chemical Engineering, the Shen's Scholarship from Speed School of Engineering and the dissertation completion award from the Graduate School at the University of Louisville.

Finally, I would like to thank my parents for their encouragement and support, without which this dissertation and research would not have been possible. 


\title{
ABSTRACT \\ CHARACTERIZATION OF MICROREACTOR AND ANALYSIS OF CARBONYL COMPOUNDS IN EXHALED BREATH
}

\author{
Qi Li
}

November 19, 2018

Analysis of trace volatile organic compounds at parts per billion (ppbv) to parts per trillion (pptv) level has become an important research frontier because of the applicability for environmental monitoring and noninvasive diagnosis of diseases. The methods of preconcentration for detection of trace aldehydes and ketones both in ambient air and human exhaled breath have increased considerably over the last decade. However, the majority of these methods are not efficient.

In this dissertation, we have improved an innovative microreactor that is suitable for quantitative analysis of volatile carbonyl compounds (VOCs) in ambient air as well as in human exhaled breath. The approach is based on microreactor chips fabricated from four inch silicon wafers. The chips have thousands of micropillars in the microfluidic channels for uniformly distributing gaseous samples flowing through the microreactors. The surfaces of the micropillars are functionalized with a quaternary ammonium aminooxy salt 2-(aminooxy)-N,N,N-trimethylethanammonium (ATM) iodide for trapping trace ketones and aldehydes by means of oximation reactions. ATM adducts and unreacted ATM are 
eluted from the microreactor with methanol and directly analyzed by UHPLC-MS.

Design and characterization of the microreactors were first investigated. The reaction kinetics of the aminooxy reagent ATM with carbonyl were obtained. A reactor model was established to predicate the relationship between the capture efficiencies of carbonyl compounds and the microreactor length at a given gaseous sample flow rate. The microreactors were then used to study the stability of breath VOCs. VOCs, collected in Tedlar bags, were stable for about two hours with less than $5 \%$ of a concentration decrease. Storage of breath samples in a refrigerator reduces the concentration changes of VOCs. The analysis of exhaled breath samples of patients for early lung cancer screening program using the microreactor indicates that $\mathrm{C}_{3} \mathrm{H}_{6} \mathrm{O}, \mathrm{C}_{2} \mathrm{H}_{4} \mathrm{O}_{2}$ and $\mathrm{C}_{4} \mathrm{H}_{8} \mathrm{O}_{2}$ can serve as biomarkers to distinguish patients with pulmonary nodules from healthy controls. The analysis of exhaled breath samples of the lung cancer (LC) patients, patients with benign pulmonary nodules and healthy controls led to three VOCs (2-butanone, 3-hydroxy-2-butanone and 4hydroxy-2-nonenal (4-HNE)) as markers for distinguishing LC patients from patients with benign pulmonary nodules and healthy controls. 4-HNE can also be used to distinguish squamous cell carcinoma from adenocarcinoma LC. 


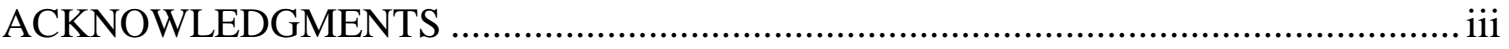

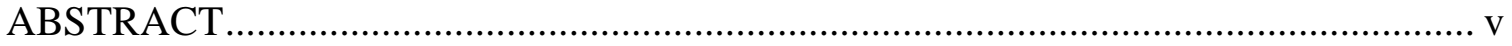

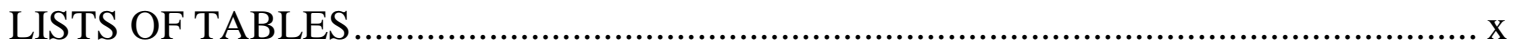

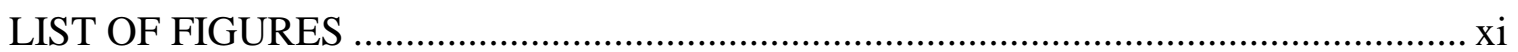

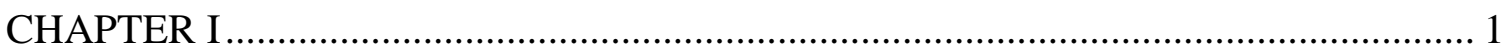

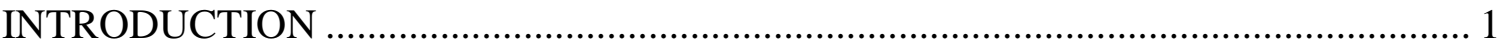

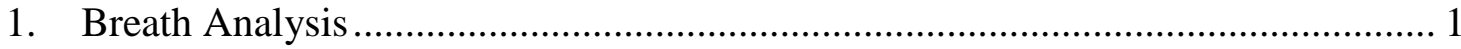

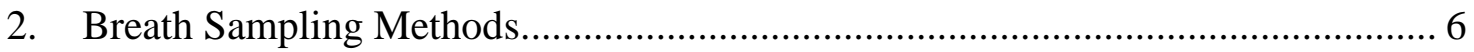

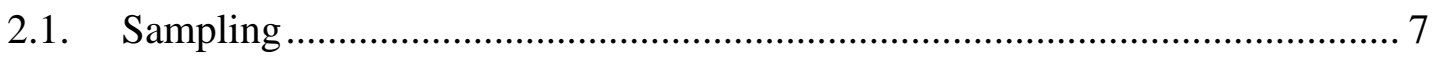

2.2. Metal containers-single breath canister (SBC) ...................................... 8

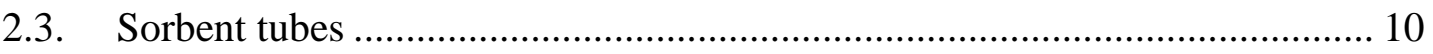

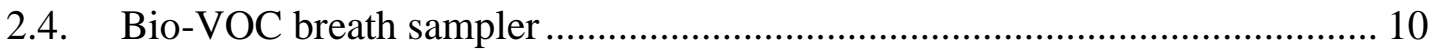

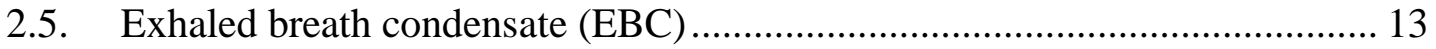

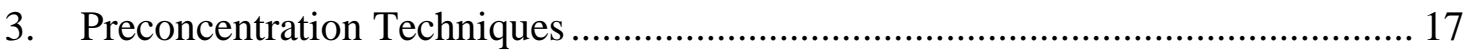

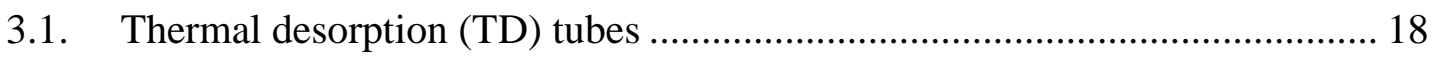

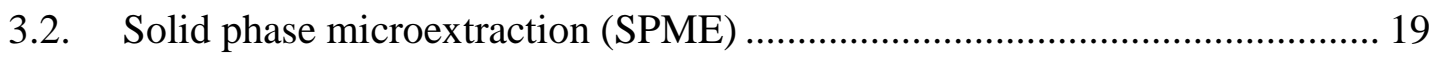

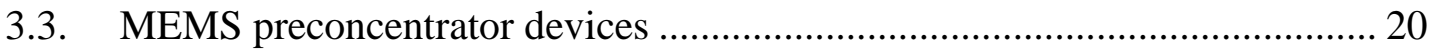



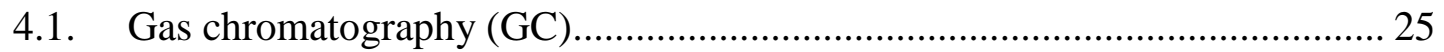

4.2. Selected ion flow tube mass spectrometry (SIFT-MS) .............................. 27

4.3. Proton transfer reaction mass spectrometry (PTR-MS) ............................... 28

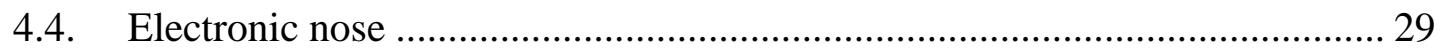

5. Lung Cancer Biomarkers In Exhaled Breath ................................................ 31

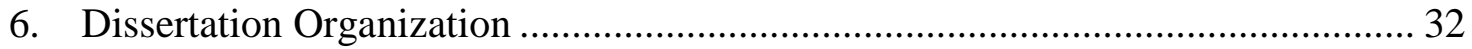

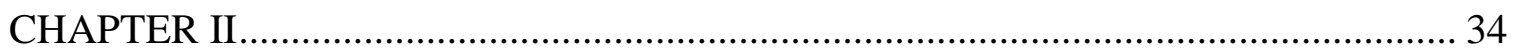

CHARACTERIZATION OF MICROREACTOR FOR BREATH ANALYSIS............ 34 


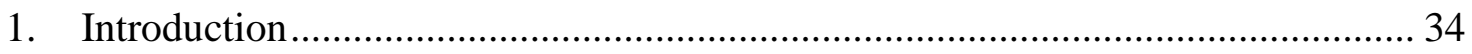

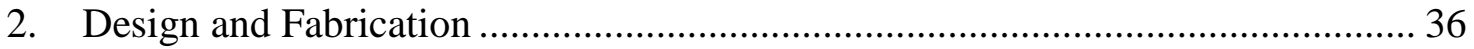

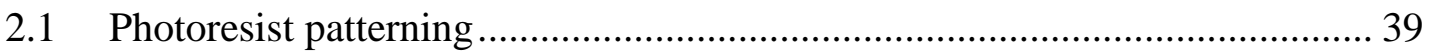

2.2 Silicon etching using deep reactive ion etching ............................................ 40

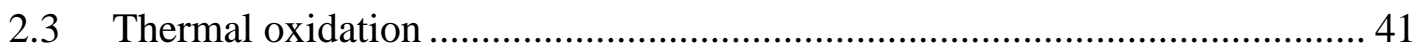

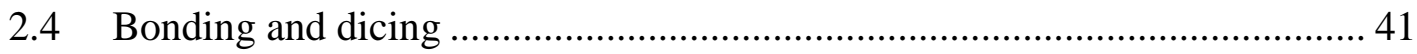

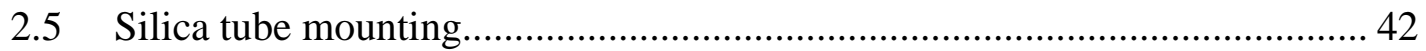

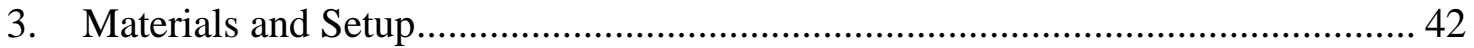

4. Results and Discussion ............................................................................... 45

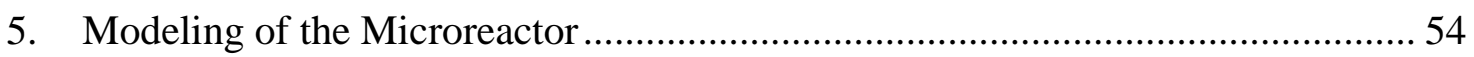

$5.1 \quad$ Kinetics study of oximation reaction in microreactor ..................................... 54

5.2 Modeling study of oximation reaction in microreactor.................................. 62

6. Human Breath Analysis With Different Length Microreactors............................... 71

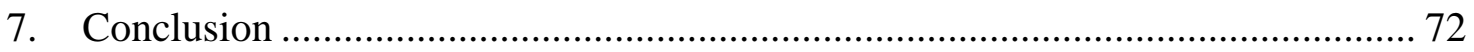

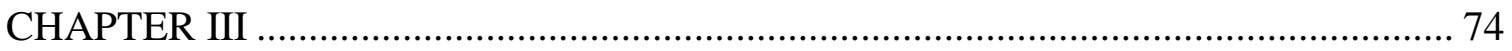

STABILITY OF BREATH VOLATILE ORGANIC COMPOUNDS IN TEDLAR BAGS 74

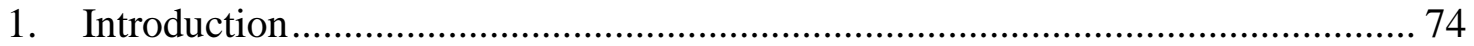

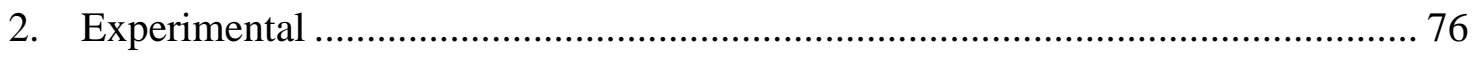

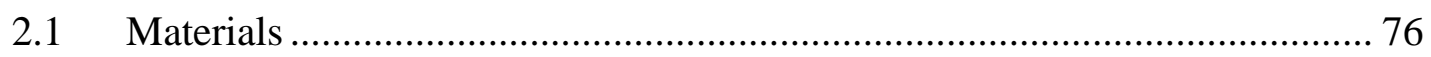

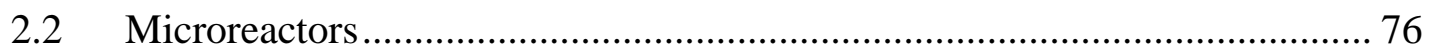

2.3 Collection and analysis of exhaled breath samples ..................................... 78

2.4 Ultra-high-performance liquid-chromatograph-mass spectrometry (UHPLC-

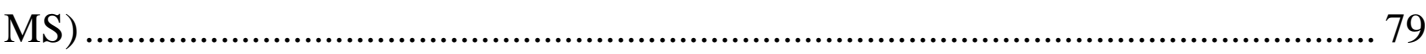

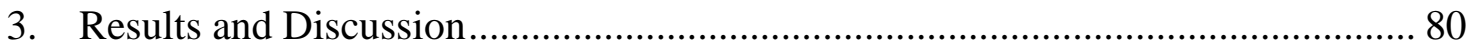

3.1 Stability of spiked deuterated carbonyl compounds in breath samples ......... 80

3.2 Stability of carbonyl compounds in exhaled breath of nonsmokers............... 81

3.3 Long term stability of carbonyl compounds in exhaled breath samples of

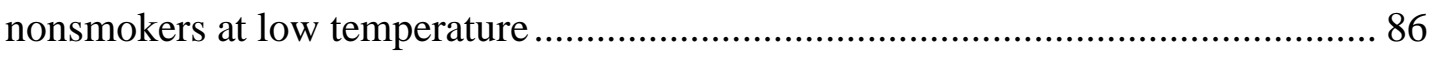

3.4 Stability of carbonyl compounds in exhaled breath of smokers at cold

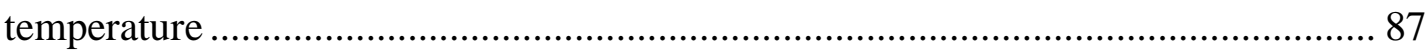

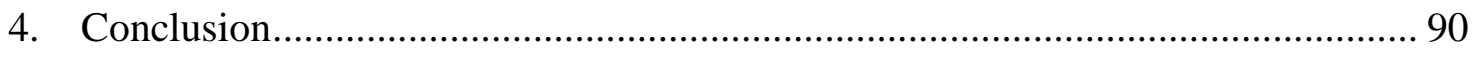

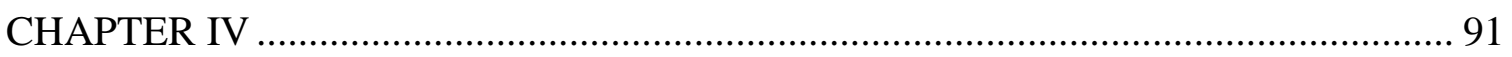




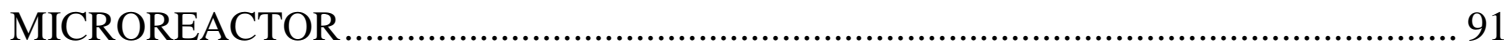

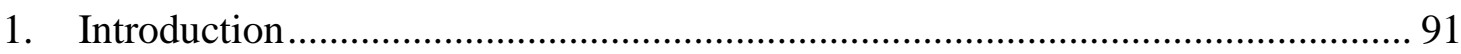

2. Breath Samples and Study Population ....................................................... 94

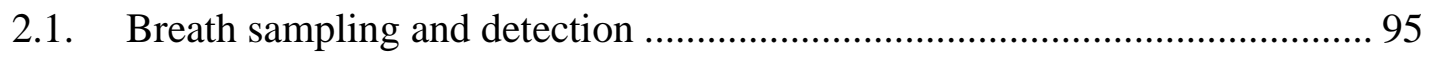

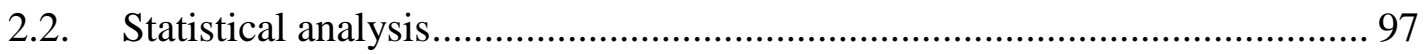

2.3. Breath analysis of patients recruited for CT screening of lung cancer......... 97

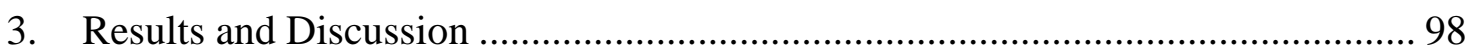

3.1 Detection of carbonyl compounds in smokers and nonsmokers .................. 98

3.2. Detection of the carbonyl compounds in patients for CT screening of lung

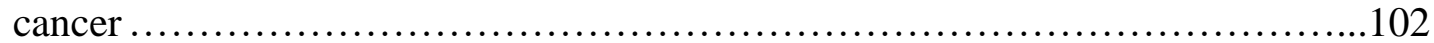

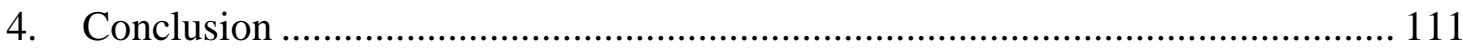

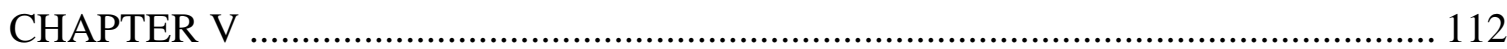

DETECTION OF LUNG CANCER FROM EXHALED BREATH USING THE

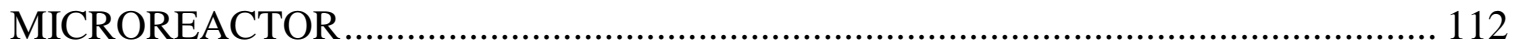

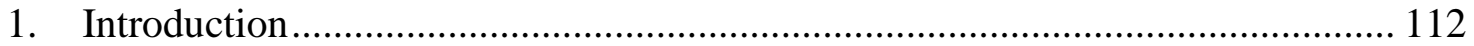

2. Breath Analysis of Lung Cancer Patient...................................................... 113

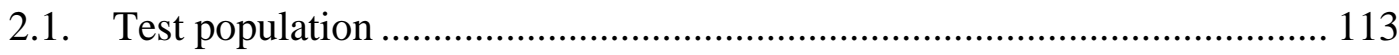

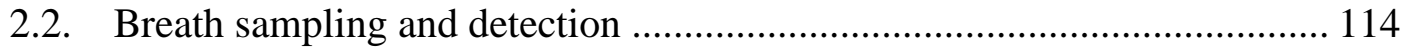

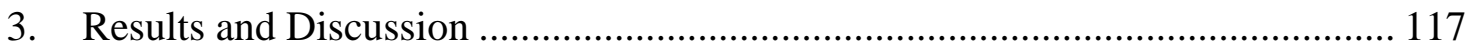

3.1. Detection of the markers and Statistical analysis ................................. 117

3.2. Lung cancer type analysis .......................................................... 127

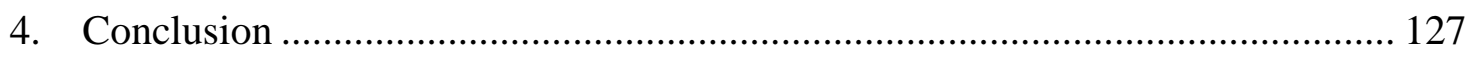

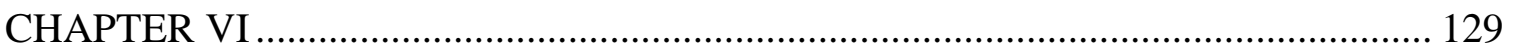

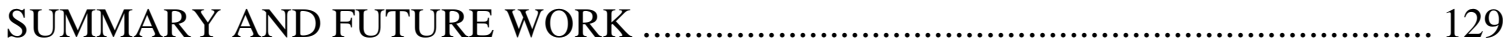

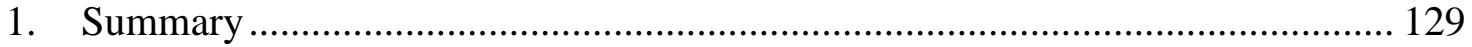

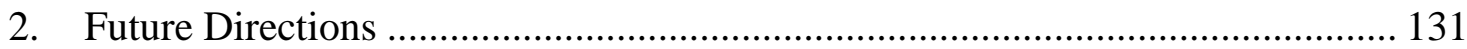

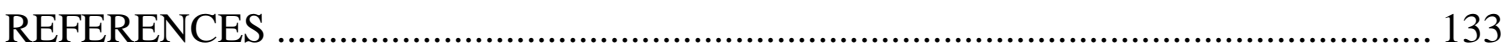

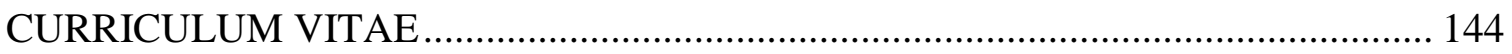




\section{LIST OF TABLES}

TABLE

PAGE

Table 1. 1 Physiological origins of some endogenous breath molecules ......................... 3

Table 1. 2 Lung Cancer-Related VOCs According to Recent Literature .......................... 4

Table 1. 3 Commercially available exhaled breath condensate collection systems ......... 16

Table 1. 4 Characterization of selected exhaled breath (EB) volatile organic compounds

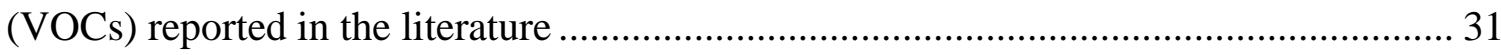

Table 2. 1 The activation energy, frequency factor and coefficient of determination of

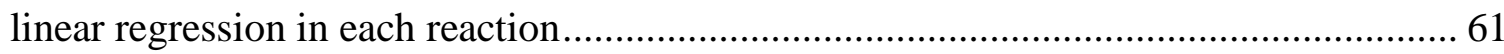

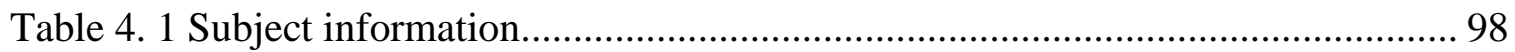

Table 4. 2 Concentration ranges and medians values of 60 never smokers and 47 current

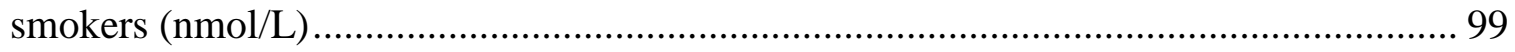

Table 4. 3 Mean and SD values of 60 never smokers (NS) and 47 current smokers (CS)

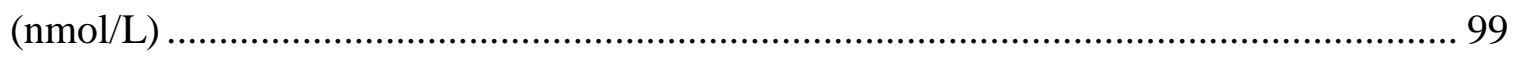

Table 4. 4 Concentration ranges, medians and mean \pm SD values of 60 never smokers (NS)

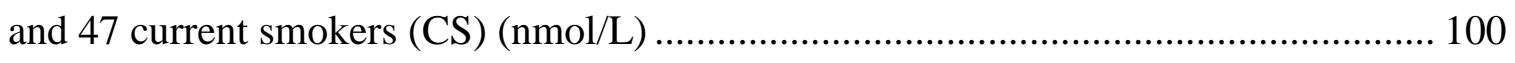

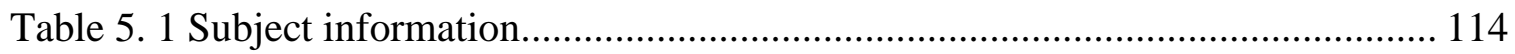

Table 5. 2 A comparison of identified lung cancer marker concentration range, mean and SD for three different groups of people. (the second line of each row is median number) 


\section{LIST OF FIGURES}

FIGURE

PAGE

Figure 1. 1 SUMMA Canister with disposable Teflon mouthpiece for sample collection. 9

Figure 1. 2 A detailed description of sorbent tubes.

Figure 1. 3 (a) Photograph of the sampler; (b) cross-sectional diagram through the breath sampler: (1)mouth piece, (2)outer ring, (3)non returnvalve, (4)outer tube, (5)adsorption tube

adaptor, 6)Tenax adsorption tube, (7)Tedlar bag, 8O-rings. 12

Figure 1. 4 Photograph of a commercial Bio-VOC sampler, disposable mouthpiece, and sorbent tube. 13

Figure 1. 5 Schematic of apparatus and instrumentation for measurement of total exhaled water and collection of exhaled breath condensate. 15

Figure 1. 6 A diagram illustrating the off-line breath sampling pipeline. 17

Figure 1. 7 SPME device modified for breath analysis. 20

Figure 1. 8 (a) A schematic cross-sectional diagram of the integrated preconcentrator consisting of a NiCr microheater, a $1 \mu \mathrm{L}$ preconcentrator, and two microvalves. (b) Device picture of the layers corresponding to (a). 21 
Figure 1. 9 (a) A schematic diagram of the PC when the valves are opened, and (b) closed.

Figure 1. 10 Design and schematic device composition; (a) platinum heater, (b) MEMS, (c)

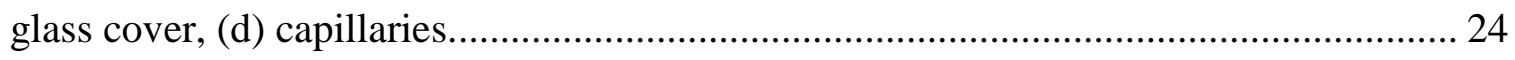

Figure 1. 11 Normal human breath chromatogram of GC-MS................................. 26

Figure 1. 12 A schematic of the SIFT used for the study of ion-molecule reactions. When configured to measure trace gases in air or breath samples it becomes a SIFT-MS....... 28 Figure 1. 13 Experiment set-up of e-nose system equipped with data acquisition software used in exhaled breath measurement. 30 Figure 2. 1 (a) Layout for a microreactor with a channel of $14 \mathrm{~mm}$ long and $7 \mathrm{~mm}$ wide. (b) Layout of microreactor with a channel of $21 \mathrm{~mm}$ long and $7 \mathrm{~mm}$ wide. (c) Layout of the triangular micropillars. Each side of the triangular micropillar is $50 \mu \mathrm{m} \ldots \ldots \ldots \ldots \ldots . . . . . . . .37$ Figure 2. 2 Fabrication process to create the microreactors. (a) Bare silicon wafer. (b) Photoresist patterning using UV exposure. (c) Photoresist development using MF319. (d) Micropillars formation using Deep Reactive Ion Etching. ....................................... 38 Figure 2. 3 Microscopic images of a) triangular and b) circular micropillars after the

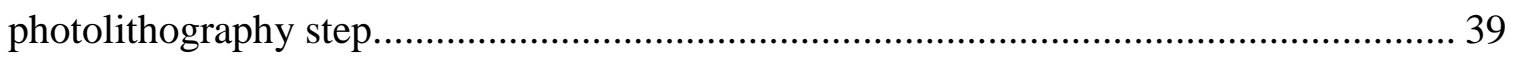

Figure 2. 4 Optical images of the devices using stereo microscope............................ 40 Figure 2. 5 SEM images of the cylindrical, diamond, square and triangular shape micropillars. 41

Figure 2. 6 The picture of $21 \mathrm{~mm}$ length microreactor compared to a Dime dollar. 42 Figure 2. 7 Schematic illustration of ATM oximation to capture ketones and aldehydes in the microreactor. 43 
Figure 2. 8 Schematic flow diagram of the evacuation process setup. 45

Figure 2. 9 Reacted ATM adducts and unreacted ATM eluted from the microreactor.... 45 Figure 2. 10 (a): Relationship between capture efficiency and flow rate of the microreactors with cylindrical micropillars, (the distance $=10 \mu \mathrm{m}, \mathrm{L}=7 \mathrm{~mm}$ ). (b): Relationship between capture efficiency and the distance at a flow rate of $5 \mathrm{ml} / \mathrm{min}$. (Square, $\mathrm{L}=7 \mathrm{~mm}$ ), (c) Relationship between capture efficiency and the shapes of the micropillars (the distance d $=10 \mu \mathrm{m}$, flow rate $=5 \mathrm{ml} / \mathrm{min}, \mathrm{L}=7 \mathrm{~mm}$ )

Figure 2. 11 Relationship between capture efficiency and flow rate of the microreactors with cylindrical micropillars at different ATM loading; (a) Acetaldehyde, (b) pentanal, (c) 2-butanone and (d) 2-pentanone (the distance $=10 \mu \mathrm{m}, \mathrm{L}=7 \mathrm{~mm}$ ). 50 Figure 2. 12 The capture efficiency with different flow rate using different length of design microreactors. (a) acetaldehyde (b) acetone (c) 2-butanone (d) pentanal....................... 53 Figure 2. 13 Relationship between carbonyls conversion and concentration................. 57 Figure 2. 14 ATM-Carbonyls formation rate at different carbonyl concentrations.......... 58 Figure 2. 15 Determination of the reaction orders: the parity of the logarithm of the ATMCarbonyls formation rate and the logarithm of the carbonyl concentrations. 58 Figure 2. 16 Linear regression plots of lnCinlet/Coutlet vs t between ATM and 2-butanone reactions at (a) 30oC, (b) 50oC, (c) 70oC, (d) $90 \mathrm{oC}$. 59 Figure 2. 17 Linear regression plots of $\ln (\mathrm{k})$ vs $1 / \mathrm{T}$ between ATM and carbonyl compounds reactions. (a) Acetone, (b) 2-Butanone, (c) Acetaldehyde, (d) Pentanal ......................... 61 Figure 2. 18 Diffusion across stagnant film surrounding catalyst pellet. 62

Figure 2. 19 Axial concentration profile in a packed bed. 63 
Figure 2. 20 Comparison of experimental data and the model simulation for capture efficiencies of 2-Butanone using five different length microreactors. 66

Figure 2. 21 Comparison of experimental data with the model simulation for capture efficiencies of acetaldehyde, acetone, 2-butanone and pentanal with $21 \mathrm{~mm}$ length microreactor, (a) aldehydes, (b) ketones.

Figure 2. 22 Comparison of experimental data with the model simulation for capture efficiencies of acetaldehyde, acetone, 2-butanone and pentanal with $21 \mathrm{~mm}$ length under reaction rate limiting condition. Error! Bookmark not defined. Figure 2. 23 Comparison of $7 \mathrm{~mm}$ length microreactor capture and $21 \mathrm{~mm}$ length microreactor. 72 Figure 3. 1 (a) Optical picture of a microreactor with an insert of a SEM micrograph of the triangular micropillar array at the top right corner; (b) the Schematic illustration of ATM coating on the micropillar and oximation of ATM to capture carbonyl compounds........ 78 Figure 3. 2 Capture efficiencies of spiked four deuterated compounds in breath samples (15 Nonsmokers and 7 Smokers) with storage time at $4^{\circ} \mathrm{C}$. The flow rate of breath sample through the microreactor was $7 \mathrm{ml} / \mathrm{min}$. (a) deuterated acetaldehyde and hexanal. 81 Figure 3. 3 Relationship between the residual percentage and storage time of four typical carbonyl compounds under two conditions of storage: room temperature and cold temperature $\left(4^{\circ} \mathrm{C}\right)$ with 15 non-smokers' breath samples (a) formaldehyde and acetaldehyde. 85

Figure 3. 4 Relationship between the recovery percentage and long term storage of representative carbonyl compounds under refrigerated cold temperature storage $\left(4^{\circ} \mathrm{C}\right)$ with 15 nonsmokers' breath samples. 87 
Figure 3. 5 The relationship between the residual percentage and storage time of carbonyl compounds under refrigerated cold temperature storage $\left(4^{\circ} \mathrm{C}\right)$ of 7 smokers' and 15 nonsmokers' breath samples. (a)Formaldehyde and Acetaldehyde, (b)Acrolein and crotonaldehyde. 89

Figure 4. 1 Schematic diagram of lung and its pathway to produce VOCs. 92

Figure 4. 2 (a) One microreactor compared with quarter coin, (b) Optical picture of fabricated microreactor and (c) SEM picture of micropillar arrays. 96 Figure 4. 3 Schematic flow diagram of the preconcentration setup for breath analysis... 96 Figure 4. 4 Typical FTICR-MS spectra of breath samples. (a) Current smoker, and (b) Never smoker. The peak of ATM is 2-(aminooxy)-N, N, N-trimethylethanammonium cations. The peak of IR is internal reference ATM-acetone-d6. 101

Figure 4. 5 Comparisons of three compounds from never smokers (NS) group(n=60) and current smokers (CS) healthy control groups (n=47). (a) Formaldehyde, (b) Acetaldehyde, (c) Acetone 102

Figure 4. 6 Comparisons of carbonyl compounds from healthy control (HC, n=107) group, pulmonary nodule $(n=47)$ and without pulmonary $(n=70)$ group. (a) C3H6O, (b) C2H4O2, (c) $\mathrm{C} 4 \mathrm{H} 8 \mathrm{O} 2$ and (d) $\mathrm{C} 4 \mathrm{H} 8 \mathrm{O}$. 104

Figure 4. 7 Comparisons of carbonyl compounds from healthy control (HC, n=107) group, $\operatorname{COPD}(n=9)$ group and smoker patients without benign pulmonary nodules (SWN, n=17) group. (a) $\mathrm{C} 2 \mathrm{H} 4 \mathrm{O} 2$, (b) $\mathrm{C} 4 \mathrm{H} 8 \mathrm{O} 2$. 105 Figure 4. 8 Comparisons of carbonyl compounds from healthy control (HC, n=107) group, asthma group (n=8). (a) $\mathrm{CH} 2 \mathrm{O}$, (b) $\mathrm{C} 2 \mathrm{H} 4 \mathrm{O}$, (c) $\mathrm{C} 4 \mathrm{H} 8 \mathrm{O} 2$. 106 
Figure 4. 9 Comparisons of carbonyl compounds from never smoker patients $(n=19)$ group, former smoking patients ( $\mathrm{n}=69$ ) and current smokers ( $\mathrm{n}=29$ ) groups. (a) $\mathrm{CH} 2 \mathrm{O}$, (b) $\mathrm{C} 2 \mathrm{H} 4 \mathrm{O}$,

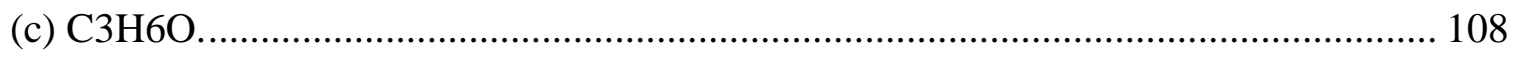

Figure 4. 10 Comparisons of carbonyl compounds from current smoker (CS) group without smoking for more than 4 hours ( $n=9)$, smoke within 2 hours (JS) group (n=20). (a) CH2O, (b) $\mathrm{C} 2 \mathrm{H} 4 \mathrm{O}$, (c) $\mathrm{C} 3 \mathrm{H} 6 \mathrm{O}$. 109 Figure 5. 1 A SEM picture of the triangular micropillars inside the microreactor and the photo of microreactor compared to a dime dollar. 116 Figure 5. 2 Schematic flow diagram of the preconcentration setup for breath analysis. 116 Figure 5. 3 UHPLC-MS spectrum separation of 2-butanone and butanal, pentanal and 2pentanone. 117 Figure 5. 4 Typical UHPLC-MS spectrum with mass mode between lung cancer patient and healthy control. 119 Figure 5. 5 Typical UHPLC-MS chromatography between lung cancer patient and healthy control. (a) 2-butanone, (b) 3-Hydroxy-2-butanone and (c) 4-HNE. 121 Figure 5. 6 Comparisons of three compounds from never smokers (NS, n=6) and healthy control current smokers (CS, n=7) groups. (a) formaldehyde, (b) acetaldehyde and (c) acetone. 122 Figure 5. 7 Comparisons of three compounds from lung cancer patients with never smokers (NS, n=3), current smokers (CS, n=6) and previous smokers (PS, n=6) groups. (a) formaldehyde, (b) acetaldehyde and (c) acetone. 123 
Figure 5. 8 Comparisons of compounds with HC group $(n=15)$, LC group $(n=15)$ and BN group (n=7). (a) C4H8O, (b) C4H8O2, (c) 4-HNE, (d) 4-HHE, (e) C2H4O2, (f) C3H6O,

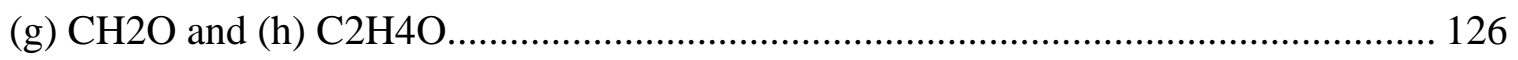

Figure 5. 9 Comparisons of 4-HNE with adenocarcinoma NSCLC $(n=9)$ and squamous cell

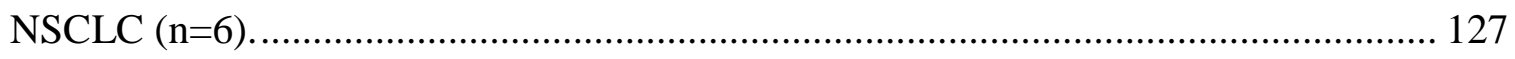




\section{CHAPTER I}

\section{INTRODUCTION}

\section{Breath Analysis}

Breath analysis is probably one of the oldest forms of disease diagnosis. Its usage for disease diagnostics dates back to ancient Greeks where physicians used exhaled breath to diagnose different diseases. ${ }^{1,2}$ They already knew that the aroma of human exhaled breath could provide clues to disease. Certain diseases have correct associations with breath. For example, the fishy smell of breath associates to liver illness, a urine-like smell can accompany failing kidneys, the diabetic patients often breathe a sweet smell due to the presence of acetone in their breath, the grapes flavor of Pseudomonas infections, ${ }^{3,4}$ or the sewer smell of the breath of patients with lung abscesses, caused by the proliferation of anaerobic bacteria. ${ }^{5-7}$

Both qualitative and quantitative methods for determination of chemical substances in breath are included in breath analysis. In the 1970s, Linus Pauling detected (though without identifying) around 200 different volatile organic compounds (VOCs) in exhaled breath by gas chromatography. It was demonstrated that normal human breath is a gas mixture with rather complex composition. In the last 30 years, researchers identified many 
of these compounds. It has turned out that exhaled breath contains many VOCs, such as acetone, methanol or isoprene and even small inorganic molecules like nitric oxide, carbon monoxide or carbonyl sulfide. ${ }^{8,9}$

Breath analysis provides a simple and convenient alternative to traditional medical diagnostics in clinical laboratory, because it is non-invasive, painless, cost-effective and it can be easily repeated. As we breathe out from our mouth, thousands of molecules are expelled into the air. The composition of breath samples is often identified as a mixture of volatile organic compounds (VOCs) (e.g., acetone, isoprene, ethane and pentane), simple gases (e.g., $\mathrm{NO}, \mathrm{CO}_{2}$, and $\mathrm{CO}$ ), and even some non-volatile substances (e.g., isoprostanes, peroxynitrite, cytokines). ${ }^{10}$ In addition to oxygen, nitrogen, carbon dioxide and water vapor, human breath contains hundreds of volatile organic compounds (VOCs) whose concentration variations may serve as biomarkers for specific diseases. It is recently proved that there are approximately 3000 VOCs have been detected at least once in human breath, and most breath samples usually contain more than 200 VOCs. Detailed analysis of their composition can provide a diverse signature of physiological processes that took place in the body (i.e. breath print) and along the pathways of ingestion or absorption since these molecules have been produced from both endogenous and exogenous origins. ${ }^{5}$ If we can capture and analyze this "breath print" correctly, it can be used to provide information of the current health status with the potential to predict future outcomes. ${ }^{11}$ In that sense, the development of efficient devices that can be practically used for the analysis and quantification of various volatile biomarkers in human breath has raised a huge interest in recent years. 
The potential advantages of breath analysis over other conventional medical tests include that it is a totally non-invasive and painless method to assess a person's health state, the sampling method of breath analysis is very easy to operate as it does not need skilled staff to operate and it can be used to people of all ages and conditions. In recent years, breath analysis attracts a lot of attention due to the great potential in clinical diagnostics and exposure assessment. ${ }^{12}$

Biomarkers are quantifiable indications of physiologic function and disease activity that provide a practical basis for diagnosis and monitoring of pathologic states. ${ }^{13}$ In the past years, researchers found some compounds can be used to define a disease in person. For example, Corradi et al. found that malondialdehyde (MDA), heptanal and hexanal are significantly increased in the EBC patients with COPD in comparison with nonsmoking control subjects. ${ }^{14}$ Other compounds, such as nitric oxide, also be identified as a biomarker of various respiratory diseases including COPD. Researchers reported that the concentration of nitric oxide in COPD patients are consistently higher compared to healthy controls. ${ }^{15-17}$ Table 1.1 lists physiological origins of some endogenous breath molecules. ${ }^{18}$ Table 1.2 includes a summary of Lung Cancer-Related VOCs According to Recent Literature. ${ }^{19}$ For example, the compounds and their possible endogenous sources.

\section{Table 1. 1}

$\underline{\text { Physiological origins of some endogenous breath molecules }}{ }^{18}$

\begin{tabular}{c|c}
\hline Compound & Physiological basis \\
\hline Acetaldehyde & Ethanol metabolism \\
Acetone & decarboxylation of acetoacetate \\
\hline
\end{tabular}




\begin{tabular}{|c|c|}
\hline Ammonia & protein metabolism \\
\hline Carbon sulfide & gut bacteria \\
\hline Carbon monoxide & production catalyzed by heme oxygenase \\
\hline Carbonyl sulfide & gut bacteria \\
\hline Ethane & lipid peroxidation \\
\hline Ethanol & gut bacteria \\
\hline Ethylene & lipid peroxidation \\
\hline hydrocarbons & lipid peroxidation/metabolism \\
\hline Hydrogen & gut bacteria \\
\hline Isoprene & cholesterol biosynthesis \\
\hline Methane & gut bacteria \\
\hline Methanethiol & methionine metabolism \\
\hline Methanol & metabolism of fruit \\
\hline Methylamine & protein metabolism \\
\hline Nitric oxide & $\begin{array}{l}\text { production catalyzed by nitric oxide } \\
\text { synthase }\end{array}$ \\
\hline Pentane & lipid peroxidation \\
\hline
\end{tabular}

Table 1. 2

$\underline{\text { Lung Cancer-Related VOCs According to Recent Literature }}{ }^{19}$

\begin{tabular}{llll}
\hline Compounds & $\begin{array}{l}\text { Possible Endogenous } \\
\text { Source }\end{array}$ & $\begin{array}{l}\text { Main Products } \\
\text { and/or Derivatives }\end{array}$ & $\begin{array}{l}\text { Exogenous } \\
\text { Origin }\end{array}$ \\
\hline
\end{tabular}




\begin{tabular}{|c|c|c|c|}
\hline Alkanes alkenes & $\begin{array}{l}\text { Oxidative stress (PUFA } \\
\text { peroxidation) }\end{array}$ & $\begin{array}{l}\text { Ethane, Pentane, } \\
\text { Heptane, Octane, } \\
\text { Decane, } \\
\text { Undecane, } \\
\text { Dodecane, } \\
\text { Nonadecane, } \\
\text { Isoprene, Propane, } \\
\text { Eicosane }\end{array}$ & $\begin{array}{l}\text { Natural, plastics } \\
\text { or petrol/fuels }\end{array}$ \\
\hline Alcohols & $\begin{array}{l}\text { Hydrocarbon } \\
\text { metabolism Absorbed } \\
\text { through GI tract }\end{array}$ & $\begin{array}{l}\text { Propanol, Butanol, } \\
\text { 2-Ethyl-1-hexanol, } \\
\text { Ethanol, } \\
\text { Methanol, } \\
\text { Heptadecanol }\end{array}$ & $\begin{array}{l}\text { Natural, diet or } \\
\text { disinfectants }\end{array}$ \\
\hline Aldehydes & $\begin{array}{l}\text { Metabolism of alcohols } \\
\text { Lipid peroxidation }\end{array}$ & $\begin{array}{l}\text { Propanal, Butanal, } \\
\text { Pentanal, Hexanal, } \\
\text { Heptanal, Octanal, } \\
\text { Nonanal, } \\
\text { Formaldehyde, } \\
\text { Acetaldehyde }\end{array}$ & $\begin{array}{l}\text { Natural, diet or } \\
\text { waste products } \\
\text { Smoking }\end{array}$ \\
\hline Ketones & $\begin{array}{l}\text { Fatty acid oxidation } \\
\text { Protein metabolism }\end{array}$ & $\begin{array}{l}\text { Acetone, } \\
\text { Butanone, } \\
\text { Pentanone, } \\
\text { Hexanone, } \\
\text { Heptanone, } \\
\text { Benzophenone, } \\
\text { Hendecanone }\end{array}$ & $\begin{array}{l}\text { Natural, diet, } \\
\text { waste products } \\
\text { or } \\
\text { drugs/fragrance } \\
\text { s /paint }\end{array}$ \\
\hline Carboxylic acids & $\begin{array}{l}\text { Metabolism of amino } \\
\text { acids }\end{array}$ & $\begin{array}{l}\text { Benzoic acid, } \\
\text { Propanoic acid, } \\
\text { Acetic acid }\end{array}$ & $\begin{array}{l}\text { Food } \\
\text { preservatives, } \\
\text { solvents, } \\
\text { polymers }\end{array}$ \\
\hline Esters & $\begin{array}{l}\text { Metabolic pathway of } \\
\text { alcohols and acids }\end{array}$ & $\begin{array}{l}\text { Ethanoate, } \\
\text { Propanoate, } \\
\text { Acetate }\end{array}$ & $\begin{array}{l}\text { Fatty oils, } \\
\text { natural wax, } \\
\text { fruit essential } \\
\text { oils }\end{array}$ \\
\hline Nitriles & --- & $\begin{array}{l}\text { Acetonitrile, } \\
\text { Azulencarbonitrile }\end{array}$ & Smoking \\
\hline
\end{tabular}




\begin{tabular}{llll}
\hline Aromatic & --- & Benzene, Toluene, & Petrol, smoking, \\
compounds & Styrene, 2,5- & natural, tar, oil \\
& Dimethylfuran, & \\
& Anthracene, & \\
& Dimethylnaphtale & \\
ne & \\
\hline
\end{tabular}

\section{Breath Sampling Methods}

Exhaled breath sampling is one of the most important steps in breath analysis and researchers should pay attention to a number of parameters, in order to avoid mistakes when make assumptions about the origin of the compounds identified. These parameters include the type and the number of breath collections, the portion of breath used, the breath storage and the interference of environmental VOCs from the collection place. Breath collection can be achieved through trapping a single breath or combining multiple breaths. Both methods have associated advantages, which should be taken into account before choosing one of the two. Overall, breath sampling is quick and simple, but the main concern is that the sampling should be totally comfortable and safe to patients when they provide exhaled breath. Since breath sampling can be performed easily, it allows large numbers of subjects to be studied. Different research groups reported different sampling methods. For example, the portion of breath being targeted can vary. The most usual techniques employed in pre-concentrating VOCs in air and exhaled breath are sampling of the air of breath in special recipients, collection in adsorbents as well as continuous sampling and online analysis. 


\subsection{Sampling}

Several types of containers, such as gas tight syringes, glass bulbs, stainless steel canisters and sampling bags, can be used for sampling and storing of breath samples. Syringes and glass bulbs are cheap and easy to use and clean, but they are also fragile and with a limited volume. Canisters (1000-3000 $\left.\mathrm{dm}^{3}\right)$ are made from stainless steel. The inner surface of the canister is electropolished to minimize adsorption and losses of target compounds. However, they are relatively heavy, bulky, expensive and require an effective cleaning procedure for multiple use. Currently, Tedlar sampling bags (made from PVF, polyvinyl fluoride) is one of the most commonly accepted materials for collecting gaseous samples in general and especially breath gas samples. ${ }^{20,21}$ PVF is considered chemically inert to a wide range of compounds and adsorption of analyte molecules on its surface. Tedlar bags also are cheaper and relatively good durability and reusability. Other polymer bags such as Kynar, Flexfilm, Teflon (PTFE, polytetrafluoroethylene), Nalophan (PET, polyethylene terephthalate) and metal-coated multilayer bags (Flexfoil and polyesteraluminum, PEA) are also used to store breath samples. Researchers have studied the stabilities of selected breath constituents in these three types of polymer bags and they

found that the Tedlar bag has the best stability. ${ }^{22}$ Another important advantage is that Tedlar bags can be reused for most applications, this will also save some experimental cost, which may be important to researchers. Prior to reuse, the Tedlar bags must be evacuated and thoroughly cleaned and flushed with purified air or nitrogen. When the Tedlar bags are reused for analysis, it is recommended that this procedure be performed three to ensure that the background levels are acceptable for use. 
Exhaled breath can also be sampled in its full composition (total breath sample or mixed expiratory air) or, alternatively, only the alveolar air may be sampled. The first choice has higher possibility to contaminations, since the sampling control is very deficient. The patient just breathes for the sample collection bags and therefore the risk of contamination with exogenous compounds from the oral cavity and dilutions in dead space are higher and may compromises the analysis. ${ }^{23}$ These problems are reflected in the variation of the number of compounds and their concentration. In contrast, alveolar air is the part of exhaled air that has been in contact with blood inside alveoli. Dead space air does not enter the gas exchange region of the lung, which includes mouth, nose, pharynx, trachea and bronchi. ${ }^{24}$

\subsection{Metal containers-single breath canister (SBC)}

In the 1990s, US Environmental Protection Agency (EPA) introduced the single breath canister method of exhaled breath collection. Beginning with the Total Exposure Assessment Methodology (TEAM) studies of the 1980s, EPA showed great interest in the use of breath sampling as an exposure assessment technique. They studied a series of population-based exposure assessment investigations designed to evaluate the most basic aspects of pollutant exposure. In the study, breath and blood samples were collected from volunteer subjects to determine which sampling technique would be most useful in determining exposures. The sampling through this method was clean, noninvasive and provided accurate information for many VOCs although this early method of exhaled collection is cumbersome. ${ }^{25}$ 
This device comprised a stainless-steel canister that contained 1-1.6 L of alveolar breath. With single breath canister (SBC), carbon dioxide was generally measured as $4.6 \%$ of the exhaled breath, while the natural concentrations of isoprene and acetone served as markers to ensure that the collected sample was alveolar breath. ${ }^{26}$ In general, the device was fitted with a Teflon tube for use as a mouth piece. ${ }^{27}$ The subject was informed to close their lips around the tube before exhaling and the valve remained open until the end of expiration. An alveolar sample was obtained using the dead-space volume expelled before the valve was opened. The SBC had the advantage that unlike other end-tidal breath collection devices, these canisters are extremely durable and no special precautions are needed when shipping samples back to the laboratory.

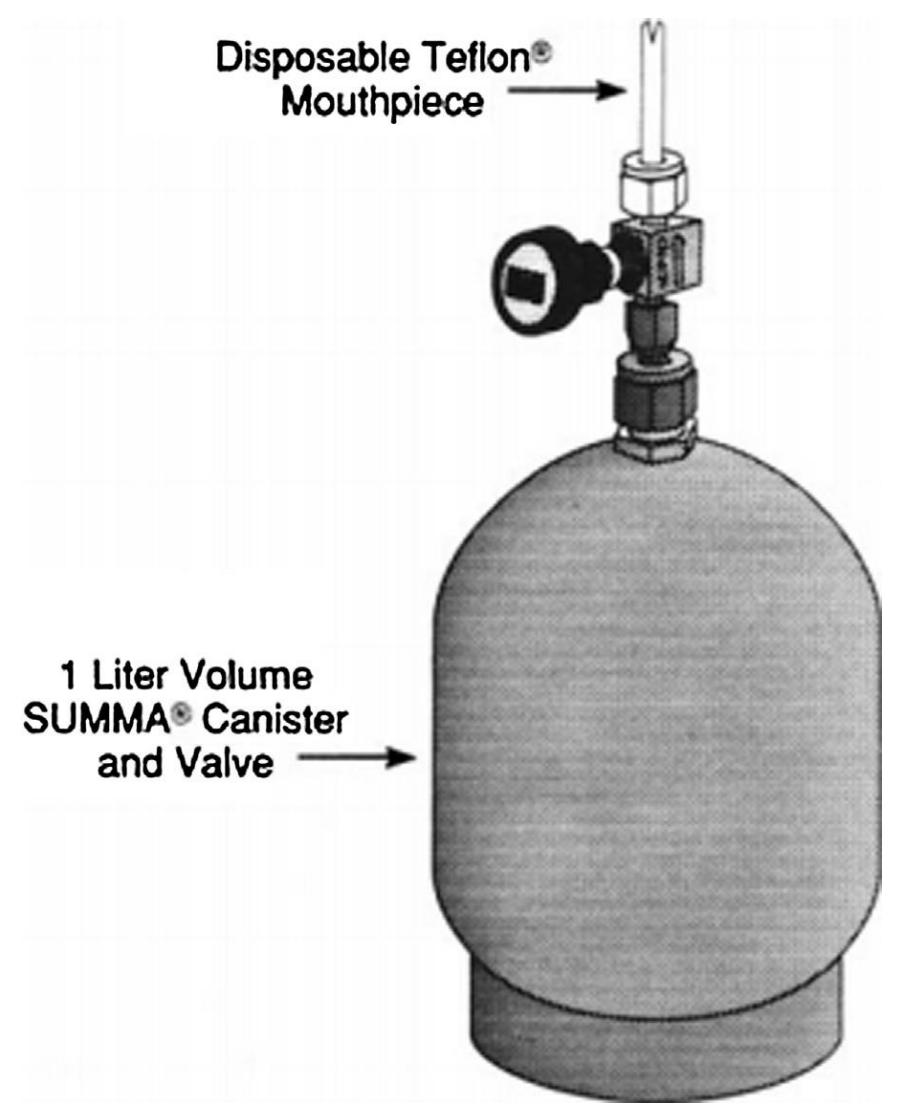

Figure 1.1 SUMMA Canister with disposable Teflon mouthpiece for sample collection. ${ }^{28}$ 


\subsection{Sorbent tubes}

Sorbent tubes are the most widely used collection media for sampling hazardous gases and vapors in air, mostly as it relates to industrial hygiene. Sorbent tubes and traps are widely used in combination with gas chromatographic analytical methods to monitor the vapor-phase fraction of organic compounds in air. Figure 1.2 shows a detailed description of commercial sorbent tubes which are commonly used recently.

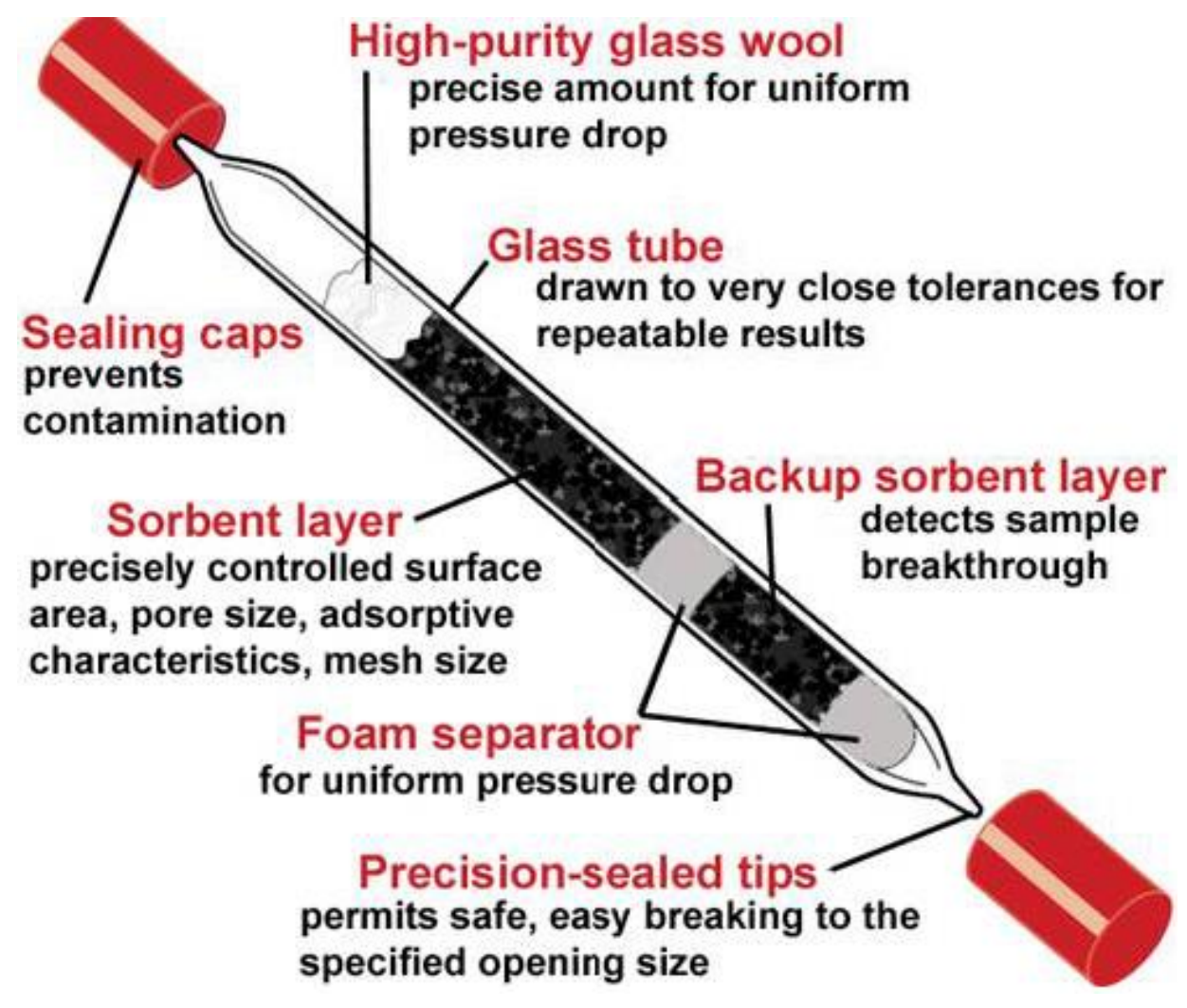

Figure 1.2 A detailed description of sorbent tubes. ${ }^{29}$

\subsection{Bio-VOC breath sampler}

Recently, the Bio-VOC ${ }^{\mathrm{TM}}$ breath sampler, a commercial sampling device, has been introduced and offers several advantages over the above techniques. A prototype of the Bio-VOC breath sampler was developed by the Health and Safety Laboratory (Sheffield, 
UK $)^{30}$ and commercialized by Markes International (South Wales, UK). The Bio-VOC breath sampler has three components: a mouthpiece, a volumetric sampler (tube/syringe) that retains around $100 \mathrm{~mL}$ air, and a plunger. A subject breathes through a disposable cardboard mouthpiece into the plastic Bio-VOC sampler, which has an open-end allowing air to be displaced as exhalation proceeds. Figure 1.3 shows a photograph of the Bio-VOC sampler with detailed information. As a result, the Bio-VOC sampler allows for the collection of alveolar air, the last portion of the exhaled breath, which is more likely to represent air from deep in the lungs. Once the breath collection is complete, the sampler is capped and VOCs are concentrated using SPME fibers, inserted into the sampler, ${ }^{31,32}$ or on sorbent tubes, collected by discharging VOCs with a plunger onto tubed media. The sorbent tubes are most commonly used. Figure 1.4 shows a photograph of a Bio-VOC sampler, disposable mouthpiece, and sorbent tube. This device has now been used widely in human exposure assessments because of its convenience.

A major limitation of the Bio-VOC sampler is the volume of the air collected. The reported volume for the device ranges from 100 to $150 \mathrm{~mL},{ }^{33,34}$ which is much lower than the volume collected with other sampling methods. However, no study has successfully measured the actual volume of air collected using the Bio-VOC sampler. However, no study has successfully measured the actual volume of air collected using the Bio-VOC sampler. 
(a)

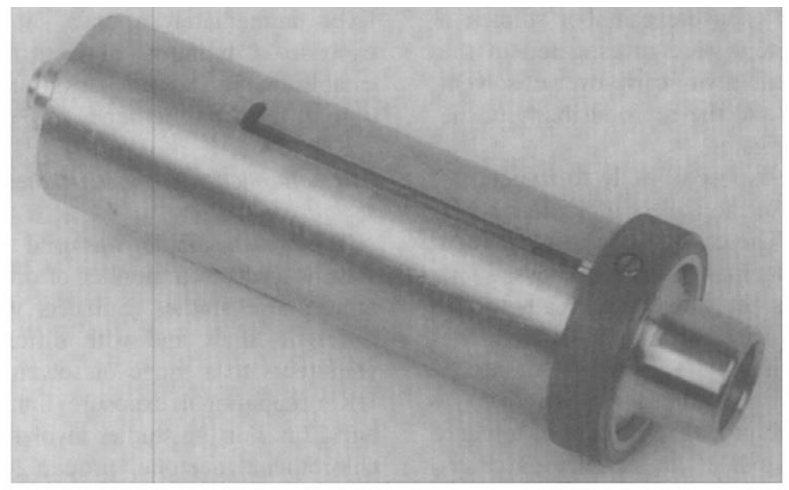

(b)

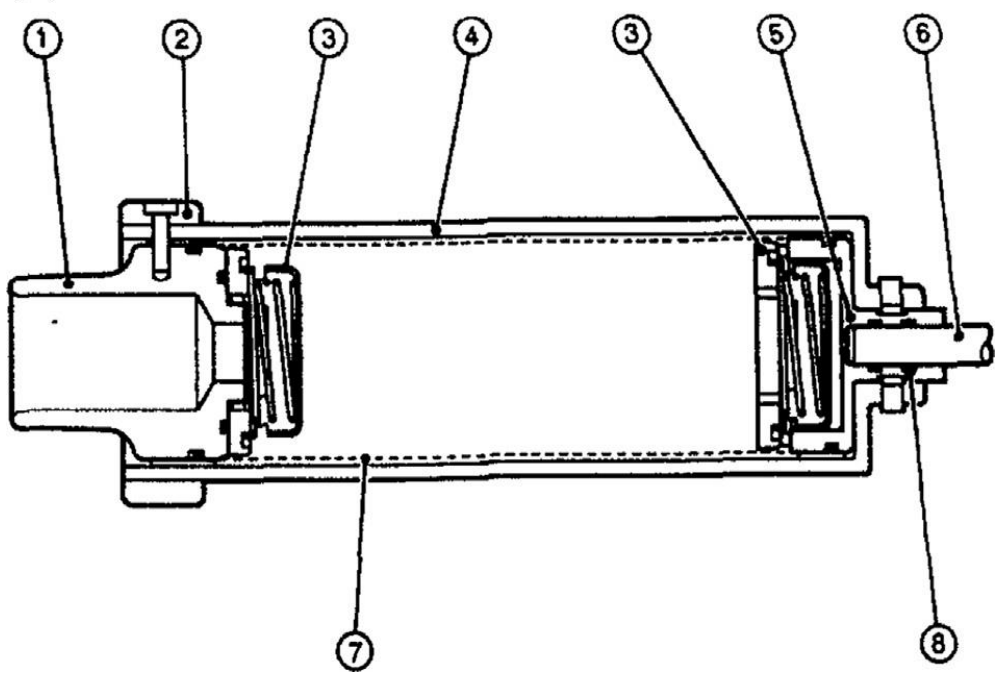

Figure 1.3 (a) Photograph of the sampler; (b) cross-sectional diagram through the breath sampler: (1)mouth piece, (2)outer ring, (3)non-return valve, (4)outer tube, (5)adsorption tube adaptor, (6)Tenax adsorption tube, (7)Tedlar bag, (8)O-rings. ${ }^{35}$ 


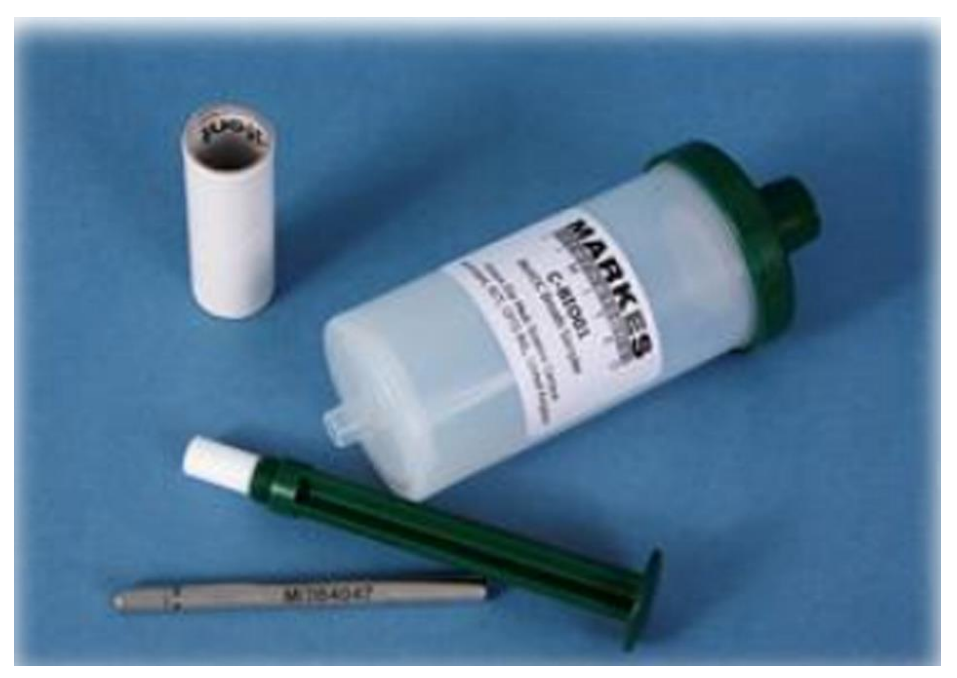

Figure 1.4 Photograph of a commercial Bio-VOC sampler, disposable mouthpiece, and sorbent tube. ${ }^{36}$

\subsection{Exhaled breath condensate (EBC)}

Exhaled breath condensate (EBC) is formed through condensation of cooled exhaled breath and has been analyzed for a variety of mediators, including hydrogen peroxide, lipid mediators, purines, and cytokines. Exhaled breath condensate (EBC) is also a promising source of biomarkers of lung disease. It is important to note that EBC is not a biomarker, but rather a matrix in which biomarkers may be identified, in that way equivalent to blood, sweat, tears, urine and saliva. EBC may be thought of either as a body fluid or as a condensate of exhaled gas (and therefore not a body fluid). This issue is relevant because of potential government regulatory issues involved with laboratory assessment of "body fluids". ${ }^{25}$

There are three principal contributors to $\mathrm{EBC} .{ }^{37}$ The first is variable-sized particles or droplets that are aerosolized from the airway lining fluid such particles presumably reflecting the fluid itself. The second is distilled water that condenses from gas phase out 
of the nearly water-saturated exhalate, substantially diluting the aerosolized airway lining fluid. The third is water soluble volatiles that are exhaled and absorbed into the condensing breath.

Exhaled breath condensate (EBC) has been proposed as a non-invasive means of measuring airway inflammation. Unlike traditional methods of sampling secretions from the lower respiratory tract such as bronchoalveolar lavage, EBC analysis has the advantage of being simple to perform, may be repeated frequently, and can be applied to patients during both the stable and exacerbation phase of disease. The condensate derives from expired water vapor and volatile gases, but the presence of non-volatile solutes suggests that droplets of airway lining fluid have also been collected due to aerosolization during turbulent airflow. Analysis of these solutes may potentially provide insights into the pathophysiology of lung diseases such as asthma, ${ }^{38,39}$ cystic fibrosis, ${ }^{40,41}$ and chronic obstructive pulmonary disease. ${ }^{42,43}$

While exhaled breath condensate shows promise as a source for biomarkers in pulmonary diseases, large variabilities in the concentration of solutes in EBC samples with considerable overlap between normal subjects and disease groups have been reported. ${ }^{43}$ With absence of supporting data, much of the differences have been attributed to variations in the proportion of water vapor diluting the airway lining fluid or variations in flow affecting the amount of aerosolized solute. 


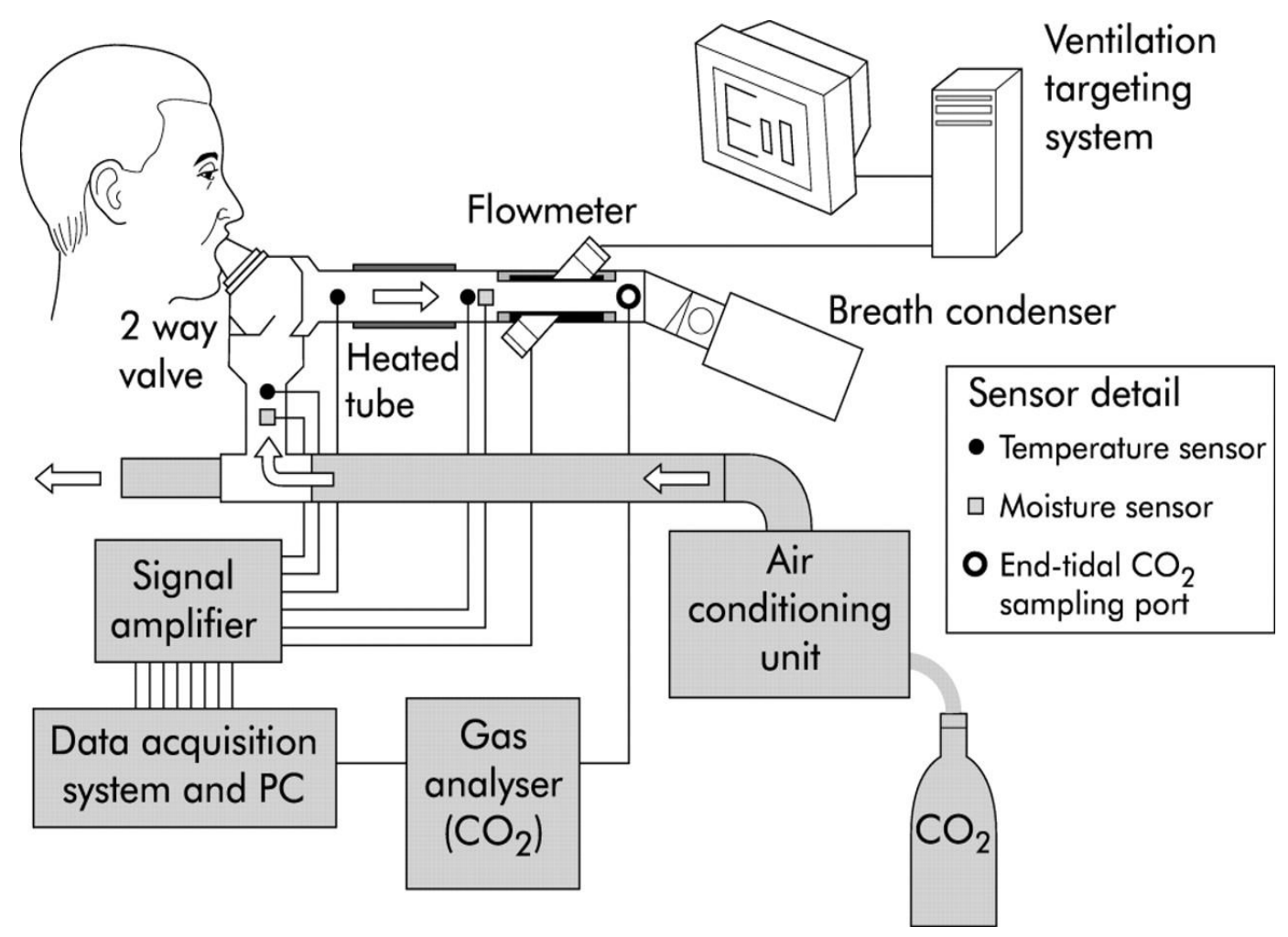

Figure 1.5 Schematic of apparatus and instrumentation for measurement of total exhaled water and collection of exhaled breath condensate. ${ }^{44}$

Figure 1.5 shows a schematic of an apparatus and instrumentation for measurement of total exhaled water and collection of exhaled breath condensate. ${ }^{44}$ Subjects breathe through a non-rebreathing two-way valve at a pattern set by the ventilation targeting system which generates an audio visual feedback signal setting ventilatory rate and expiratory flow, respectively. An air conditioning unit controls the temperature and moisture content of the inspired air. Temperature and humidity sensors are located as shown. ${ }^{44}$

Several options exist for collection of EBC samples. Multiple custom devices have been used throughout the years, using various cooling techniques and device shapes and 
materials. In terms of parts-which are often found about a respiratory laboratory-such homemade systems often can be made cheaply, although the expense in terms of personnel time may be surprisingly substantial. Commercially available equipment is also available as shown in Table 1.3. ${ }^{45}$

The whole process of breath analysis contains sampling, pre-concentration, measurement and data analysis as showed in Figure 1.6. So here we discussed different sampling methods recently used, then different pre-concentration methods were introduced following.

Table 1. 3

$\underline{\text { Commercially available exhaled breath condensate collection systems }}^{45}$

\begin{tabular}{|c|c|c|c|}
\hline $\begin{array}{l}\text { EBC } \\
\text { collection } \\
\text { system }\end{array}$ & Manufacturer & Advantages & Disadvantages \\
\hline $\begin{array}{l}\text { ECoScre } \\
\text { en I and } \\
\text { ECoScre } \\
\text { en II }\end{array}$ & $\begin{array}{l}\text { Viasys, USA, } \\
\text { Europe }\end{array}$ & $\begin{array}{l}\text { Most commonly published EBC } \\
\text { collection system. More common } \\
\text { in European centers. Optional } \\
\text { package for determination of } \\
\text { total exhaled volume. }\end{array}$ & $\begin{array}{l}\text { Not readily portable. } \\
\text { Cleaning between } \\
\text { patients may need to be } \\
\text { extensive to abide by } \\
\text { standard respiratory } \\
\text { care practices. No } \\
\text { ability to control } \\
\text { condensation } \\
\text { temperature }(\text { Eco } 1) \text {. }\end{array}$ \\
\hline RTube & $\begin{array}{l}\text { Respiratory } \\
\text { Research, } \\
\text { USA }\end{array}$ & $\begin{array}{l}\text { More total EBC collections } \\
\text { performed using RTube than } \\
\text { other systems. Multiple } \\
\text { collections can be performed } \\
\text { concurrently. More common in } \\
\text { North American centers. } \\
\text { Disposable (no cleaning between } \\
\text { patients). Portable. Can be } \\
\text { prepared for use in a standard } \\
\text { freezer. }\end{array}$ & $\begin{array}{l}\text { Choice } r \text { and } \\
\text { maintenance of set } \\
\text { condensing temperature } \\
\text { requires optional } \\
\text { cooling unit, otherwise } \\
\text { condensation } \\
\text { temperature is chosen } \\
\text { by cooling sleeve } \\
\text { preparation temperature } \\
\text { and rises during } \\
\text { collection. }\end{array}$ \\
\hline
\end{tabular}




\begin{tabular}{llll}
\hline Anacon & Biostec, & $\begin{array}{l}\text { Controllable temperature of Few publications } \\
\text { collection. Designed for use on } \\
\text { ventilated patients }\end{array}$ \\
\hline Spain & Italchil, Italy & $\begin{array}{l}\text { Has both non-disposable and Few publications. } \\
\text { disposable portions. Controllable Simple system. One } \\
\text { collection temperature. collection at a time. } \\
\text { Moderately portable. Readily } \\
\text { cleanable because of disposable } \\
\text { components. }\end{array}$ \\
\hline
\end{tabular}

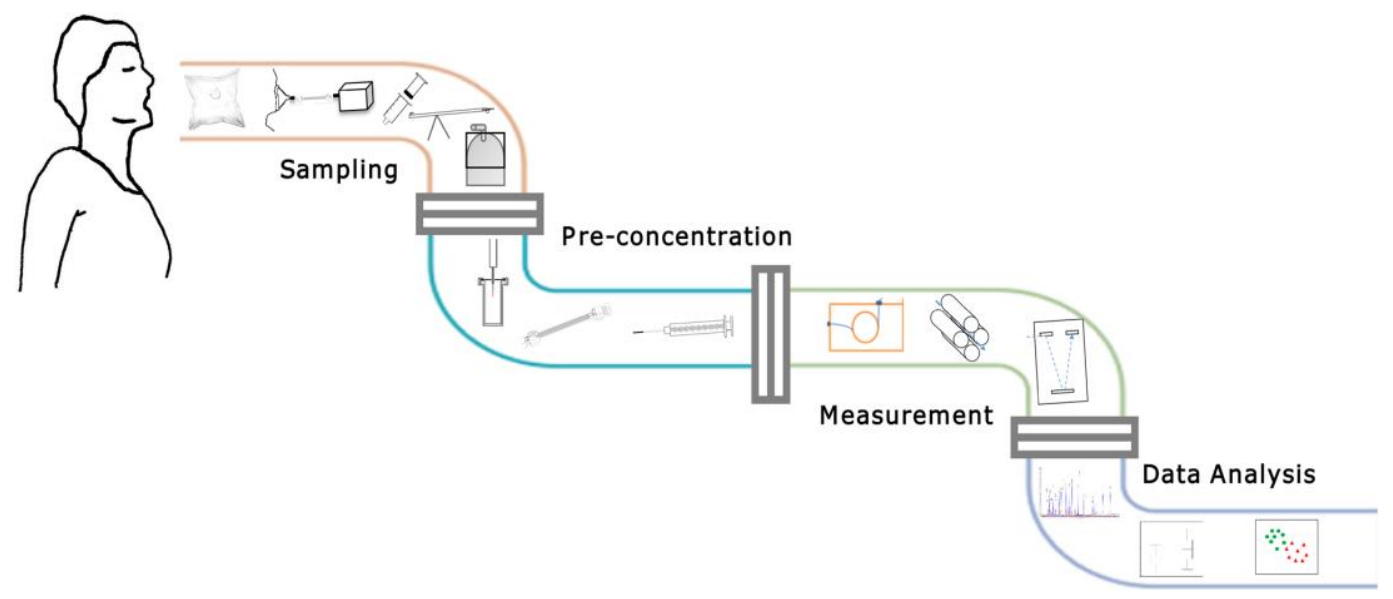

Figure 1.6 A diagram illustrating the off-line breath sampling pipeline. ${ }^{46}$

\section{Preconcentration Techniques}

As mentioned above, the concentrations of VOCs in exhaled breath are very low. Therefore, small interfering compounds could affect the analytical results. To minimize this interference, an intermediate step between sampling and analysis is sometimes necessary and advantageous to increase the concentration level of the target analytes over the possible interfering compounds. There are several concentration techniques available, such as cryogenic 
trapping, usually used with the canister breath sampling, and adsorption in different thermal desorption tubes (TD-tubes), sorbent traps and coated fibers. The adsorption option requires a thermodesorption step, being usually followed by gas chromatography combined with mass spectrometry (GC/MS). Commonly used pre-concentration methods include sorbentcontaining thermal desorption (TD) tubes, the employment of solid phase microextraction (SPME), as well as needle trap devices (NTDs).

\subsection{Thermal desorption (TD) tubes}

TD tubes are popular for pre-concentration of VOCs and account for almost half of the pre-concentration methods published to date. Sorbents can be manually packed into the tubes or tubes can be purchased pre-packed from suppliers. Commonly used sorbents include Tenax TA\&GR, Carbograph 5TD, Carboxen. Due to the distinct properties of these materials there is much variability in the range of volatiles that are trapped. Sample volume should be considered in order to prevent breakthrough and subsequent loss of analytes. Strong sorbents such as Carboxen are suitable for trapping very volatile organic compounds(C2-C4) while Tenax sorbents trap less volatile VOCs in breath (C7-C15). ${ }^{47}$ Whether to use single or multi-bed sorbents which will depend on analytes of interest, and also the quantity of sorbent used.

When breath has been temporarily stored in polymer bags, VOC-capture proceeds by attaching one end of the TD tube to the bag and the other end to a pump which functions to pull gaseous breath from the bag across the sorbent. Although the use of these sorbentcontaining TD tubes is stated to be highly sensitive, it will cost a lot of time. Also, sorbents like Carboxen are hydrophilic thus retain moisture which can negatively affect the 
quantitative capture of some analytes. Introducing a dry purging step especially when using a hydrophilic sorbent may be a solution.

\subsection{Solid phase microextraction (SPME)}

Solid-phase microextraction (SPME) has been applied to the quantitative determination of ethanol, acetone and isoprene in human breath. Solid-phase microextraction (SPME), originally developed by Pawliszyn et al., ${ }^{48,49}$ is a rapid, inexpensive, and efficient technique for sampling solid, liquid, or gaseous samples. It requires no solvents or complicated apparatus and provides linear results over a wide range of analyte concentrations. Analysis of the extracts is performed using GC, GC/MS, or HPLC. ${ }^{48,49}$ In the SPME technique, a fused silica fiber coated with a polymeric stationary phase is contained in a specially designed syringe whose needle protects the fiber when septa are pierced. Figure 1.7 shows a SPME device modified for breath analysis. ${ }^{49}$ The fiber is directly exposed to a liquid or gaseous sample to extract and concentrate the analytes. After the absorption equilibration is attained, the fiber is withdrawn into the needle and introduced into an injector of a gas chromatograph, where the extracted compounds are thermally desorbed and analyzed. SPME can be performed manually or by an autosampler. The method is economical, because one single fiber can be used repeatedly. Unlike in conventional methods for analysis of gaseous samples, modified equipment like a complex valve injection system, a thermal desorption device, or a cooling trap is not

required by SPME. The SPME fiber is easily cleaned by desorbing any contaminants in a hot GC injector. The SPME technique coupled with GC has been used to analyze volatile and semivolatile air compounds. The fiber can be exposed directly to the air or to a sample collected in a gas sampling bulb. 


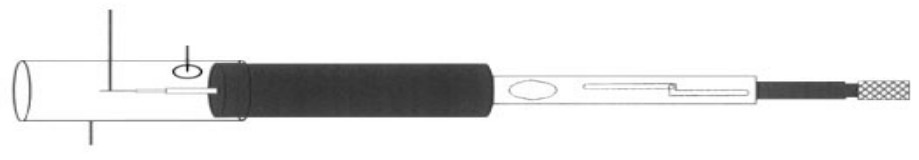

Figure 1.7 SPME device modified for breath analysis. ${ }^{49}$

\subsection{MEMS preconcentrator devices}

Many efforts are being made to develop a microfabricated GC system ( $\mu \mathrm{GC})$ that is small enough to be carried by individuals. A micro pre-concentrator ( $\mu \mathrm{PC})$ is a key component in such a device. The $\mu \mathrm{PC}$ increases the concentration of analytes from low concentration (e.g. parts-per-billion) to higher concentrations (e.g. parts per million) so that low concentrations of analytes can be detected. ${ }^{50} \mathrm{Micro}-\mathrm{PCs}$, including a heated membrane with a thin adsorbent layer, were developed by Frye-Mason et al. for detecting specific chemical warfare agents. ${ }^{51}$ Tian et al. developed a multiple-stage microfabricated PC with a large adsorbent capacity. ${ }^{52,53}$

A new type of fully integrated MEMS $\mu \mathrm{PC}$ that has been fabricated and tested for the rapid concentration of vapor species are introduced to a flame ionization detector (FID). A one microliter size $\mu \mathrm{PC}$ filled with polyethyleneimine (PEI) coated microposts is integrated with fast microvalves ${ }^{54}$ (response time $<50 \mu \mathrm{s}$ ) and a resistive microheater (ramping to $200{ }^{\circ} \mathrm{C}$ in 0.5 seconds). ${ }^{55}$ The integrated PC can sample a cubic centimeter of gas in 0.2 seconds with an $50 \mathrm{kPa}$ inlet pressure, adsorb targeted species, heat and desorb them in 0.5 seconds, and inject the now concentrated gaseous species using fast acting microvalves in pulses as small as 50 microseconds into separation columns in a $\mu \mathrm{GC}$, or directly into a detector. The unprecedented speed of this $\mu \mathrm{PC}(<1 \mathrm{~s})$ is enabled by MEMS 
sizing and fabrication, allowing sniffing of phosphonates, toxic industrial compounds (TICs), and other volatile compounds in seconds, rather than tens of minutes with conventional systems. The micropost structures, which are subsequently coated with PEI, are fabricated using deep reactive ion etching to achieve a high surface area-to-volume ratio while permitting a relatively low pressure drop during the loading and injecting phases of operation in order to reduce both power consumption and analysis time. ${ }^{56}$

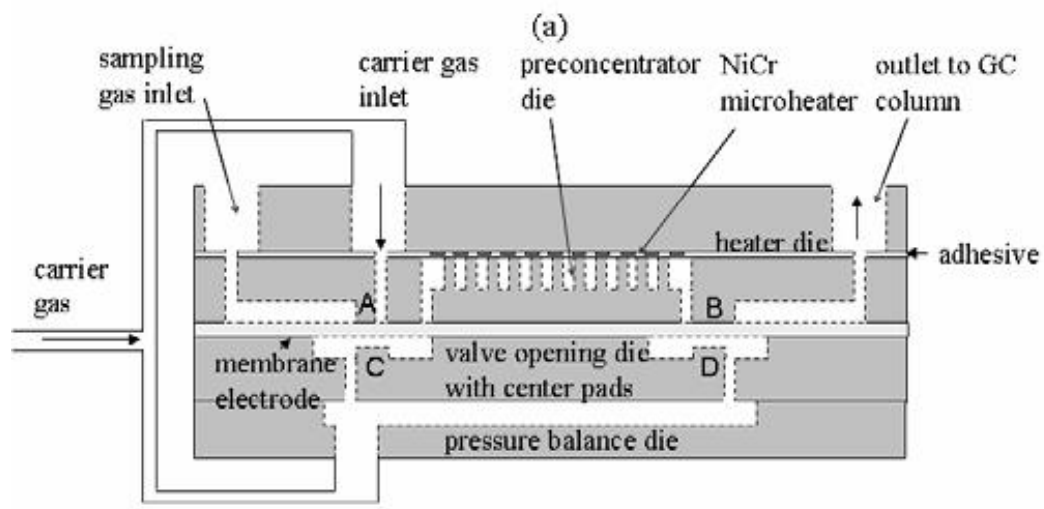

(b)
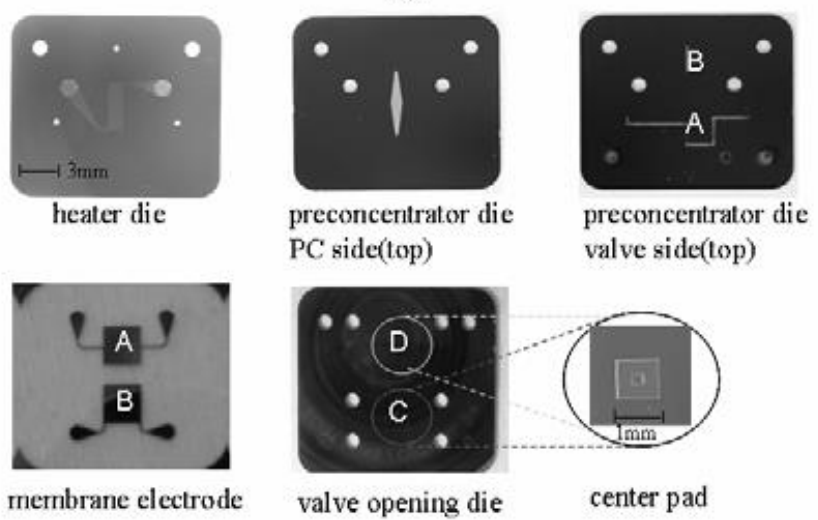

Figure 1.8 (a) A schematic cross-sectional diagram of the integrated preconcentrator consisting of a $\mathrm{NiCr}$ microheater, a $1 \mu \mathrm{L}$ preconcentrator, and two microvalves. (b) Device picture of the layers corresponding to (a). ${ }^{57}$ 
Figure 1.8 shows a schematic diagram and device pictures of the integrated $\mu \mathrm{PC} .{ }^{57}$ It consists of a $\mathrm{NiCr}$ microheater, the posted preconcentrator cavity, and two electrostatic microvalves. The $\mathrm{NiCr}$ microheater heats the silicon surface immediately adjacent to the $\mu \mathrm{PC}$ to subsequently heat the gas and analyte up to $200{ }^{\circ} \mathrm{C}$ using a feedback control of resistance-temperature relationships obtained in off-line calibration. The microvalves are composed of a valve seating electrode, whose topside the $\mu \mathrm{PC}$ is integrated within, a membrane electrode, and a valve opening electrode. The membrane electrodes located at the inlet (A) and outlet (B) of the $\mu \mathrm{PC}$, respectively, are opened by applying a voltage V1 and closed by applying V2, as shown in Figure 1.9. ${ }^{57}$ This feature enables the injection band width from the $\mu \mathrm{PC}$ to be controlled by the operation of the microvalves, rather than by a slower desorption heating rate. Portable gas chromatographs or micro-gas chromatographs ( $\mu$-GCs) provide an analytical tool that permits a quick analysis of volatile organic compounds (VOC) for online monitoring. Figure 1.9 illustrates the (a) on and (b) off operation of the microvalves, as well as important features contributing to a switching performance on the order of microseconds. These features include pneumatically balanced membranes (by P1), which is designed to have almost zero net pressure across the membrane to handle increasing pressures, and center pads which are designed to increase the electrostatic force between the membrane and the lower electrode. 


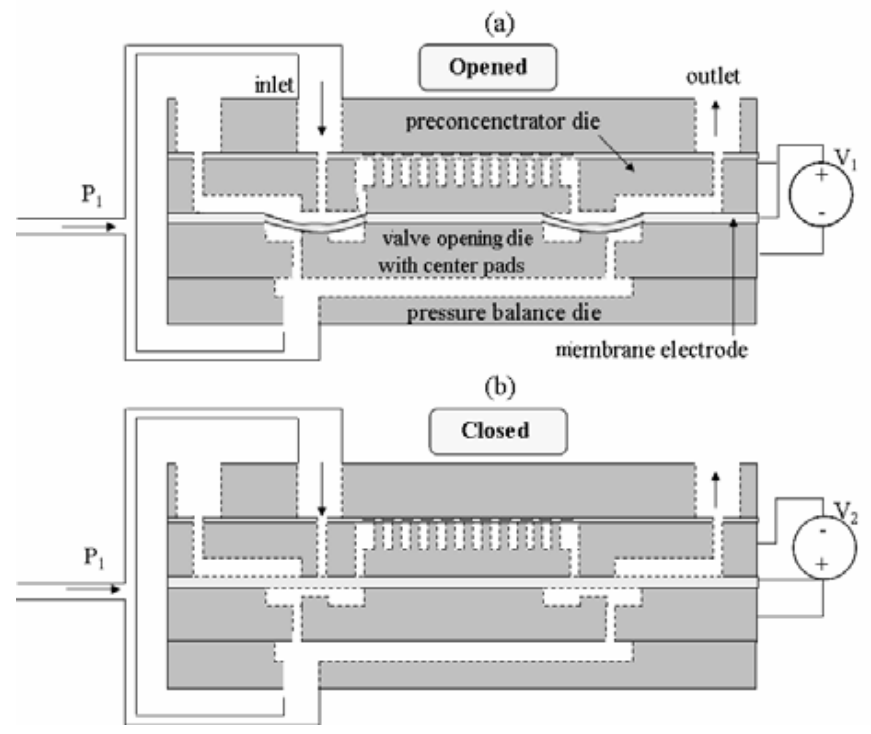

Figure 1.9 (a) A schematic diagram of the PC when the valves are opened, and (b) closed. ${ }^{57}$

The development of $\mu$-GC system has driven an important research effort. Portable gas chromatographs or micro-gas chromatographs ( $\mu$-GCs) provide an analytical tool that permits a quick analysis of volatile organic compounds (VOC) for online monitoring. Adding a preconcentration step should allow increasing the sensitivity of miniaturized analyzer. ${ }^{58}$ The SRA Instruments Company developed and commercialized a MEMS gas preconcentrator into a $\mu$-GC module. Some research experiments conducted with a preconcentrator filled with carbon nanopowder and compled to a micro chromatograph have shown an accurate separation and identification of various trace VOCs within a gas mixture.

The device developed by C. Pijolat et al. ${ }^{59}$ is a silicon microchannel $\left(20 \times 85 \mathrm{~mm}^{2}\right.$, thickness $500 \mu \mathrm{m}$ ) obtained by deep reactive ion etching (DRIE) and designed with fluidic micro-structures at the inlet/outlet leading to a preconcentration chamber with a volume of $14 \mu \mathrm{l}$. The microchannels were produced on a $5 \Omega \cdot \mathrm{cm}$, n-type, (100)-oriented $1 \mathrm{~mm} \mu \mathrm{m}$ - 
thick silicon wafers. The first step of the fabrication was the DRIE with a thick photoresist used as an etching mask. Then the micro-channels were bonded with a PyrexR glass wafer by anodic bonding. Finally capillaries were sealed at the inlet/outlet with ceramic cement and a glass paste. The inlet/outlet has a depth of $500 \mu \mathrm{m}$, corresponding to the diameter of the capillaries used as fluidics interconnections. ${ }^{59}$

The preconcentrator allows desorbing at relatively high temperature $\left(230{ }^{\circ} \mathrm{C}\right)$ all the molecules collected after an adsorption step made at ambient temperature thanks to an adsorbent which is described. Figure 1.10 shows that on the backside of the silicon device, a platinum resistance was screen printed to act as a heater with a heating rate of $40^{\circ} \mathrm{C} / \mathrm{min}$. 60

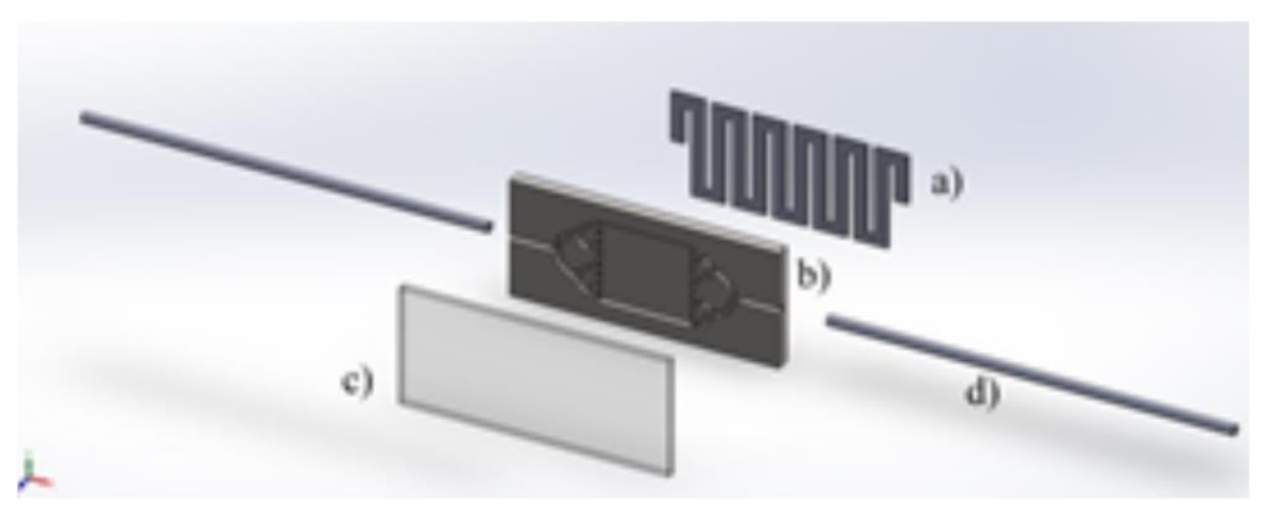

Figure 1.10 Design and schematic device composition; (a) platinum heater, (b) MEMS, (c) glass cover, (d) capillaries. ${ }^{60}$

\section{Analytical Methods}

The detection and quantification of extraordinarily low concentrations of nonvolatile biomarkers/compounds in EBC requires highly sensitive analytical methods. 
During the last decade, separation methods have become the method of choice for the trace analysis of various compounds contained in complex biological matrices.

\subsection{Gas chromatography (GC)}

The most popular method employed for the analysis of trace components in human breath has been GC or its combination with flame ionization detection (FID), MS, or ionmobility spectrometry (IMS). In fact, almost all the exhaled breath VOCs reported so far have been identified and quantified using MS-based methods, most often GC-MS. ${ }^{61}$ GCMS is possibly the most common and comprehensive approach to characterize exhaled breath volatile organic compounds. It allows the selective analysis of one or simultaneous analysis of many compounds that may be in the range from ppb to ppt. The GC-MS involves separation of volatilized samples in chromatographic column based on different parameters, such as the boiling point of the sample components or polarity of the GC column. GC-MS system ionizes the target ions, separate them by mass to-charge $(\mathrm{m} / \mathrm{z})$ ratios and uses the resolved fragmentation patterns to quantify the amount of each specific VOC in the sample. However, there are other detection systems that have been coupled to GC for breath analysis, namely FID and IMS. In the FID detection system, VOCs are burned in the FID, producing ions and electrons that can conduct the electric potential and this information is used for detection and eventually quantification. The advantages of GCFID system are high sensitivity, large linear response range and low noise. However, the GC-FID system also has disadvantage that the FID detector is mass sensitive and its response is not altered significantly by changes in mobile-phase flow rate. In turn, in the GC-IMS system, ions are separated according to their mobility as they travel through a purified gas, in an electric field at the atmospheric pressure. The IMS detector is also 
selective, allowing the quantification of VOCs in the exhaled breath. Regardless of the detection method used in a GC analysis, this approach presents, however, some drawbacks, for example, the requirement for sample pre-treatment (sampling and pre-concentration). Therefore, a GC analysis is only suitable for indirect sampling and not for real-time analysis, also the GC analysis usually takes hours, a time-consuming process. Thus, the important concerns inherent to the sample pre-treatment that need to be carefully addressed to improve the quality of the data obtained in a GC analysis are analytes loss and degradation, particularly of those of reactive or thermally labile metabolites, and possible contaminations. $^{62-65}$ Figure 1.11 shows that GC-MS chromatography has been also used for the identification of metabolic end products including pentane, acetone, ethanol, isoprene and other VOCs in normal human breath.

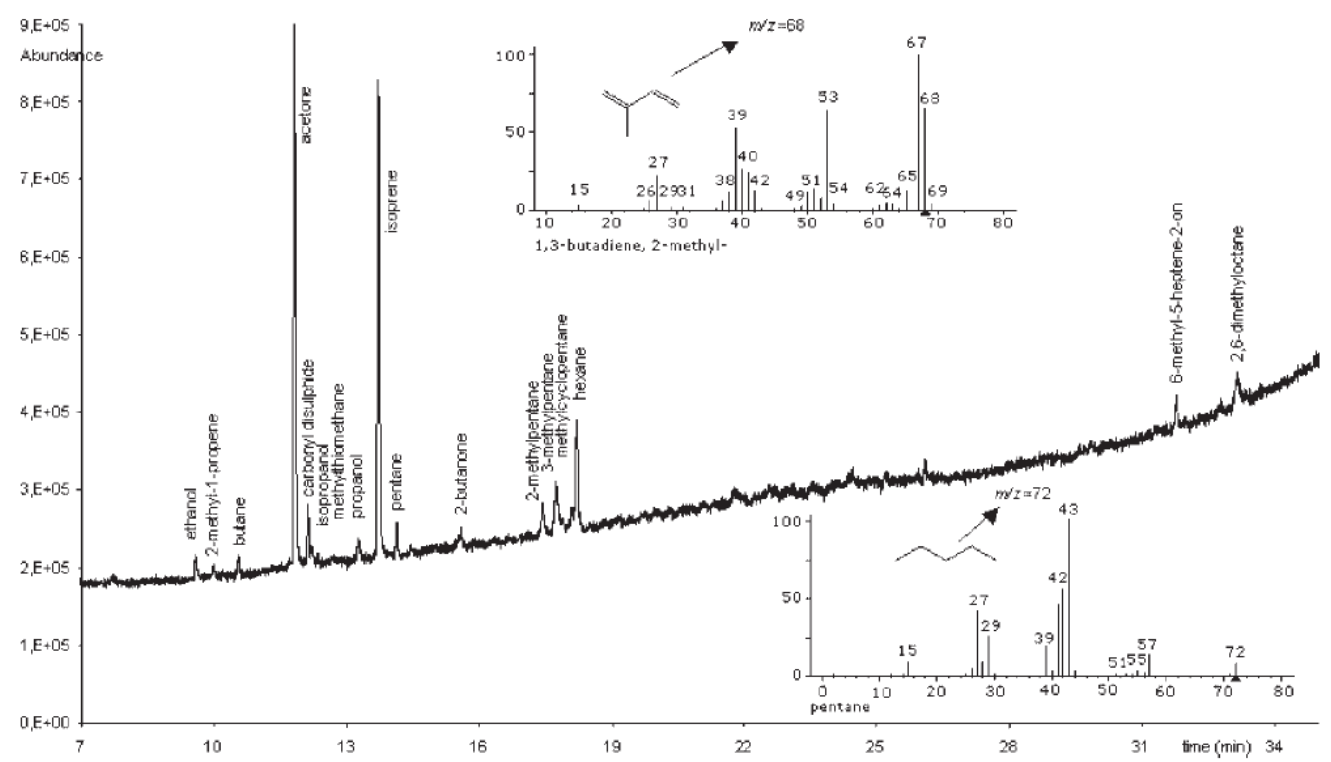

$\underline{\text { Figure } 1.11}$ Normal human breath chromatogram of GC-MS. ${ }^{66}$ 


\subsection{Selected ion flow tube mass spectrometry (SIFT-MS)}

Selected ion flow tube mass spectrometry (SIFT-MS) is a new analytical technique for the real-time quantification of several trace gases simultaneously in air and breath. It relies on chemical ionization of the trace gas molecules in air or breath samples introduced into helium carrier gas using $\mathrm{H}_{3} \mathrm{O}^{+}, \mathrm{NO}^{+}$, and $\mathrm{O}_{2}{ }^{+}$precursor ions. Reactions between the precursor ions and trace gas molecules proceed for an accurately defined time, the precursor and product ions being detected and counted by a downstream mass spectrometer, thus effecting quantification. Absolute concentrations of trace gases in single exhaled breath can be determined by SIFT-MS down to ppb levels, obviating sample collection and calibration. Illustrative examples of SIFT-MS studies include (i) ethanol metabolism, exogenous compounds, elevated acetone during ovulation and breath and urinary headspace studies of metabolites; (ii) analysis of gases from combustion engines, animals and their waste, and food; and (iii) urinary infection and the presence of tumors, the influence of dialysis on breath ammonia, acetone, and isoprene, and acetaldehyde released by cancer cells in vitro. Figure 1.12 shows the principle of the SIFT technique. ${ }^{49}$ The ions listed in the flow tube are the precursor ions (upstream) and examples of the product ions (downstream). Other types of product ions are possible. ${ }^{49}$ 


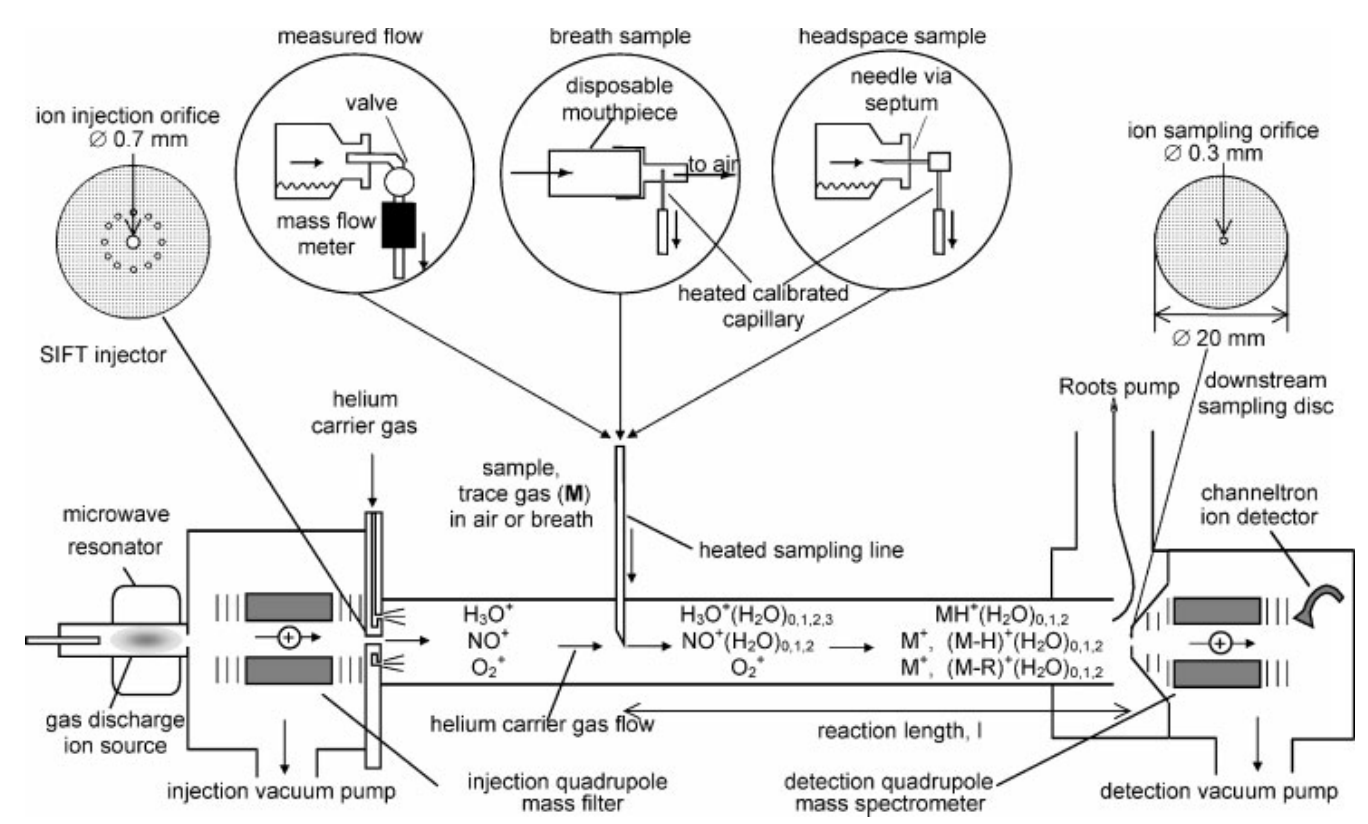

Figure 1.12 A schematic of the SIFT used for the study of ion-molecule reactions. When configured to measure trace gases in air or breath samples it becomes a SIFT-MS.

\subsection{Proton transfer reaction mass spectrometry (PTR-MS)}

PTR-MS is a relatively new technique developed by Lindinger et al. ${ }^{67,68}$ for use in breath research, but very promising because it can deliver results in a real-time online measurement, with high sensitivities for VOCs detection and quantification (up to the pptv range). PTR-MS uses $\mathrm{H}_{3} \mathrm{O}^{+}$ions for proton-transfer reactions with many common VOCs, while having little to no reaction with the highly abundant atmospheric gases $\left(\mathrm{N}_{2}, \mathrm{CO}_{2}\right.$ and $\mathrm{H}_{2} \mathrm{O}$ ) that compose more than $99 \%$ of exhaled breath. ${ }^{67,68}$ PTR-MS is advantageous for complex gas mixtures (like breath samples), as it does not require pre-concentration and separation of samples prior to analysis. The instrument also has very high sensitivity due to the high intensity and relatively high purity of the primary $\mathrm{H}_{3} \mathrm{O}^{+}$that allows the injection of higher currents of reagent ions directly into the drift region without prior mass selection. It is demonstrated that PTR-MS can be used to determine the concentrations of about 30 
VOCs at a sensitivity of a few tens of ppt level (in 2 min). ${ }^{68}$ PTR-MS is suitable for noninvasive, on-line observation of biochemical reactions in the human body. This type of approach is demonstrated to offer some insights into metabolic processes that were previously inaccessible. However, there are a few disadvantages of PTR-MS, for example, the limit of detection and the number of compounds that can be simultaneously analyzed. Further, it is also impossible to separate nominally isobaric VOCs using the classic PTRMS since these compounds all result in protonated molecules via proton transfer reactions with $\mathrm{H}_{3} \mathrm{O}^{+} .{ }^{69}$ According to Herbig et al., ${ }^{70}$ in order to resolve individual phases, it is necessary to have a minimum of $3 \mathrm{~Hz}$ of sampling frequency in an online breath analysis. Thus, this trade-off between the signal-to-noise ratio $(\mathrm{S} / \mathrm{N})$ and the number of measured $\mathrm{m} / \mathrm{z}$ limits the number of compounds that can be simultaneously monitored and the respective limit of detection (LOD) that can be obtained.

\subsection{Electronic nose}

Array-based gas sensors ("Electronic Nose") now offer the potential of a robust analytical approach to exhaled breath analysis for medical use. Electronic noses rely on chemical vapor sensor arrays that respond to particular chemical characteristics of individual molecules, such as VOCs. By analyzing the data obtained from the sensor arrays using statistical or structural algorithms, we can discriminate and identify volatile patterns. The advantages of electronic nose compared to other analytical methods for breath analysis are revealed to be rapid, simple and promising for reducing the time and costs of an early diagnosis of the investigated diseases. 
The most updated electronic nose system used for breath analysis is shown in Figure 13. It is comprised of an array of six commercial chemical gas sensors: MQ-2, MQ3, MQ-9, MQ-135, MQ-137 and MQ-138. ${ }^{71}$ The selection of the gas sensors was based on their sensitivity and selectivity towards different gaseous compounds that can be found in the exhaled breath. In this system, the sensors' limit of detection is sometimes below the VOC's concentration present in breath, so the use of a sensor array distinguishes between the investigated diseases. Immediately after breath collection, the samples were transferred to sensors chamber by pumping the content of each bag at a constant flow rate of 200mL/min. Each sensor underwent a reversible change in its electrical resistance upon exposure to exhaled breath. During the experiment, a relative humidity sensor was used for constantly monitoring this parameter. The total acquisition time for all sensor signals are 5 minutes. Data acquisition system was accomplished using a PCI-6221 and a DAQ interface running on the computer for visualizing and saving the data provided by sensors. Figure 1.13 shows the experimental set-up of a e-nose system.

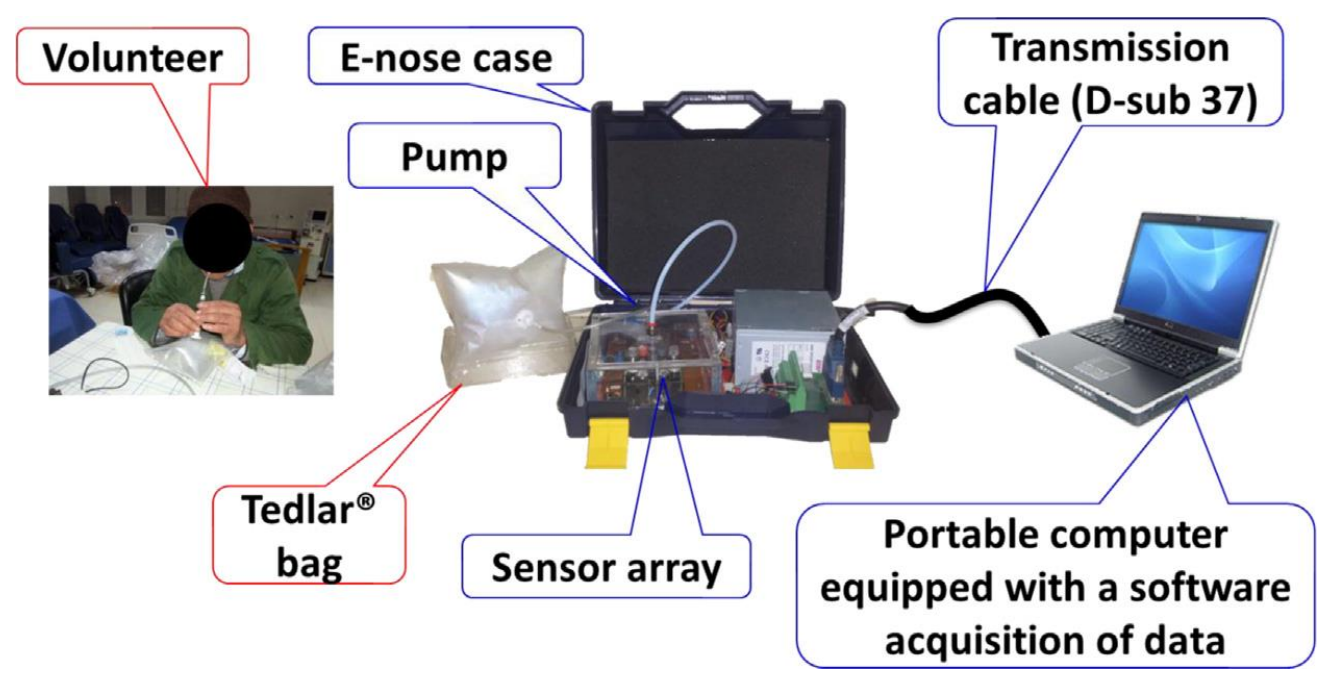

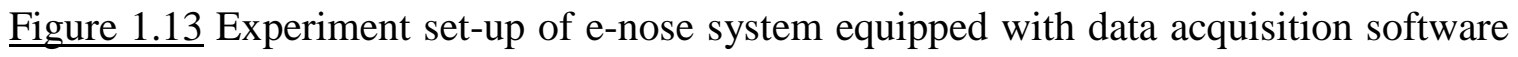
used in exhaled breath measurement. ${ }^{71}$ 


\section{Lung Cancer Biomarkers In Exhaled Breath}

Table 1.4 shows a summary of lung cancer biomarkers researchers have found in recent years. For examples, in 2014, Fu's group used FT-ICR-MS method to detect the carbonyl VOCs in exhaled breath of lung cancer patients and healthy controls. They found that 4 different biomarkers can be used to distinguish the lung cancer patients from healthy controls. They also define the cut off concentration range for the 4 biomarkers. ${ }^{77}$ In 2013 , Broza group using SPME/GC-MS method also found that 3 biomarkers for lung cancer patients although they did not provide the cut off concentration range of these compounds.

Table 1.4

Characterization of selected exhaled breath (EB) volatile organic compounds (VOCs) reported in the literature

\begin{tabular}{|c|c|c|c|c|}
\hline Author, Year & Disease & $\begin{array}{l}\text { Detection } \\
\text { Method }\end{array}$ & Volatile Compounds & Concentration \\
\hline $\begin{array}{l}\text { Kischkel, } \\
2010^{72}\end{array}$ & Lung Cancer & $\begin{array}{l}\text { SPME/GC- } \\
\text { MS }\end{array}$ & $\begin{array}{l}\text { Isoprene } \\
\text { 2-butanone } \\
\text { pentanal }\end{array}$ & $\begin{array}{l}0.095 \mathrm{nM} \\
0.158 \mathrm{nM} \\
0.436 \mathrm{nM}\end{array}$ \\
\hline Fuchs, $2010^{73}$ & & $\begin{array}{l}\text { SPME- } \\
\text { GC/MS }\end{array}$ & $\begin{array}{l}\text { Pentanal } \\
\text { Hexanal } \\
\text { Octanal } \\
\text { Nonanal }\end{array}$ & $\begin{array}{l}0.275 \mathrm{nM} \\
1.208 \mathrm{nM} \\
1.068 \mathrm{nM} \\
8.433 \mathrm{nM} \\
\end{array}$ \\
\hline $\begin{array}{l}\text { Calderia, } \\
2011^{74}\end{array}$ & Asthma & GC-MS & $\begin{array}{l}\text { Decane } \\
\text { Nonane } \\
\text { 3,6-dimethyldecane }\end{array}$ & $\mathrm{NG}$ \\
\hline $\begin{array}{l}\text { Philips, } \\
2012^{75}\end{array}$ & $\begin{array}{l}\text { Pulmonary } \\
\text { tuberculosis }\end{array}$ & GC/MS & $\begin{array}{l}\text { Alkanes and } \\
\text { derivatives } \\
\text { Cyclohexane } \\
\text { Benzene derivatives }\end{array}$ & NG \\
\hline Broza, $2013^{76}$ & Lung Cancer & $\begin{array}{l}\text { SPME/GC- } \\
\text { MS } \\
\text { Sensors }\end{array}$ & $\begin{array}{l}\text { 2-hexanone } \\
\text { 3-heptanone } \\
\text { 2,2,4-Trimethyl- } \\
\text { hexane }\end{array}$ & NG \\
\hline
\end{tabular}




\begin{tabular}{|c|c|c|c|c|}
\hline $\mathrm{Fu}, 2014^{77}$ & Lung Cancer & $\begin{array}{l}\text { FT-ICR- } \\
\text { MS }\end{array}$ & $\begin{array}{l}\text { 2-butanone } \\
\text { 2- } \\
\text { hydroxyacetaldehyde } \\
\text { 3-hydroxy-2-butanone } \\
\text { 4-hydrohexenal }\end{array}$ & $\begin{array}{l}1.78-8.38 \mathrm{nM} \\
0.13-0.77 \mathrm{nM} \\
0.23-1.13 \mathrm{nM} \\
0.005-0.05 \mathrm{nM} \\
\end{array}$ \\
\hline Zou, $2014^{78}$ & Lung Cancer & GC/MS & Hexadecanal & $<2-10 \mathrm{ppb}$ \\
\hline & & & Hexylpentadecane & 72-81.5ppb \\
\hline Handa, $2014^{79}$ & Lung Cancer & IMS & $\begin{array}{l}\text { Dodecane } \\
\text { Hexadecanal } \\
\text { Dec-1-ene } \\
\text { Octanal } \\
\end{array}$ & $\mathrm{NG}$ \\
\hline $\mathrm{Li}, 2015^{80}$ & Lung Cancer & $\begin{array}{l}\text { FT-ICR- } \\
\text { MS }\end{array}$ & $\begin{array}{l}\mathrm{C}_{4} \mathrm{H}_{8} \mathrm{O} \\
4-\mathrm{HHE} \\
\mathrm{C}_{4} \mathrm{H}_{8} \mathrm{O}_{2} \\
\mathrm{C}_{2} \mathrm{H}_{4} \mathrm{O}_{2}\end{array}$ & $\begin{array}{l}2.255 \mathrm{nM} \\
0.00672 \mathrm{nM} \\
0.1595 \mathrm{nM} \\
0.3875 \mathrm{nM}\end{array}$ \\
\hline $\begin{array}{l}\text { Fernandes, } \\
2015^{81}\end{array}$ & Lung Cancer & GC/MS & $\begin{array}{l}\text { Acetaldehyde } \\
\text { Isopropene }\end{array}$ & $\begin{array}{l}<2-10 \mathrm{ppb} \\
72-81.5 \mathrm{ppb}\end{array}$ \\
\hline Bouza, $2017^{82}$ & Oral Cancer & $\begin{array}{l}\text { SPME/GC- } \\
\text { MS }\end{array}$ & $\begin{array}{l}\text { Undecane } \\
\text { Octene } \\
\text { Decanal } \\
\text { benxaldehyde }\end{array}$ & $\mathrm{NG}$ \\
\hline
\end{tabular}

\section{Dissertation Organization}

This dissertation includes six chapters. Chapter 1 provides a review of different methods of detection and analysis of volatile organic compounds in exhaled breath. Chapter 2 investigates different design of microreactors and characterizes them and the kinetics studies of oximation reactions of the aminooxy reagent ATM. Chapter 3 studies the stability of breath VOCs in Tedlar bags. Chapter 4 investigates exhaled breath samples of the patients from Floyd Memorial Hospital and finds that $\mathrm{C}_{3} \mathrm{H}_{6} \mathrm{O}, \mathrm{C}_{2} \mathrm{H}_{4} \mathrm{O}_{2}$ and $\mathrm{C}_{4} \mathrm{H}_{8} \mathrm{O}_{2}$ can serve as biomarkers to distinguish patients with pulmonary nodules from healthy controls. Chapter 5 analyzes exhaled breath samples of the lung cancer patients, patients 
with benign pulmonary nodules and healthy volunteers and found three VOCs (2-butanone, 3-hydroxy-2-butanone and 4-hydroxy-2-nonenal (4-HNE)) to distinguish LC from patients with benign pulmonary nodules and healthy controls. 4-HNE can also be used to distinguish squamous cell carcinoma from adenocarcinoma LC. Chapter 6 provides a summary of overall conclusions and future work for continuous research on this exciting technology. 


\section{CHAPTER II}

\section{CHARACTERIZATION OF MICROREACTOR FOR BREATH ANALYSIS}

\section{Introduction}

In recent years, many studies have shown that certain ketones and aldehydes in human breath could be used as biomarkers for noninvasive diagnosis of lung cancer. PTRMS and SIFT-MS detected ketones and aldehydes in human breath without any preconcentration process. ${ }^{83-86}$ The most difficult part for PTR-MS and SIFT-MS, however, was to identify compounds with certainty since several compounds overlaped on a specific mass-to-charge ratio. Solid phase microextraction (SPME) with adsorbed O-2, 3,4,5,6(pentafluorobenzyl) hydroxylamine hydrochloride (PFBHA) has been used for analysis of aldehydes in human breath. SPME was introduced as a rapid extraction technique for analysis of volatile compounds from a variety of matrices and it was a popular preconcentration method a decade ago. But the SPME method has one major disadvantage, which is its small surface area for reaction. ${ }^{87-91}$ The preconcentrators fabricated on silicon wafers using microelectromechanical system (MEMS) technology typically consist of a microhotplate and an adsorbent placed adjacent to the heating element. Physical adsorption for preconcentration of trace VOCs and thermal desorption to release the adsorbed VOCs 
procedures were used for MEMS preconcentrators. ${ }^{10,11}$ However, MEMS-based preconcentrators have low physical adsorption efficiency and poor selectivity issues. The drawbacks for electronic nose are its low sensitivity and specificity for detecting lung cancer. Exhaled breath condensate (EBC) provides a convenient and non-invasive method for sampling of the airway lining fluid of the respiratory tract, but it is easy for volatilization so it is hard to detect when operating. The exhaled breath is easy to degrade with analysis time increasing, so the most important thing for improving accuracy is to decrease the sample process time as short as possible..$^{92-95}$

In this chapter, we describe a fabricated microreactor with custom-engineered surface functionality for preconcentrating ketones and aldehydes in exhaled breath as cationic derivatives through oximation reaction instead of physical adsorption. The custom-engineered surface functionality was realized by adsorbing quaternary ammonium aminooxy salt, 2-(aminooxy) ethyl-N, N, N-trimethylammonium iodide (ATM), on the surfaces of micropillars in the microreactor. Then we use methanol flow through the microreactor so that the entire trapped analytes can be eluted out and directly analyzed by UHPLC-MS system. In order to decrease the time for analysis, we designed different structures of microreactors. The width of the microreactors was unchanged. The difference is the length; we set $7 \mathrm{~mm}$ as a unit for length. Then we fabricated microreactors with lengths of $7 \mathrm{~mm}, 14 \mathrm{~mm}, 21 \mathrm{~mm}, 28 \mathrm{~mm}$, and $42 \mathrm{~mm}$. All microreactors were then tested for capture of ketones and aldehydes. We also changed the air flow rate through the microreactor to decrease the time for analysis. If we can get same capture efficiency in a very fast flow rate with the longer microreactor compared to the microreactor with $7 \mathrm{~mm}$ in length with very slow flow rate, then this will be a significant improvement. After testing 
this, we use chemical reaction engineering theory to set up a model that can be used to predict the effect of length and flow rate with capture efficiency.

\section{Design and Fabrication}

The design and fabrication process are referring to the procedures of the MEMS device. The design contains 16 microreactors, and each microreactor has a microfluidic channel that has micropillars of circular and triangular shapes. Figure 2.1 shows four screen shots of the photomask design. Figures 2.1.a\&b show the dimensions of the devices, the channel is $7 \mathrm{~mm}$ in width, $14 \mathrm{~mm}$ and $21 \mathrm{~mm}$ in length. Figures $2.1 . c \& d$ show the design of the circular and triangular micropillars. The circular micropillar has a diameter of $50 \mu \mathrm{m}$ and the gap between the pillars is $10 \mu \mathrm{m}$. Each side of the triangular micropillar is $50 \mu \mathrm{m}$ with $10 \mu \mathrm{m}$ gap between the micropillars.

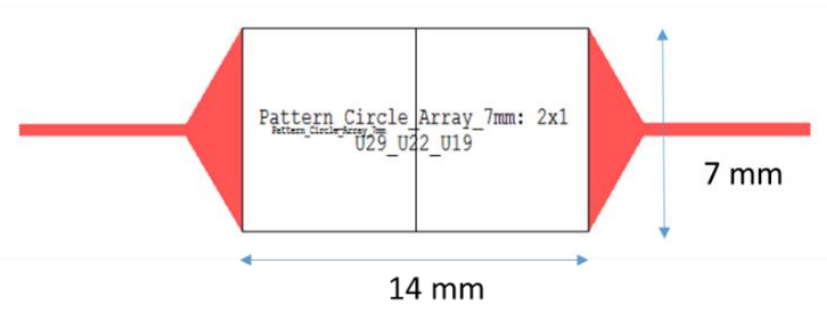

a

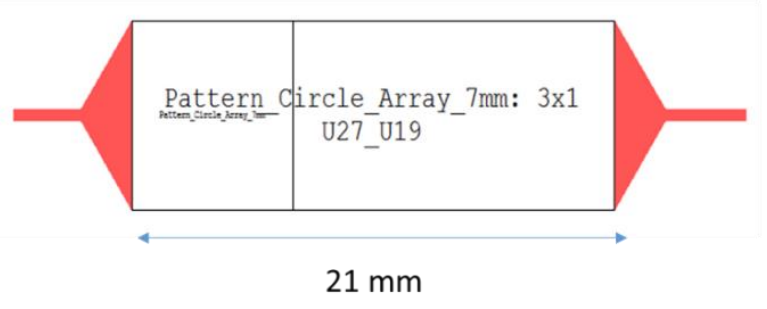

b

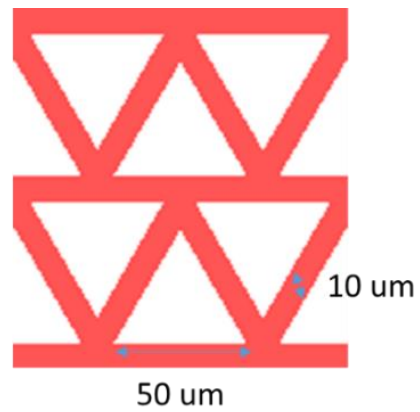

C

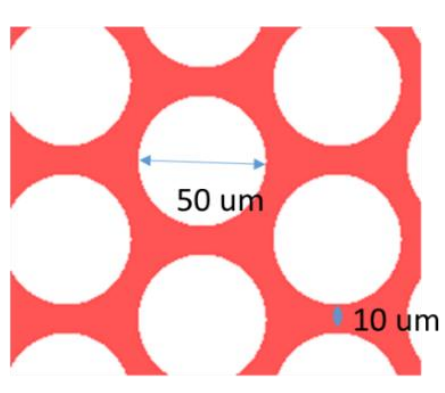

d 


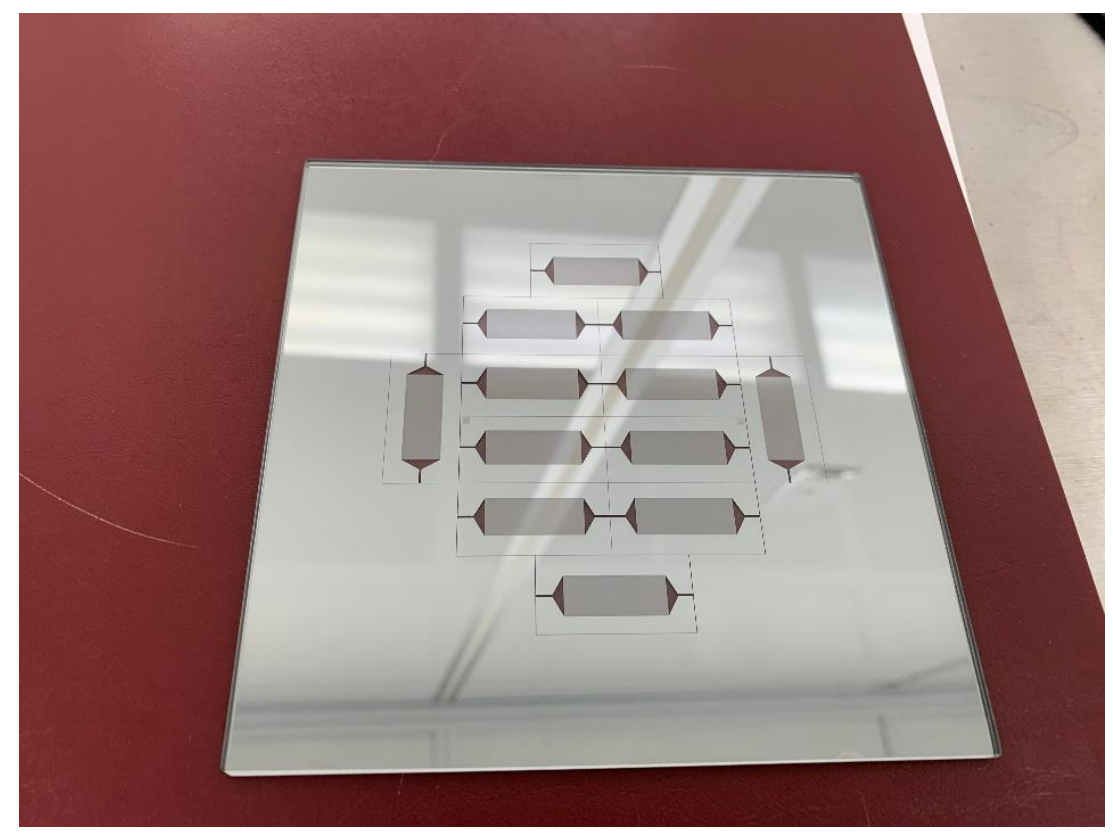

$\mathrm{e}$

Figure 2.1 (a) Layout for a microreactor with a channel of $14 \mathrm{~mm}$ long and $7 \mathrm{~mm}$ wide. (b) Layout of microreactor with a channel of $21 \mathrm{~mm}$ long and $7 \mathrm{~mm}$ wide. (c) Layout of the triangular micropillars. Each side of the triangular micropillar is $50 \mu \mathrm{m}$ and the gap between the adjacent triangles is $10 \mu \mathrm{m}$. (d) Layout of the circular micropillars. The diameter is $50 \mu \mathrm{m}$ and the gap between the micropillars is $10 \mu \mathrm{m}$. (e) Mask layout of $21 \mathrm{~mm}$ length microreactor.

Figure 2.2 illustrates the fabrication steps used to produce the microreactors. The fabrication process was done in the cleanroom of the Micro/Nano Technology Center (MNTC) at University of Louisville. The wafer used for the microreactor fabrication was $100 \mathrm{~mm}$ in diameter, $1000 \mu \mathrm{m}$ in thickness, $<100>\mathrm{p}$ type single side polished silicon wafer. The resistivity of the wafer was $1-20 \Omega-\mathrm{cm}$. The wafer was successively rinsed using acetone, methanol and then deionized (DI) water, dried using a stream of pure $\mathrm{N}_{2}$ gas, and then heated on a hot plate at $115^{\circ} \mathrm{C}$ for 10 minutes before fabrication. Photoresist was 
patterned on the wafer using a photomask containing 16 microreactors. The microreactor had microchannels that contained micropillars with circular and triangular shapes. These micropillars were created by using Deep Reactive Ion Etching (DRIE). The micropillars were thermally oxidized to form an oxidation layer with a thickness from 50 to $100 \mathrm{~nm}$. The last step was bonding the oxidized wafer with Pyrex glass wafer using an anodic wafer bonding process. The bonded wafers were diced into separate microreactors. Fused silica was connected to the ports created by the gap between the etched inlet and outlet and the pyrex glass.

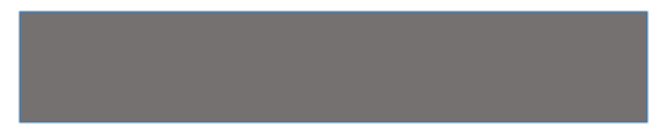

A. Bare Silicon Wafer
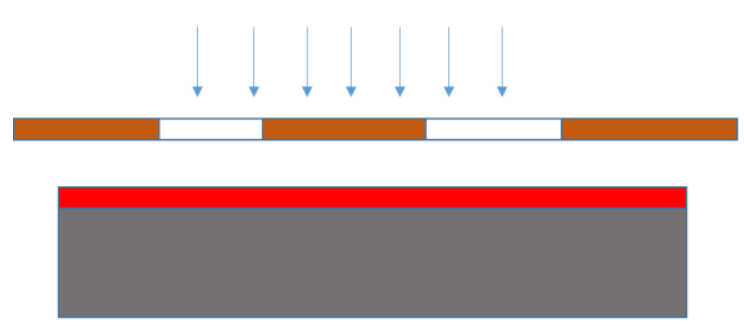

B. Photoresist Coating and UV Exposure



C. Photoresist Development

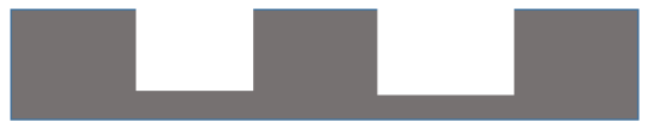

D. Deep Reactive Ion Etching

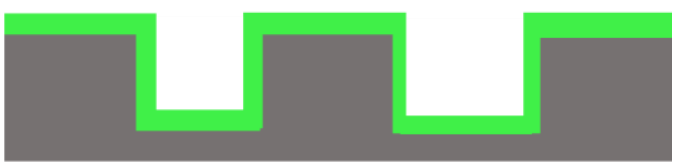

E. Growing of oxidation layer

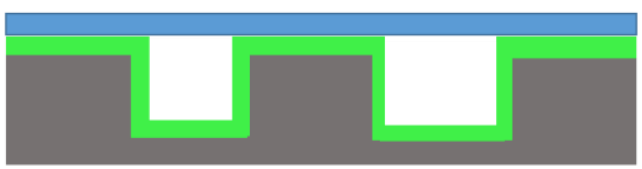

F. Glass Bonding

Figure 2.2 Fabrication process to create the microreactors. (A) Bare silicon wafer. (B) Photoresist patterning using UV exposure. (C) Photoresist development using MF319. (D) Micropillars formation using Deep Reactive Ion Etching. (E) Thermal oxidation of thickness $50 \mathrm{~nm}$ to $100 \mathrm{~nm}$. (F) Anodic bonding of Pyrex glass and the oxidized wafer. 
Details of the fabrication steps are as follows.

\subsection{Photoresist patterning}

A positive photoresist MEGAPOSIT® SPR ® 2207.0 was coated on the prepared silicon wafer at a spin speed of 500 RPM for 1 second and a spread speed of 4000 RPM for 30 seconds. The wafer is soft baked at $115^{\circ} \mathrm{C}$ for 2 minutes. After exposing to the UV source for 55 seconds exposure at $12 \mathrm{~W} / \mathrm{cm}^{2}$ through a photomask on a Karl Suss contact aligner, the wafer is developed in MF319 solution for 90 seconds. The wafer is observed under optical microscope to check whether the patterns are of channel and pillar arrays match the photo mask. If not, the wafer is washed by acetone, methanol and DI water to remove the residual photoresist, blew dry by pure $\mathrm{N}_{2}$, heat up at $115^{\circ} \mathrm{C}$ for 2 minutes and redo the photolithography process. After development, the wafer is hard baked at $115^{\circ} \mathrm{C}$ for 5 minutes. The hard-baked photoresist was used as a protective mask during the etching process. Figure 2.3 shows the microscopic images of the micropillars. The photoresist thickness, measured by the Dektak profilometer, at the center of the wafer was $6 \mu \mathrm{m}$.

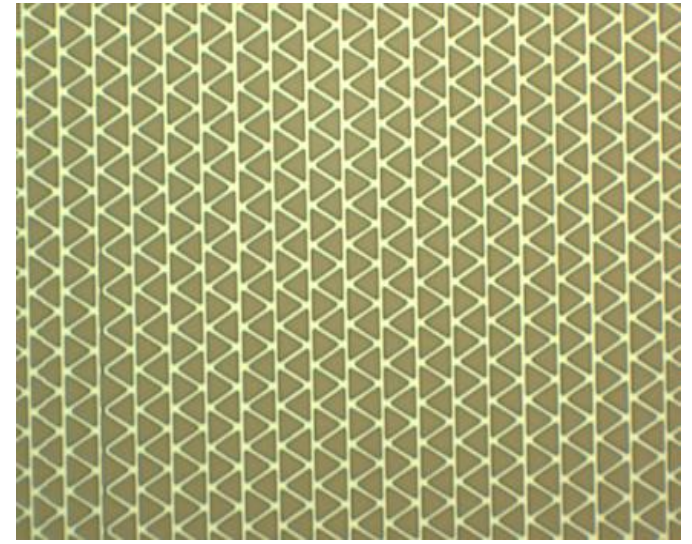

(a)

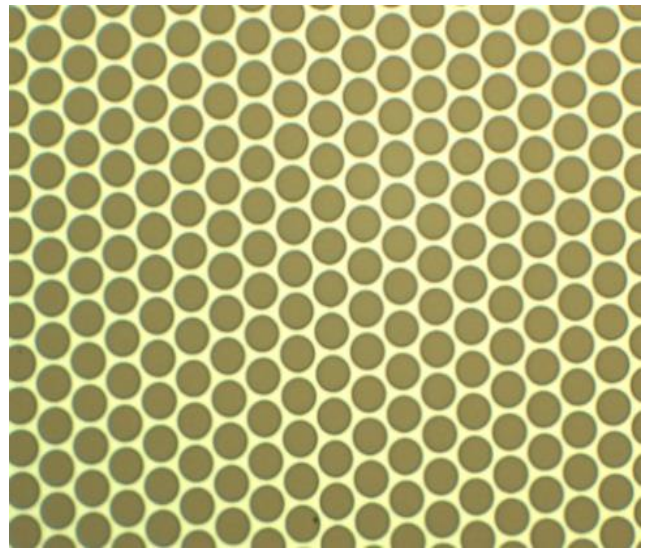

(b)

Figure 2.3 Microscopic images of a) triangular and b) circular micropillars after the photolithography step. 


\subsection{Silicon etching using deep reactive ion etching}

The $370 \pm 10 \mu \mathrm{m}$ height micropillars in the microreactor channel were defined by deep reactive ion etching (DRIE) using STS silicon DRIE machine. The gases used were Sulfur Hexoflouride $\left(\mathrm{SF}_{6}\right)$ and Oxygen $\left(\mathrm{O}_{2}\right)$. The plasma was generated using R.F. signal of frequency $13.56 \mathrm{MHz}$ and power of 800 Watts. The etching time was 83 minutes. The depth of the channel and the height of the micropillars are checked using profilometer. The wafers were put in N-Methyl-2-pyrrolidone (NMP) bath to strip the photoresist followed by oxygen plasma in the March RIE etcher for 1 minute to completely remove any photoresist residues at a condition of 300 watts, Pressure 300 mTorr $\mathrm{O}_{2}$ flow (20\% sccm). Figure 2.4 shows the optical images of the devices were taken using a stereo microscope after the etching process. Figure 2.5 shows the SEM pictures of different shape micropillars.



Figure 2.4 Optical images of the devices using stereo microscope. 

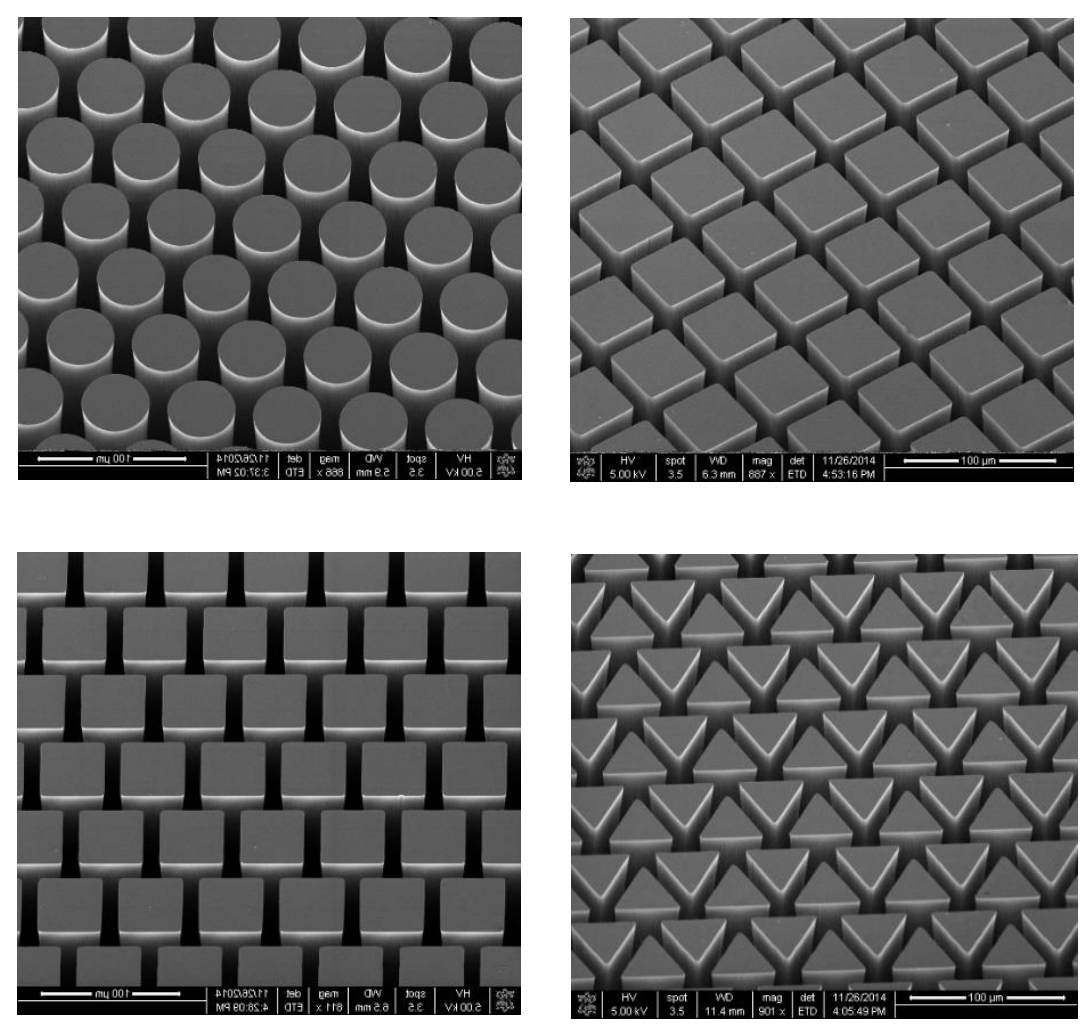

Figure 2.5 SEM images of the cylindrical, diamond, square and triangular shape micropillars.

\subsection{Thermal oxidation}

The wafer is oxidized to form a $50 \mathrm{~nm} \mathrm{SiO}$ layer on the micropillar surfaces in a "wet" $\mathrm{O}_{2}$ and $\mathrm{H}_{2} \mathrm{O}$ atmosphere in a thermal oxidation furnace at $1000^{\circ} \mathrm{C}$ for 12 minutes. The oxide layer thickness was measured using a FILMETRICS system.

\subsection{Bonding and dicing}

The wafer was sealed by anodic bonding with a glass wafer using Suss bonder. Subsequently, the wafer is diced and the connection ports are opened. 


\subsection{Silica tube mounting}

The inlet and outlet of the microreactor were connected with $360 \mu \mathrm{m}$ O.D., $250 \mu \mathrm{m}$ I.D. deactivated fused silica tubes using $3 \mathrm{M}^{\mathrm{TM}}$ Scotch-Weld ${ }^{\mathrm{TM}}$ Instant Adhesive CA4. Figure 2.6 shows the microreactor connected with silica tubes compared to a dime dollar.

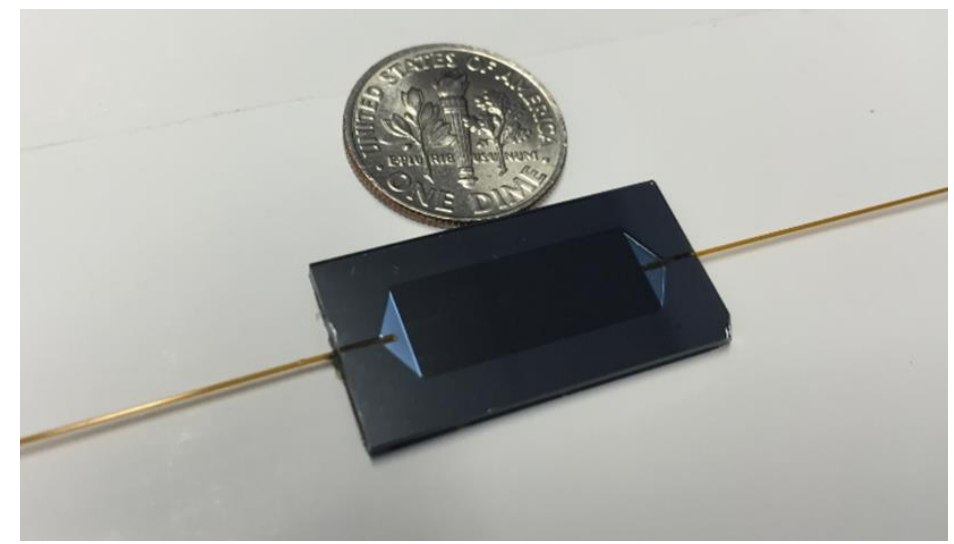

Figure 2.6 The picture of $21 \mathrm{~mm}$ length microreactor compared to a US ten-cent coin.

\section{Materials and Setup}

All reagents and solvents, including deuterated acetone (acetone-d6) (99.9\%), acetone (99\%), 2-butanone (99\%), 2-pentanone (99.5\%), pentanal (99\%), acetaldehyde (98\%), and methanol (99.9\%), were purchased from Sigma-Aldrich. The quaternary ammonium aminooxy compound ATM was synthesized by professor Nantz's group at University of Louisville using the literature procedure. ${ }^{137}$

The quaternary ammonium aminooxy salt, ATM was used as a "capture phase" by coated to the micropillars to trap ketones and aldehydes via oximation reactions. Figure 2.7 shows that schematic illustration of oximation reaction of ATM to capture ketones and 
aldehydes in the microreactor. The surface functionalization of the channels and micropillars with 2-(aminooxy)-N,N, N-trimethylethanam-monium (ATM) iodide was performed by infusion of ATM iodide in methanol solution of known concentration from a $2 \mathrm{~mL}$ vial into the microreactor from one connection port followed by evaporation of the solvent under vacuum. The electrostatic binding of the cationic ATM on the surfaces of the micropillars can be done by the slightly negative surface charge of the silicon oxide micropillars. ATM reacts chemoselectively with trace carbonyl VOCs in exhaled breath by means of oximation with high reactivity. This approach is suitable for quantitative analysis of ketones and aldehydes in exhaled breath. For rapid analysis and identification of trace VOC adducts in a microliter volume sample, UHPLC-MS system was used in the experiment.
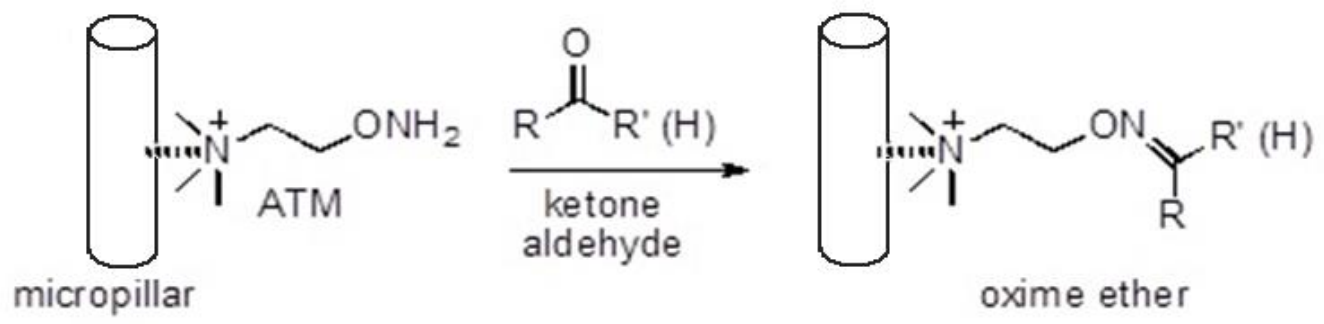

Figure 2.7 Schematic illustration of ATM oximation to capture ketones and aldehydes in the microreactor.

Figure 2.8. Shows the illustration of the instrument set up. A microreactor is connected to a Tedlar bag (Sigma-Aldrich, St. Louis, MO) which contains the air sample from synthetic air in a cylinder. We can adjust the flow rate by using a mechanical needle valve. The flow rate of the sample through the microreactor can be measured by a flow meter. In these experiments, we use a flow meter to set different flow rates: $3.5 \mathrm{~mL} / \mathrm{min}$, 
$5 \mathrm{~mL} / \mathrm{min}, 7 \mathrm{~mL} / \mathrm{min}, 8 \mathrm{~mL} / \mathrm{min}, 10 \mathrm{~mL} / \mathrm{min}, 15 \mathrm{~mL} / \mathrm{min}$ and $20 \mathrm{~mL} / \mathrm{min}$. The microreactor was loaded $30 \mu \mathrm{L}$ ATM in methanol solution which is $1.5 \mu \mathrm{mol}$ in advance and dried in an oven with $60 \mathrm{kpa}$ vacuum and $50{ }^{\circ} \mathrm{C}$ over night.

Air and exhaled breath samples were collected in 1-L Tedlar bag. The detailed protocol for collection of exhaled breath samples was approved by the Institutional Review Board (IRB) at the University of Louisville. For the characterization of different types of microreactors, 1-L $\mathrm{N}_{2}$ collected from a cylinder as carrier gas was infused into Tedlar bag. Then use syringe to add $5 \mu \mathrm{L}$ standard solution to Tedlar bag. The $5 \mu \mathrm{L}$ standard solution contains $5 \mathrm{nmol}$ of each acetaldehyde, pentanal, 2-butanone and 2-pentanone. For the flow rate through the microreactor, we use flow meter to change the valve until the flow rate is $3.5 \mathrm{ml} / \mathrm{min}$. After preparing the samples, the Tedlar bags were collected to the inlet port of the microreactor through one fused silica tube. The exit port of the microreactor was connected to a vacuum pump through the other fused silica tube on the microreactor as shown in Figure 2.8. Then turn on the vacuum pump to pull gaseous sample from a Tedlar bag through the ATM-coated microreactor. After evacuation, disconnect the microreactor. Finally, the reacted ATM adduct and unreacted ATM are eluted from the microreactor by flowing $150 \mu \mathrm{L}$ methanol from one slightly pressurized vial through the microreactor and then into an empty collecting sample vial. Figure 2.9 shows a process of elution. The eluted solutions were directly used for UHPLC-MS analysis without any further process. A known amount of deuterated acetone completely reacted with ATM (ATM-acetone-d6) in methanol was added to the eluted solution as an internal reference (IR). The amount of captured compounds was determined by comparing the UHPLC-MS signal abundance of ATM-acetone-d6 with that of reacted ATM-ketone and ATM-aldehyde. The capture 
percentage can be determined by dividing the amount of captured ketones or aldehydes by the added amount of carbonyl compounds in the Tedlar bag. Then test the flow rate of $5 \mathrm{~mL} / \mathrm{min}, 7 \mathrm{~mL} / \mathrm{min}, 8 \mathrm{~mL} / \mathrm{min}, 10 \mathrm{~mL} / \mathrm{min}, 15 \mathrm{~mL} / \mathrm{min}$ and $20 \mathrm{ml} / \mathrm{min}$ to obtain the capture efficiency at different flow rates.

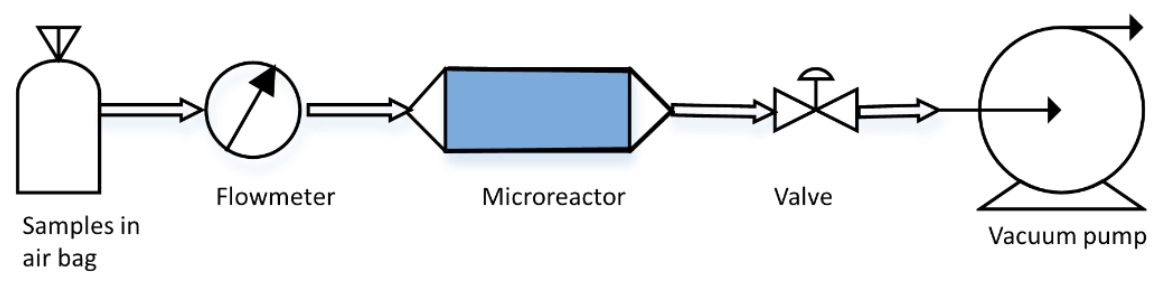

Figure 2.8 Schematic flow diagram of the evacuation process setup.

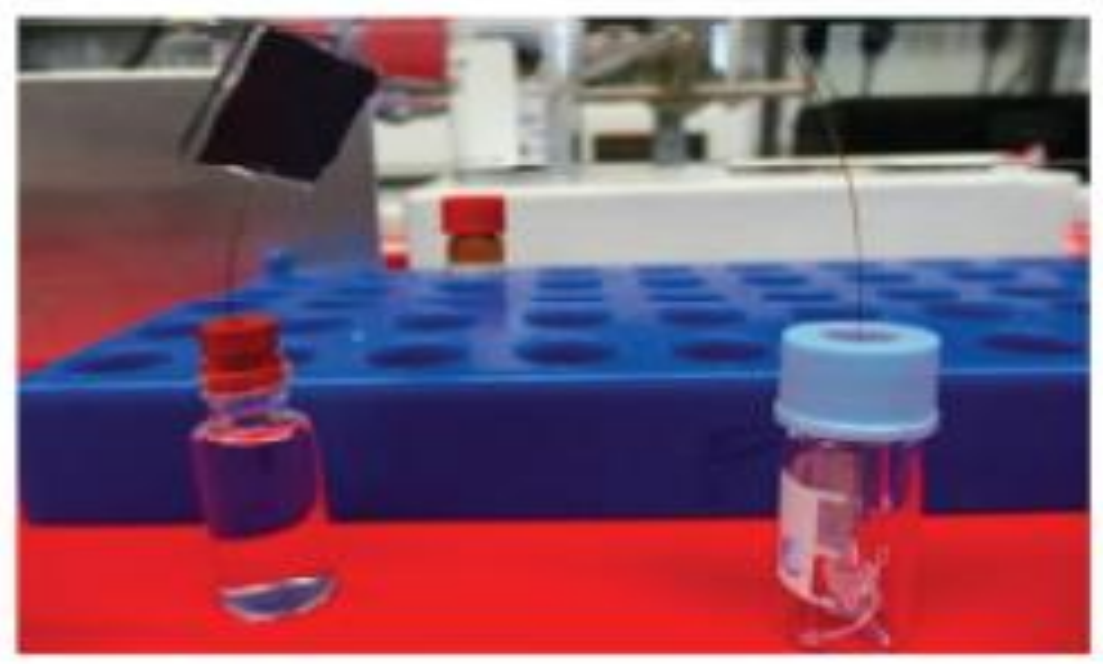

Figure 2.9 Elution of reacted ATM adducts and unreacted ATM from the microreactor.

\section{Results and Discussion}

Besides the flow rate effects on capture efficiency, we also designed experiments to study whether the distance between micropillars and different pillar shapes affect capture efficiency. For the pillar distance effect experiment, we designed 3 different distance 
micropillars, $10 \mu \mathrm{m}, 25 \mu \mathrm{m}$ and $50 \mu \mathrm{m}$. We also designed the 4 different shapes micropillars, triangle, circle, diamond and square shape.

$1.5 \times 10^{-6} \mathrm{~mol}$ of ATM in methanol was loaded into the microreactor and dried, then $5 \times 10^{-9} \mathrm{~mol} 2$-pentanone, 2-butanone, acetaldehyde and pentanal dissolved in $5 \mu \mathrm{L}$ methanol were injected into $1 \mathrm{~L}$ Tedlar bag which contain $1 \mathrm{~L}$ pure nitrogen. Then the samples were evacuated through the microreactors under vacuum. After evacuation, ATM-carbonyl adducts were eluted from the microreactors with $150 \mu 1$ methanol to afford $\geq 99 \%$ recovery of adducts. The eluted solution was analyzed by UHPLC-MS system. Figure 2.10 (a) shows that for the microreactors with cylindrical micropillars, as the flow rate increases from 2.5 $\mathrm{ml} / \mathrm{min}$. The capture efficiencies of 2-butanone, 2-pentanone, acetaldehyde and pentanal all are linearly decreased. Figure 2.10 (b) shows that as the gap between micropillars decrease from $50 \mu \mathrm{m}$ to $10 \mu \mathrm{m}$, the capture efficiencies of 2-butanone, 2-pentanone, acetaldehyde and pentanal all are linearly increase. We also examined the micropillar shape effect on the capture efficiency. Figure 2.10(c) show four different shapes of the microreactors with the capture efficiencies. The shape of triangle has the highest capture efficiency. After these experiments, we conclude that the smaller the micropillar distance, the higher capture efficiency. High flow rate will decrease the capture efficiency and the triangular shape micropillars can achieve the highest capture efficiency. After this study, we find the optimal design of microreactors for capture trace ketones and aldehydes. So in the following research, we designed optimized microreactors with the triangular shape of micropillars and the distance between micropillars at $10 \mu \mathrm{m}$. 


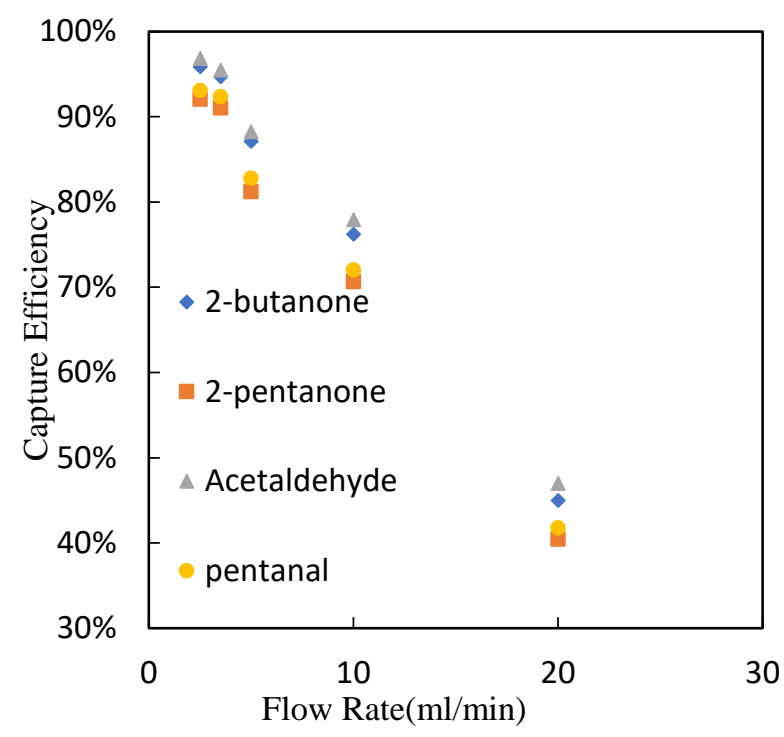

(a)

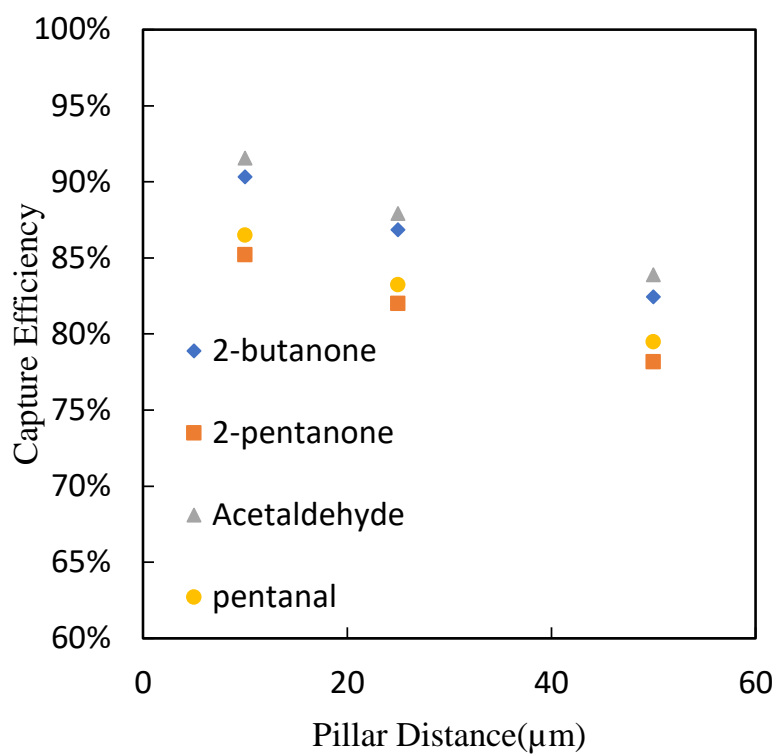

(b)

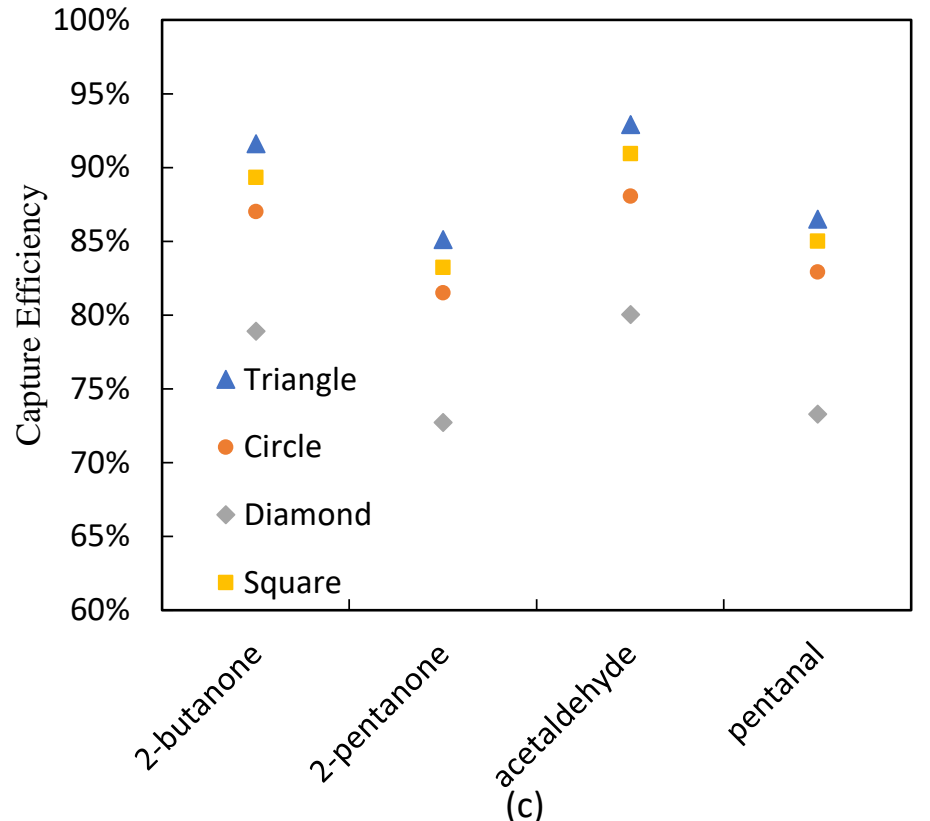

(c)

Figure 2. 10 (a): Relationship between capture efficiency and flow rate of the microreactors with cylindrical micropillars, (the distance $=10 \mu \mathrm{m}, \mathrm{L}=7 \mathrm{~mm}$ ). (b): Relationship between capture efficiency and the distance at a flow rate of $5 \mathrm{ml} / \mathrm{min}$. (Square, $\mathrm{L}=7 \mathrm{~mm}$ ), (c) 
Relationship between capture efficiency and the shapes of the micropillars (the distance $d$ $=10 \mu \mathrm{m}$, flow rate $=5 \mathrm{~mL} / \mathrm{min}, \mathrm{L}=7 \mathrm{~mm}$ )

Although we found the optimal design of microreactors that have a high capability to capture trace ketones and aldehydes in air and breath, there still exists a significant issue, which is that the operating time is very long. Currently, the volume of the bag we use is $1 \mathrm{~L}$ and the flow rate experiment shows that high flow rate significantly decreases the capture efficiency of the microreactors. In order to achieve higher than $90 \%$ capture efficiency, we can only use a flow rate of $3.5 \mathrm{~mL} / \mathrm{min}$ which means the time needed to evacuate the sample is about 5 hours. This is a huge drawback. So our next target is to reduce the evacuation time. There are two ways that we considered. One is to load more ATM into the microreactor, and the other is to increase the flow rate but need to get the same capture efficiency. For the first method, we use a $7 \mathrm{~mm}$ length microreactor with triangle shape micropillars and pillar distance $10 \mu \mathrm{m} .1 \times 10^{-6} \mathrm{~mol}$ ATM was loaded into microreactor as a onetime loading, second set $1.5 \times 10^{-6} \mathrm{~mol}$ ATM was loaded, third set $3 \times 10^{-6} \mathrm{~mol} \mathrm{ATM}$ was loaded into microreactor. $5 \mathrm{nmol}$ acetaldehyde, pentanal, 2-butanone and 2-pentanone dissolved in $5 \mu \mathrm{L}$ methanol was injected into $1 \mathrm{~L}$ Tedlar bag which filled with $1 \mathrm{~L}$ pure Nitrogen. Different capture efficiencies were achieved under different flow rate. Figure 2.11 shows that 4 different compounds capture efficiencies under different flow rate with different ATM loading. The loading change almost has no effect on capture efficiencies of all compounds. This is mostly because the concentration of ATM was much larger than that of the compounds to be captured. In this case, we need to use the second way. For the second way, we proposed a different design of microreactor with increasing the length of the microreactor, this increase the numbers of micropillars inside the microreactor and also 
the residence time which make it possible to capture more carbonyl compounds in a short time.

A designed microreactor with triangular micropillar shape and $10 \mu \mathrm{m}$ distance between micropillars was fabricated. The difference compared with the $7 \mathrm{~mm}$ generation chip is that the length is double, triple, 4 times and 6 times of the first generation chip. In order to obtain higher capture efficiency with higher evacuation flow rate. $1.5 \mu \mathrm{mol}$ of ATM was loaded into the microreactor with $14 \mathrm{~mm}$ length, $21 \mathrm{~mm}$ length, $28 \mathrm{~mm}$ length and $42 \mathrm{~mm}$ length microreactor. 1L pure nitrogen was filled in Tedlar bags from a cylinder of 99.99\% high purity nitrogen to evacuate through the microreactor by a vacuum pump. $5 \mu \mathrm{L}$ mix standard solution (this $5 \mu \mathrm{L}$ solution contains $5 \mathrm{nmol}$ of Acetaldehyde, Acetone, 2butanone and Pentanal, respectively), was injected to the $1 \mathrm{~L}$ nitrogen Tedlar bag. With the fabricated microreactors, we start to characterize the microreactor with different flow rates. Here we tested the flow rate of $3.5 \mathrm{~mL} / \mathrm{min}, 5 \mathrm{~mL} / \mathrm{min}, 7 \mathrm{~mL} / \mathrm{min}, 8 \mathrm{~mL} / \mathrm{min}, 10 \mathrm{~mL} / \mathrm{min}$, $15 \mathrm{~mL} / \mathrm{min}$ and $20 \mathrm{~mL} / \mathrm{min}$. After the evacuation process, ATM and its adducts were eluted out of the microreactor with $200 \mu \mathrm{L}$ methanol and the eluted solutions were then analyzed by UHPLC-MS. The capture efficiencies at different flow rates were then obtained. 


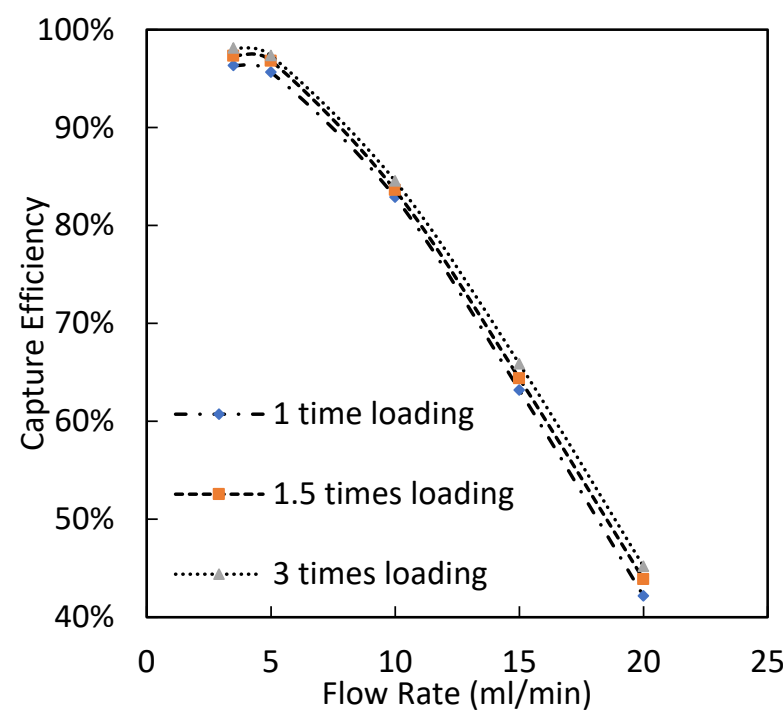

(a)

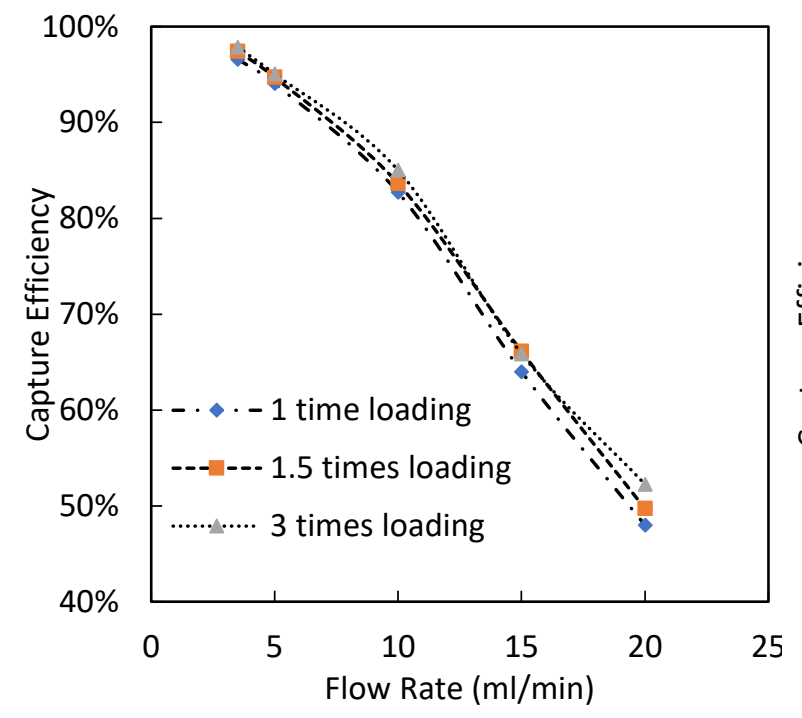

(c)

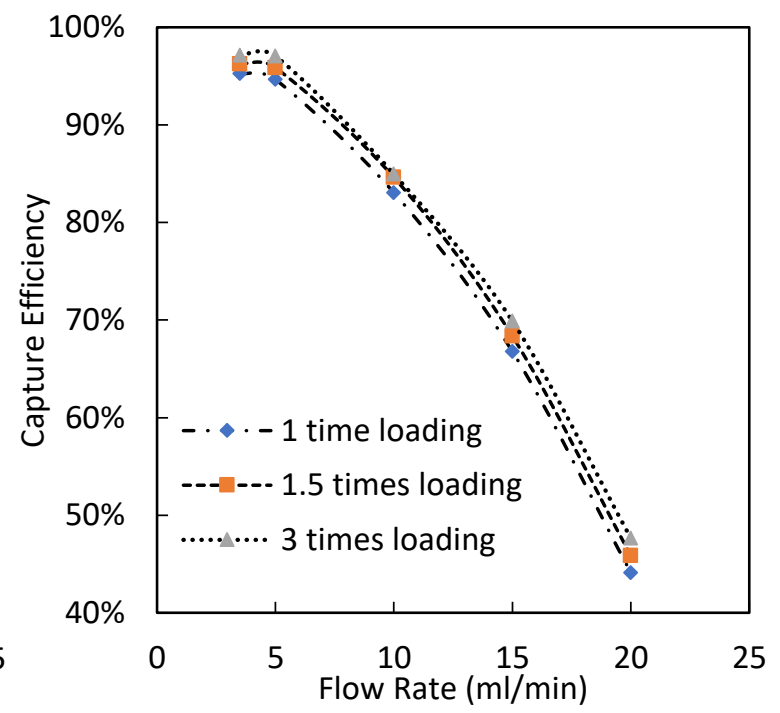

(b)



(d)

Figure 2.11 Relationship between capture efficiency and flow rate of the microreactors with cylindrical micropillars at different ATM loading; (a) Acetaldehyde, (b) pentanal, (c) 2-butanone and (d) 2-pentanone (the distance $=10 \mu \mathrm{m}, \mathrm{L}=7 \mathrm{~mm}$ ).

Figure 2.12 shows that all the capture efficiencies decrease as the flow rate increases. It is obvious that the microreactor with six times of the length $(42 \mathrm{~mm})$ of the 
first generation microreactors has the highest capture efficiencies compared to other design of microreactors at the same flow rate. When the flow rate is less than $5 \mathrm{~mL} / \mathrm{min}$, the difference of the capture efficiencies among different length microreactors is very small because at low flow rate, the capture efficiency already reaches above $95 \%$. For the 4 - and 6-times length microreactors, the capture efficiency is still above $95 \%$ even though the flow rate is at $10 \mathrm{~mL} / \mathrm{min}$ and the difference between these two length microreactor is small. When the flow rate increases to higher than $10 \mathrm{~mL} / \mathrm{min}$, the capture efficiencies of all microreactors decrease to below $90 \%$. Therefore, the flow rate of $10 \mathrm{~mL} / \mathrm{min}$ should be the maximum flow rate that can be used for evacuation of exhaled breath samples. Now the process time will only take one-third of the original process time which is a great progress of this research. Previously we use the flow rate of $3.5 \mathrm{~mL} / \mathrm{min}$ to evacuate breath samples, it will take about 6 hours to finish one $1 \mathrm{~L}$ sample. For the one length $(7 \mathrm{~mm})$ microreactor, in order to achieve $95 \%$ capture efficiency, the flow rate needs to be lower than $3.5 \mathrm{ml} / \mathrm{min}$. For $21 \mathrm{~mm}$ length or longer length microreactor, the flow rate can increase up to $8 \mathrm{ml} / \mathrm{min}$ with the same $95 \%$ capture efficiency. It is not always better to increase the length of microreactor, one concern is that if the microreactor is too long, it will be hard to operate during the process and it is not good for loading more ATM and eluting process due to contamination and recovery of ATM adducts. Also the cost of fabrication will increase for the longer microreactors. After considering the effect of operation, economic and practical application, we conclude that $21 \mathrm{~mm}$ length microreactors will be the best design for breath analysis since it can achieve high capture efficiency at high flow rate (up to $8 \mathrm{~mL} / \mathrm{min}$ ). 


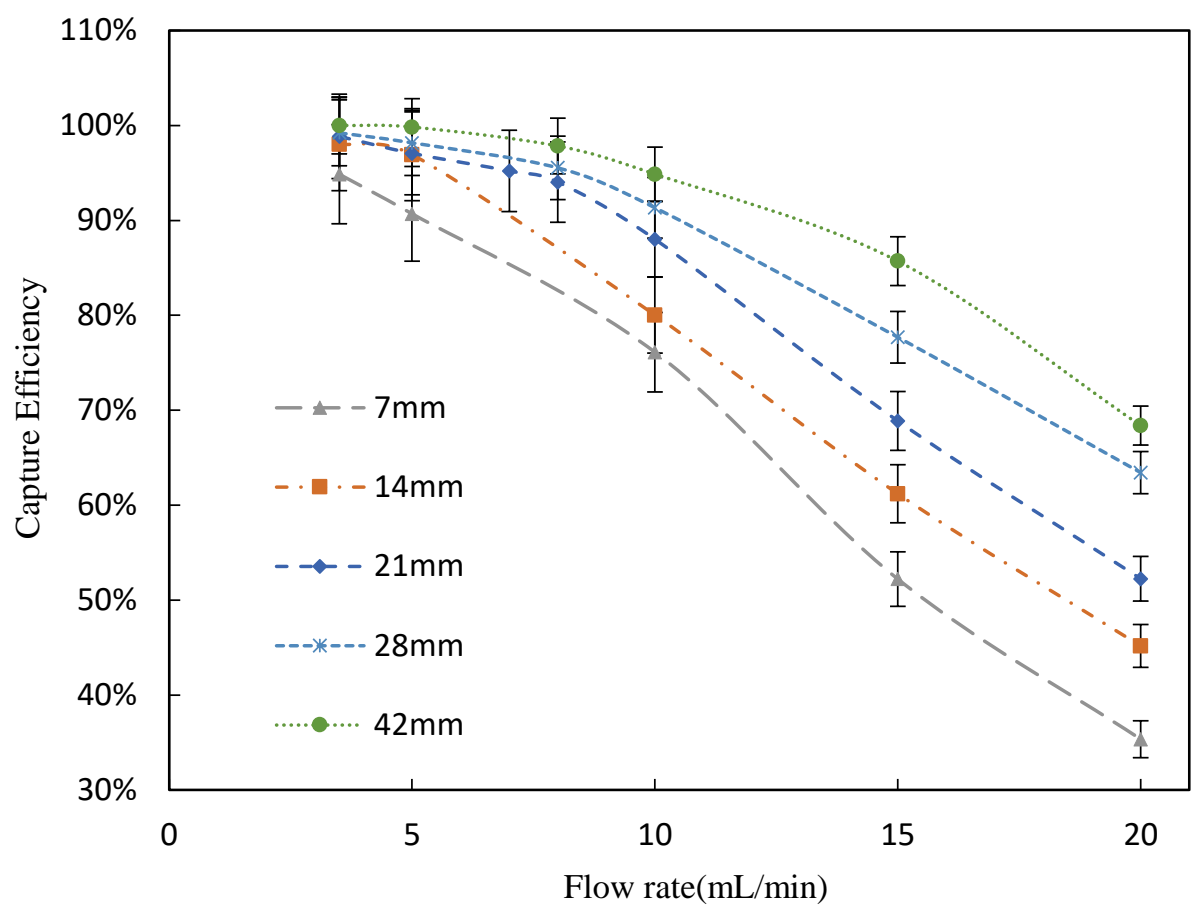

(a)

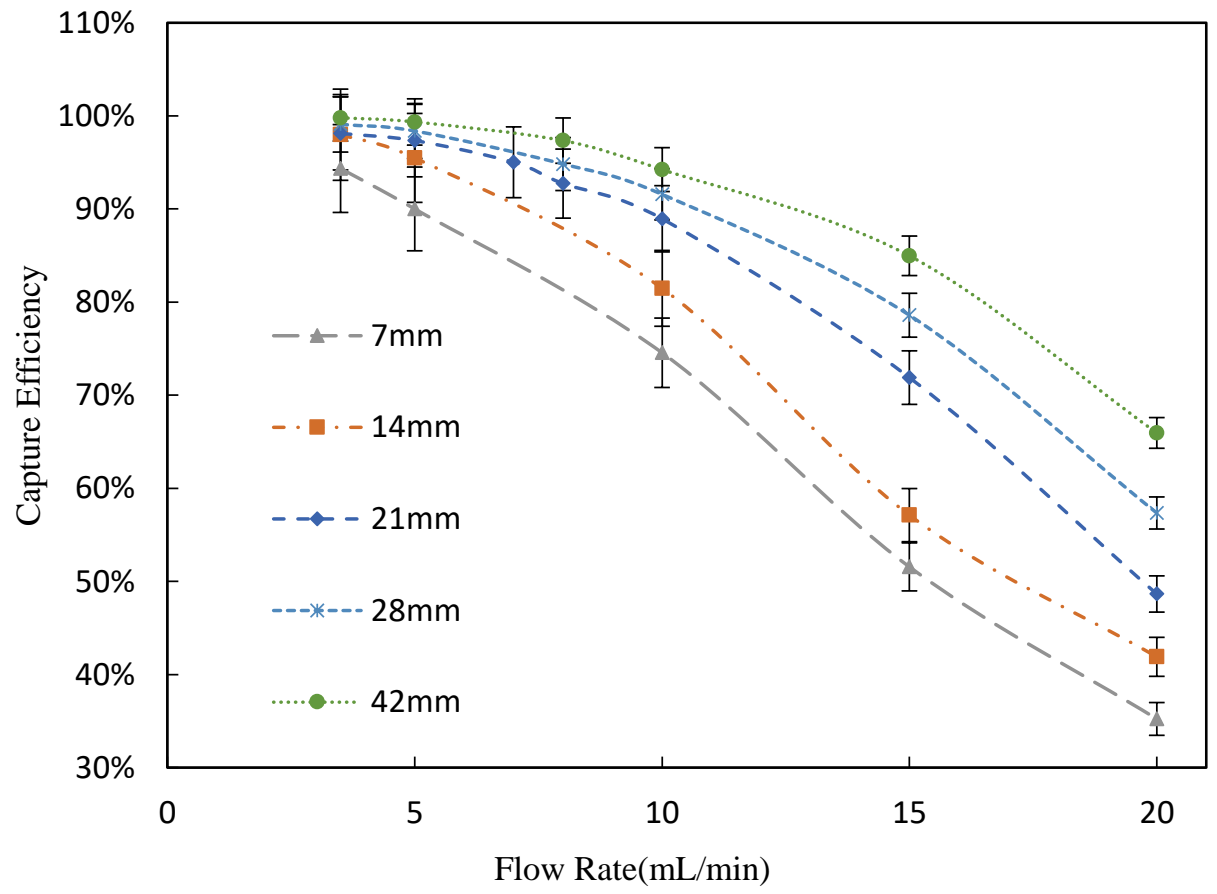

(b) 


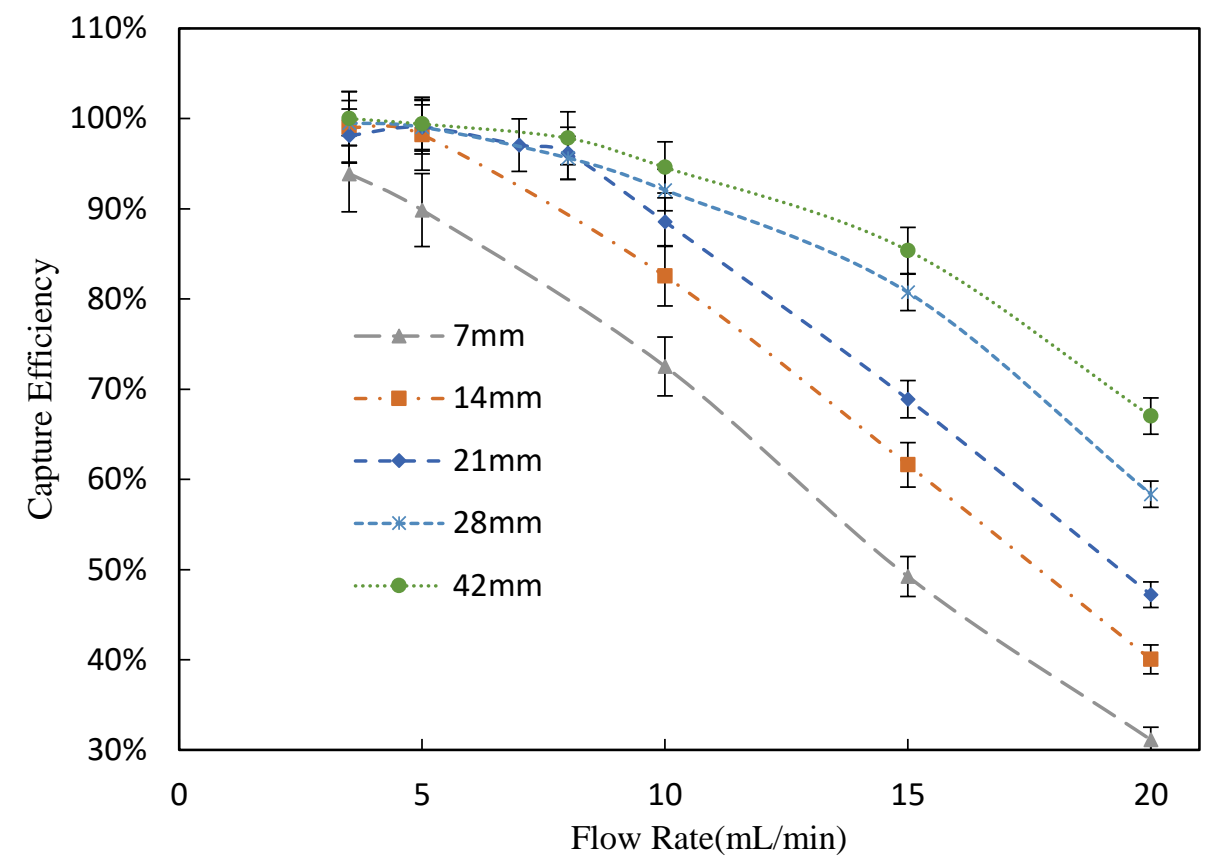

(c)

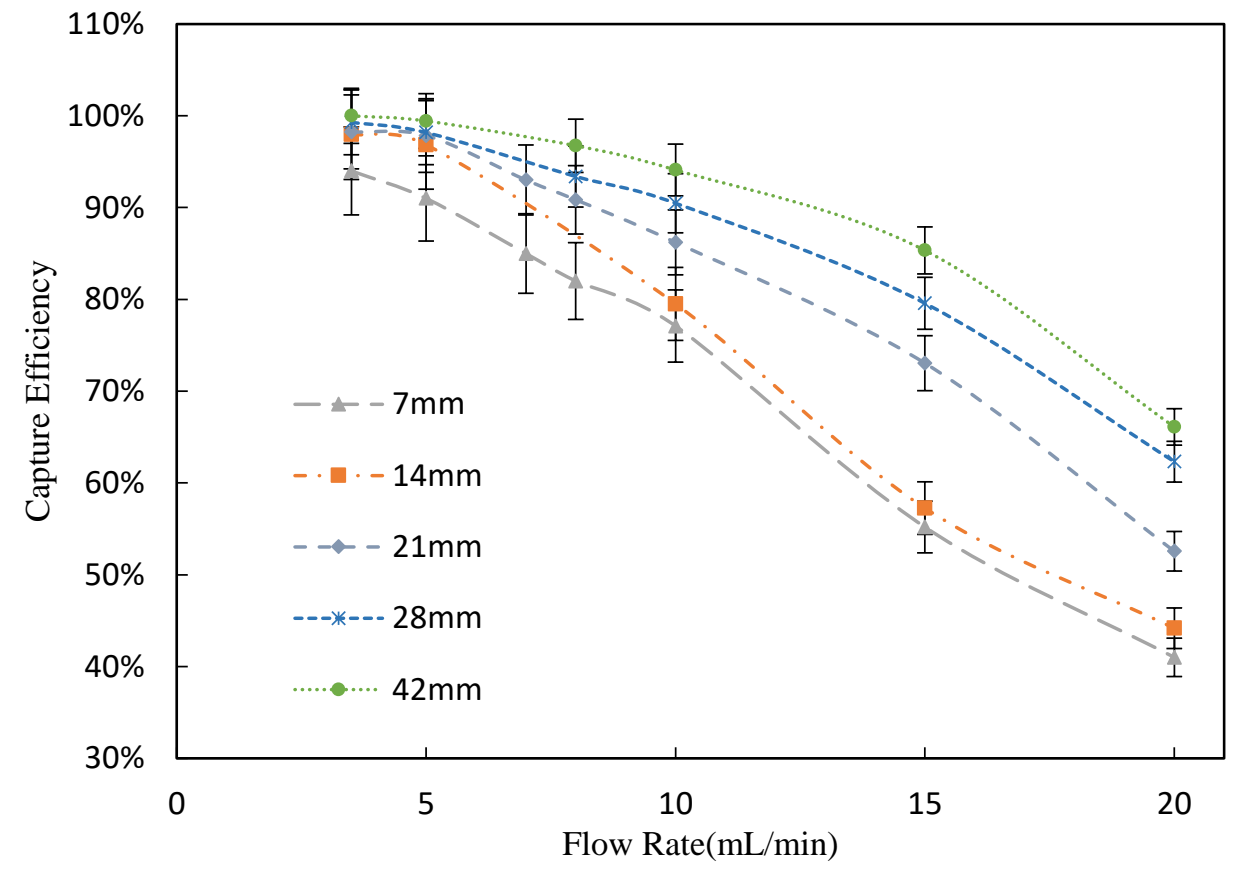

(d)

Figure 2.12 The capture efficiency with different flow rate using different length of design microreactors. (a) acetaldehyde (b) acetone (c) 2-butanone (d) pentanal. 


\section{Modeling of the Microreactor}

In the previous study, we found that the different length of microreactors can achieve different capture efficiency under different flow rate of gaseous samples. Overall, the longer microreactors can achieve higher capture efficiency. So, we finally choose to use $21 \mathrm{~mm}$ length microreactor for capture VOCs in order to balance the cost of wafer, ATM loading and the capture efficiency. In order to further understand the relationship between the capture efficiency and the length of the microreactors, we endeavor to establish a model to predict the relationship between the flow rate and the capture efficiencies of carbonyl compounds.

The microreactors are microliter-sized reactors that have thousands of vertical micropillars which are coated with ATM on the surfaces. The air flows through the empty area between micropillars and ATM captures VOCs by oximation reaction during this process. So we simplify this microreactor as a packed bed reactor. Applying chemical reaction theory, we can find whether this capture process is mass transfer-limited, or reaction limited.

\subsection{Kinetics study of oximation reaction in microreactor}

In order to further design aminooxy salts for selective capture of some specific carbonyl compounds, the reaction kinetics of aminooxy salts with ketones, aldehydes were studied.

The whole experiment set up is the same as previous described, $21 \mathrm{~mm}$ length microreactor was used in this experiment. A constant amount of $1.5 \times 10^{-6}$ mol ATM was loaded into microreactor and dried in oven. $5 \times 10^{-9}$ to $1 \times 10^{-6}$ mol 2-butanone, acetone, 
acetaldehyde and pentanal dissolved in $5 \mu \mathrm{L}$ methanol was injected into Tedlar bag which filled with $500 \mathrm{~mL}$ pure nitrogen. The flow rate of gaseous samples was adjusted to $7 \mathrm{~mL} / \mathrm{min}$ by a flowmeter. Each experiment was operated under four different temperatures $\left(30^{\circ} \mathrm{C}, 50^{\circ} \mathrm{C}, 70^{\circ} \mathrm{C}\right.$ and $\left.90^{\circ} \mathrm{C}\right)$. The microreactor was eluted out with $200 \mu \mathrm{L}$ methanol for UHPLC-MS analysis. Different conversions were measured from difference concentrations of carbonyl compounds. Figure 2.13 shows that, as carbonyl concentration increases, the conversion also increases. The conversion of acetone was higher than those of 2-butanone, acetaldehyde and pentanal at the same carbonyl concentration while 2butanone conversion is higher than pentanal. These results also imply that the ATM reaction rate with low molecular weight aldehydes may be greater than that with high molecular weight aldehydes, same trend for ketones. These results may imply the difference in reaction kinetics of carbonyls with ATM. The dependence of the ATMcarbonyl formation rate on the carbonyl concentrations is displayed in Figure 2.14. It is clearly visible, how the reaction rate increased with the increase of the carbonyl concentrations. Figure 2.14 shows that the curve of different carbonyl concentrations is rather linear. Thus, it reveals that the carbonyl reaction order is close to one. In order to figure out the exact reaction order of carbonyl reaction, the logarithm of the rate of formation of ATM-Carbonyls as a function of the logarithms of the carbonyl concentrations is plotted in Figure 2.15. It reveals the apparent reaction order for carbonyl is 0.9024 , which is very close to the first order reaction.

The volume of $21 \mathrm{~mm}$ length microreactor is $0.0588 \mathrm{~mL}$, five different flow rates of $3.5 \mathrm{~mL} / \mathrm{min}, 5 \mathrm{~mL} / \mathrm{min}, 7 \mathrm{~mL} / \mathrm{min}, 10 \mathrm{~mL} / \mathrm{min}$ and $15 \mathrm{~mL} / \mathrm{min}$ was used for evacuating all samples. $5 \times 10^{-9} \mathrm{~mol}$ of 2-butanone, acetone, acetaldehyde and pentanal was injected into 
$500 \mathrm{~mL}$ Tedlar bags, each sample was tested under 5 different flow rate and calculate capture efficiency. (take 2-butanone as an example, if we consider the molecular flow through the microreactor during the residence time which is effective reaction time $(\mathrm{t}=1.008 \mathrm{~s}$ for $3.5 \mathrm{~mL} / \mathrm{min}$ flow rate), during this time, the ATM will capture some of the molecular and some molecular escapes from the microreactor. When the $500 \mathrm{~mL}$ Tedlar bad was fully evacuated, the capture amount of 2-butanone inside the microreactor was calculated, the uncaptured amount escaped from the microreactor. The uncaptured amount also accumulated from the time the gas flow through the microreactor. So at a very short time, the volume of gaseous goes from the inlet of microreactor equals to that from outlet port. The whole process of evacuation was accumulated by lots of residence time. So the natural logarithm of the ration of concentration of inlet and outlet $\ln \frac{C_{\text {inlet }}}{C_{\text {outlet }}}$ can be calculated byln $\left.\left(\frac{1}{1-C E}\right)\right)$ CE stands for capture efficiency.

$$
\text { ATM }+2 \text { - butanone } \rightarrow \text { ATM }-2 \text { - butanone }+\mathrm{H}_{2} \mathrm{O}
$$

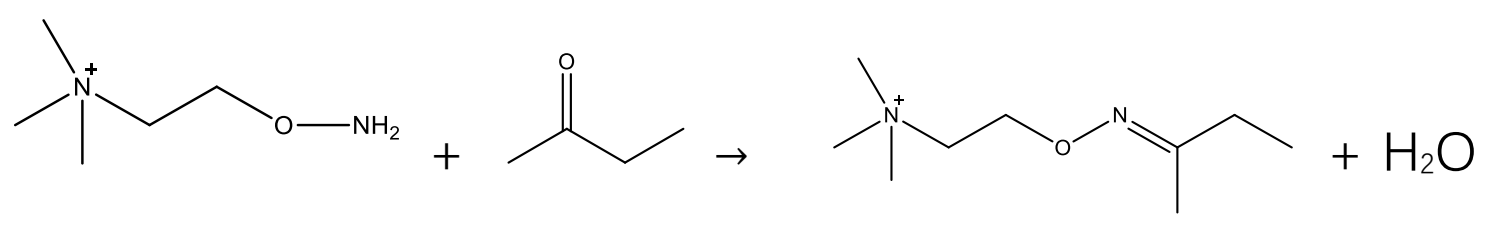

Scheme 1. A Scheme of ATM reacted with 2-butanone.

The reaction is first order for both ATM and carbonyl compounds. The molar amount of ATM in the experiments is much larger than carbonyls (at least 100:1), ATM concentration (amount) is considered as a constant and is included in the reaction constant $k$. Thus, the reaction rate (r) of 2-butanone with ATM is given as follow: 


$$
\begin{aligned}
& r=\frac{d C_{2-\text { butanone }}}{d t}=-k C_{2-\text { butanone }} \\
& \frac{d C_{2-\text { butanone }}}{C_{2-\text { butanone }}}=-k \mathrm{dt}
\end{aligned}
$$

Integrating with initial condition $\mathrm{C}=\mathrm{C}_{0}$ at $\mathrm{t}=0$, we have:

$$
\ln \frac{C_{\text {inlet }}}{C_{\text {outlet }}}=k t
$$

The reaction rate constant $k$ can be obtained by linear regression between the natural logarithm of the ratio of concentration of inlet and outlet $\ln \frac{C_{\text {inlet }}}{C_{\text {outlet }}}$, which can be calculated from the measured capture amount of compound, and the reaction time (t). Figure 2.16 shows the regression plots between these two with 2-butanone.

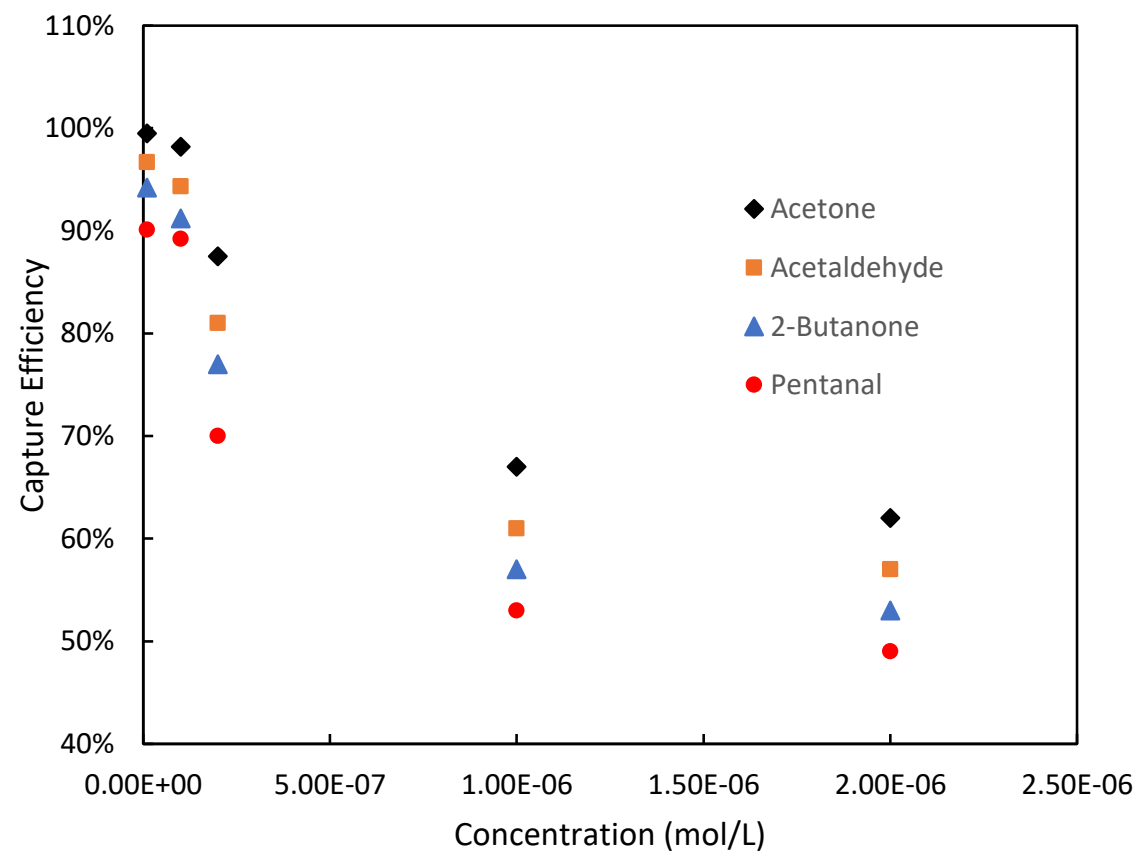

Figure 2.13 Relationship between carbonyls conversion and concentration. 


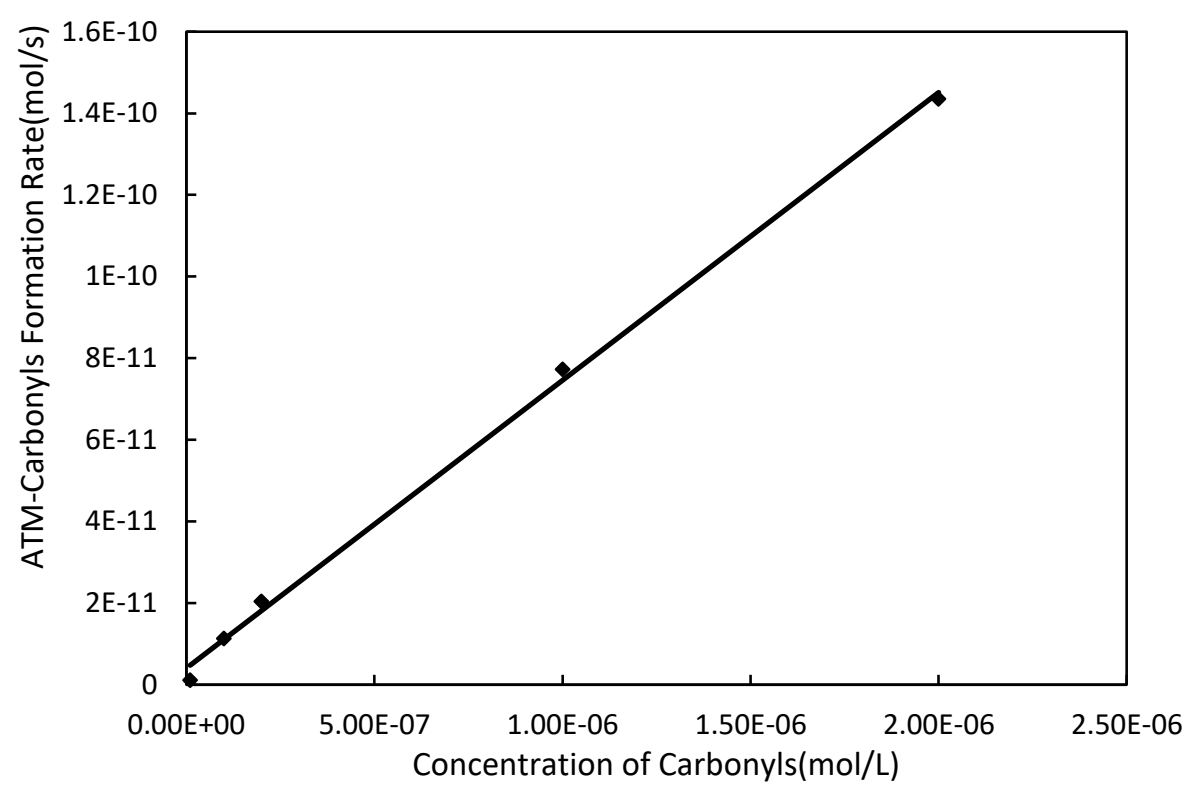

Figure 2.14 ATM-Carbonyls formation rate at different carbonyl concentrations.

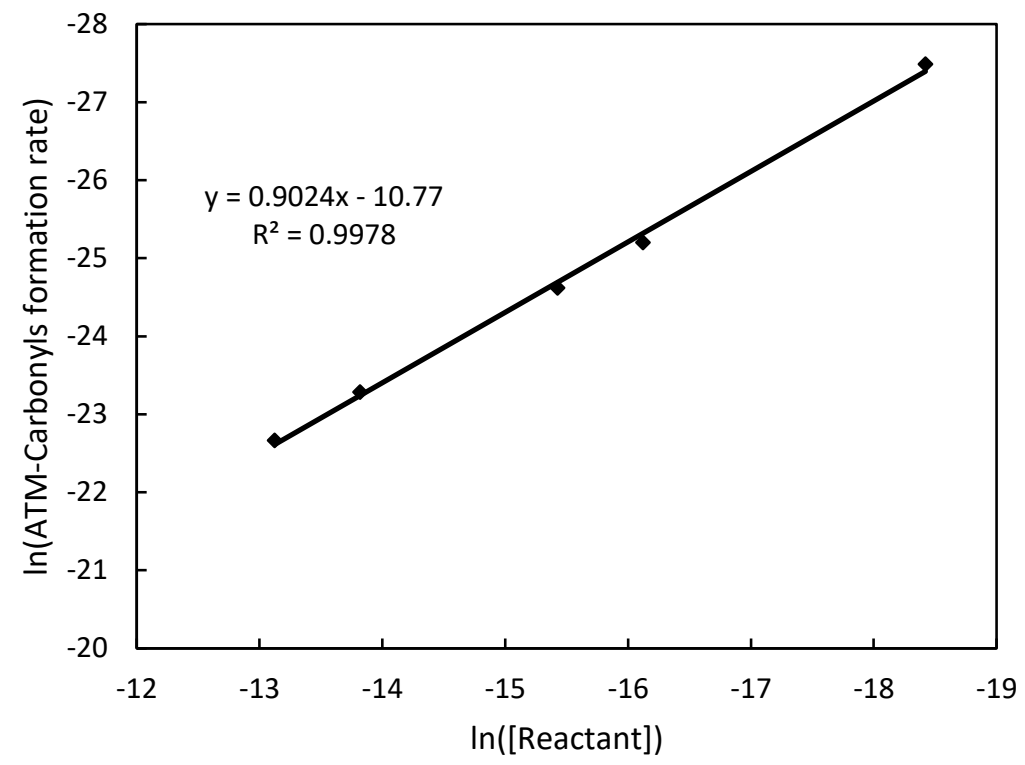

Figure 2.15 Determination of the reaction orders: the parity of the logarithm of the ATMCarbonyls formation rate and the logarithm of the carbonyl concentrations. 


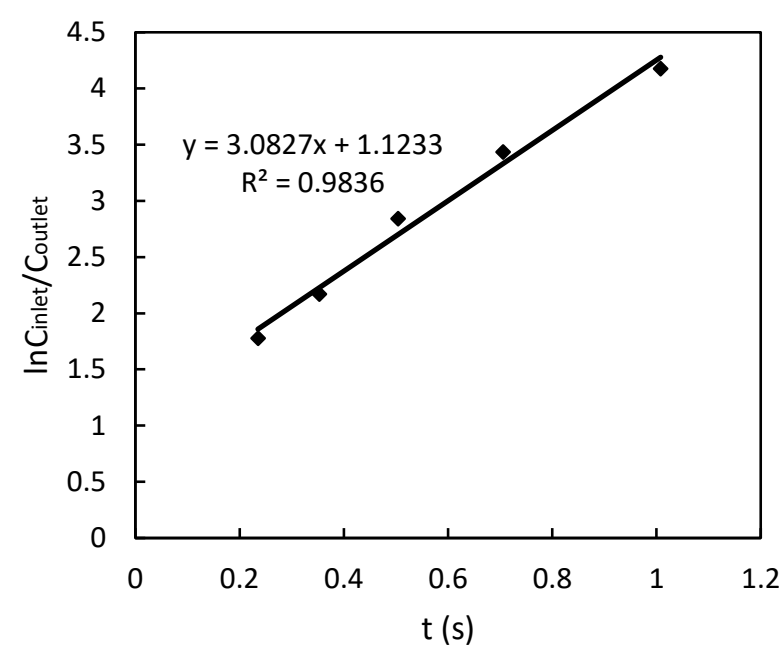

(a)

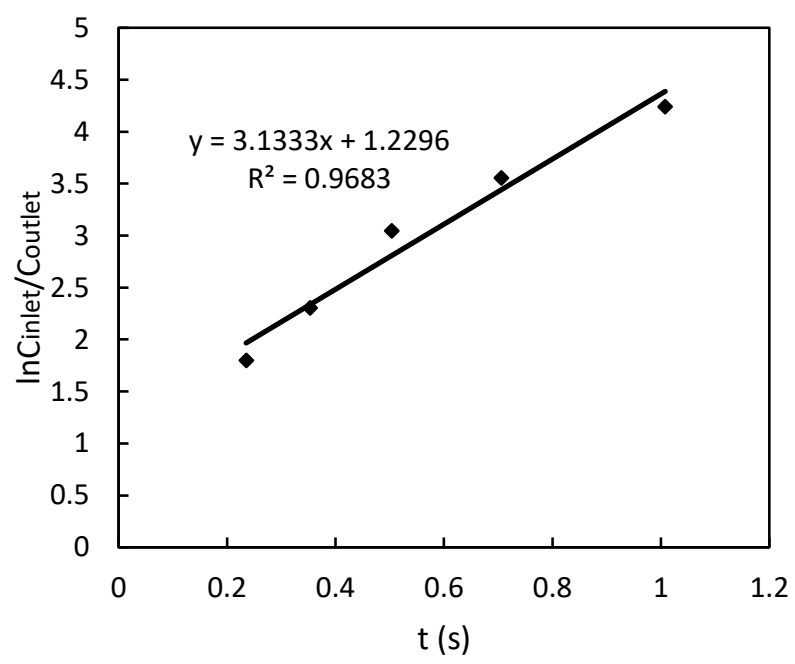

(c)

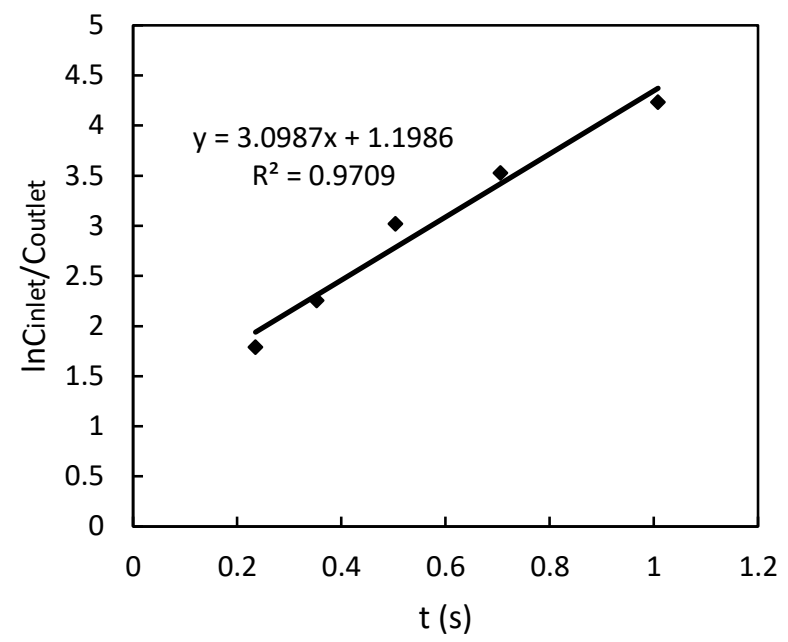

(b)

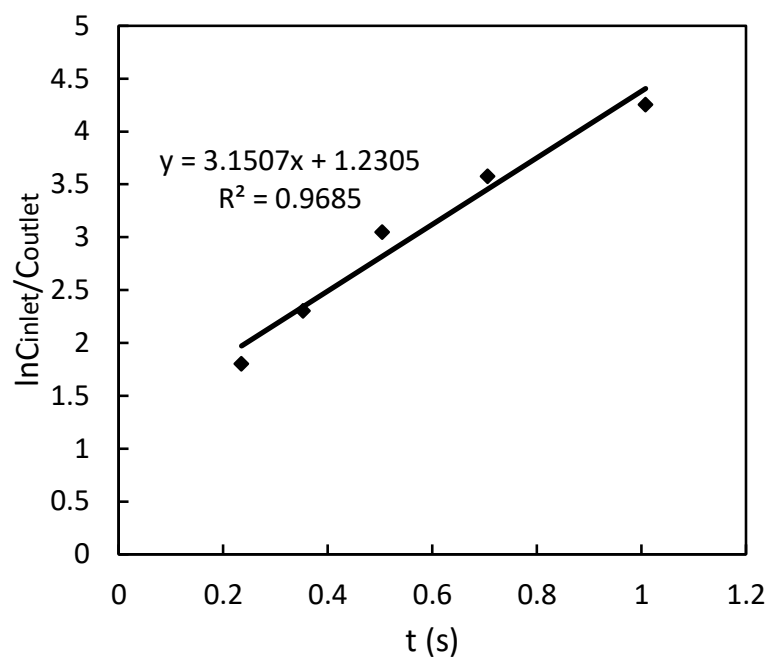

(d)

Figure 2.16 Linear regression plots of lnCinlet/Coutlet vs t between ATM and 2-butanone reactions at (a) $30^{\circ} \mathrm{C}$, (b) $50^{\circ} \mathrm{C}$, (c) $70^{\circ} \mathrm{C}$, (d) $90^{\circ} \mathrm{C}$.

From the regression plots, the slope the plot represents the $k$. 
From the Arrhenius Equation:

$$
k=k_{0} e^{-\frac{E_{a}}{R T}}
$$

where $k$ is the rate constant of the reaction, $k_{0}$ is the frequency factor, $E_{a}$ is the activation energy, $\mathrm{T}$ is the temperature (in kelvin), and $R$ is the gas constant. We can obtain:

$$
\ln k=-\left(\frac{E_{a}}{R}\right) \cdot\left(\frac{1}{T}\right)+\ln k_{0}
$$

The activation energy and frequency factor were determined after linear regression between the mean of $\ln (k)$ in four different reaction time at the same temperature and $1 / T$.

The reaction kinetics of acetone, 2-butanone, acetaldehyde and pentanal were measured using the same procedures as that of acetone. Figure 2.17 shows the linear regression plots of the natural logarithm of reaction constant $(\ln (k))$ between ATM and carbonyl compounds vs $1 / \mathrm{T}$.

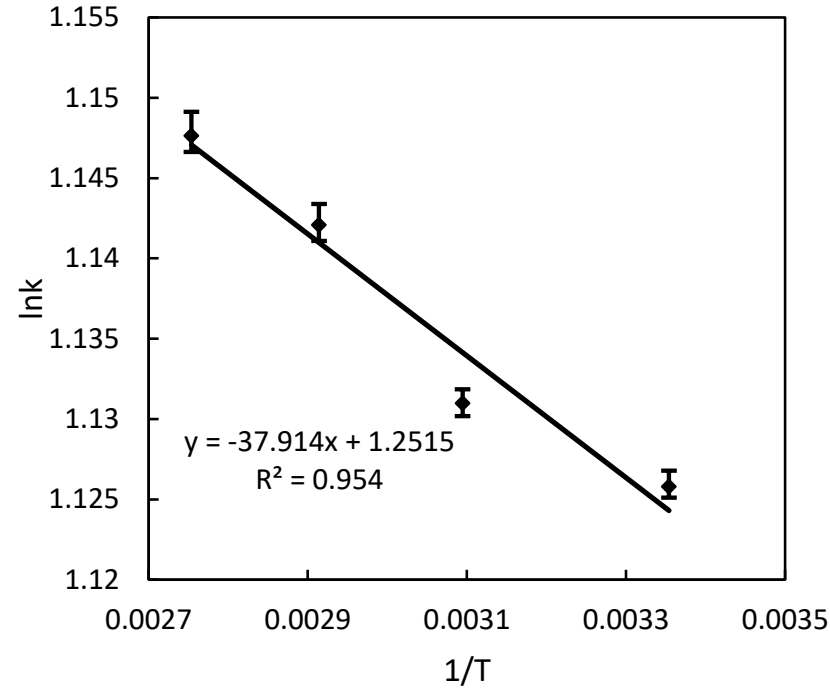

(a)

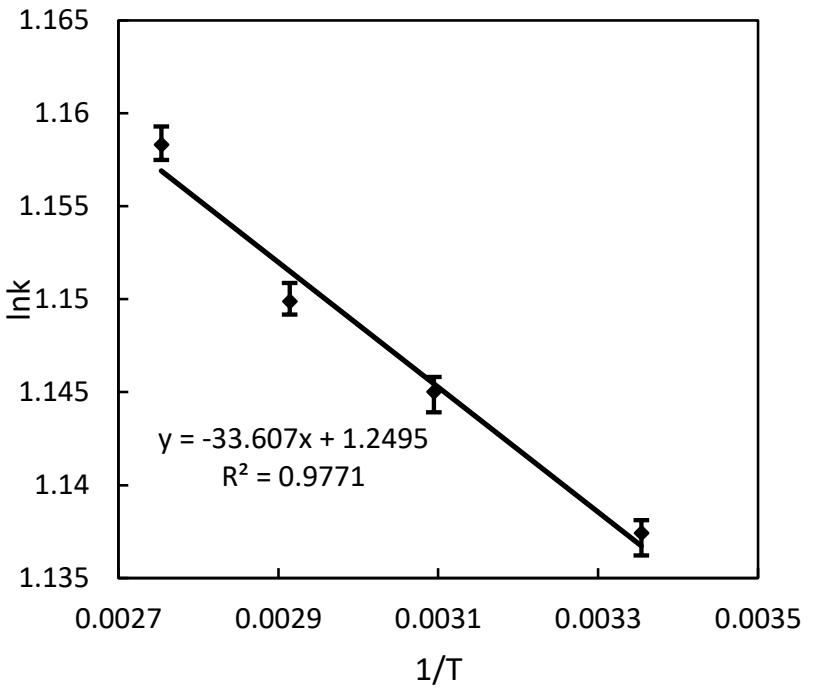

(b) 


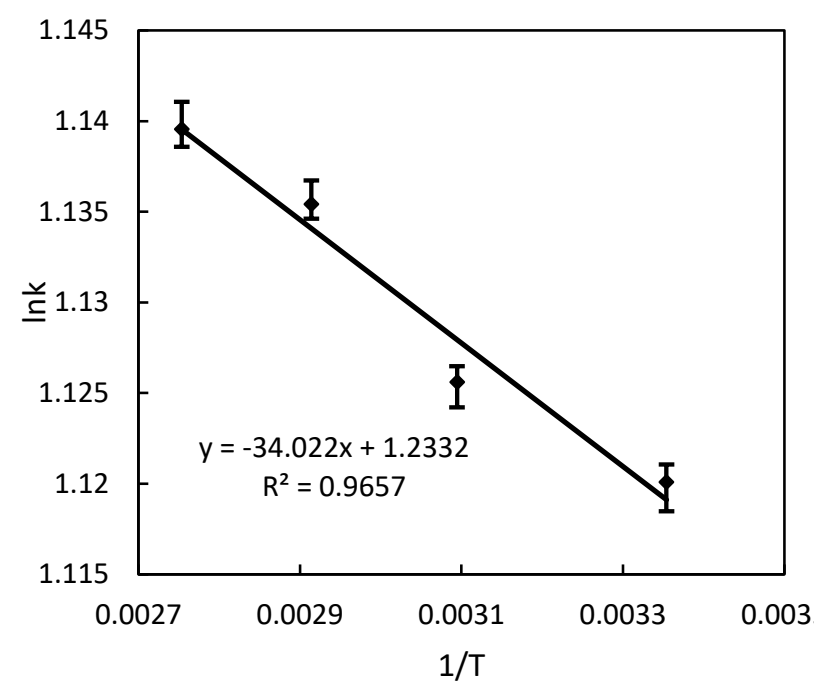

(c)



(d)

Figure 2.17 Linear regression plots of $\ln (\mathrm{k}) \mathrm{vs} 1 / \mathrm{T}$ between ATM and carbonyl compounds reactions. (a) Acetone, (b) 2-Butanone, (c) Acetaldehyde, (d) Pentanal.

Table 2.1 shows the activation energy and frequency factor of each reaction.

\section{Table 2. 1}

The activation energy, frequency factor, coefficient of determination of linear regression and reaction constant in each reaction.

\begin{tabular}{|c|c|c|c|c|}
\hline & $\mathrm{Ea}(\mathrm{J} / \mathrm{mol})$ & $\mathrm{K}_{0}\left(\mathrm{~S}^{-1}\right)$ & $\mathrm{R}^{2}$ & $\mathrm{~K}\left(\mathrm{~S}^{-1}\right)$ \\
\hline Acetone & 315.22 & 3.496 & 0.954 & 3.1587 \\
\hline 2-Butanone & 279.41 & 3.487 & 0.9771 & 3.0827 \\
\hline Acetaldehyde & 282.86 & 3.432 & 0.9657 & 3.1416 \\
\hline Pentanal & 268.29 & 3.231 & 0.932 & 3.0107 \\
& & & & \\
\hline
\end{tabular}




\subsection{Modeling study of oximation reaction in microreactor}

We simplify the microreactor as a packed bed reactor. In many packed bed reactions, the overall rate of reaction is limited by the rate of mass transfer of reactants and products between the bulk fluid and the catalytic surface. Mass transfer usually refers to any process in which diffusion plays a role.

In this section we consider two limiting cases of diffusion and reaction in the microreactor. In the first case the reaction is so rapid that the rate of diffusion of the reactant to the surface limits the reaction rate. In the second case, the reaction is so slow that virtually no concentration gradient exists in the gas phase.

In our microreactor model, the carbonyl compounds reaction is fast enough than diffusion, we first consider this oximation reaction is mass transfer limited and we will discuss the details information below. Under this circumstance the specific reaction rate constant is much greater than the mass transfer coefficient, $k_{r} \gg k_{c}$, and $\frac{k_{c}}{k_{r}} \ll 1$, so

$$
-r_{A}^{\prime \prime}=\frac{k_{c} C_{A}}{1+k_{c} / k_{r}}=k_{C} C_{A}
$$

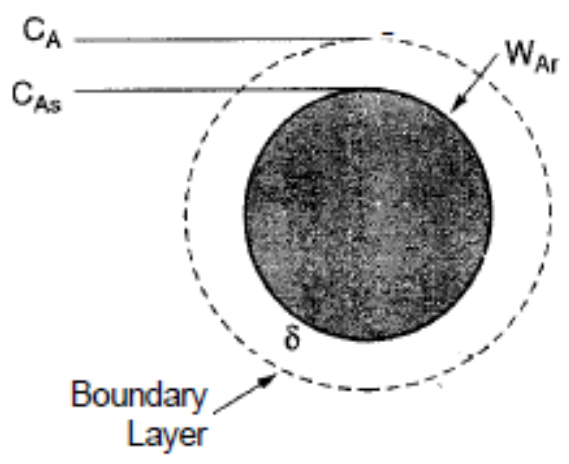

Figure 2.18 Diffusion across stagnant film surrounding catalyst pellet. 
The boundary condition at the external surface is

$$
-\mathrm{r}_{\mathrm{A}}^{\prime \prime}=\mathrm{W}_{\mathrm{Ar}}=\mathrm{k}_{\mathrm{c}}\left(\mathrm{C}_{\mathrm{A}}-\mathrm{C}_{\mathrm{As}}\right)
$$

Where $\mathrm{k}_{\mathrm{c}}=$ mass transfer coefficient

$$
\begin{gathered}
\mathrm{C}_{\mathrm{A}}=\text { bulk concentration } \\
\mathrm{C}_{\mathrm{As}}=\text { concentration of } \mathrm{A} \text { at the catalytic surface }
\end{gathered}
$$

According to the book 'Elements of Chemical Reaction Engineering', ${ }^{95}$ we have, for the constant superficial velocity $\mathrm{U},-\mathrm{U} \frac{d_{C_{A}}}{d z}+\mathrm{r}_{\mathrm{A}}{ }^{\prime \prime} \mathrm{a}_{\mathrm{c}}=0$

Substituting for $\mathrm{r}_{\mathrm{A}}$ "in above equation, we have $-\mathrm{U} \frac{d_{C_{A}}}{d z}-\mathrm{k}_{\mathrm{c}} \mathrm{a}_{\mathrm{c}}\left(\mathrm{C}_{\mathrm{A}}-\mathrm{C}_{\mathrm{As}}\right)=0$

In most mass transfer-limited reaction, the surface concentration is negligible with

respect to the bulk concentration $\left(\mathrm{C}_{\mathrm{A}} \gg \mathrm{C}_{\mathrm{As}}\right)$, so $-\mathrm{U} \frac{d_{C_{A}}}{d z}=\mathrm{k}_{\mathrm{c}} \mathrm{a}_{\mathrm{c}} \mathrm{C}_{\mathrm{A}}$

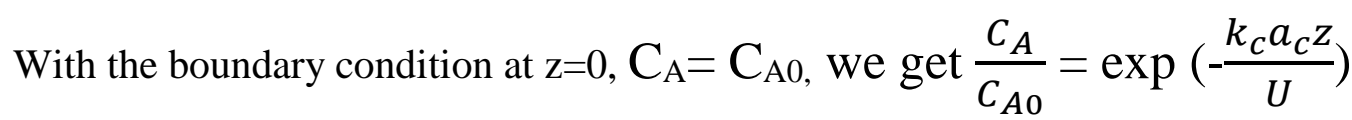

The concentration profile down a reactor of length $\mathrm{L}$ is shown in Figure

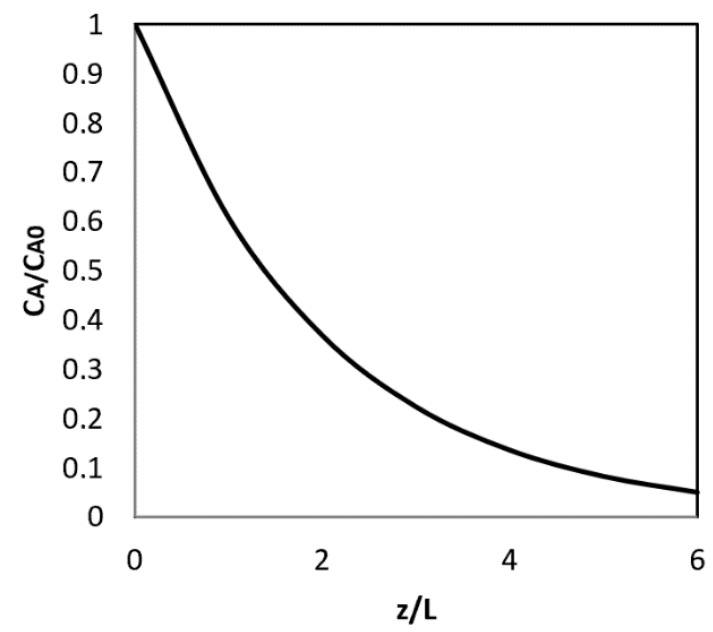

Figure 2.19 Axial concentration profile in a packed bed. 
The definition of conversion is $\mathrm{X}=\frac{C_{A 0}-C_{A L}}{C_{A 0}}$, with $\mathrm{z}=\mathrm{L}$ use equation (11), we obtain $\ln$ $\frac{1}{1-X}=\frac{k_{c} a_{c} L}{U}$

Solve the equation, then we get $X=1-\exp \left(-\frac{k_{c} a_{c} L}{U}\right)$

Where $a_{c}$ is surface area per volume of pillar.

Since the microreactor has thousands of micropillars inside it. We can take one of these pillars as a cell to study. the height of this cell is $400 \mu \mathrm{m}$ and the length of triangular micropillar is $50 \mu \mathrm{m}$. we calculate $\mathrm{a}_{\mathrm{c}}$ use following equation.

$$
\begin{aligned}
& \mathrm{a}_{\mathrm{c}}=\frac{6(1-\emptyset)}{d p}=\frac{6 \times(1-0.3056)}{9.388 \times 10^{-5} \mathrm{~m}}=44380 \mathrm{~m}^{2} / \mathrm{m}^{3} \\
& \mathrm{~d}_{\mathrm{p}}=\sqrt[3]{\frac{6 V}{\pi}}=\sqrt[3]{\frac{\sqrt{3} \times 6 \times 400 \mu \mathrm{m} \times(50 \mu m)^{2}}{4 \pi}}=9.388 \times 10^{-5} \mathrm{~m} \\
& \varnothing=\frac{V_{v}}{V_{T}}=\frac{\sqrt{3} / 4 \times 60^{2} \times 400-\sqrt{3} / 4 \times 50^{2} \times 400}{\sqrt{3} / 4 \times 60^{2} \times 400}=0.3056
\end{aligned}
$$

Where $A$ is surface area of the pellet, $d_{p}$ is particle diameter and $\varnothing_{\text {porosity. }}$

The $\mathrm{k}_{\mathrm{c}}$, mass transfer coefficient can be calculated by the equation of textbook "Elements of Chemical Reaction Engineering, third edition", the equation is

$$
\mathrm{k}_{\mathrm{c}}=0.6 \times \frac{D_{A B}^{2 / 3}}{\mathrm{v}^{1 / 6}} \times \frac{U^{1 / 2}}{d_{p}^{1 / 2}}
$$

Since we use cylinder air as carrier gas, at room temperature and standard pressure, the $u$ which is kinematic viscosity is $14.8 \times 10^{-6} \mathrm{~m}^{2} / \mathrm{s}$. We take $7 \mathrm{~mm}$ length microreactor as an example to calculate, the parameters of microreactor are $7 \mathrm{~mm}$ length, $7 \mathrm{~mm}$ length width and $400 \mu \mathrm{m}$ depth of micropillars. For the flow rate of $7 \mathrm{~mL} / \mathrm{min}$, we can convert to get the velocity of flow is $0.417 \mathrm{~m} / \mathrm{s}$. Refer to $\mathrm{Li}$ L. etc paper ${ }^{96}$, the gas phase diffusivity $\left(\mathrm{D}_{\mathrm{AB}}\right)$ of 
2-butanone is $0.8 \times 10^{-6} \mathrm{~m}^{2} / \mathrm{s}$, Acetone is $0.85 \times 10^{-6} \mathrm{~m}^{2} / \mathrm{s}$, Acetaldehyde is $0.75 \times 10^{-6} \mathrm{~m}^{2} / \mathrm{s}$ and Pentanal is $0.78 \times 10^{-6} \mathrm{~m}^{2} / \mathrm{s}$. Then we can calculate $\mathrm{k}_{\mathrm{c}}$ for the reaction of 2-butanone with ATM was determined to be $0.02255 \mathrm{~m} / \mathrm{s}$ and the $\mathrm{k}_{\mathrm{c}}$ for acetone, acetaldehyde and pentanal are $0.022817 \mathrm{~m} / \mathrm{s}, 0.02059 \mathrm{~m} / \mathrm{s}$ and $0.02013 \mathrm{~m} / \mathrm{s}$ respectively. Then we plug $\mathrm{k}_{\mathrm{c}}$ and $\mathrm{a}_{\mathrm{c}}$ into equation (12).

With equation (12), when we have the microreactor length and flow rate the air flow through the micropillar, we can get capture efficiency of the microreactor. A plot of different flow rate and capture efficiency of these different design microreactors was showed below to describe the modeling results and the experimental results. A relatively high matching trend was discovered. Figure 2.20 shows the 2-butanone experimental data compared to model calculated data of the microreactors with 5 different lengths under different flow. As clearly see from the figure, the model equation described the experimental data almost equally except that at high flow rate $(>15 \mathrm{ml} / \mathrm{min})$, there is a slight difference between experimental data and model data. 


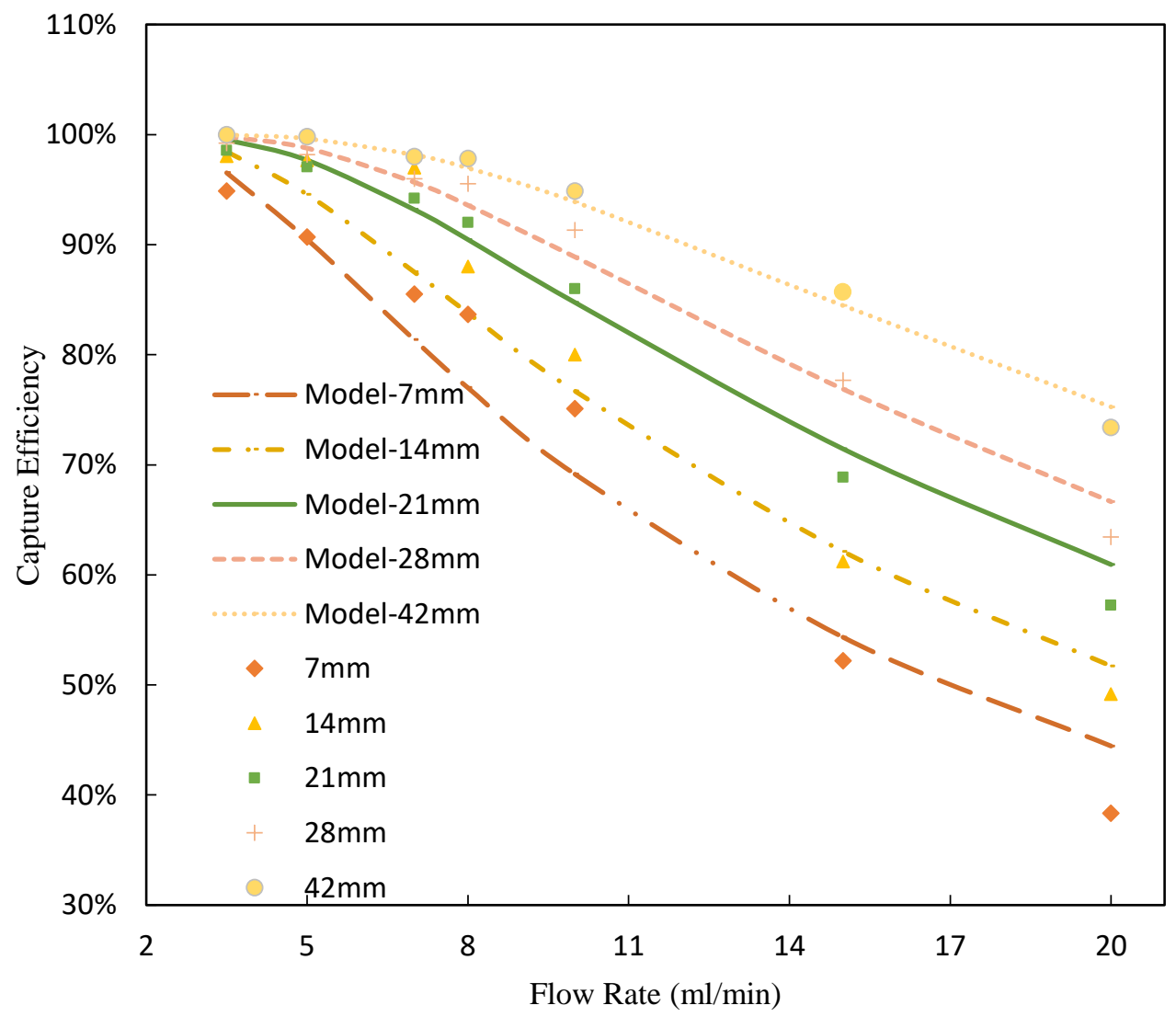

Figure 2.20 Comparison of experimental data and the model simulation for capture efficiencies of 2-Butanone using five different length microreactors.

Figure 2.21 shows that the $21 \mathrm{~mm}$ length of microreactor's experimental data compared with simulated data at mass transfer limiting. As can be seen from the figure, when the flow rate under $15 \mathrm{ml} / \mathrm{min}$, the model shows a very fit to the experimental data. Only when the flow rate at $20 \mathrm{ml} / \mathrm{min}$, there is slightly different between the model data and experimental data. These can be explained by the theory we discussed previously, when the flow rate is high enough that the diffusion between carbonyls and ATM are fast enough that the reaction between them dominate the whole process. 


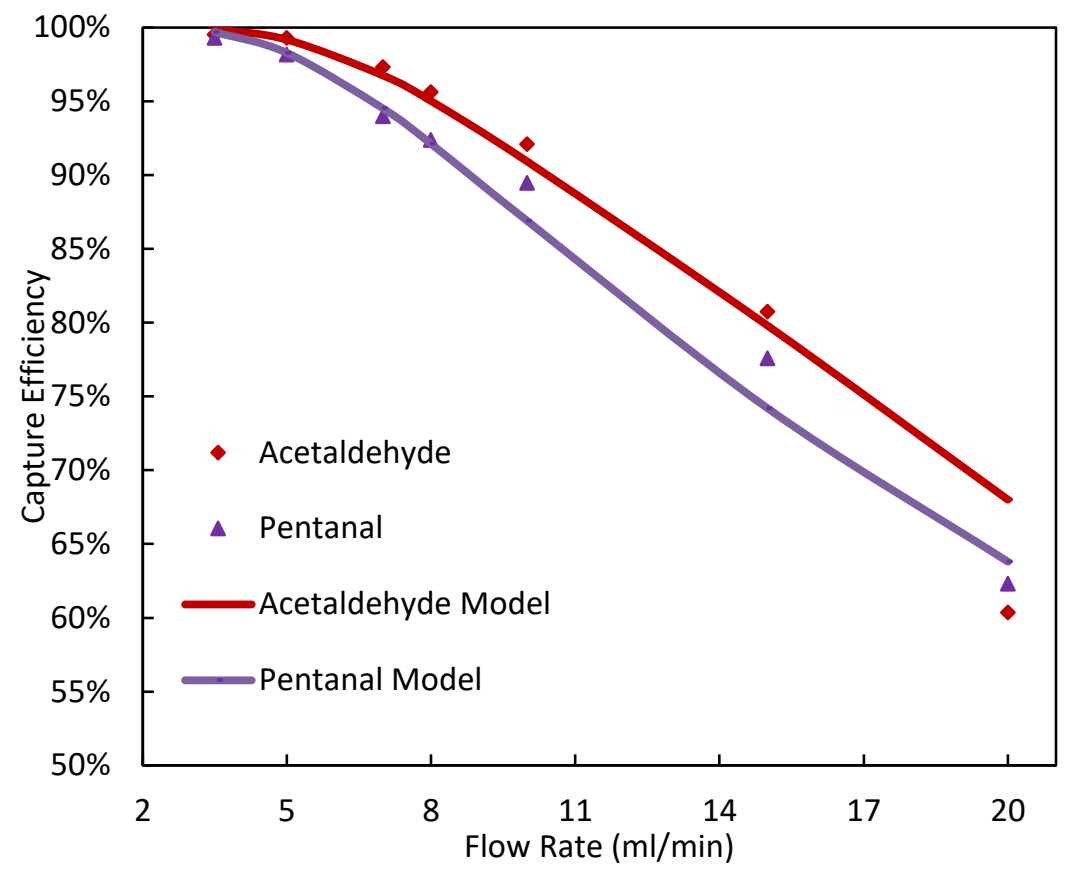

(a)

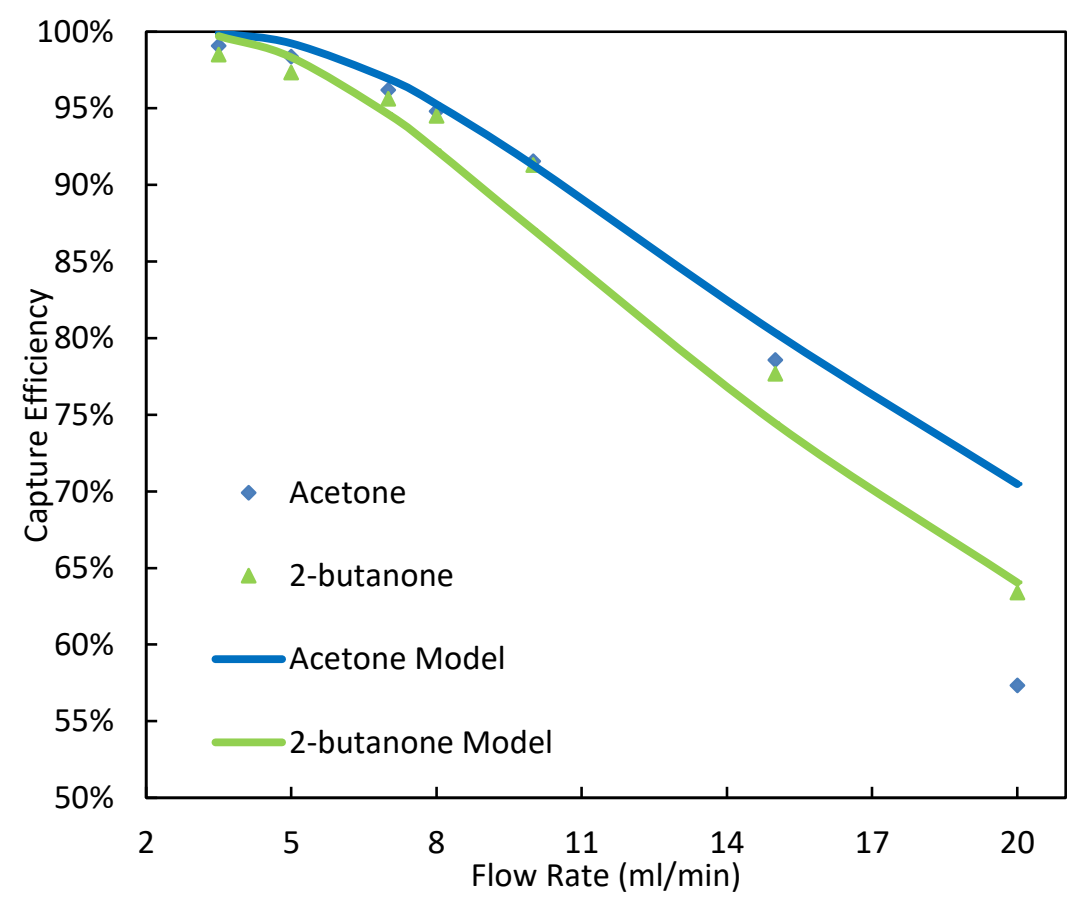

(b)

Figure 2.21 Comparison of experimental data with the model simulation for capture efficiencies of acetaldehyde, acetone, 2-butanone and pentanal with $21 \mathrm{~mm}$ length microreactor, (a) aldehydes, (b) ketones. 
When the reaction is slow and reaction rate limiting when mass transfer effects are not important. When the specific reaction rate is small with respect to the mass transfer coefficient, $k_{c^{»}} k_{r}$, and $\frac{k_{c}}{k_{r}} \gg 1$, so

$$
-r_{A}^{\prime \prime}=\frac{k_{r} C_{A}}{1+k_{r} / k_{c}}=k_{r} C_{A}
$$

The $k$ (reaction constant) already calculated from the kinetic study when the reaction is rate limiting, at room temperature, the $k$ for 2-butanone is $3.0827 \mathrm{~s}^{-1}$, and the $k$ for acetone, acetaldehyde and pentanal are $3.1587 \mathrm{~s}^{-1}, 3.1416 \mathrm{~s}^{-1}$ and $3.0107 \mathrm{~s}^{-1}$ respectively. In order to use model equation at reaction rate limiting, $k_{r}$ need to be calculated. By the unit calculation of equation (7) and (17) we get the $k_{r}$ calculated by $1000 \mathrm{k} / \mathrm{a}_{\mathrm{c}}$. Then the calculated $k_{r}$ of 2-butanone is $0.06946 \mathrm{~m} / \mathrm{s}$, and the $k_{r}$ for acetone, acetaldehyde and pentanal are $0.07117 \mathrm{~s}^{-1}, 0.07079 \mathrm{~s}^{-1}$ and $0.06784 \mathrm{~s}^{-1}$ respectively.

In order to further study the oximation reaction in the microreactor, we further plot the ATM-carbonyls formation rate with $\mathrm{U}^{1 / 2}$. if the ATM-carbonyls formation rate (mol/s) linearly to the $\mathrm{U}^{1 / 2}$, the reaction is mass transfer limited, otherwise, it is reaction limited. Figure 2.22 shows the relationship between ATM-carbonyls formation rate and $\mathrm{U}^{1 / 2}$ with $7 \mathrm{~mm}$ length microreactor and $42 \mathrm{~mm}$ microreactor. As can clearly see from the figure, with $7 \mathrm{~mm}$ length microreactor, at low flow rate (smaller than $10 \mathrm{~mL} / \mathrm{min}$ ), the ATM-carbonyls formation rate is linearly to $\mathrm{U}^{1 / 2}$. At low velocities the mass transfer boundary layer thickness is large and diffusion limits the reaction. As the velocity past the micropillars is increased, the boundary layer thickness decreases and mass transfer across the boundary layer no longer limits the rate of reaction, it is reaction limited. This data also demonstrates that at low flow rate the reaction is mass transfer limited and when use calculated $\mathrm{Kc}$ for 
model equation, it shows a good fit with experimental data. When at high flow rate it is not fitting to experimental data since it is reaction rate limited.
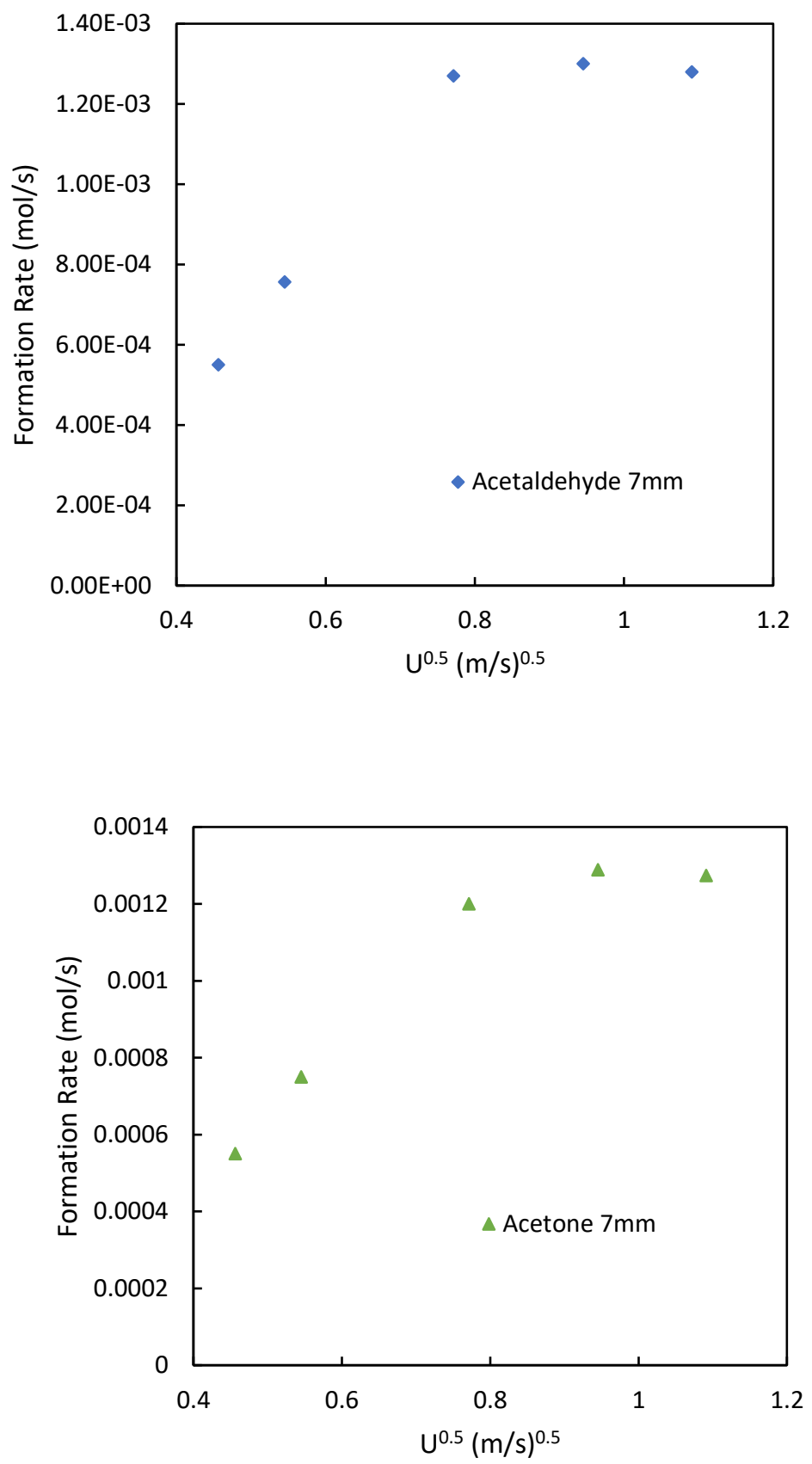

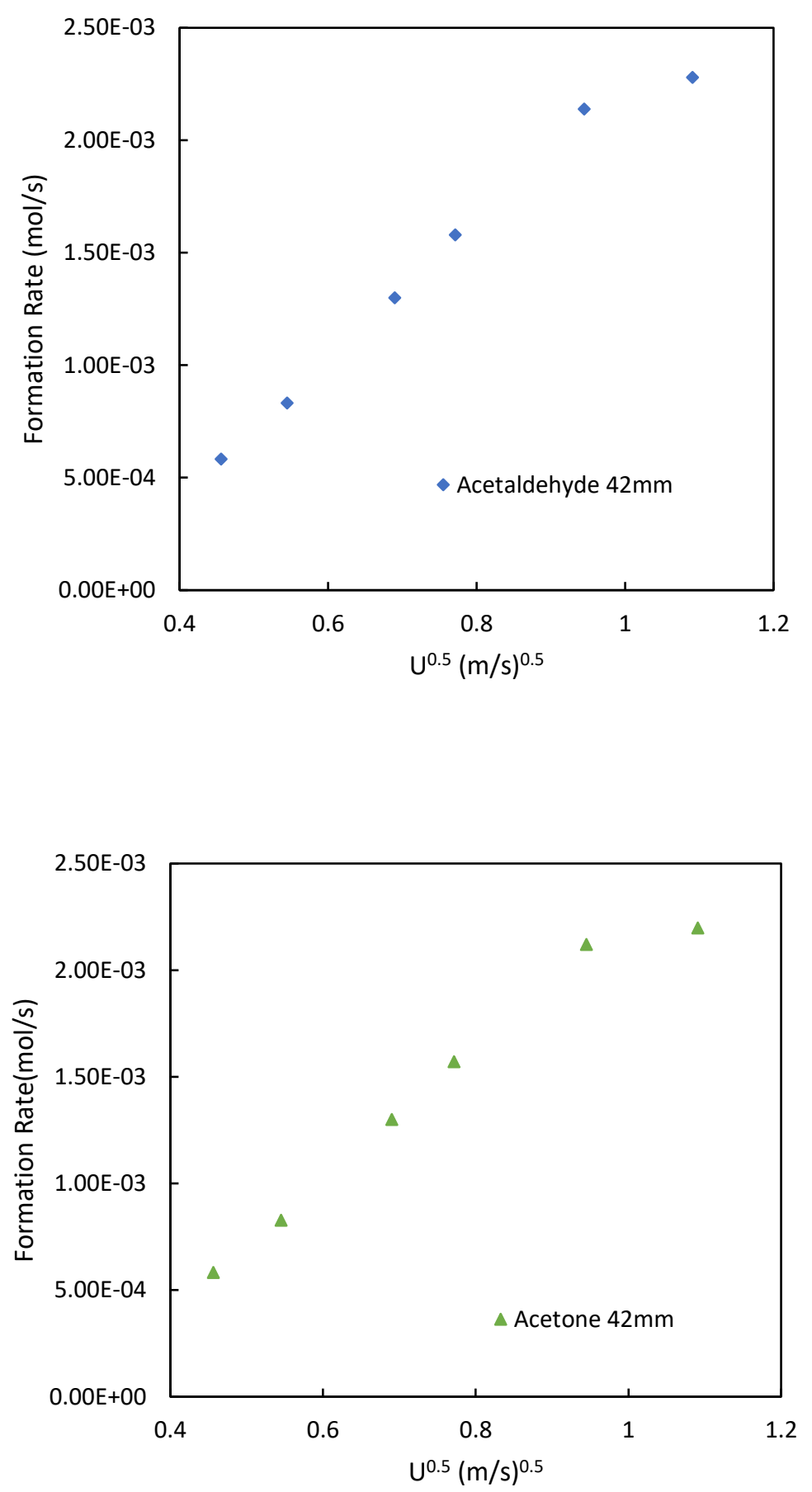

Figure 2.22 Relationship ATM-Carbonyls formation rate with U1/2 with $21 \mathrm{~mm}$ and $42 \mathrm{~mm}$ length microreactor. 


\section{Human Breath Analysis With Different Length Microreactors}

After the modeling, the next step is the practical application of the microreactor for human breath analysis. In this part, we collect 5L exhaled breath sample in one Tedlar bag from healthy subjects, then separate each 5L breath sample into aliquots of $500 \mathrm{~mL}$ breath samples. $7 \mathrm{~mm}$ and $21 \mathrm{~mm}$ length microreactors were prepared by loading $1.5 \times 10^{-6} \mathrm{~mol}$ ATM and drying in oven. Then the $7 \mathrm{~mm}$ length microreactor was evacuated under a flow rate of $3.5 \mathrm{ml} / \mathrm{min}$ while the $21 \mathrm{~mm}$ length microreactors were evacuated under flow rate of $8 \mathrm{ml} / \mathrm{min}$ and $10 \mathrm{ml} / \mathrm{min}$. The calculated capture amount of $7 \mathrm{~mm}$ length microreactor at $3.5 \mathrm{ml} / \mathrm{min}$ flow rate was set as a reference. For the captured amount of $21 \mathrm{~mm}$ length microreactors was compared to the $7 \mathrm{~mm}$ length microreactor under $3.5 \mathrm{ml} / \mathrm{min}$ flow rate. Figure 2.23 shows the capture amount of carbonyl VOCs in same exhaled breath in 3 different conditions. It is clearly seen from the figure that the $21 \mathrm{~mm}$-length microreactor at a flow rate of $8 \mathrm{~mL} / \mathrm{min}$ has a higher capture efficiency than that of the $7 \mathrm{~mm}$ length microreactor at $3.5 \mathrm{~mL} / \mathrm{min}$ for all compounds. So we conclude that a $21 \mathrm{~mm}$ length microreactor can use at a flow rate of up to $8 \mathrm{~mL} / \mathrm{min}$ which can still have high capture efficiency than $7 \mathrm{~mm}$ length microreactor. This significantly decreases the analysis time by more than half. 


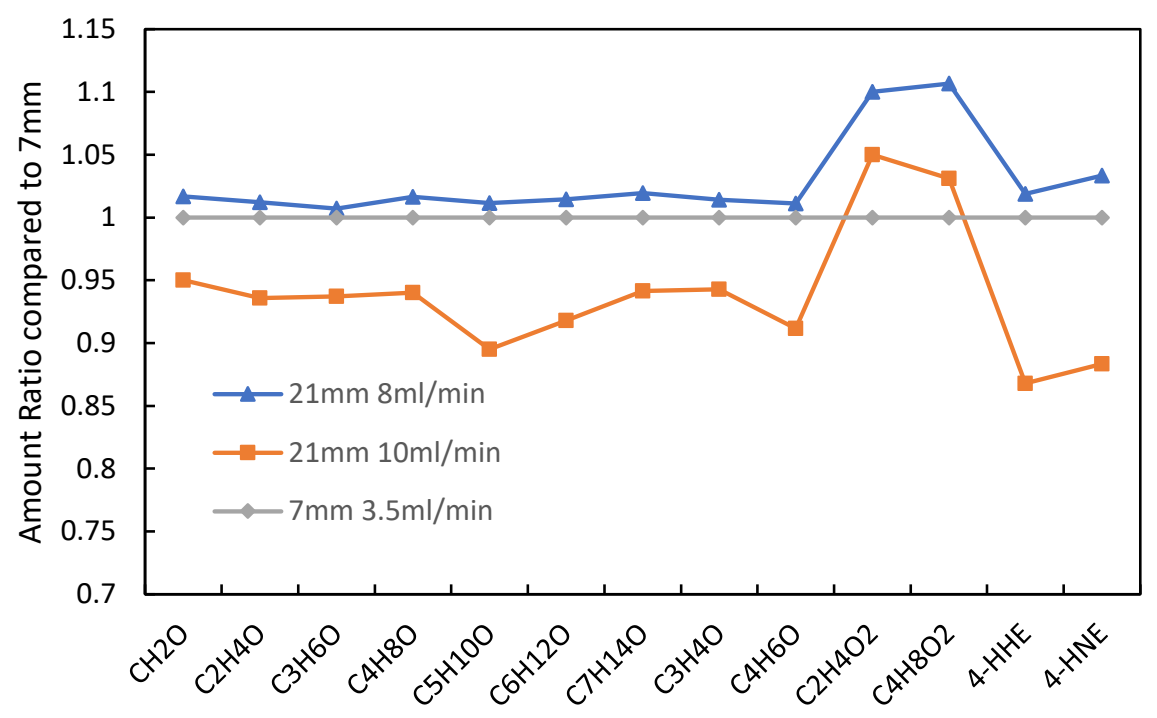

Figure 2.23 Comparison of $7 \mathrm{~mm}$ length microreactor capture and $21 \mathrm{~mm}$ length microreactor.

\section{Conclusion}

The results of this work show that a microreactor can be used to capture more than 95\% carbonyl compounds in nitrogen. The microreactor is functionalized with the quaternary ammonium aminooxy compound ATM for oximation reactions with ketones and aldehydes. The advantages of thousands of micropillars in the microreactor include increasing the contact surface area for gaseous sample flowing through the chip and uniformly distribute gas flow to increase the chance of collision probability of ATM with ketones and aldehydes in the gas phase flowing through the microreactor. After studying the different design of microreactors with different length and micropillar shape, we find the capture efficiency of microreactor increasing with the increase of length at the same flow rate. When the length of the microreactor increases, the capture efficiency increases. This indicates that increase of the surface area of the microreactor can improve the capture 
efficiency of it. But the increasing trend of capture efficiency will slow down when the length was increased to a certain length like $21 \mathrm{~mm}$, when further increase to $28 \mathrm{~mm}$ and $42 \mathrm{~mm}$, the capture efficiency is not a big difference compared to $21 \mathrm{~mm}$. The longer length microreactor are hard to operate. Therefore considering all these aspects, the microreactor with $21 \mathrm{~mm}$ in length was recommended for future research of breath analysis.

A novel microreactor with $21 \mathrm{~mm}$ in length was designed to efficiently capture VOCs in human breath. With $21 \mathrm{~mm}$ length microreactor, the flow rate can increase up to $8 \mathrm{ml} / \mathrm{min}$ which can still achieve $90 \%$ capture efficiency. This significantly decrease the sample processing time compared to previous research. A theoretical model was developed to predict the capture efficiency of the microreactor related to the microreactor length and sample flow rate. The results of the model show a good prediction to the experimental data at mass transfer limiting case. 


\section{CHAPTER III}

\section{STABILITY OF BREATH VOLATILE ORGANIC COMPOUNDS IN TEDLAR BAGS}

\section{Introduction}

The analysis of volatile organic compounds (VOCs) in exhaled breath is promising for early detection of diseases including lung cancer and other cancers, diabetes, Tuberculosis, cystic fibrosis, and nephropathy. ${ }^{98}$ Early detection of lung cancer is a key for increasing survival rate of cancer patients. ${ }^{99,} 100$ Many studies have suggested that early stage cancers can be detected by molecular analysis of VOCs in exhaled breath. ${ }^{101-106}$ More than one thousand VOCs have been reported in human exhaled breath. ${ }^{107-109}$ In recent years, exhaled breath has become a highly researched sampling medium for identifying specific VOCs as disease biomarkers for non-invasive diagnosis. However, due to trace concentrations (ppbv to pptv) of VOCs in exhaled breath, these analytes require preconcentration for quantitative analysis. ${ }^{120}$

Recent review papers report that gas chromatography (GC) coupled with mass spectrometry (MS) is the most widely used system for analysis of VOCs in breath. ${ }^{111-113}$ Since there are hundreds of trace VOCs in exhaled breath, a preconcentration process is 
generally required to concentrate VOCs before they can be analyzed by GC-MS. There are several methods that can be used for preconcentration. The most common preconcentration methods are physical adsorption and thermal desorption using carbon-based adsorbents, polymer adsorbents in tube or in needle, and solid-phase microextraction (SPME). ${ }^{114-}$ ${ }^{120}$ Proton transfer reaction mass spectrometry (PTR-MS) and selected ion flow tube mass spectrometry (SIFT-MS) are also used for breath analysis without preconcentration process. ${ }^{121-123}$ Other techniques including sensor array or electronic noses are also used for analysis of VOCs in exhaled breath. ${ }^{124,125}$

Although breath samples can be analyzed by many analytical instruments, preservation of the sample integrity during sample storage and sampling process is critical for reliable analysis of VOCs in breath samples. ${ }^{126-131}$ Tedlar bag is the most commonly accepted materials for collecting breath samples. ${ }^{128,130,131}$ The storage of selected VOCs within sampling bags has been extensively studied. ${ }^{126-131}$ However, most of the previous work studied VOC stability by spiking selected VOCs into air and nitrogen matrices. The results indicate that the concentrations of VOCs in Tedlar bags decrease with time. Since there is no publication studying the stability of real breath VOCs in Tedlar bags, it is still not clear how long breath samples can be stored in Tedlar bags for standardizing breath sample storage. The stability of real breath VOCs adsorbed on sorbents (Tenax TA and carbograph) in tube samples has recently been studied. ${ }^{132-133,135}$

The objective of this study is to investigate the stabilities of breath VOCs in Tedlar bags in order to identify appropriate storage time of breath samples at ambient temperature and cold temperature $\left(4^{\circ} \mathrm{C}\right)$. A subset of VOCs named carbonyl compounds in exhaled breath were measured because these compounds are very reactive. Furthermore, carbonyl 
compounds including 2-butanone, 3-hydroxy-2-butanone, hexanal, heptanal, nonanal, hydroxy-acetaldehyde, 4-hydroxy-2-hexenal (4-HHE) and 4-hydroxy-2-nonenal (4-HNE) have been reported as lung cancer biomarkers in exhaled breath. ${ }^{116-117,134,136}$ In this work, a silicon microreactor approach was used to capture trace carbonyl compounds in exhaled breath. Thousands of micropillars in the microreactors distribute gaseous breath flowing through the microreactors and provide surface areas for trapping target VOCs. The surfaces of the micropillars were functionalized by a quaternary ammonium aminooxy salt, 2(aminooxy)ethyl- $N, N, N$-trimethylammonium iodide (ATM), for chemoselective capture of aldehydes and ketones via oximation reaction. The ATM-carbonyl adducts were analyzed by a system of ultra high performance liquid chromatography-mass spectrometry (UHPLC-MS).

\section{Experimental}

\subsection{Materials}

All reagents and solvents, including deuterated acetone (acetone-d6) (99.9\%), deuterated 2-butanone (2-butanone-d4) (99.9\%), deuterated acetaldehyde (acetaldehyded4) (99.9\%), deuterated hexanal (hexanal-d6) (99.9\%), deuterated 2-pentanone (2pentanone-d5) (99.9\%), acetone (99\%), 2-butanone (99\%), 2-pentanone and methanol (99.9\%), 5 Liter and 0.5 liter size Tedlar® bags were purchased from Sigma-Aldrich in St. Louis, MO. The aminooxy-based reactive coating, 2-(aminooxy) ethyl-N, N, N trimethylammonium iodide (ATM) was synthesized according to a published method. ${ }^{137}$

\subsection{Microreactors}


The design and fabrication process of silicon microreactors follow standard MEMS device fabrication procedures. A detailed description of the fabrication of the microreactors has been published elsewhere. ${ }^{139}$ The microreactors have been used for capturing carbonyl compounds in environmental air and exhaled breath. ${ }^{140}$ The microreactor consists of thousands of micropillars in an area of $21 \mathrm{~mm}$ in length and $7 \mathrm{~mm}$ in width. The micropillars are equilateral triangular prisms with the side length of $50 \mu \mathrm{m}$ and the height of about $400 \mu \mathrm{m}$ and the distance between two closest prisms are $10 \mu \mathrm{m}$. Figure 3.1 shows a picture of the silicon microreactor chip and a SEM micrograph of the micropillar array. The surfaces of the micropillars were functionalized with ATM by infusing a solution of ATM $(1.5 \mu \mathrm{mol}$ in $30 \mu \mathrm{L})$ in methanol into the microreactor through one connection port followed by evaporation of the solvent in a vacuum oven. Fused silica capillary tubes with $350 \mu \mathrm{m}$ in O.D. and $250 \mu \mathrm{m}$ in I.D. were connected to the inlet and outlet ports of the microreactor with a bonding agent.

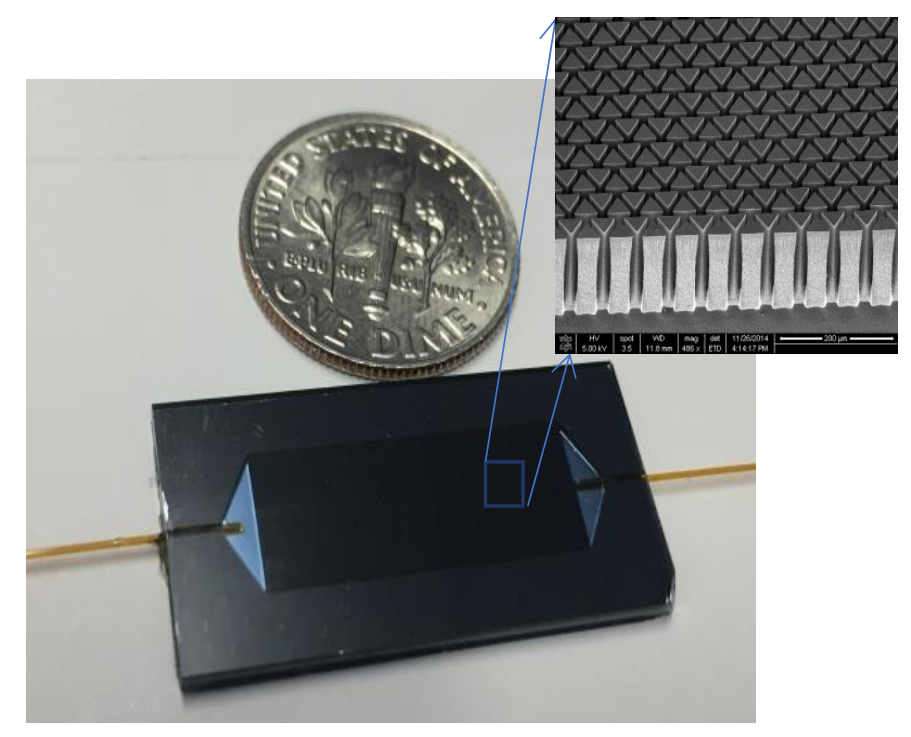

(a) 


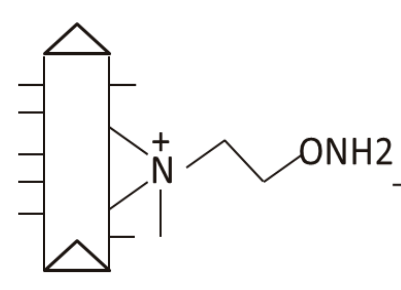

Micropillar

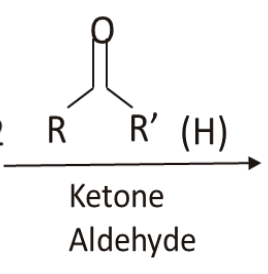

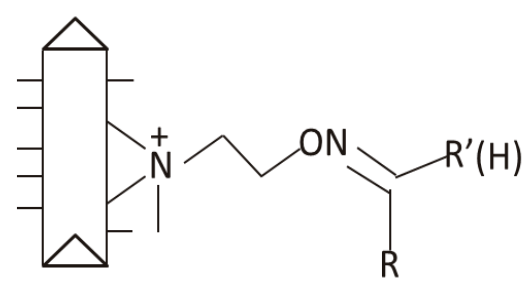

Oxime ether

(b)

Figure 3.1 (a) Optical picture of a microreactor with an insert of a SEM micrograph of the triangular micropillar array at the top right corner; (b) the Schematic illustration of ATM coating on the micropillar and oximation of ATM to capture carbonyl compounds.

\subsection{Collection and analysis of exhaled breath samples}

After approval by the Internal Review Board of the institution and after having obtained written informed consent, exhaled breath samples were collected from 15 never smoking and 7 current smoking healthy subjects. The Tedlar bags were cleaned with high purity nitrogen and tested free of ketone and aldehyde contamination. Subjects directly breathed about a mixture of 5 liter tidal and alveolar breath into five-liter size Tedlar bags through the attached Teflon tube. A mixture of tidal and alveolar breath was collected in the sampling bags. The breath samples from smokers were collected about 10 minutes after smoking. After collection of breath samples, a number of $500 \mathrm{~mL}$ aliquots of the breath samples were immediately transferred into $500 \mathrm{~mL}$-size Tedlar bags. Then, 5 nmole of each deuterated acetaldehyde, 2-butanone, hexanal, and 2-pentanone in $10 \mu \mathrm{L}$ methanol was added to the $500 \mathrm{~mL}$ breath aliquots. The breath aliquots were stored either at room temperature or at $4{ }^{\circ} \mathrm{C}$ in a refrigerator before evacuation of the samples through the 
microreactors. The first $500 \mathrm{~mL}$ aliquot was immediately evacuated through a microreactor. The setup for evacuation of the breath samples to capture carbonyl VOCs includes a vacuum pump to pull the gaseous breath from the Tedlar bag through the microreactor. ${ }^{139-}$

${ }^{140}$ The sample bags were connected to the inlet of the microreactors through septa and fused silica tube. The outlet of the microreactor was connected to a vacuum pump and the flow rate of breath sample through the microreactor was adjusted to $7 \mathrm{~mL} / \mathrm{min}$. During the evacuation process, carbonyl compounds react with the ATM coating and are trapped in the microreactor while the rest of the breath sample flows through the microreactor. Figure 3.1 shows a schematic illustration of ATM coating on the surfaces of the micropillars and the oximation reaction between ATM and carbonyl compounds. After a breath sample was completely pulled through a microreactor, the microreactor chip was disconnected. Finally, the reacted ATM adduct and unreacted ATM were eluted from the chip with $200 \mu \mathrm{L}$ methanol to afford $\geqslant 99 \%$ of recovered ATM-VOCs. An internal reference for UHPLCMS analysis was established by adding a solution of $5 \times 10^{-9}$ mol of ATM-acetone-d6 adduct in methanol to each eluted solution. The eluted solutions were directly analyzed by an ultra-high-performance liquid-chromatograph-mass spectrometry (MS) (UHPLC-MS) system.

\subsection{Ultra-high-performance liquid-chromatograph-mass spectrometry (UHPLC-MS)}

A Thermo Scientific ultra-high-performance liquid-chromatograph-mass spectrometry (MS) system equipped with an automatic sampler, a Vanquish UHPLC and a Q Exactive Focus Obitrap Mass Spectrometer was used for analysis. The UHPLC column compartment equipped with a Thermo Scientific Syncronis HILIC column (100 mm length, $2.1 \mathrm{~mm}$ I.D., $1.7 \mu \mathrm{m}$ particle size). The liquid flow rate through the column was $600 \mu \mathrm{L} / \mathrm{min}$. 
The column temperature stabilized at $30{ }^{\circ} \mathrm{C}$ with a total running time of 8 minutes. The mobile phase A was ammonium formate and formic acid in methanol with a $\mathrm{pH}$ of 3.0 and the mobile phase B was acetonitrile. The flow system consisted of $95 \%$ of phase A and 5\% of phase B. The injection volume of the sample was $10 \mu \mathrm{L}$.

\section{Results and Discussion}

\subsection{Stability of spiked deuterated carbonyl compounds in breath samples}

To determine both the capture efficiencies of carbonyl compounds by the microreactors and the stability of VOCs in exhaled breath, deuterated acetaldehyde, 2butanone, 2-pentanone and hexanal were spiked into the breath samples and then stored at $4{ }^{\circ} \mathrm{C}$ in a refrigerator. The use of the microreactors with aminooxy coating for chemoselective capture of trace carbonyl compounds via oximation reactions has been established. ${ }^{137-138,93}$ Figure 3.2 shows that at time zero defined as immediately starting evacuation of the breath samples after spiking the deuterated carbonyl compounds above $95 \%$ of these deuterated compounds were captured. Only less than 5\% of each deuterated compound lost due to reaction in the bags and escape from the microreactor during about 75 minutes of evacuation process. All of the spiked deuterated carbonyl compounds have above $85 \%$ recovery after stored for two hours before starting evacuation of the samples through the microreactors at room temperature. The recovery percentages of these compounds for the samples stored at cold temperature $\left(4{ }^{\circ} \mathrm{C}\right)$ are slightly higher than that stored at room temperature. The spiked carbonyls in the breath samples decreased much faster in the first 5 hours than after 5 hours stored both at room temperature and at cold temperature. The two aldehydes and butanone decreased to about $80 \%$, while pentanone decreased to below $80 \%$ after stored for 5 hours at cold temperature. The recovery 
percentages of these deuterated compounds in breath samples of nonsmokers are slightly higher than that in breath samples of smokers. Furthermore, the recovery percentages of lighter acetaldehyde and butanone were higher than that of heavier hexanal and 2pentanone. This result is in good agreement with previous findings of higher molecular masses with higher losses for the study of the stability of spiked volatile breath constituents in Tedlar bags. ${ }^{128}$



(a)

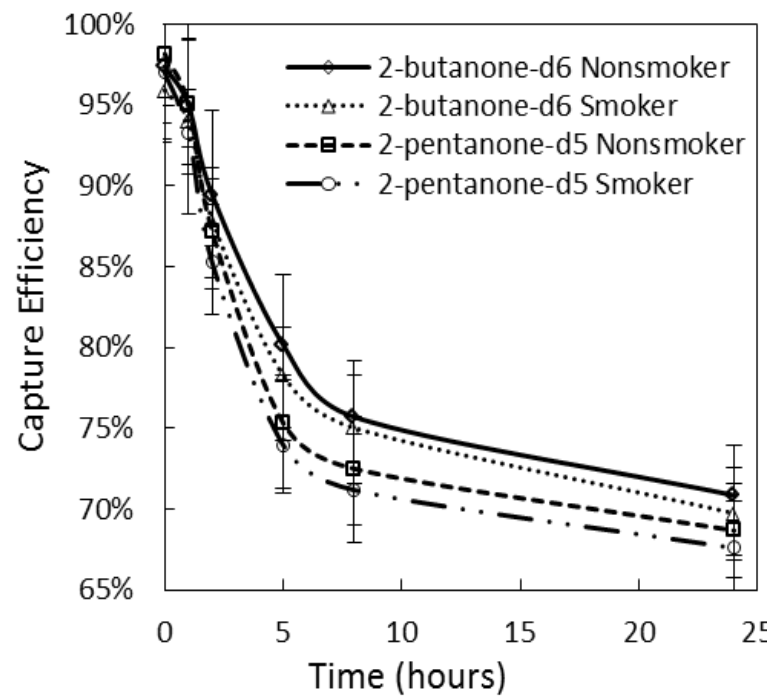

(b)

Figure 3.2 Capture efficiencies of spiked four deuterated compounds in breath samples (15 Nonsmokers and 7 Smokers) with storage time at $4^{\circ} \mathrm{C}$. The flow rate of breath sample through the microreactor was $7 \mathrm{ml} / \mathrm{min}$. (a) deuterated acetaldehyde and hexanal, (b) deuterated 2-butanone and 2-pentanone.

\subsection{Stability of carbonyl compounds in exhaled breath of nonsmokers}


In order to compare the recovery percentages of carbonyl compounds in Tedlar bags at different storage time and temperature, the amounts of breath carbonyl compounds in $500 \mathrm{~mL}$ aliquots of all breath samples in Tedlar bags from 15 nonsmokers were determined by evacuation through the microreactors and analyzed by UHPLC-MS in the same way. Given the less than 5\% of loss of spiked deuterated carbonyl compounds in exhaled breath samples at time zero determined above, the measured amounts of carbonyl compounds at time zero were set as reference for calculation of the recovery percentages of the same compounds at the corresponding storage time both at room temperature and at cold temperature. The stability of breath samples was examined as the recovery percentages of each carbonyl compounds in the aliquots of the breath samples stored for up to 24 hours.

Figure 3.3 shows the recovery percentages of ketones and aldehydes in exhaled breath samples. The recovery percentages of all carbonyl compounds show the trends of decreasing with storage time. The data also indicate that the samples stored at $4{ }^{\circ} \mathrm{C}$ have higher recovery percentages than that stored at room temperature. The decreases of the recovery percentages of carbonyl compounds in the first five hours are faster than that after the first five hours. The recovery percentages of saturated carbonyl compounds are above $80 \%$ after storage for 5 hours at $4{ }^{\circ} \mathrm{C}$. Hydroxyacetaldehyde degraded faster than acetaldehyde while 3-hydroxy-2-butanone degraded faster than 2-butanone. Unsaturated aldehydes including acrolein, crotonaldehyde, 4-hydroxy-hexenal and 4-hydroxy-nonenal decrease to about $80 \%$ in 1 hour stored at cold temperature. Given the evacuation time of 75 minutes, the breath samples can be stored for a total of 2 hours to keep above $80 \%$ unsaturated aldehydes at cold temperature. The obviously lower recovery percentages of 
unsaturated aldehydes in comparison with that of saturated hydroxy-carbonyl compounds indicate that higher reactivity of these compounds is a key factor of the loss. The loss from diffusion of the compounds through the films of the Tedlar bags is probably not important because the recovery percentages of smaller and more volatile compounds such as formaldehyde and acetaldehyde are higher than that of heavier compounds.

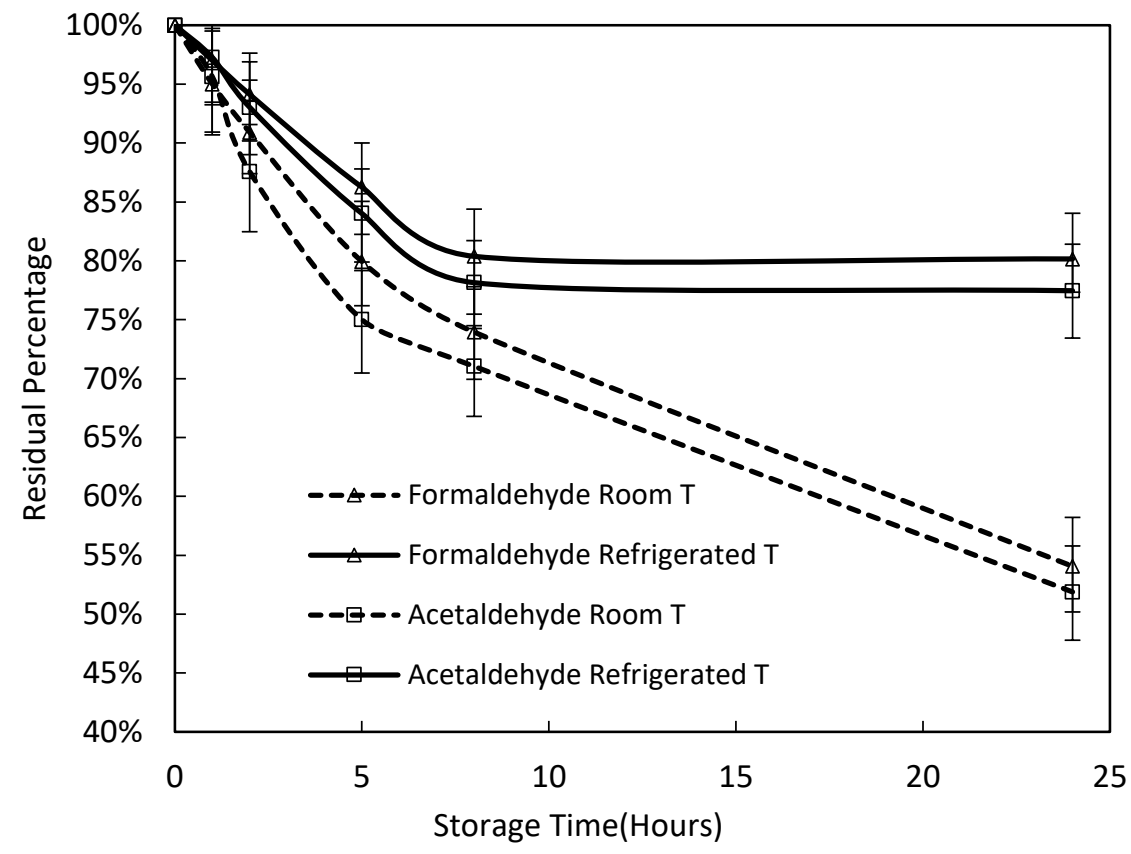

(a) 


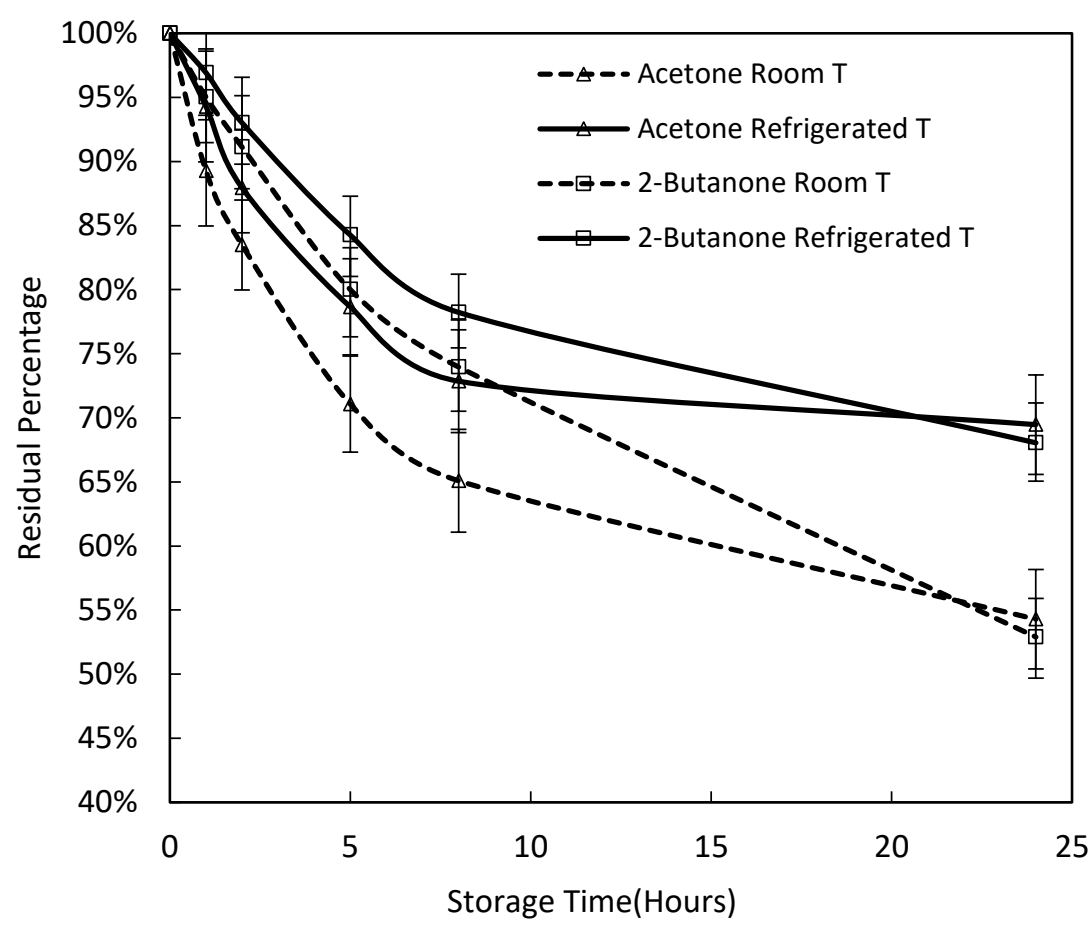

(b)



(c) 


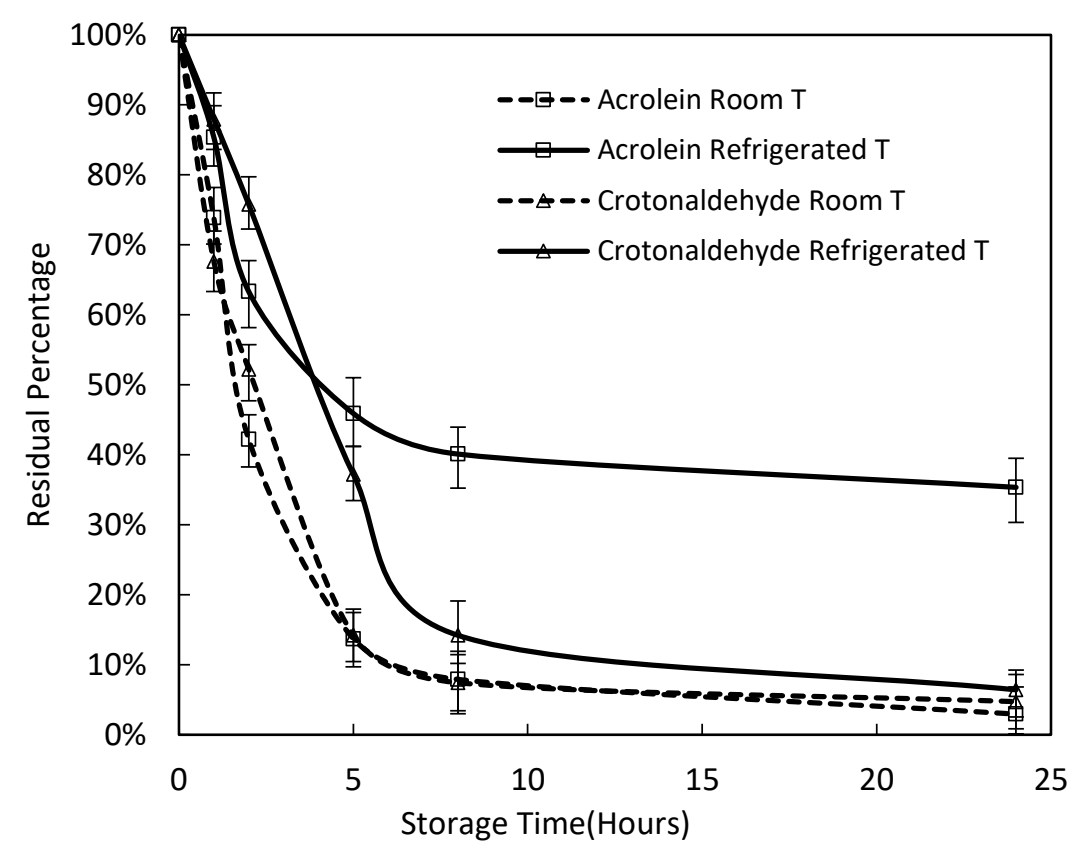

(d)

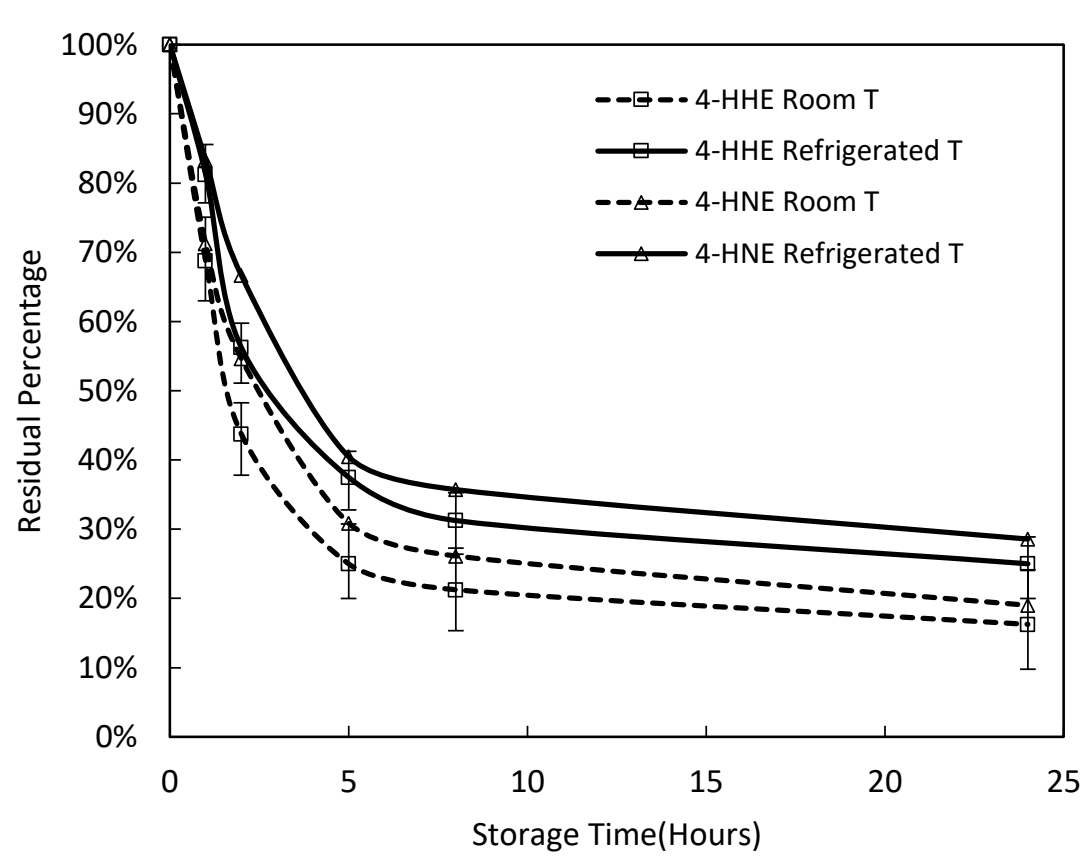

(e)

Figure 3.3 Relationship between the residual percentage and storage time of four typical carbonyl compounds under two conditions of storage: room temperature and cold temperature $\left(4^{\circ} \mathrm{C}\right)$ with 15 non-smokers' breath samples (a) formaldehyde and 
acetaldehyde, (b) acetone and 2-butanone, (c) hydroxyacetaldehyde and 3-hydroxy-2butanone (d) acrolein and crotonaldehyde, (e) 4-HHE and 4-HNE.

\subsection{Long term stability of carbonyl compounds in exhaled breath samples of nonsmokers at low temperature}

Since lower temperature can keep higher recovery percentages of breath VOCs in Tedlar bags, long term stability of breath samples of the 15 nonsmokers was tested by storing breath samples in refrigerator at $4{ }^{\circ} \mathrm{C}$. The recovery percentages of carbonyl compounds in breath aliquots were determined after 1, 2, 4, 7 and 14 days. Figure 3.4 shows a consistent trend of reduction in recovery percentages of ten breath carbonyl compounds. While all saturated carbonyl compounds decreased to about $60 \%$ to $70 \%$ range, unsaturated acrolein and crotonaldehyde decreased to about 39\% and 4-HHE and 4-HNE decreased to $30 \%$ after 24 hours. The very low concentrations and high reactivity of 4HHE and 4-HNE make it difficult to detect them by other methods. The recovery percentages of lighter compounds are higher than that of heavier compounds. The fastest

decrease of the recovery percentages are 4-HHE and 4-HNE. This long-term stability study indicates that breath samples can only be stored for a short period of time even at cold temperature. In order to recover at least $80 \%$ of carbonyl VOCs for quantitative analysis, breath samples in Tedlar bags will need to be stored at cold temperature and to be processed or analyzed within 2 hours. 


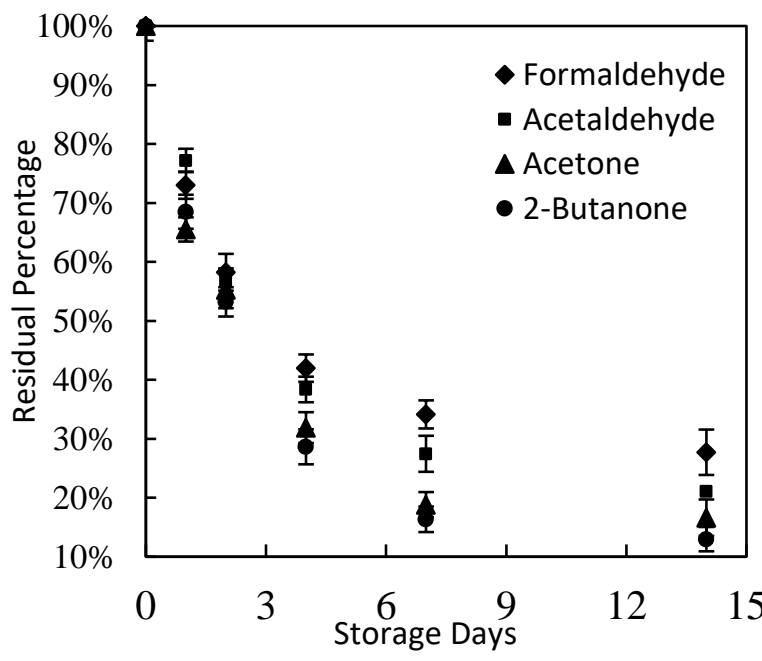

(a)

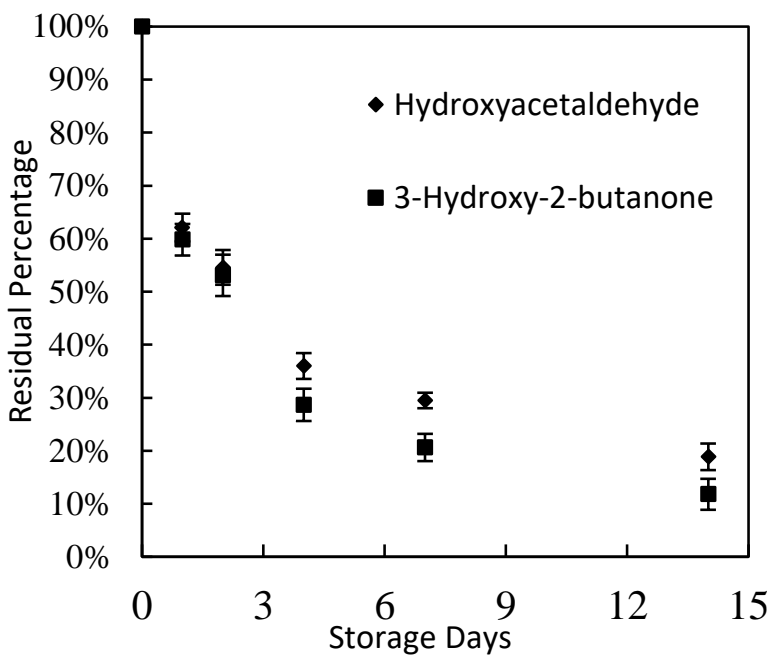

(c)

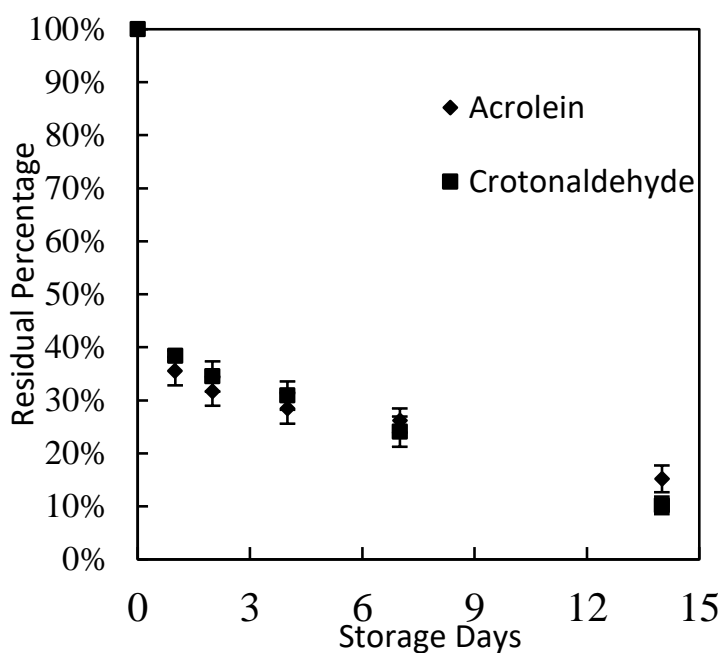

(b)

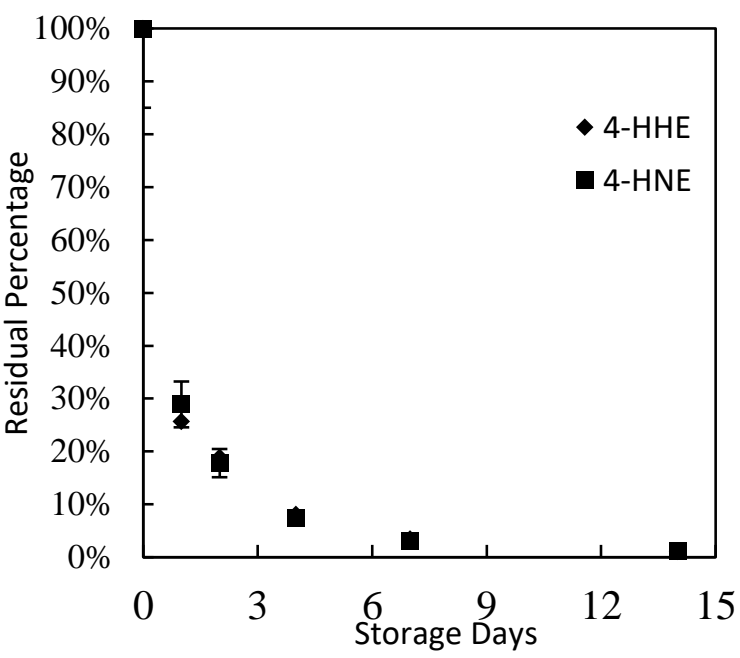

(d)

Figure 3.4 Relationship between the recovery percentage and long term storage of representative carbonyl compounds under refrigerated cold temperature storage $\left(4^{\circ} \mathrm{C}\right)$ with 15 nonsmokers' breath samples.

\subsection{Stability of carbonyl compounds in exhaled breath of smokers at cold temperature}

To investigate the stability of carbonyl compounds in exhaled breath of current smokers at cold temperature and compare the stability difference with nonsmoker exhaled 
breath, seven breath samples of smokers were collected and stored in a refrigerator at $4{ }^{\circ} \mathrm{C}$ for analysis. Figure 3.5 shows that the recovery percentages of all saturated carbonyl compounds in breath samples of smokers were lower than that in nonsmoker breath samples which is consistent with the stability of deuterated saturated carbonyl compounds spiked into smoking and nonsmoker breath samples described above. The recovery percentages of formaldehyde, acetaldehyde, acetone and 2-butanone, hydroxyacetaldehyde and 3-hydroxy-2-butanone in breath samples of nonsmokers are obviously higher that in breath samples of smokers. However, the recovery percentages of unsaturated carbonyl compounds in smoker's breath samples were slightly higher than that in the breath samples of nonsmokers. The concentrations of some carbonyl compounds including acetaldehyde, formaldehyde, acetone and 2-butanone, hydroxyacetaldehyde in breath of cigarette smokers are much higher than that in breath of nonsmokers. ${ }^{135-137}$ The stability differences of carbonyl compounds in breath of smokers and nonsmokers are probably caused by higher concentrations of these compounds and other VOCs in breath of smokers produced in cigarette smoking.

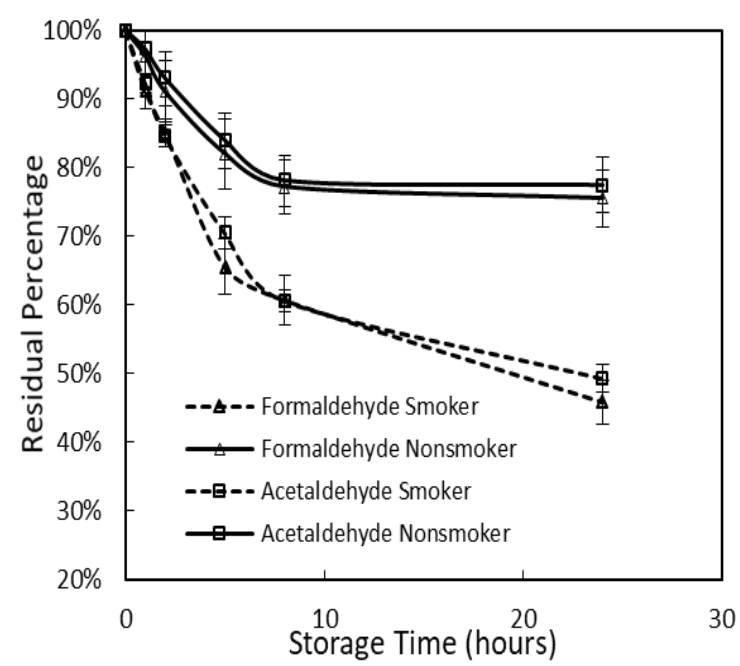

(a)

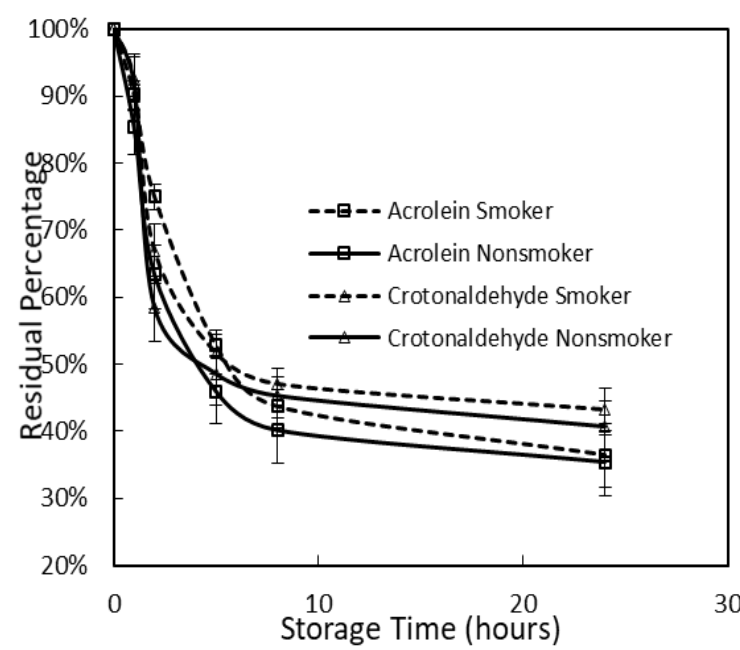

(b) 


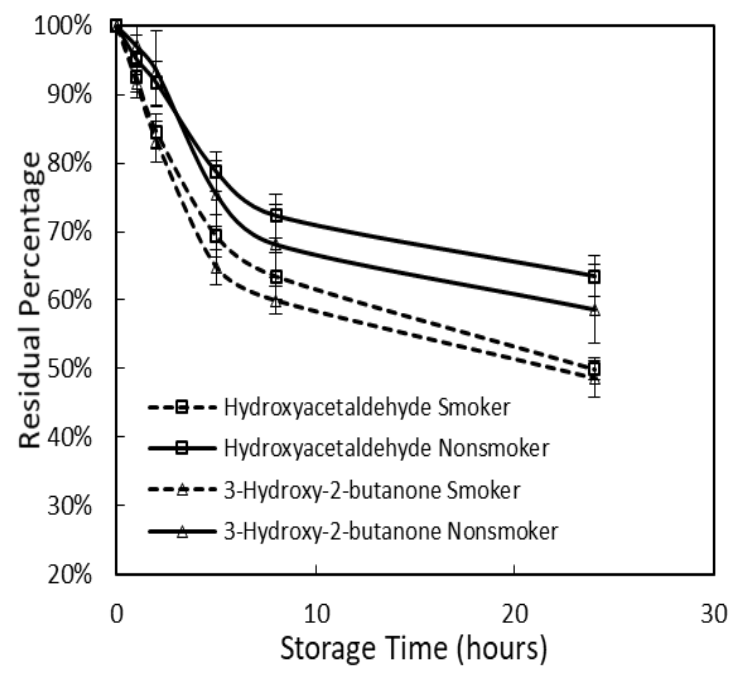

(c)

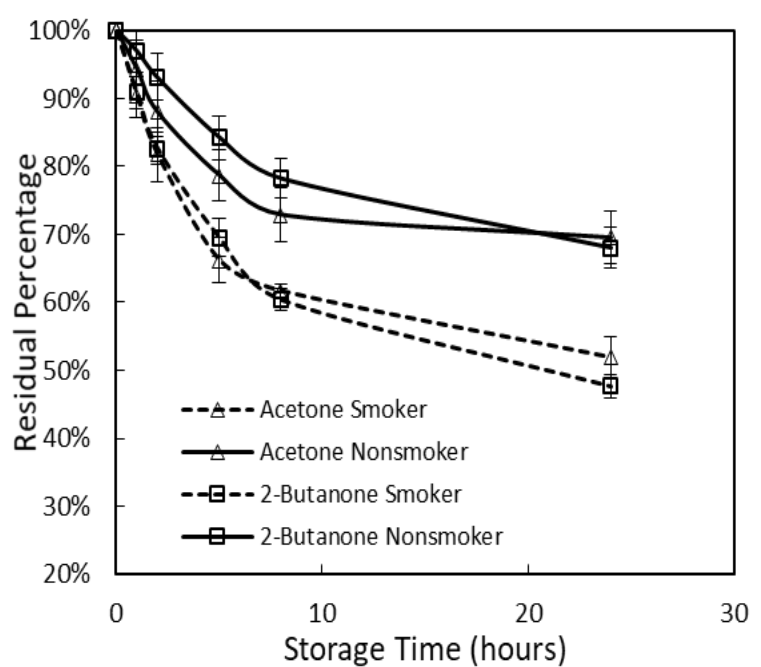

(d)

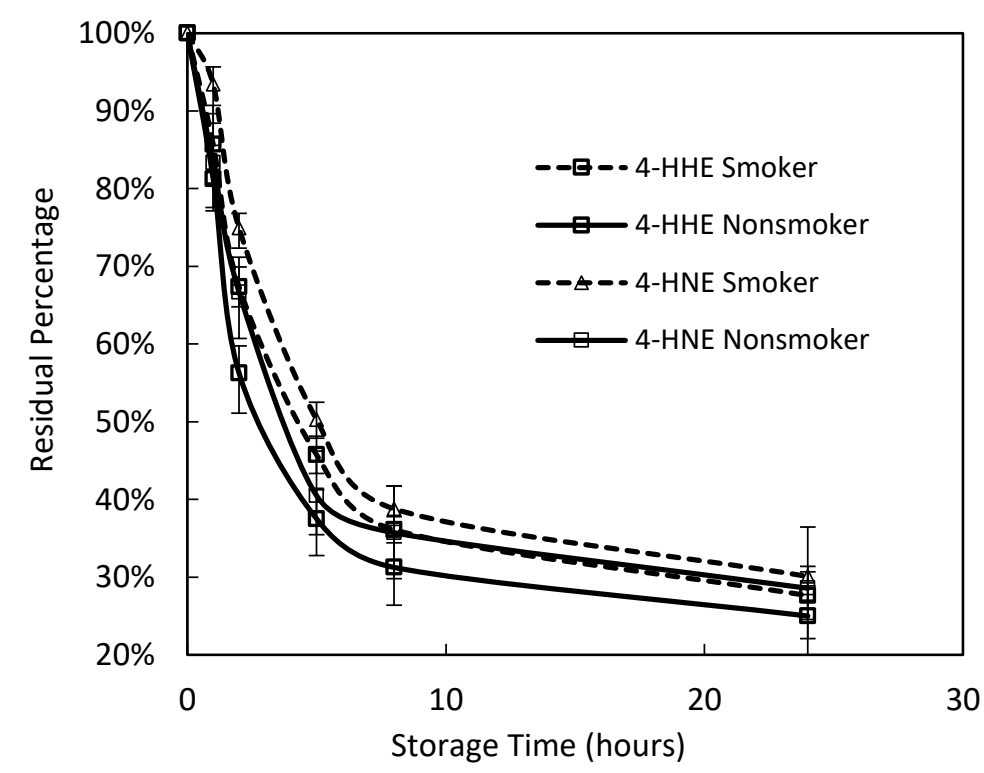

(e)

Figure 3.5 The relationship between the residual percentage and storage time of carbonyl compounds under refrigerated cold temperature storage $\left(4^{\circ} \mathrm{C}\right)$ of 7 smokers' and 15 nonsmokers' breath samples. (a)Formaldehyde and Acetaldehyde, (b)Acrolein and crotonaldehyde, (c)Hydroxyacetaldehyde and 3-hydroxy-2-butanone, (d)acetone and 2butanone, (e) 4-HHE and 4-HNE. 


\section{Conclusion}

The recovery percentages of carbonyl VOCs in breath samples stored at cold temperature $\left(4^{\circ} \mathrm{C}\right)$ are higher than that stored at room temperature. Breath samples are recommended to be stored at cold temperature and to be processed in 2 hours to recover above $80 \%$ of carbonyl compounds. Unsaturated aldehydes degrade much faster than saturated carbonyl compounds. The long term stability tests indicate that the recovery percentages of saturated carbonyl in breath samples stored at cold temperature can be above $50 \%$ for two day while unsaturated aldehydes decrease to less than $40 \%$ within only one

day. The recovery percentages of saturated carbonyl compounds in the breath samples of smokers are obviously lower than that in the breath samples of nonsmokers. 


\section{CHAPTER IV}

\section{ANALYSIS OF CARBONYL COMPOUNDS IN EXHALED BREATH USING THE MICROREACTOR}

\section{Introduction}

Lung cancer (LC) is one of the most frequently diagnosed cancers in the world and is the leading causes of death worldwide, with more than 1 million deaths worldwide every year due to its late diagnosis and the ineffectiveness of treatment for locally advanced and metastatic disease. The fact that there are few symptoms during the early stages and those appearing during advanced stages may be not specific which caused the delayed diagnosis. All of this attracted a considerable interest in finding methods of diagnosis during the early stages. The World Health Organization classification recognizes 20 different types of malignant lung neoplasms. ${ }^{141,142}$ Non-small cell LC (NSCLC) and small-cell LC (SCLC) represent two major forms of LC disease. NSCLC is subdivided into three major histologic subtypes: adenocarcinoma, squamous-cell carcinoma, and large-cell carcinoma. It was reported that SCLC and squamous-cell carcinoma are most strongly linked with smoking while adenocarcinoma is the most common type of lung cancer in patients who have never smoked. ${ }^{143}$ 
The growing use of computed tomography (CT) has considerably increased the number of incidentally detected small lung nodules, especially after recent publications showing that low-dose CT for lung cancer screening in heavy former smokers and current smokers increase $20 \%$ of lung cancer patient survival rate. ${ }^{144,145}$ However, CT screening of lung cancer is not specific which causes $94 \%$ of false positive prediction and a significant number of subjects with falsely positive radiological results undergo unnecessary invasive diagnostic approaches, including surgical resection although imaging techniques have increased the frequency of diagnosis. ${ }^{146}$ In practice, due to consolidated protocols, imaging techniques can reduce the number of false negatives while the positive predictive value remains. False positive subjects will undergo unnecessary invasive diagnostic interventions. ${ }^{147,148}$ Figure 4.1 shows a schematic diagram of the lung and its pathway to produce the VOCs.

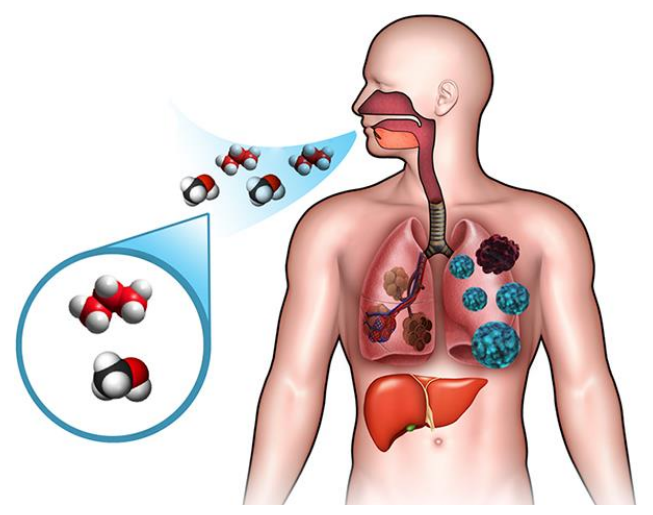

Figure 4.1 Schematic diagram of lung and its pathway to produce VOCs.

About $50 \%$ of subjects undergoing CT in European trials had pulmonary nodules; $20 \%$ of the subjects with pulmonary nodules were required specific management and 1-2\% were invasively treated, leading to a false positive rate of $50-60 \% .{ }^{149,150}$ So it has been suggested that diagnostic procedures, for example, CT scans, may lead to an excess risk of 
cancer due to radiation. ${ }^{151}$ In this situation, an inexpensive and non-invasive test with good accuracy is required to identify high and low risk subjects.

An emerging approach for diagnosing early lung cancer or other lung diseases relies on measuring volatile organic compounds (VOCs). It is well known that breath gas contains different volatile organic compounds, furthermore, lung cancer-related changes of VOCs are documented. The cancer cell formation and growth is accomplished by immunity system changes that can lead to emit different volatile organic compounds implicated the oxidative stress and peroxidation of the cell membrane species. There is a significant difference with the concentrations of VOCs in exhaled breath between healthy controls and lung cancer patients. By analysis of exhaled breath of lung cancer patients, researchers found that some volatile organic compounds can serve as biomarkers of lung cancer. ${ }^{152-154}$

As of now, smoking is a strong lung cancer (LC) risk factor and plays an important role in the carcinogenesis of cells in lung and affects the immunological activity and metabolic procedure ${ }^{155}$ How smoking affects the body will be studied by detecting the exhaled VOCs from nonsmokers and smokers with different smoking behaviors. Recently a lot of researchers proved that tobacco smoking is a major risk factor for lung cancer. ${ }^{156,157}$ Cigarette smoking is a mixture of more than 5000 chemical compounds, more than 60 are recognized to have a specific carcinogenic potential. ${ }^{158}$ With the number of cigarettes smoked per day and the years of smoking, there is a high risk to have lung disease. For non-smoking people, exposure to secondhand smoke also increases the risk of lung cancer.

Most of the studies reported analyzed VOCs using gas chromatography mass spectrometry (GC-MS). GC-MS is a powerful system which enables analysis of VOCs 
qualitatively and quantitatively, however, it needs a long time to analyze the sample and requires skilled operators. Solid phase microextraction-gas chromatography mass spectrometry (SPME-GCMS) analysis also has been used to identify exhaled breath biomarkers of lung cancer. But SPME also has some disadvantages, the surface area of SPME polymer extraction phase is small.

The MEMS based microreactor has been successfully proved for capture of trace level carbonyl compounds with high capture efficiency. There are thousands of micropillars in the microreactors to distribute the gas flow. It also has a large surface area for capturing the target VOCs. In this chapter, we use microreactors which have been described before for quantitative analysis of trace carbonyls in exhaled breath.

\section{Breath Samples and Study Population}

Smoking can cause many lung diseases, for example, chronic obstructive pulmonary disease (COPD), emphysema and lung cancer. Tobacco smoking will have a large effect on exhaled breath when we analyze VOCs in it. Some other diseases such as asthma and heart disease can also affect the VOCs in our breath. To find the difference in breath samples between smoker group and non-smoker group for future identification of carbonyl markers of lung cancer, a total of 107 healthy subjects, 47 current smokers (CS) and 60 never smokers (NS) free from chronic lung disease or respiratory tract infection in the age from 25 to 80 were recruited to provide exhaled breath samples in this study, after approval by the Internal Review Board (IRB) at the university of Louisville and after having obtained written informed consent from the subjects. 


\subsection{Breath sampling and detection}

Each volunteer breathed normally to fill a 1L Tedlar bag by directly breathe into the air sampling bags through the attached Teflon tube. A mixed alveolar and tidal breath is collected. The Tedlar bag was directly connected to the silicon microreactor through deactivated silica tubes and septa as shown in Figure 4.3. Then, the vacuum pump forced gaseous breath in Tedlar bags flowing through the fabricated microreactor at a fixed flow rate of $3.5 \mathrm{ml} / \mathrm{min}$. Figure 4.2 shows photos of a microreactor compared to a dime dollar, SEM picture of triangular shape micropillars and microscopy photo of a microreactor. Figure 4.3 shows a schematic setup for preconcentration of all carbonyl compounds in breath samples by the silicon microreactor. The microreactor length is $7 \mathrm{~mm}$. There are thousands of micropillars in the microreactor which were functionalized by a quaternary ammonium aminooxy, ATM salt for capture of all carbonyl compounds by oximation reactions. The unreacted ATM and reacted ATM adducts were eluted from the microreactor by flowing $150 \mu \mathrm{L}$ methanol from one slightly pressurized vial through the microreactor and then into an empty collecting sample vial. The eluted solutions were directly used for FT-ICR-MS analysis without any further process. A $5 \mu \mathrm{L}$ solution containing $5 \times 10^{-9}$ mole of acetone-d6 completely reacted with ATM in methanol was added to each eluted methanol solution as an internal reference for FTICR-MS analysis in order to determine the concentrations of the carbonyl compounds in exhaled breath samples. The amount of captured carbonyl compounds was determined by using a calibration curve. 


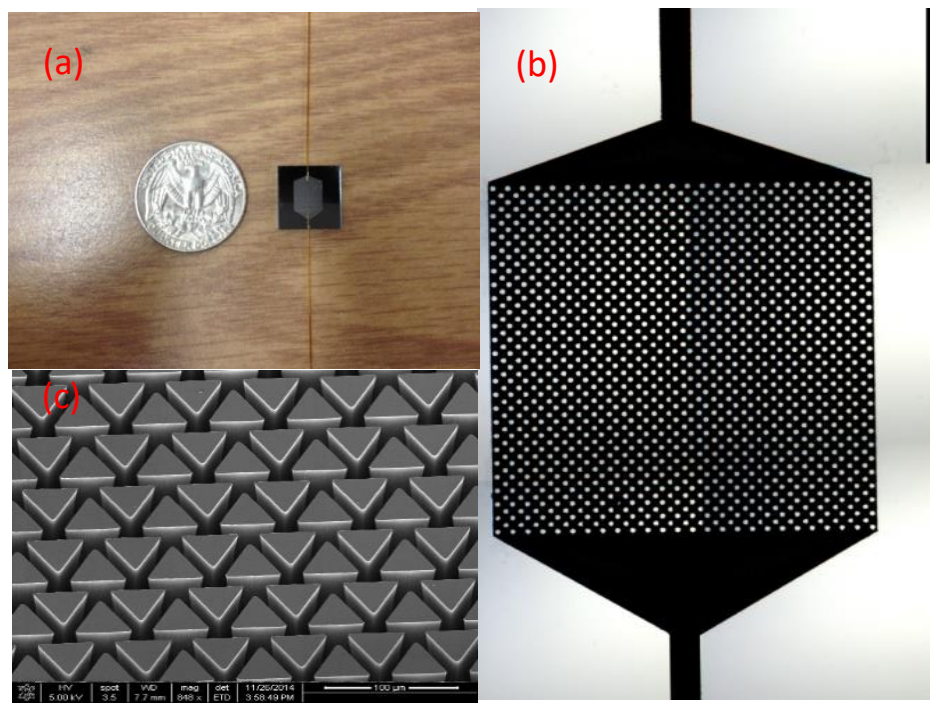

Figure 4.2 (a) One microreactor compared with quarter coin, (b) Optical picture of fabricated microreactor and (c) SEM picture of micropillar arrays.

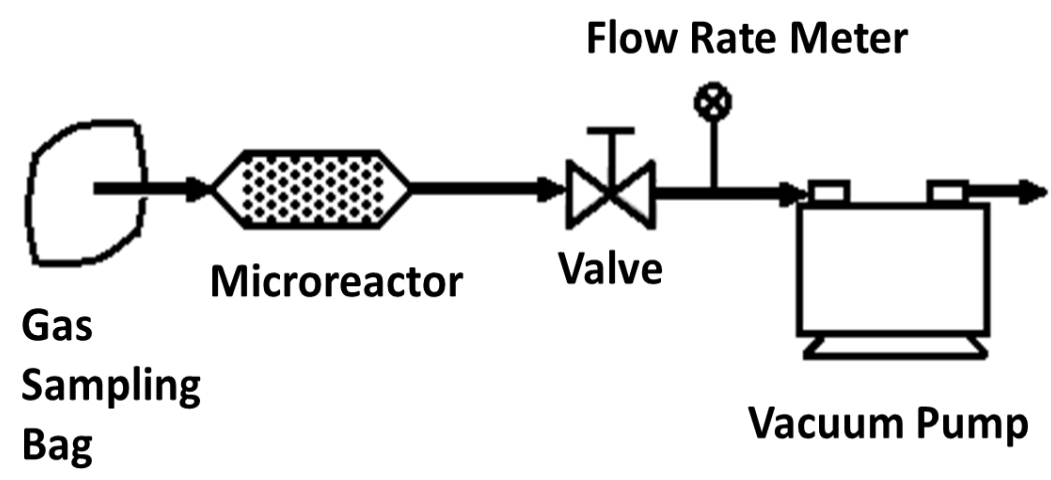

Figure 4.3 Schematic flow diagram of the preconcentration setup for breath analysis. 


\subsection{Statistical analysis}

The carbonyl VOC concentrations in exhaled breath sample of current smokers and never smokers were measured by FTICR-MS. Figure 4.4 shows an example spectrum of current smokers and never smokers. In order to further find out the difference between these two groups, a Wilcoxon test was applied. The Wilcoxon test can be used for comparing two related samples to assess whether their population means differ when the population cannot be assumed to be normally distributed $(\mathrm{p}<0.05$ was regarded as significant).

\subsection{Breath analysis of patients recruited for CT screening of lung cancer}

After approved by the Internal Review Board at University of Louisville in Kentucky and after having obtained written informed consent, exhaled breath samples of 117 patients, of them, 47 patients with pulmonary nodules, 70 without pulmonary nodules and 9 patients with COPD were collected and analyzed. All patients were recruited from a CT screening of early lung cancer program at Floyd Memorial Hospital. 107 healthy subjects, 47 current smokers (CS) and 60 never smokers (NS) described above were used as healthy control (HC) group. Table 4.1 shows the study population distribution of the subjects. 


\section{Table 4. 1}

\section{$\underline{\text { Subject information }}$}

\begin{tabular}{|c|c|c|c|c|c|}
\hline \multirow[t]{2}{*}{ Subjects } & \multirow[t]{2}{*}{$\mathbf{M} / \mathbf{T}^{*}$} & \multirow[t]{2}{*}{$\operatorname{Age}($ mean \pm SD $)$} & \multicolumn{3}{|c|}{ Smoking History } \\
\hline & & & Current & Former & Never \\
\hline pulmonary nodules & $17 / 47$ & $62.25 \pm 7.25$ & 20 & 19 & 8 \\
\hline Without nodules & $32 / 70$ & $64.2 \pm 7.45$ & 9 & 50 & 11 \\
\hline COPD & $2 / 9$ & $64.2 \pm 7.45$ & 2 & 6 & 1 \\
\hline Asthma & $1 / 8$ & $60.5 \pm 7.28$ & 3 & 3 & 2 \\
\hline Healthy controls & $35 / 107$ & $58.25 \pm 12.27$ & 47 & 0 & 60 \\
\hline
\end{tabular}

\section{Results and Discussion}

\subsection{Detection of carbonyl compounds in smokers and nonsmokers}

Tables 4.2-4.4 show the concentration ranges, median, mean and standard deviation (SD) value of compounds for both healthy never smoker and smoker control groups. After ANOVA test, Formaldehyde $(\mathrm{p}=0.000)$, Acetaldehyde $(\mathrm{p}=0.012)$ and Acetone $(\mathrm{p}<0.0001)$ show a significant higher concentration for smokers in comparison with nonsmokers. Figure 4.5 shows boxplots of concentrations of these three compounds in exhaled breath samples from current and never smokers. The results imply that formaldehyde, acetaldehyde and acetone are significantly affected by cigarette smoke, which may be because there are residuals of these three compounds in the lungs of smokers. 


\section{Table 4. 2}

Concentration ranges and medians values of 60 never smokers and 47 current smokers $\underline{(\mathrm{nmol} / \mathrm{L})}$

\begin{tabular}{|c|c|c|c|c|c|c|}
\hline $\mathrm{OCs}$ & $\begin{array}{l}\text { Formaldehyd } \\
\text { e } \\
\mathrm{CH}_{2} \mathrm{O}\end{array}$ & $\begin{array}{l}\text { Acetaldehyde } \\
\mathrm{C}_{2} \mathrm{H}_{4} \mathrm{O}\end{array}$ & $\begin{array}{l}\text { Acetone } \\
\mathrm{C}_{3} \mathrm{H}_{6} \mathrm{O}\end{array}$ & $\begin{array}{l}\text { 2-Butanone } \\
\mathrm{C}_{4} \mathrm{H}_{8} \mathrm{O}\end{array}$ & $\begin{array}{l}\text { 3-Hydroxy- } \\
\text { 2-butanone } \\
\mathrm{C}_{4} \mathrm{H}_{8} \mathrm{O}_{2}\end{array}$ & $\begin{array}{l}\text { Pentanone } \\
\text { \& pentanal } \\
\mathrm{C}_{5} \mathrm{H}_{10} \mathrm{O}\end{array}$ \\
\hline $\begin{array}{c}\text { Never } \\
\text { smokers }\end{array}$ & $\begin{array}{c}0.117-0.439 \\
(0.296)\end{array}$ & $\begin{array}{c}0.27-2.70 \\
(0.72)\end{array}$ & $\begin{array}{c}1.39-11.2 \\
(2.16)\end{array}$ & $\begin{array}{c}0.25-2.45 \\
(1.95)\end{array}$ & $\begin{array}{c}0.022-0.157 \\
(0.075)\end{array}$ & $\begin{array}{c}0.28-1.59 \\
(0.75)\end{array}$ \\
\hline $\begin{array}{l}\text { Current } \\
\text { smokers }\end{array}$ & $\begin{array}{c}0.205-2.165 \\
(0.621)\end{array}$ & $\begin{array}{c}0.23-3.67 \\
(1.33)\end{array}$ & $\begin{array}{c}2.15-16.98 \\
(6.44)\end{array}$ & $\begin{array}{c}0.45-2.78 \\
(1.78)\end{array}$ & $\begin{array}{c}0.023-0.188 \\
(0.09)\end{array}$ & $\begin{array}{c}0.06-1.77 \\
(0.78)\end{array}$ \\
\hline
\end{tabular}

\section{Table 4. 3}

Mean and SD values of 60 never smokers (NS) and 47 current smokers (CS) (nmol/L)

\begin{tabular}{cllllll}
\hline VOCs & $\begin{array}{l}\text { Formaldehyd } \\
\text { e }\end{array}$ & $\begin{array}{l}\text { Acetaldehyde } \\
\mathrm{C}_{2} \mathrm{H}_{4} \mathrm{O}\end{array}$ & $\begin{array}{l}\text { Acetone } \\
\mathrm{C}_{3} \mathrm{H}_{6} \mathrm{O}\end{array}$ & $\begin{array}{l}\text { 2-Butanone } \\
\mathrm{C}_{4} \mathrm{H}_{8} \mathrm{O}\end{array}$ & $\begin{array}{l}\text { 3-Hydroxy- } \\
\text { 2-butanone } \\
\mathrm{C}_{4} \mathrm{H}_{8} \mathrm{O}_{2}\end{array}$ & $\begin{array}{l}\text { Pentanone } \\
\text { \& pentanal } \\
\mathrm{C}_{5} \mathrm{H}_{10} \mathrm{O}\end{array}$ \\
& & & & & & \\
Sample & & & & & & \\
\hline NS & $0.267 \pm 0.06$ & $1.258 \pm 0.27$ & $4.21 \pm 0.57$ & $1.12 \pm 0.21$ & $0.067 \pm 0.01$ & $0.98 \pm 0.1$ \\
$\mathrm{CS}$ & $1.18 \pm 0.25$ & $1.921 \pm 0.31$ & $8.35 \pm 0.69$ & $1.25 \pm 0.25$ & $0.078 \pm 0.02$ & $1.15 \pm 0.15$ \\
\hline
\end{tabular}




\section{Table 4. 4}

Concentration ranges, medians and mean \pm SD values of 60 never smokers (NS) and 47 current smokers (CS) (nmol/L)

\begin{tabular}{ccccc}
\hline VOCs & $\begin{array}{c}\text { Hydroxyacetaldehyde } \\
\mathrm{C}_{2} \mathrm{H}_{4} \mathrm{O}_{2}\end{array}$ & $\begin{array}{l}4-\mathrm{HHE} \\
\mathrm{C}_{2} \mathrm{H}_{4} \mathrm{O}\end{array}$ & $\begin{array}{l}\text { 4- } \mathrm{HNE} \\
\mathrm{C}_{3} \mathrm{H}_{6} \mathrm{O}\end{array}$ & $\begin{array}{c}\text { Acrolein } \\
\mathrm{C}_{4} \mathrm{H}_{8} \mathrm{O}\end{array}$ \\
& & & & \\
\hline Never & $0.007-0.296$ & $0-2.67 \times 10^{-5}$ & $0-0.00035$ & $0-0.1162$ \\
Smokers & $(0.092)$ & $\left(7.37 \times 10^{-5}\right)$ & $(0.0004)$ & $(0.011)$ \\
& $0.123 \pm 0.09$ & $0.00098 \pm 0.0023$ & $0.0398 \pm 0.1383$ & $0.022 \pm 0.033$ \\
& & & & \\
Current & $0.025-0.857$ & $0-0.00383$ & $0-0.317$ & $0-0.215$ \\
smokers & $(0.204)$ & $(0.00099)$ & $(0.00341)$ & $(0)$ \\
& $0.209 \pm 0.164$ & $0.00177 \pm 0.0021$ & $0.0181 \pm 0.066$ & $0.0204 \pm 0.05$ \\
& & & & \\
\hline
\end{tabular}



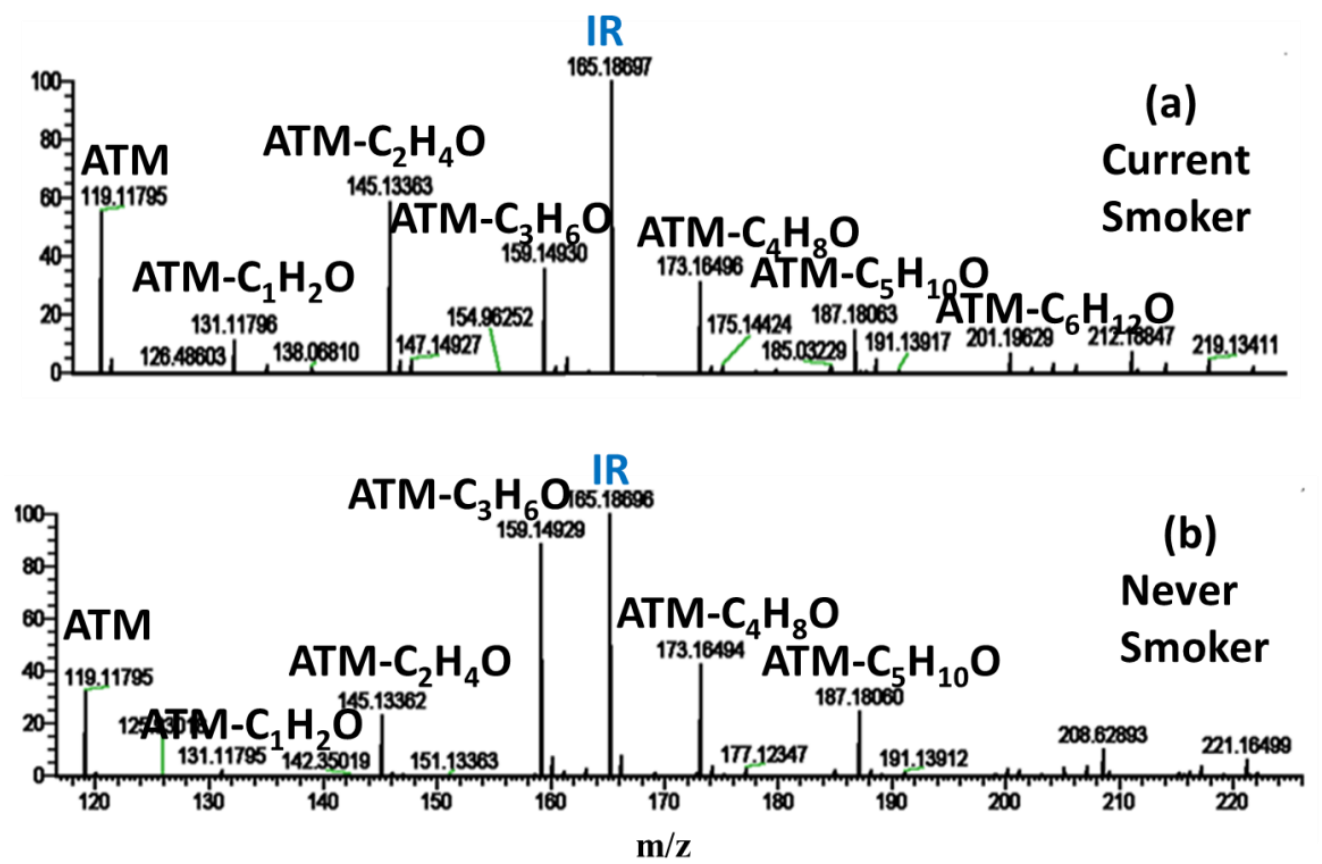

Figure 4.4 Typical FTICR-MS spectra of breath samples. (a) Current smoker, and (b) Never smoker. The peak of ATM is 2-(aminooxy)-N, N, N-trimethylethanammonium cations. The peak of IR is internal reference ATM-acetone-d6. All other peaks are ATM reacted with carbonyl VOCs. For example: ATM- $\mathrm{C}_{1} \mathrm{H}_{2} \mathrm{O}$ is ATM reacted with formaldehyde and ATM- $\mathrm{C}_{2} \mathrm{H}_{4} \mathrm{O}$ is ATM reacted with acetaldehyde. 


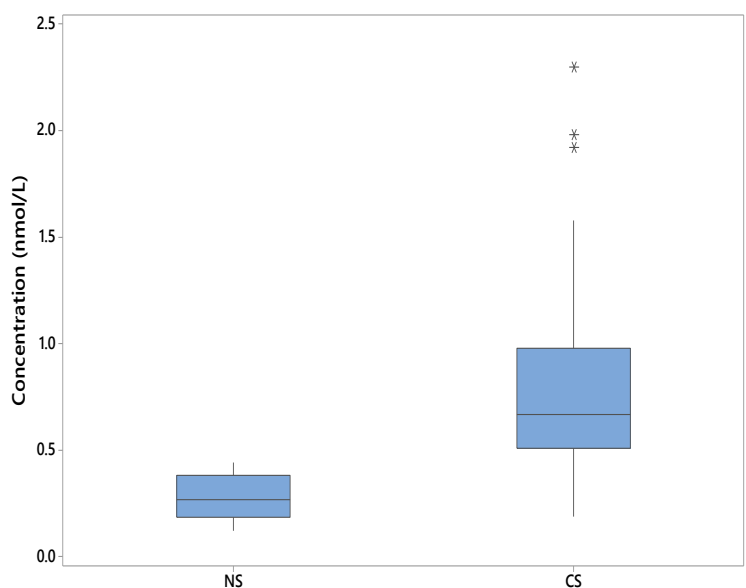

(a) Formaldehyde

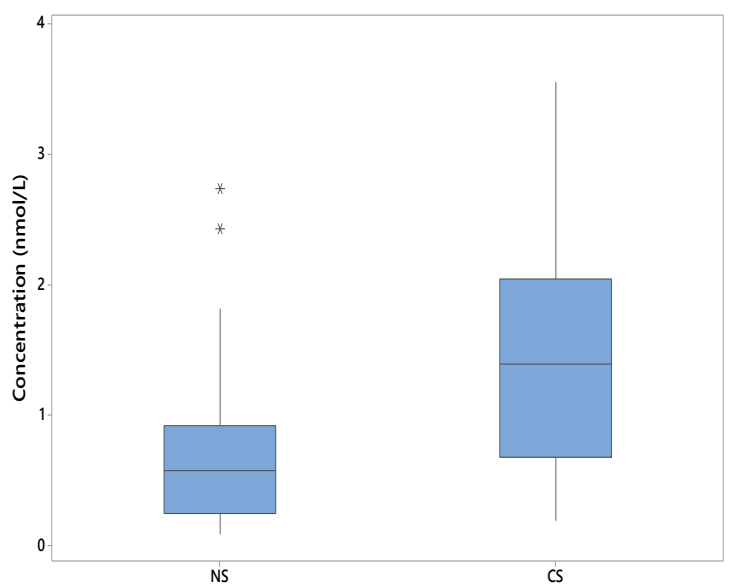

(b) Acetaldehyde

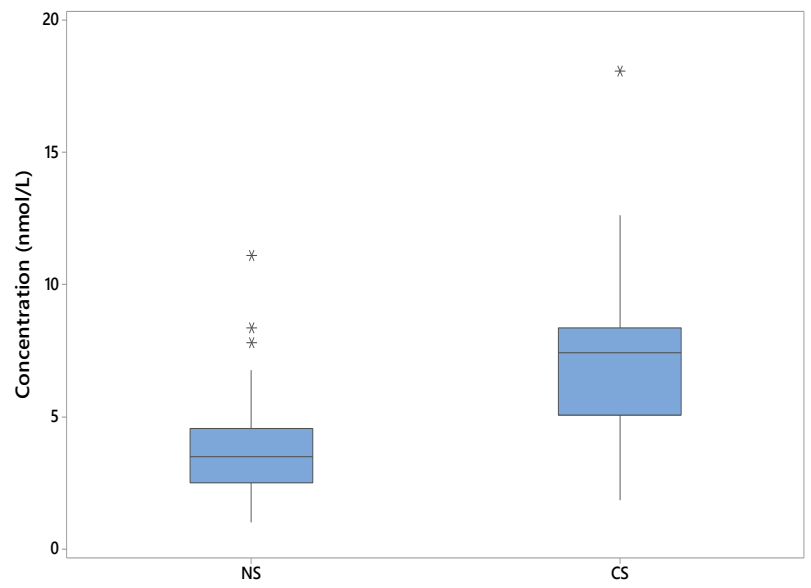

(c) Acetone

Figure 4.5 Comparisons of three compounds from never smokers (NS) group(n=60) and current smokers (CS) healthy control groups (n=47). (a) Formaldehyde, (b) Acetaldehyde, (c) Acetone.

\subsection{Detection of the carbonyl compounds in patients for CT screening of lung cancer}

Fourteen carbonyl compounds were also found in exhaled breath samples and their concentrations were determined. They are $\mathrm{CH}_{2} \mathrm{O}, \mathrm{C}_{2} \mathrm{H}_{4} \mathrm{O}, \mathrm{C}_{3} \mathrm{H}_{6} \mathrm{O}, \mathrm{C}_{3} \mathrm{H}_{4} \mathrm{O}, \mathrm{C}_{4} \mathrm{H}_{8} \mathrm{O}, \mathrm{C}_{5} \mathrm{H}_{10} \mathrm{O}$, 
$\mathrm{C}_{6} \mathrm{H}_{12} \mathrm{O}, \mathrm{C}_{7} \mathrm{H}_{14} \mathrm{O}, \mathrm{C}_{8} \mathrm{H}_{16} \mathrm{O}, \mathrm{C}_{9} \mathrm{H}_{18} \mathrm{O}, \mathrm{C}_{10} \mathrm{H}_{20} \mathrm{O}, \mathrm{C}_{2} \mathrm{H}_{4} \mathrm{O}_{2}, \mathrm{C}_{3} \mathrm{H}_{4} \mathrm{O}_{2}, \mathrm{C}_{4} \mathrm{H}_{8} \mathrm{O}_{2}$. After analysis of exhaled breath samples of pulmonary nodule patients groups, without pulmonary nodules groups and healthy controls groups, $\mathrm{C}_{3} \mathrm{H}_{6} \mathrm{O}(\mathrm{p}=0.018), \mathrm{C}_{2} \mathrm{H}_{4} \mathrm{O}_{2}(\mathrm{p}=0.002)$ and $\mathrm{C}_{4} \mathrm{H}_{8} \mathrm{O}_{2}$ $(\mathrm{p}=0.009)$ were found to have statistical significance between the pulmonary nodule group and $\mathrm{HC}$ group. $\mathrm{C}_{2} \mathrm{H}_{4} \mathrm{O}_{2}(\mathrm{p}=0.001)$ and $\mathrm{C}_{4} \mathrm{H}_{8} \mathrm{O}(\mathrm{p}=0.003)$ was found to have significantly higher concentrations in pulmonary nodule group than these without nodules. Figure 4.6 shows boxplots of the concentrations of four compounds between pulmonary nodule group, without pulmonary nodule group and $\mathrm{HC}$ group.

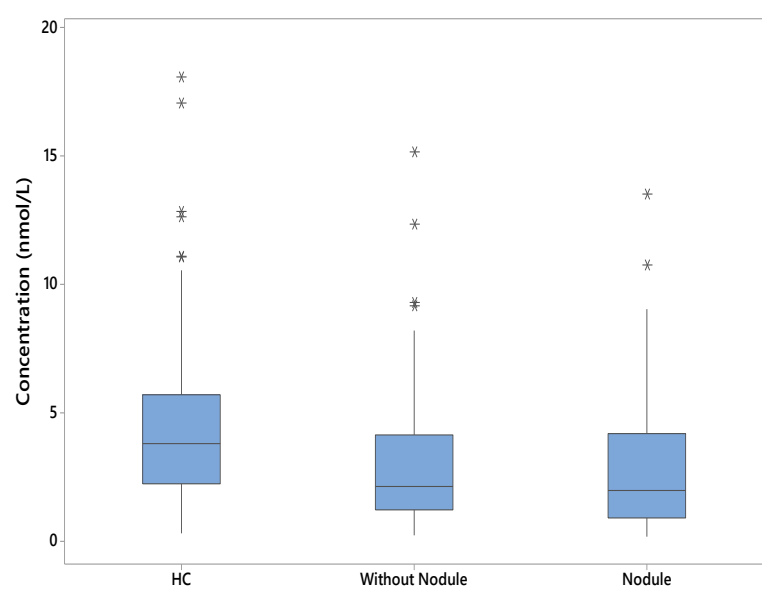

(a) $\mathrm{C}_{3} \mathrm{H}_{6} \mathrm{O}$

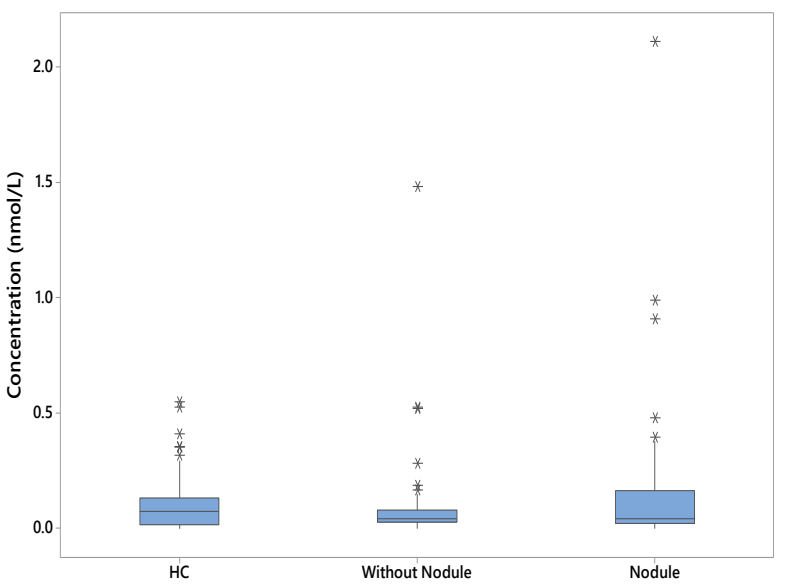

(c) $\mathrm{C}_{4} \mathrm{H}_{8} \mathrm{O}_{2}$

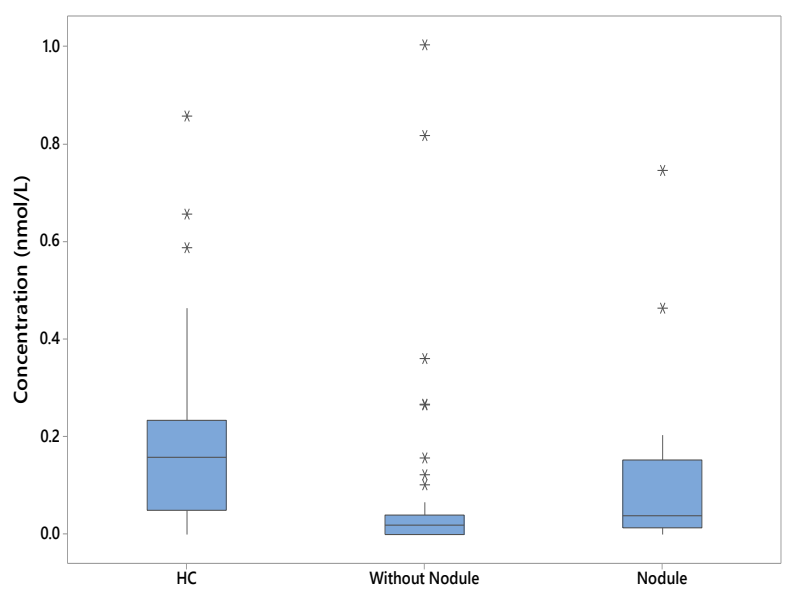

(b) $\mathrm{C}_{2} \mathrm{H}_{4} \mathrm{O}_{2}$

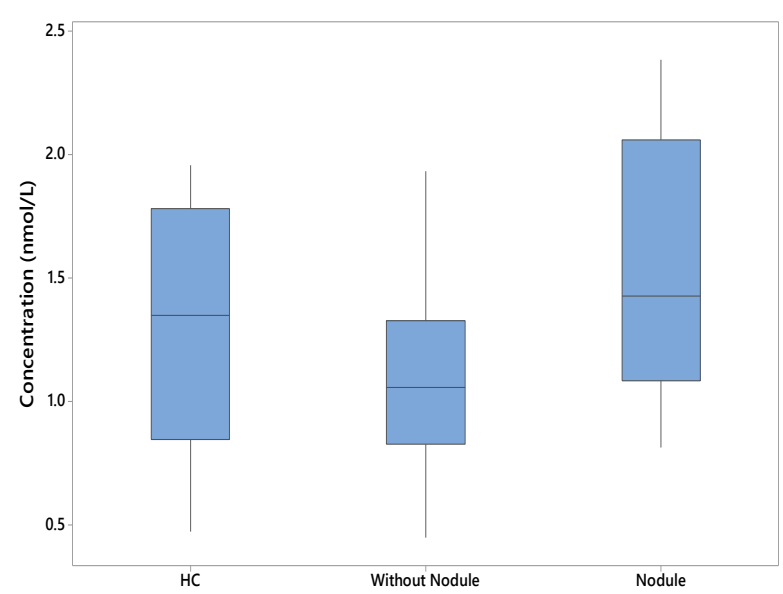

(d) $\mathrm{C}_{4} \mathrm{H}_{8} \mathrm{O}$ 
Figure 4.6 Comparisons of carbonyl compounds from healthy control (HC, n=107) group, pulmonary nodule ( $\mathrm{n}=47$ ) and without pulmonary (n=70) group. (a) $\mathrm{C}_{3} \mathrm{H}_{6} \mathrm{O}$, (b) $\mathrm{C}_{2} \mathrm{H}_{4} \mathrm{O}_{2}$, (c) $\mathrm{C}_{4} \mathrm{H}_{8} \mathrm{O}_{2}$ and (d) $\mathrm{C}_{4} \mathrm{H}_{8} \mathrm{O}$.

According to the World Health Organization estimations, chronic obstructive disease (COPD) will become the third leading cause of death worldwide by $2030 .{ }^{159-161}$ The types and concentrations of the detected VOCs can reflect the pathophysiological changes in human body and be linked to a specific disease, including COPD. Among the 117 patients at Floyd Hospital, 9 patients were with COPD. After conducting ANOVA test between healthy control and COPD patients, $\mathrm{C}_{2} \mathrm{H}_{4} \mathrm{O}_{2}(\mathrm{p}=0.005)$ and $\mathrm{C}_{4} \mathrm{H}_{8} \mathrm{O}_{2}(\mathrm{p}=0.008)$ were found have significant difference. For $\mathrm{C}_{4} \mathrm{H}_{8} \mathrm{O}_{2}(\mathrm{p}=0.008)$, there is a statistically significant higher concentrations for COPD patients and thus can be used to discriminate COPD patients from healthy controls while $\mathrm{C}_{2} \mathrm{H}_{4} \mathrm{O}_{2}$ (p=0.005) shows a significant lower concentration for COPD patients when compared to healthy controls. Figure 4.7 shows boxplots of the concentrations of the 2 compounds in exhaled breath samples from COPD patients, healthy controls and smoker patients without benign pulmonary nodules. The ANOVA test shows that there is no significant difference between smoker patients without benign pulmonary nodules, healthy controls and COPD patients. 


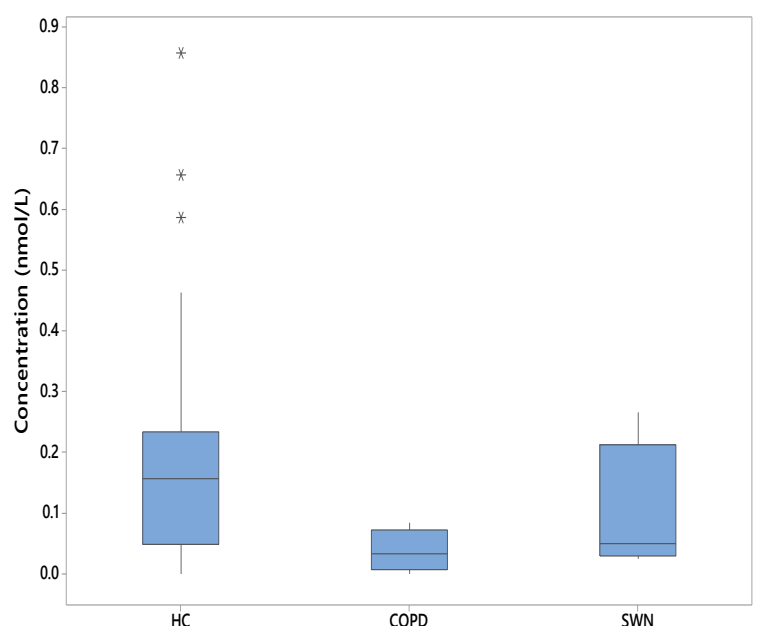

(a) $\mathrm{C}_{2} \mathrm{H}_{4} \mathrm{O}_{2}$

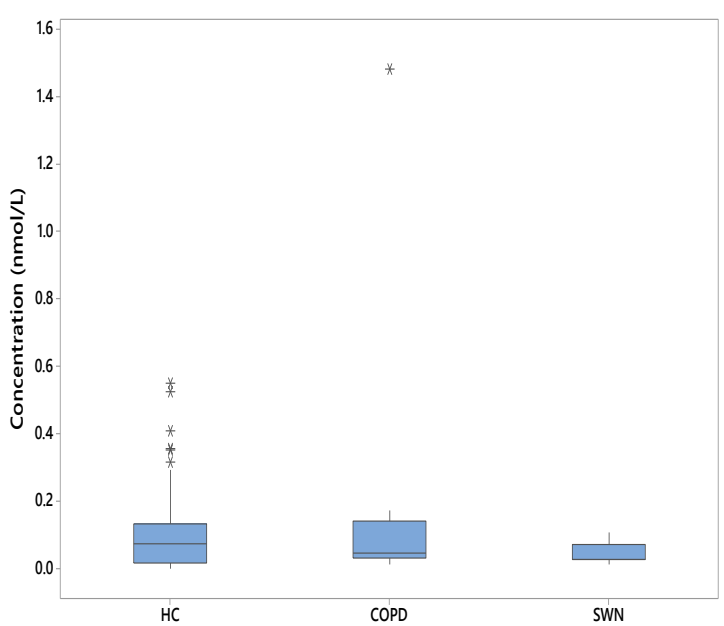

(b) $\mathrm{C}_{4} \mathrm{H}_{8} \mathrm{O}_{2}$

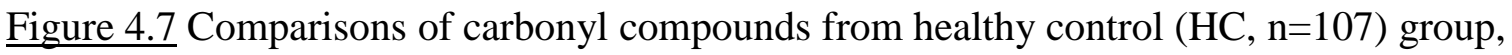
$\operatorname{COPD}(\mathrm{n}=9)$ group and smoker patients without benign pulmonary nodules (SWN, n=17) group. (a) $\mathrm{C}_{2} \mathrm{H}_{4} \mathrm{O}_{2}$, (b) $\mathrm{C}_{4} \mathrm{H}_{8} \mathrm{O}_{2}$.

Asthma and chronic obstructive pulmonary disease (COPD) are widespread respiratory diseases involving airway inflammation. Asthma is a chronic inflammation of the airways that involves airflow obstruction and increased airway responsiveness to a variety of stimuli. ${ }^{162,163}$ A key feature is the inflammation in both proximal and distal lung airways. Although asthma affects people of all ages, it often starts in childhood. Asthma is a growing medical problem with its incidence increasing in recent years. Among the 117 patients at Floyd Hospital, 8 patients were with asthma patients. By doing the ANOVA test, we found three compounds $\mathrm{CH}_{2} \mathrm{O}(\mathrm{p}=0.003), \mathrm{C}_{2} \mathrm{H}_{4} \mathrm{O}(\mathrm{p}=0.000)$ and $\mathrm{C}_{4} \mathrm{H}_{8} \mathrm{O}_{2}(\mathrm{p}=0.000)$ have significant higher concentrations than healthy control group. Therefore, $\mathrm{CH}_{2} \mathrm{O}$, $\mathrm{C}_{2} \mathrm{H}_{4} \mathrm{O}$ and $\mathrm{C}_{4} \mathrm{H}_{8} \mathrm{O}_{2}$ were chosen as the markers of asthma for diagnosis purpose. Figure 
4.8 shows the boxplots of three compounds $\mathrm{CH}_{2} \mathrm{O}, \mathrm{C}_{2} \mathrm{H}_{4} \mathrm{O}$ and $\mathrm{C}_{4} \mathrm{H}_{8} \mathrm{O}_{2}$ between healthy control group and asthma patients group.

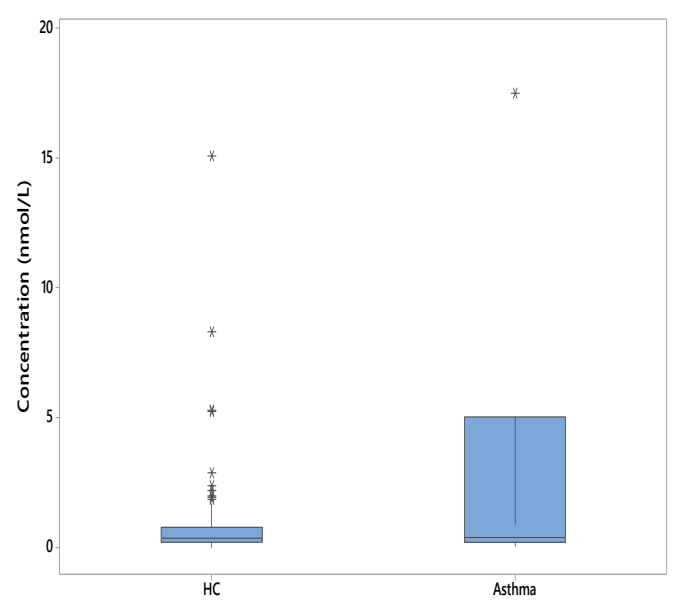

(a) $\mathrm{CH}_{2} \mathrm{O}$

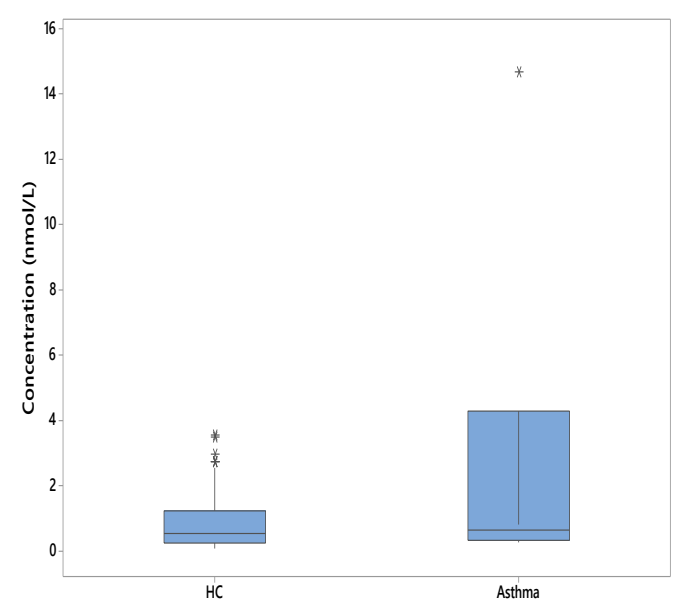

(b) $\mathrm{C}_{2} \mathrm{H}_{4} \mathrm{O}$

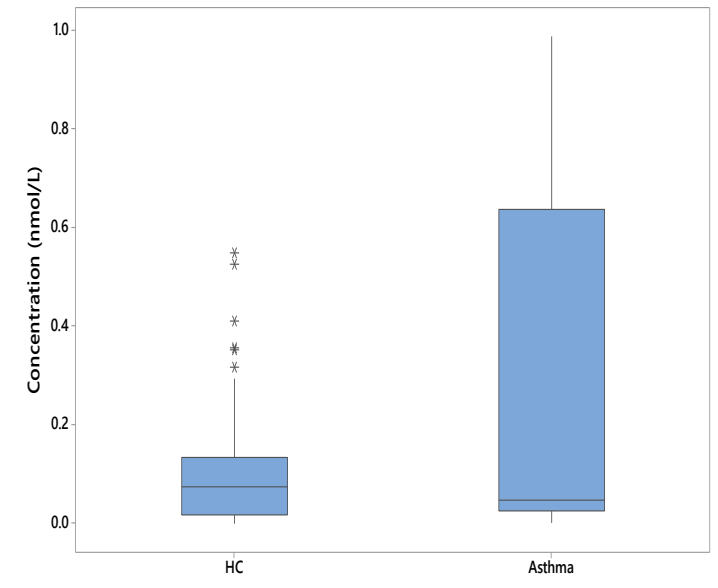

(c) $\mathrm{C}_{4} \mathrm{H}_{8} \mathrm{O}_{2}$

Figure 4.8 Comparisons of carbonyl compounds from healthy control (HC, $\mathrm{n}=107)$ group, asthma group (n=8). (a) $\mathrm{CH}_{2} \mathrm{O}$, (b) $\mathrm{C}_{2} \mathrm{H}_{4} \mathrm{O}$, (c) $\mathrm{C}_{4} \mathrm{H}_{8} \mathrm{O}_{2}$. 
Since tobacco smoking and involuntary smoking are well documented in the scientific literature to cause cancer. It is also known that smoking cigarettes increases the amount of free radicals in human body. So, it is important for us to learn the smoking effect in breath. Of all the 117 subjects collected from Floyd hospital, it was separated into three groups: 19 never smokers, 69 former smokers and 29 current smokers. The criteria for former smokers is subjects without smoking for more than 2 days. The other smoker subjects were treated as current smokers. All patients were asked to fill in a questionnaire describing their current smoking status, for example, active smokers, non-smokers, passive smokers and the time elapsed since their last smoke. The classification to the appropriate group was done on the basis self-declaration of the volunteers. The exhaled breath was collected in 1L Tedlar bags which were cleaned by flushing with nitrogen gas. Then the microreactor method was used to evacuate the samples followed by a FTICR-MS analysis. Using ANOVA test, we found three carbonyl compounds (formaldehyde, acetaldehyde and acetone) were significant change among these groups. Figure 4.9 shows the boxplots of concentrations of the three identified compounds in exhaled breath samples from never smoker (NS) group, former smoker (FS) group and current smoker (CS) group. 


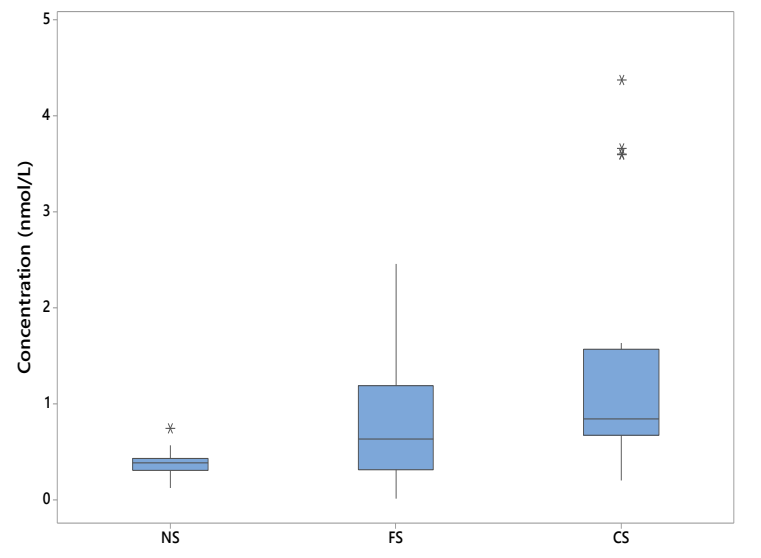

(a) $\mathrm{CH}_{2} \mathrm{O}$

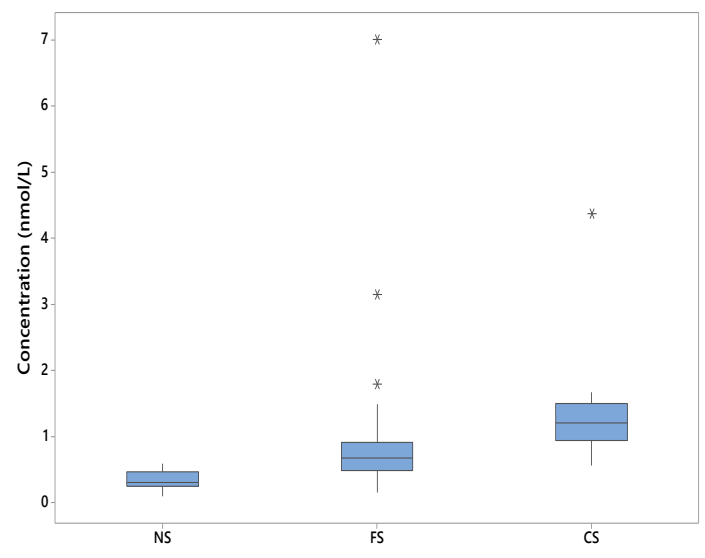

(b) $\mathrm{C}_{2} \mathrm{H}_{4} \mathrm{O}$

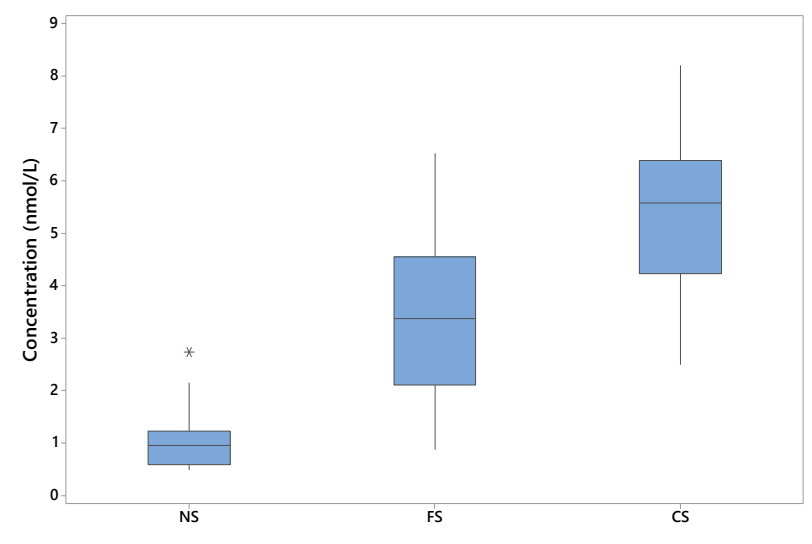

(c) $\mathrm{C}_{3} \mathrm{H}_{6} \mathrm{O}$

$\underline{\text { Figure 4.9 }}$ Comparisons of carbonyl compounds from never smoker patients $(n=19)$ group, former smoking patients ( $n=69)$ and current smokers $(n=29)$ groups. (a) $\mathrm{CH}_{2} \mathrm{O}$, (b) $\mathrm{C}_{2} \mathrm{H}_{4} \mathrm{O}$, (c) $\mathrm{C}_{3} \mathrm{H}_{6} \mathrm{O}$.

To further demonstrate the tobacco smoking will have a high effect on exhaled breath. We further separate the 29 current smokers into two subgroups. 20 subjects just smoked within 2 hours, 5 subjects did not smoke more than 4 hours but less than 2 days and 4 subjects did not smoke more than 2 days as former smokers (FS). After conducting 
same ANOVA test, Formaldehyde $(\mathrm{p}=0.017)$, Acetaldehyde $(\mathrm{p}=0.001)$ and Acetone $(p=0.042)$ were also found to be significant higher in JS group than CS group. Figure 4.10 shows the boxplots of this situation.

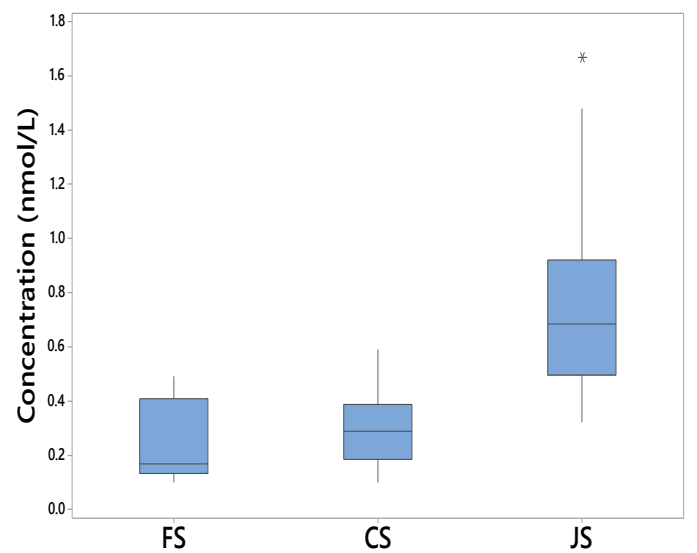

(a) $\mathrm{CH}_{2} \mathrm{O}$

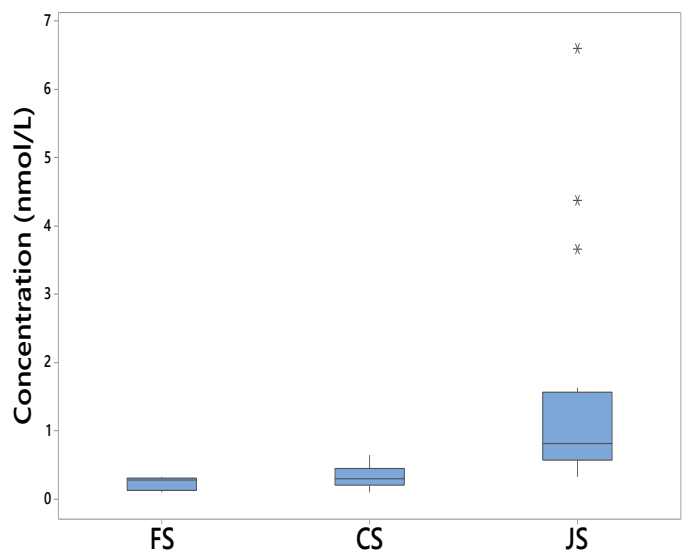

(b) $\mathrm{C}_{2} \mathrm{H}_{4} \mathrm{O}$

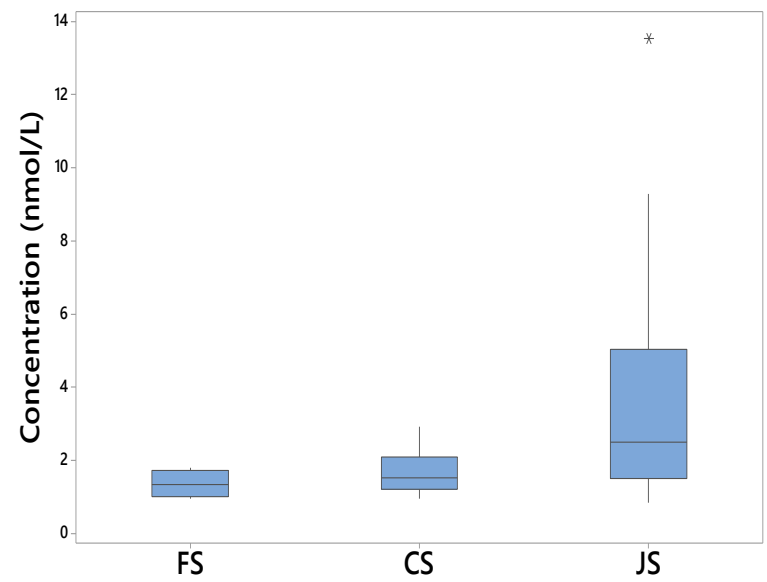

(c) $\mathrm{C}_{3} \mathrm{H}_{6} \mathrm{O}$

Figure 4.10 Comparisons of carbonyl compounds from current smoker (CS) group without smoking for more than 4 hours ( $\mathrm{n}=5)$, former smoker (FS) without smoking for more than 2 days ( $\mathrm{n}=4$ ) and smoke within 2 hours (JS) group ( $\mathrm{n}=20$ ). (a) $\mathrm{CH}_{2} \mathrm{O}$, (b) $\mathrm{C}_{2} \mathrm{H}_{4} \mathrm{O}$, (c) $\mathrm{C}_{3} \mathrm{H}_{6} \mathrm{O}$. 
This study demonstrates the potential of MEMS based microreactors combined with FTICR-MS system to identify breath markers for the distinction of subjects with benign pulmonary nodules from healthy controls. Also, the patients with COPD and asthma from healthy controls. The significant differences in concentrations of these certain compounds in exhaled breath are related to metabolic differences of different types of lung diseases. The data analysis in this study did not require complicated biostatistics models. The biostatistics study in this research imply that breath test can be capable of detection of lung diseases.

There are several advantages for this microreactor study. The microreactors are designed to have high capture efficiencies of all carbonyl compounds. The ATM reaction with carbonyl compounds through oximation reactions enables to analyze carbonyl compounds related to biochemical metabolites. There is also one limition for FTICR-MS which it is not able to identify untargeted components of a breath mixture, although it provides accurate chemical formula. The microreactor method is noninvasive and inexpensive. It does not require trained staff for their use and analysis. The microreactor system can also be loaded with other chemical or physical adsorbent to capture other VOCs in exhaled breath. The eluted analytes can be analyzed by gas chromatography-mass spectrometry or proton transfer reaction mass spectrometry to satisfy the need to explain the metabolism mechanism of VOCs in breath. 


\section{Conclusion}

This study shows that smoking history effects on exhaled breath. The concentration ranges of formaldehyde, acetaldehyde and acetone for current smoking subjects are much higher than those who did not smoke. The increasing number of carbonyl compounds in the exhaled breath from smokers was caused by smoking cigarette. The study between current smokers and smokers who just smoked within two hours further shows that smoking can increase formaldehyde, acetaldehyde and acetone concentrations in exhaled breath. The study between healthy controls, patients with pulmonary nodules and patients without pulmonary nodules show that $\mathrm{C}_{3} \mathrm{H}_{6} \mathrm{O}, \mathrm{C}_{2} \mathrm{H}_{4} \mathrm{O}_{2}$ and $\mathrm{C}_{4} \mathrm{H}_{8} \mathrm{O}_{2}$ can serve as biomarkers to distinguish patients with pulmonary nodules from healthy controls. $\mathrm{C}_{2} \mathrm{H}_{4} \mathrm{O}_{2}$ and $\mathrm{C}_{4} \mathrm{H}_{8} \mathrm{O}$ and serve as biomarkers for distinguish patients with pulmonary nodules from patients without pulmonary nodules. For COPD, we found that $\mathrm{C}_{2} \mathrm{H}_{4} \mathrm{O}_{2}$ and $\mathrm{C}_{4} \mathrm{H}_{8} \mathrm{O}_{2}$ can serve as biomarkers to identify them. Also, $\mathrm{CH}_{2} \mathrm{O}, \mathrm{C}_{2} \mathrm{H}_{4} \mathrm{O}_{2}$ and $\mathrm{C}_{4} \mathrm{H}_{8} \mathrm{O}_{2}$ are good biomarkers that distinguish asthma from healthy controls. 


\section{CHAPTER V}

\section{DETECTION OF LUNG CANCER FROM EXHALED BREATH USING THE MICROREACTOR}

\section{Introduction}

Lung cancer is one of the leading causes of death in the world and can be classified into two main types-non-small cell lung cancer (NSCLC) and small cell lung cancer (SCLC). Most lung cancer patients are diagnosed at an advanced stage when the symptoms (i.e., dyspnea, cough, fatigue, pain in thorax) appear and this often leads to poor prognosis. The most effective treatment for lung cancer currently is pulmonary surgical resection, however, the 5-year survival rate after surgical resection of stage $ш$ patients is only $30 \%$ while stage I patients show up to $70 \% .^{164,165}$ Therefore, earlier detection of lung cancer is the key to increase patient survival rates. Various diagnosis tools for lung cancer such as chest x-ray, chest computed tomography (CT) scan, bronchoscopy, fluorodeoxyglucosepositron emission tomography (FDG-PET) and lung biopsy are applied. However, the existing diagnostic procedures are invasive, expensive and inaccurate. Currently, low-dose CT screening is adopted for early detection of lung cancer but the false positive prediction is too high (96\%). Recent years, more and more researchers proposed exhaled breath analysis can be used to detect lung cancer. There is strong evidence that molecular analysis

of exhaled breath can be used to detect particulate cancers. ${ }^{166-168}$ Breath analysis represent 
a new diagnostic technique that is commonly thought without risk for the patient even if repeated frequently and it can provide information beyond conventional analysis of blood and urine. ${ }^{169-171}$ Even patients at an intensive care unit or during surgery it can still be applied with. ${ }^{172,173}$

There are novel cancer biomarkers in exhaled breath for lung cancer patients. Various volatile organic compounds are contained in breath gas. Exhaled VOCs can originate from two main sources; exogenous volatiles that are inhaled and then exhaled and those endogenously produced by different biochemical processes through basic cellular functions. ${ }^{174}$

Most of the studies reported analyzed VOCs using gas chromatography mass spectrometry (GC-MS). ${ }^{175-177}$ Although GC-MS is a powerful system which enables analysis of VOCs qualitatively and quantitatively, it also has some disadvantages, for

example, it is high cost, time consuming and requires skilled operators. ${ }^{178}$ Biomarkers from lung cancer patients are hard to define although many different VOCs are detected from human exhaled breath by GC-MS. In this study, we used a microreactor system for analyzing VOCs from exhaled breath to detect early stage lung cancer. A UHPLC-MS was used to analyze the breath samples.

\section{Breath Analysis of Lung Cancer Patient}

\subsection{Test population}

After approval by the Internal Review Board at the University of Louisville in Kentucky and after having obtained written informed consent, exhaled breath samples of 15 patients with untreated LC, 7 patients with benign pulmonary nodules $(\mathrm{BN})$ and 15 
healthy controls were collected and analyzed. All patients with pulmonary nodules were recruited in the James Graham Brown Cancer Center at the University of Louisville. Wilcoxon test was applied to identify specific VOCs as lung cancer markers from the clinically diagnosed lung cancer subjects in comparison with healthy controls. All subjects were patients with pulmonary nodules to be diagnosed at the time of collection of exhaled breath samples. The concentration ranges of these VOCs markers were determined for healthy controls, patients with cancer. Then these VOC markers were used to diagnose cancer for all other breath analysis results. A diagnostic conclusion was made based on the concentration levels of the specific VOCs. The diagnostic conclusions from breath analysis were late confirmed by the clinical diagnosis. The general sample information is listed in Table 5.1.

Table 5. 1

$\underline{\text { Subject information }}$

\begin{tabular}{cccccc}
\hline Subjects & M/T & Age $($ mean \pm SD) & \multicolumn{3}{c}{ Smoking History } \\
\cline { 3 - 6 } & & & Current & Former & Never \\
\hline Lung cancers & $12 / 15$ & $64.22 \pm 9.1$ & 6 & 6 & 3 \\
Benign nodules & $2 / 7$ & $52.45 \pm 14.6$ & 3 & 2 & 2 \\
Healthy controls & $7 / 15$ & $52.21 \pm 15.1$ & 7 & 2 & 6 \\
${ }^{*} \mathrm{M} / \mathrm{T}=$ the ratio of male subjects to total subjects & & & \\
\hline
\end{tabular}

${ }^{*} \mathrm{M} / \mathrm{T}=$ the ratio of male subjects to total subjects

\subsection{Breath sampling and detection}

Each volunteer breathed normally to fill two Tedlar bags, the two Tedlar bags were connected to a two-way switch valve. The first Tedlar bag is $600 \mathrm{~mL}$ and second Tedlar 
bag is $400 \mathrm{~mL}$. The $600 \mathrm{~mL}$ is tidal breath and $400 \mathrm{~mL}$ is alveolar breath. $3 \mathrm{~L}(21 \mathrm{~mm})$ length microreactors with triangular micropillars were used to evacuated breath samples. Figure 5.1 shows a SEM photo of the microreactor with triangular micropillars. After collection, the Tedlar bags were directly connected to the silicon microreactor through deactivated silica tubes and septa as shown in Figure 5.2. Then, a vacuum pump was used to force gaseous breath in Tedlar breath flowing through the microreactor at a flow rate of $7 \mathrm{~mL} / \mathrm{min}$. Figure 5.2 shows a schematic setup for preconcentration of all carbonyl compounds in breath samples by the silicon microreactor. A quaternary ammonium aminooxy compound, ATM salt for capture of all carbonyl compounds by oximation reactions was coated on the surface of thousands of micropillars in the microreactor. After evacuation, unreacted ATM and reacted ATM adducts were eluted from the microreactor by flowing $200 \mu \mathrm{L}$ methanol. The eluted solutions were directly used for UHPLC-MS system analysis without any further process. To determine the concentrations of the carbonyl compounds, a $5 \mu \mathrm{L}$ solution containing $5 \times 10^{-9}$ mole of acetone-d6 completely reacted with ATM in methanol was added to each eluted methanol solution as an internal reference for UHPLC-MS analysis.

One of the most important advantages of UHPLC-MS compared to FT-ICR-MS is that the UHPLC-MS has the ability to separate ketone and aldehyde with same molecular formula. Figure 5.3 shows examples of separation results of mixtures of 2-butanone and butanal, 2-pentanone and pentanal in the same solution. Also, another advantage is that UHPLC-MS system is more sensitive and accurate than FT-ICR-MS. 


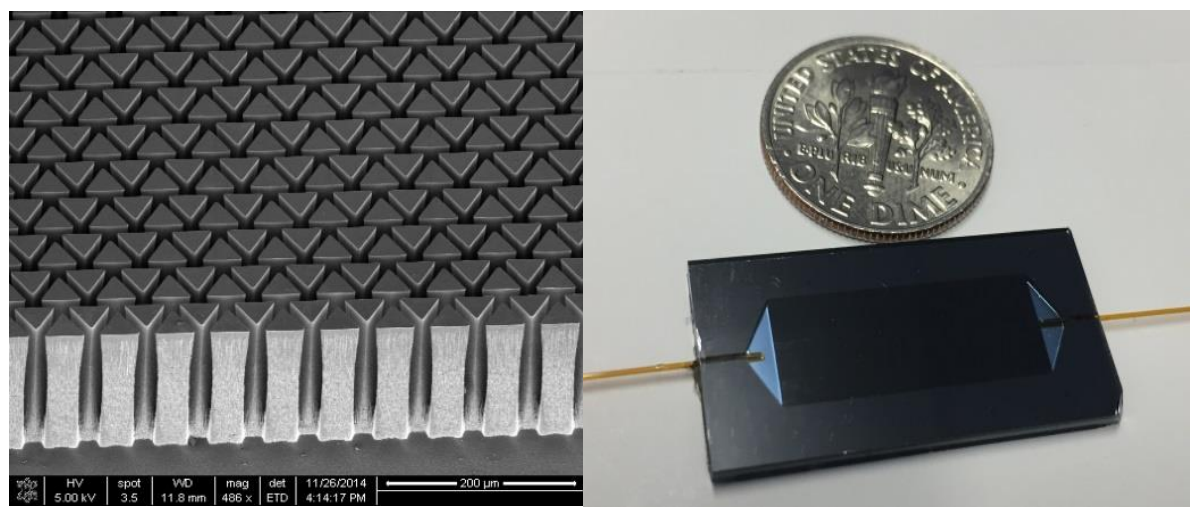

Figure 5.1 A SEM picture of the triangular micropillars inside the microreactor and the photo of the microreactor compared to a dime dollar.



Figure 5.2 Schematic flow diagram of the preconcentration setup for breath analysis. 

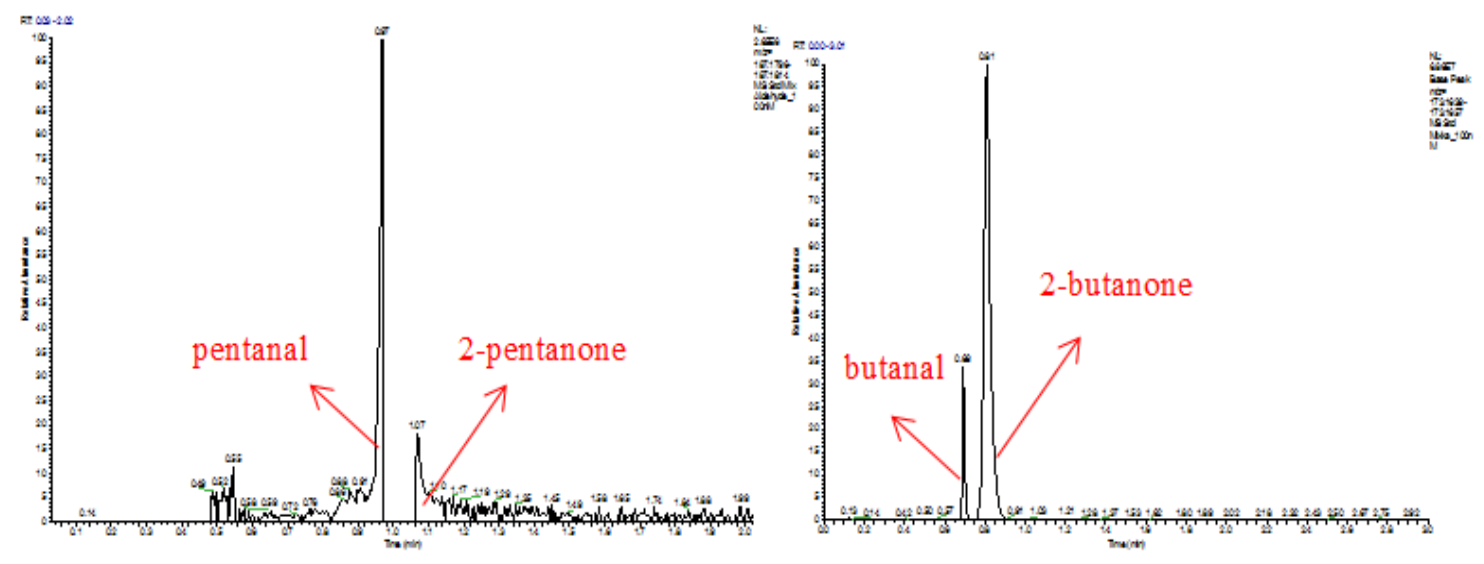

Figure 5.3 UHPLC-MS spectrum separation of 2-butanone and butanal, pentanal and 2pentanone.

\section{Results and Discussion}

\subsection{Detection of the markers and Statistical analysis}

The measured carbonyl VOC concentrations in exhaled breath sample of current smokers and never smokers from healthy controls were fist separated and analyzed. ANOVA test was applied to determine statistically significant differences between the groups. After ANOVA test, Formaldehyde $(\mathrm{p}=0.013)$, acetaldehyde $(\mathrm{p}=0.002)$ and acetone $(\mathrm{p}=0.036)$ presented significant higher concentrations for smokers in comparison with nonsmokers. Figure 5.6 shows boxplots of the concentrations of three compounds in exhaled breath samples from never smokers and current smokers.

Furthermore, we separate the lung cancer patients into three groups: current smokers, previous smokers and never smokers. This statistical was designed to see whether there is same effect of smoking when a person has lung cancer. Also, all the data was input into Minitab software and conduct ANOVA test, after ANOVA test, formaldehyde, acetaldehyde and acetone in current smoker's lung cancer patients group have significant 
increase compared to lung cancer patients with previous smokers and never smokers. There are significant differences between the lung cancer patients with never smokers and current smokers $(\mathrm{p}<0.05)$ with the formaldehyde, acetaldehyde and acetone. Figure 5.7 shows the boxplots of the concentrations of three compounds in exhaled breath samples from lung cancer patients with never smokers, current smokers and previous smokers.

Twenty carbonyl compounds $\left(\mathrm{CH}_{2} \mathrm{O}, \mathrm{C}_{2} \mathrm{H}_{4} \mathrm{O}, \mathrm{C}_{3} \mathrm{H}_{6} \mathrm{O}, \mathrm{C}_{3} \mathrm{H}_{4} \mathrm{O}, \mathrm{C}_{4} \mathrm{H}_{8} \mathrm{O}, \mathrm{C}_{5} \mathrm{H}_{10} \mathrm{O}\right.$, $\mathrm{C}_{6} \mathrm{H}_{12} \mathrm{O}, \mathrm{C}_{7} \mathrm{H}_{14} \mathrm{O}, \mathrm{C}_{8} \mathrm{H}_{16} \mathrm{O}, \mathrm{C}_{9} \mathrm{H}_{18} \mathrm{O}, \mathrm{C}_{10} \mathrm{H}_{20} \mathrm{O}, \mathrm{C}_{11} \mathrm{H}_{22} \mathrm{O}, \mathrm{C}_{12} \mathrm{H}_{24} \mathrm{O}, \mathrm{C}_{13} \mathrm{H}_{26} \mathrm{O}, \mathrm{C}_{2} \mathrm{H}_{4} \mathrm{O}_{2}$, $\mathrm{C}_{3} \mathrm{H}_{4} \mathrm{O}_{2}, \mathrm{C}_{4} \mathrm{H}_{8} \mathrm{O}_{2}, \mathrm{C}_{5} \mathrm{H}_{8} \mathrm{O}, \mathrm{C}_{7} \mathrm{H}_{11} \mathrm{O}$ and $\mathrm{C}_{12} \mathrm{H}_{22} \mathrm{O}$ ) were detected in exhaled breath samples from lung cancer patients and healthy controls and their concentrations were determined. Figure 5.4 shows a typical UHPLC-MS spectrum under MS mode with lung cancer patient and healthy control. It can clearly see from the figure that most of the compounds detected in lung cancer patient are higher than that in healthy control. After AVOVA test of exhaled breath samples from the clinically diagnosed lung cancer subjects, $\mathrm{C}_{4} \mathrm{H}_{8} \mathrm{O}(\mathrm{p}=0.022)$, $\mathrm{C}_{4} \mathrm{H}_{8} \mathrm{O}_{2}(\mathrm{p}=0.037)$ and 4-HNE $(\mathrm{p}=0.016)$ were found to have statistical significance between the LC group and the HC group. Figure 5.5 shows the UHPLC-MS chromatographs of these three compounds in lung cancer patient and healthy control. 4HHE ( $\mathrm{p}=0.098)$ and Hydroxyacetaldehyde $(\mathrm{p}=0.100)$ was also found have considerable difference between lung cancer group and healthy control group. Here our standard for defining the significant difference is $p<0.05$. However, there is no significant difference in concentrations of these lung cancer markers between BN patients and HC. Figure 5.8 shows the boxplots of the eight compounds between HC group, LC group and BN group. The concentration of $\mathrm{C}_{4} \mathrm{H}_{8} \mathrm{O}$ and $\mathrm{C}_{4} \mathrm{H}_{8} \mathrm{O}_{2}$ in $\mathrm{LC}$ group was significantly higher than that in HC group while concentration of 4-HNE in LC group was significantly lower than HC 
group. Therefore, $\mathrm{C}_{4} \mathrm{H}_{8} \mathrm{O}, \mathrm{C}_{4} \mathrm{H}_{8} \mathrm{O}_{2}$ and 4-HNE were chosen as the biomarkers of lung cancer for diagnosis purpose. 4-HHE and hydroxyacetaldehye $(\mathrm{p}<0.1)$ also have a considerable difference between lung cancer and healthy control, but since our criteria here for ANOVA test is $\mathrm{p}<0.05$. We do not choose these two compounds for lung cancer biomarkers. Table 5.2 shows the concentration ranges of these marker compounds in exhaled breath of lung cancer patients, benign nodule patients and healthy controls. Simple rules were made from the concentration ranges for lung cancer diagnosis: if 2 or more marker concentrations are in the lung cancer range (including the overlap area), the subject was assigned as lung cancer patient; otherwise the subject was considered as patient with benign pulmonary nodules.

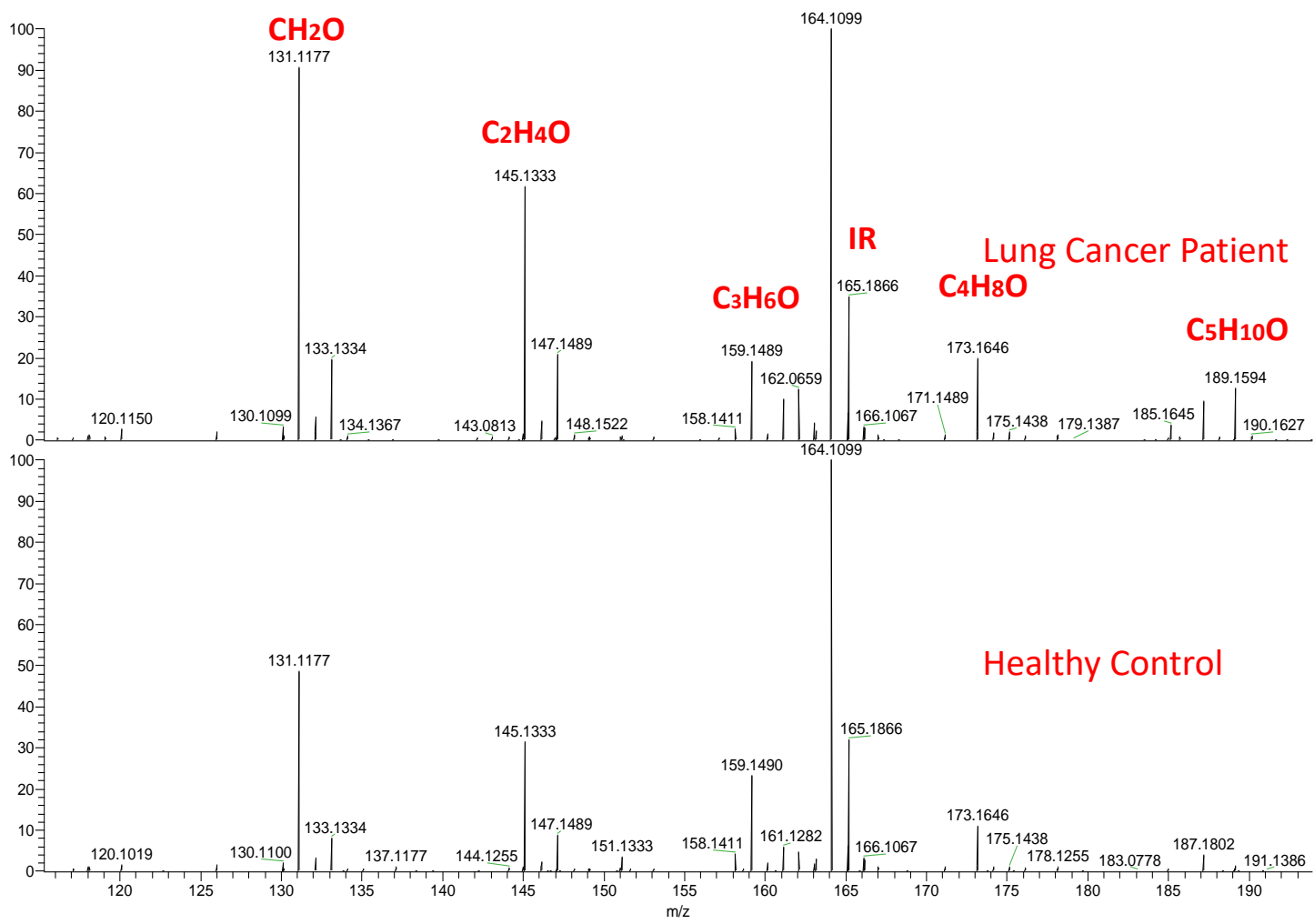

Figure 5.4 Typical UHPLC-MS spectrum with mass mode between lung cancer patient and healthy control. 




(a)

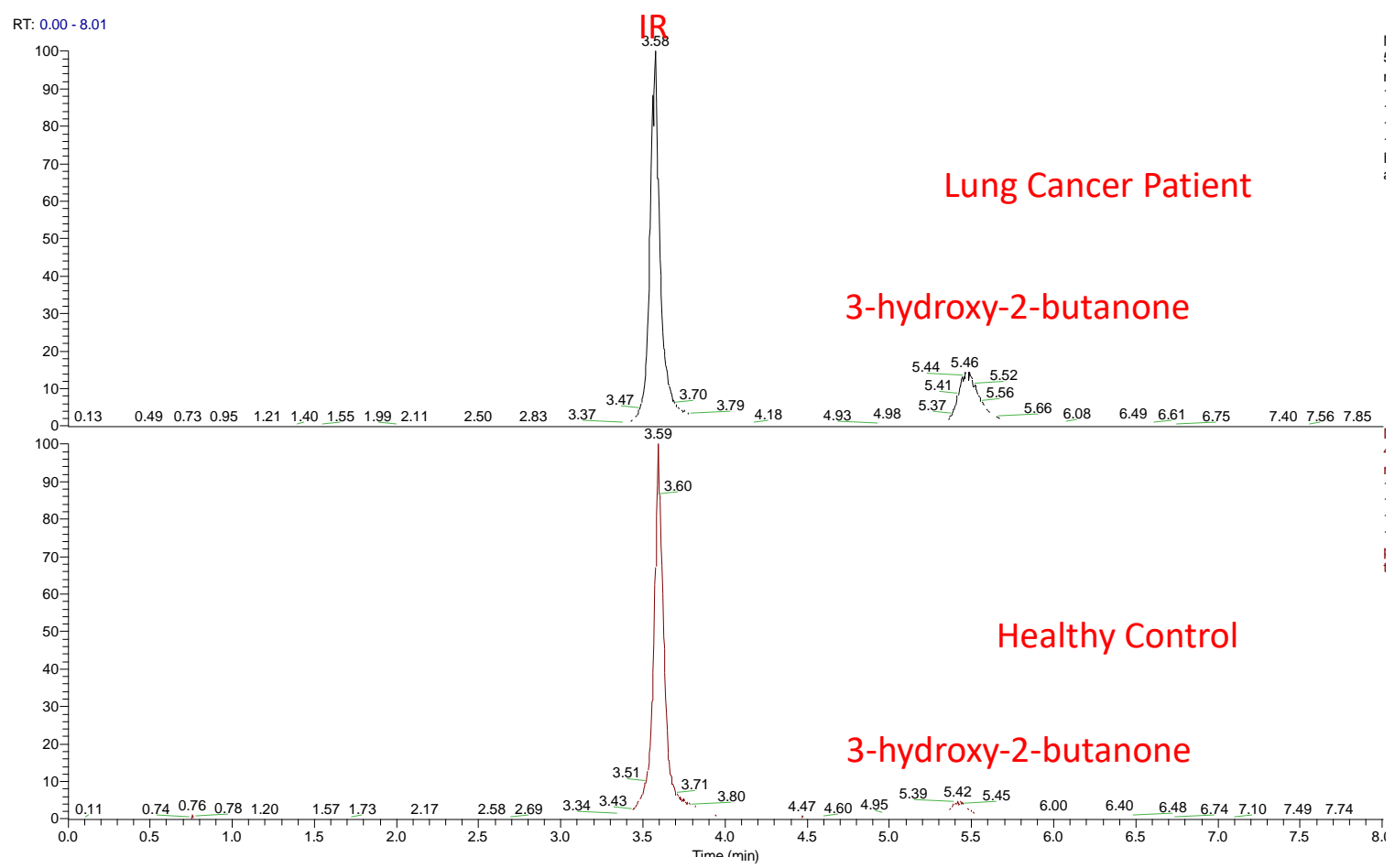

(b) 


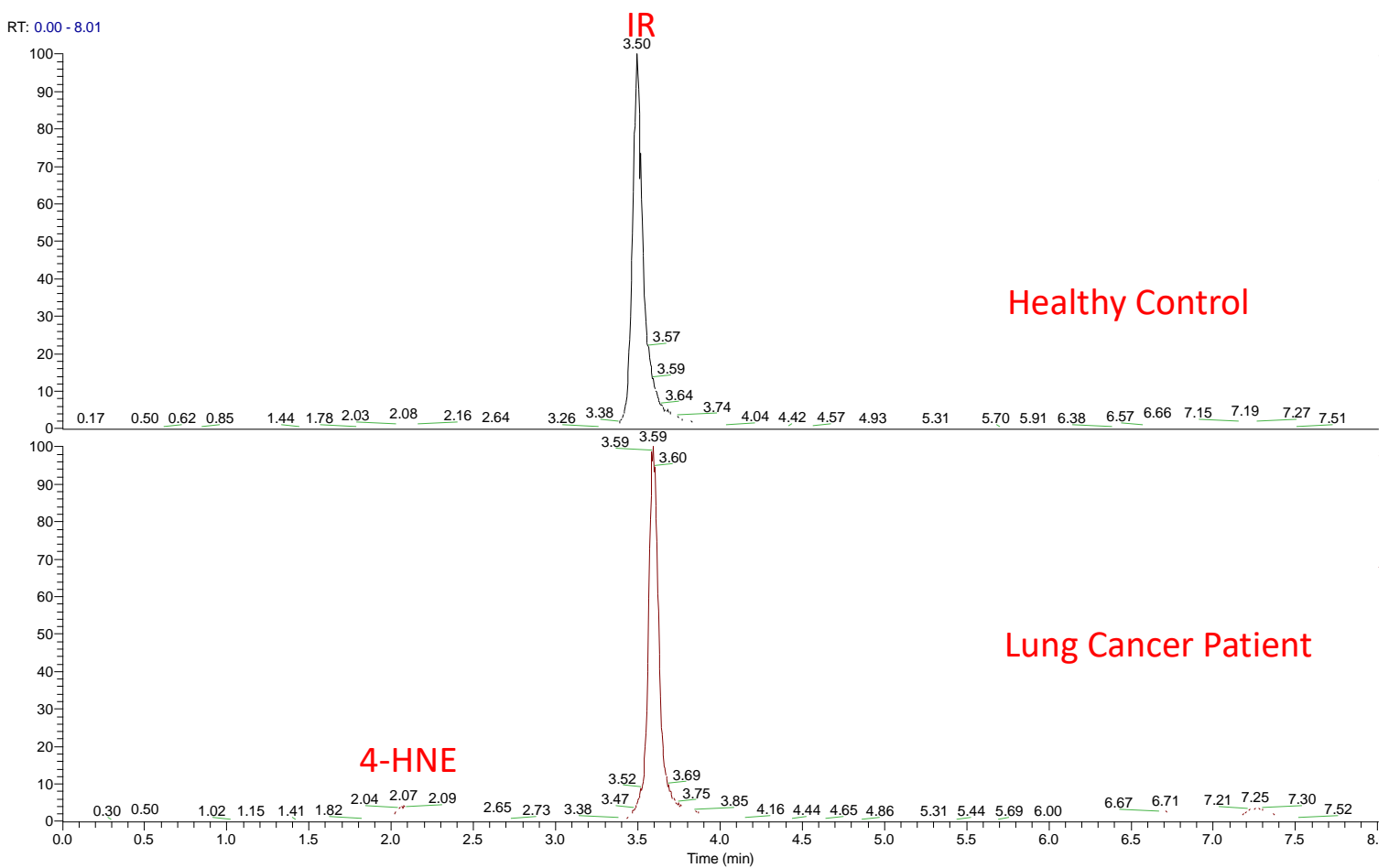

(c)

Figure 5.5 Typical UHPLC-MS chromatography between lung cancer patient and healthy control. (a) 2-butanone, (b) 3-Hydroxy-2-butanone and (c) 4-HNE. 


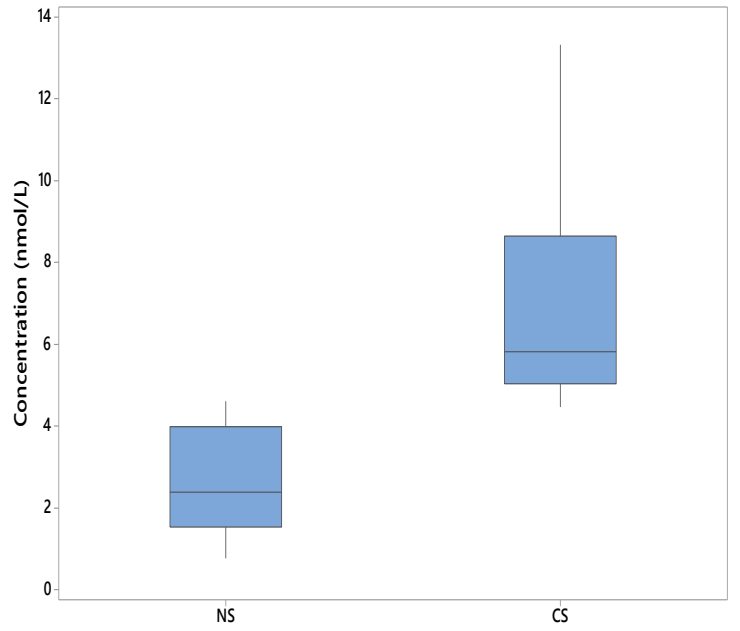

(a) Formaldehyde

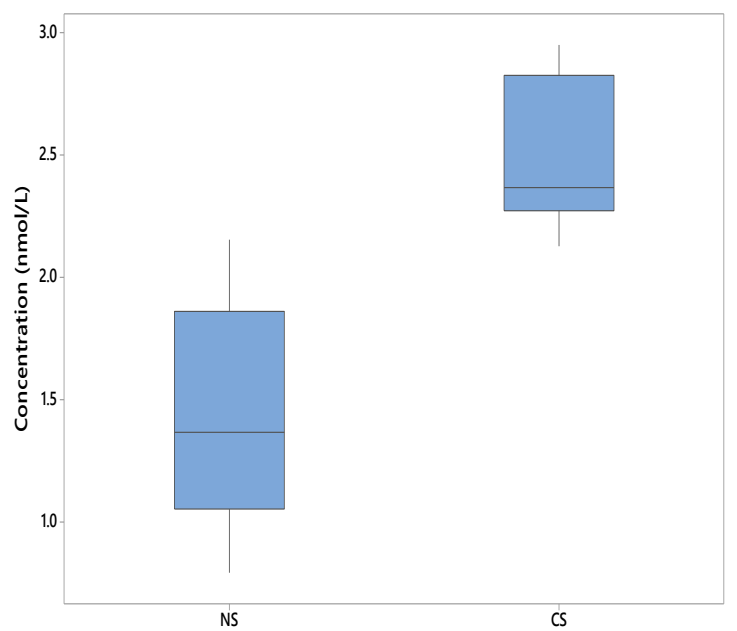

(b) Acetaldehyde

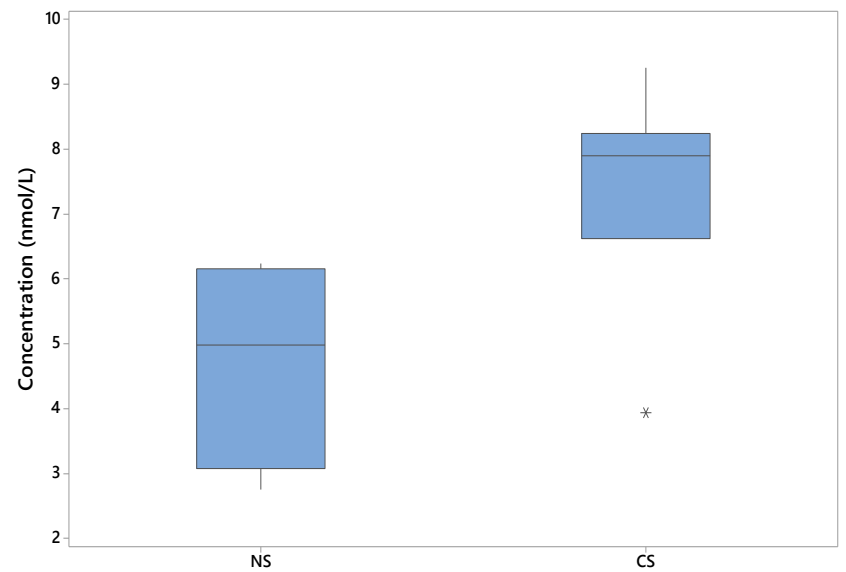

(c) Acetone

Figure 5.6 Comparisons of three compounds from never smokers (NS, n=6) and healthy control current smokers (CS, n=7) groups. (a) formaldehyde, (b) acetaldehyde and (c) acetone. 


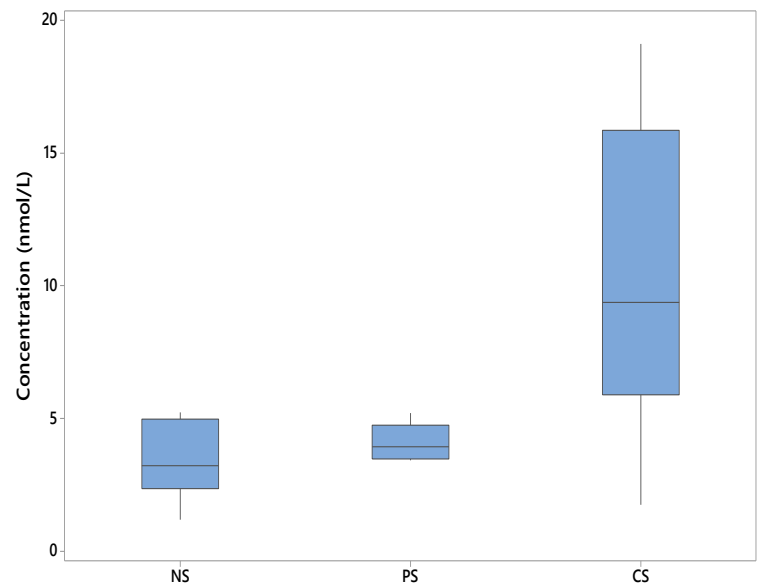

(a) Formaldehyde

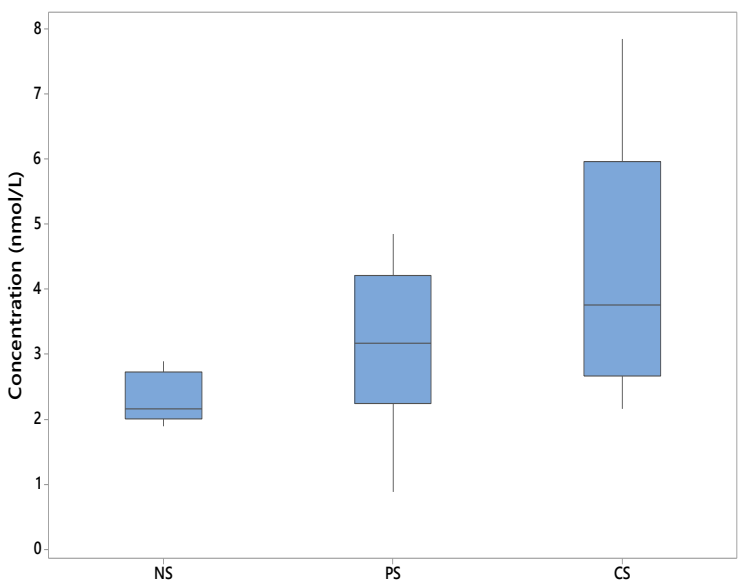

(b) Acetaldehyde

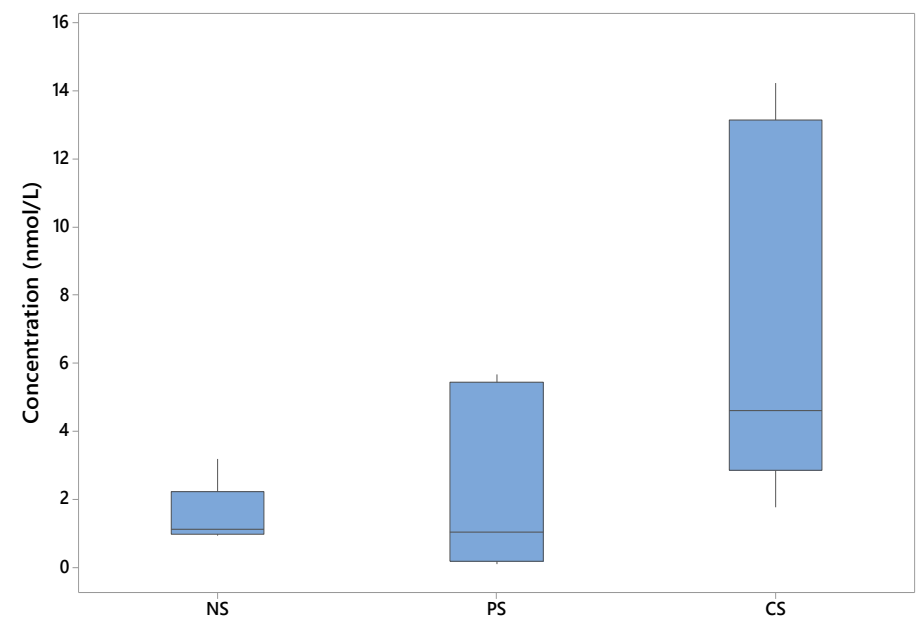

(c) Acetone

Figure 5.7 Comparisons of three compounds from lung cancer patients with never smokers (NS, n=3), current smokers (CS, n=6) and previous smokers (PS, n=6) groups. (a) formaldehyde, (b) acetaldehyde and (c) acetone.

\section{Table 5.2}


$\underline{\text { A comparison of identified lung cancer marker concentration range, mean and SD for }}$ three different groups of people. (the second line of each row is median number)

\begin{tabular}{lllllll}
\hline & $\mathbf{C}_{4} \mathrm{H}_{8} \mathrm{O}$ & Mean \pm SD & $\mathrm{C}_{4} \mathrm{H}_{8} \mathrm{O}_{2}$ & Mean \pm SD & 4-HNE & Mean \pm SD \\
& $(\mathrm{nmol} / \mathrm{L})$ & $(\mathrm{nmol} / \mathrm{L})$ & $(\mathrm{nmol} / \mathrm{L})$ & $(\mathrm{nmol} / \mathrm{L})$ & $(\mathrm{nmol} / \mathrm{L})$ & $(\mathrm{nmol} / \mathrm{L})$ \\
\hline $\mathbf{L C}$ & $0.748-5.37$ & $1.94 \pm 1.17$ & $0.178-1.78$ & $0.45 \pm 0.39$ & $1 \times 10^{-5}-1.5 \times 10^{-3}$ & $0.002 \pm 0.003$ \\
& $(1.767)$ & & $(0.338)$ & & $(0.001029)$ & \\
\hline $\mathbf{B N}$ & $0.79-3.25$ & $1.32 \pm 0.81$ & $0.05-0.82$ & $0.24 \pm 0.25$ & $0.0085-0.0052$ & $0.003 \pm 0.003$ \\
& $(1.025)$ & & $(0.125)$ & & $(0.002094)$ & \\
\hline $\mathbf{H C}$ & $0.126-1.23$ & $0.76 \pm 0.35$ & $0.013-0.14$ & $0.09 \pm 0.04$ & $0.0052-0.0439$ & $0.016 \pm 0.017$ \\
& & & $(0.106)$ & & $(0.00734)$ & \\
& $(0.713)$ & & & & & \\
\hline
\end{tabular}




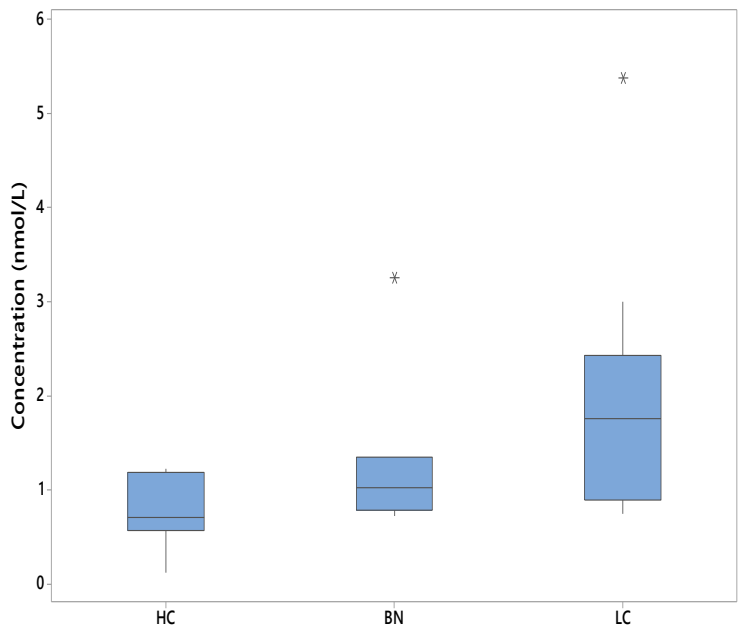

(a) $\mathrm{C}_{4} \mathrm{H}_{8} \mathrm{O}$

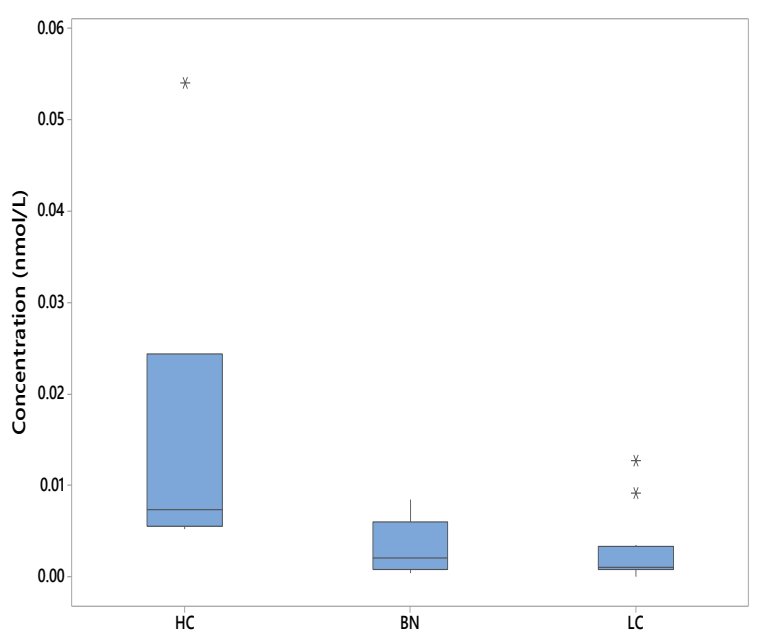

(c) 4-HNE

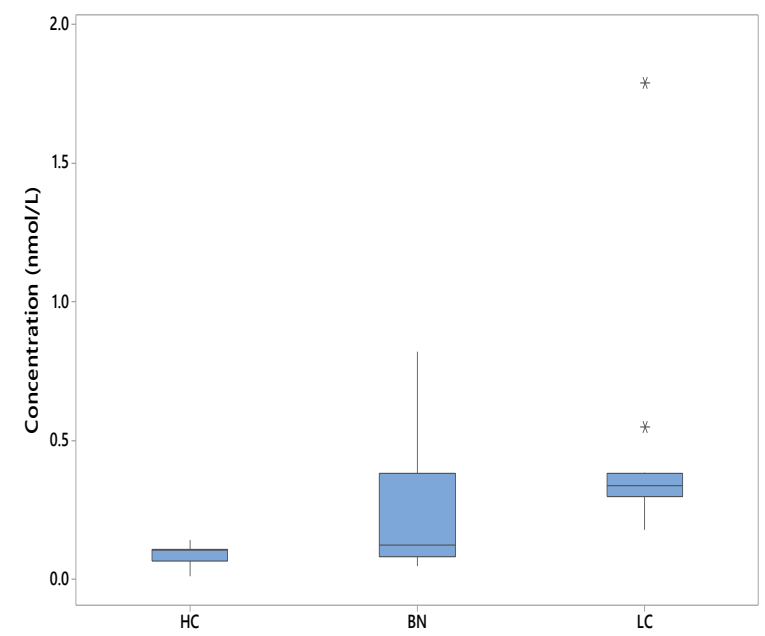

(b) $\mathrm{C}_{4} \mathrm{H}_{8} \mathrm{O}_{2}$

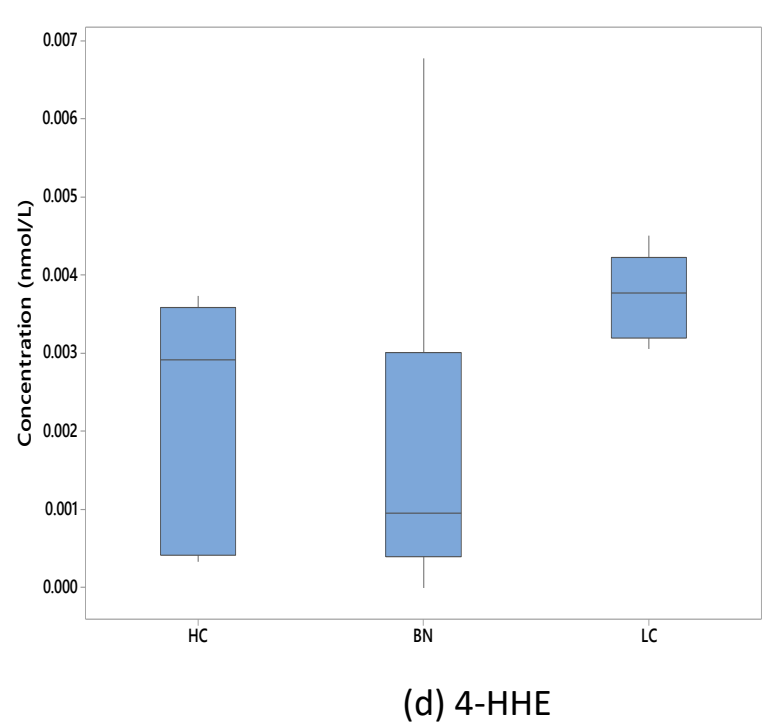




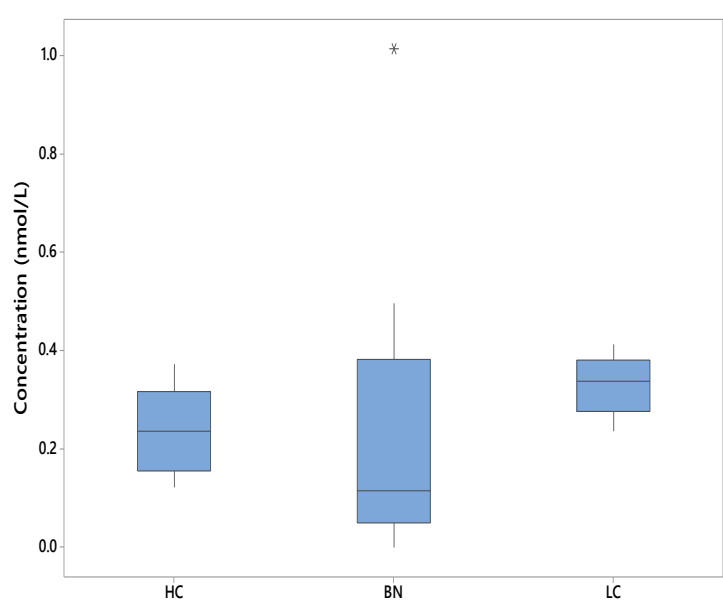

(e) $\mathrm{C}_{2} \mathrm{H}_{4} \mathrm{O}_{2}$

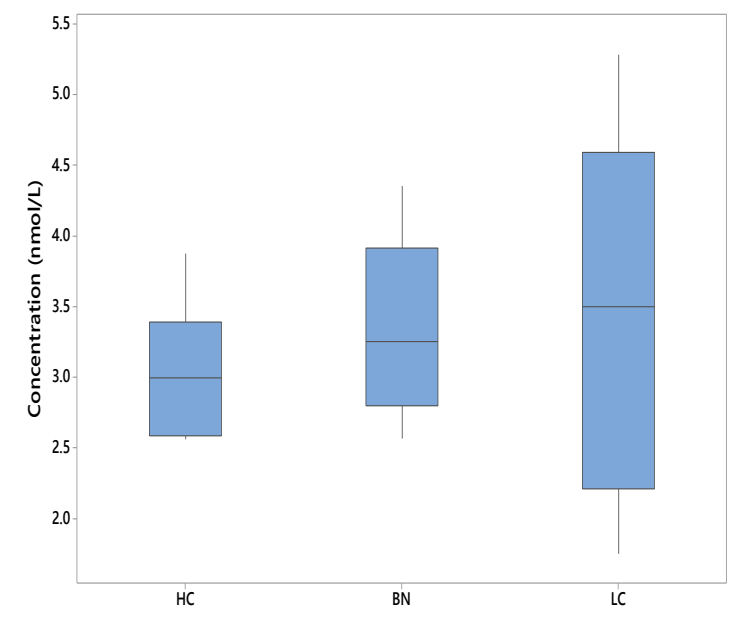

(g) $\mathrm{CH}_{2} \mathrm{O}$

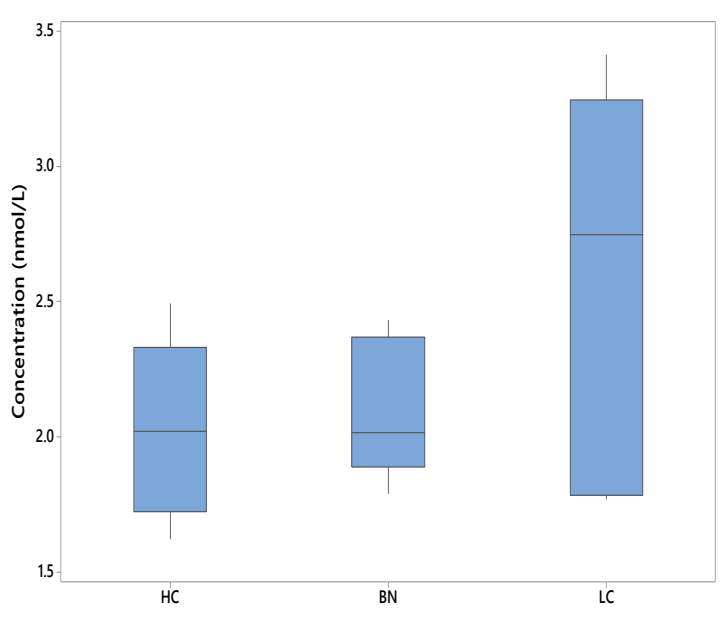

(f) $\mathrm{C}_{3} \mathrm{H}_{6} \mathrm{O}$

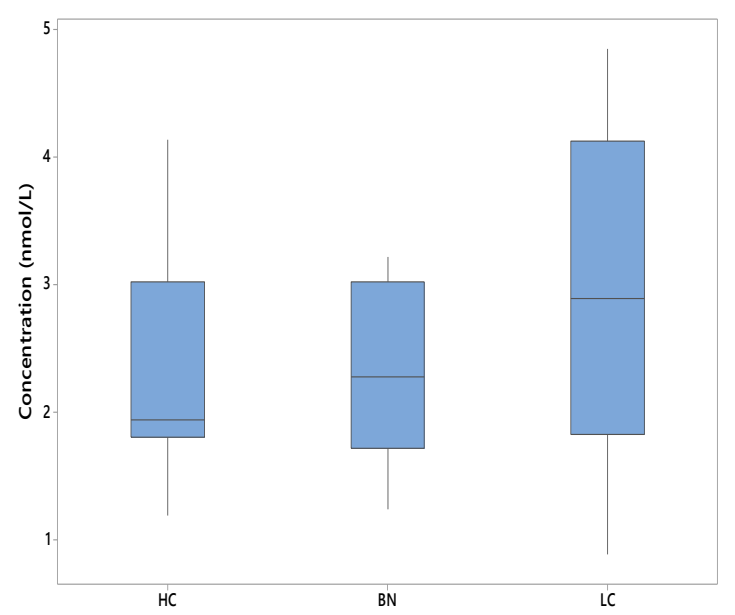

(h) $\mathrm{C}_{2} \mathrm{H}_{4} \mathrm{O}$

Figure 5.8 Comparisons of compounds with HC group $(\mathrm{n}=15)$, LC group $(\mathrm{n}=15)$ and $\mathrm{BN}$ group (n=7). (a) $\mathrm{C}_{4} \mathrm{H}_{8} \mathrm{O}$, (b) $\mathrm{C}_{4} \mathrm{H}_{8} \mathrm{O}_{2}$, (c) 4- $\mathrm{HNE}$, (d) 4- $\mathrm{HHE}$, (e) $\mathrm{C}_{2} \mathrm{H}_{4} \mathrm{O}_{2}$, (f) $\mathrm{C}_{3} \mathrm{H}_{6} \mathrm{O}$, (g) $\mathrm{CH}_{2} \mathrm{O}$ and (h) $\mathrm{C}_{2} \mathrm{H}_{4} \mathrm{O}$. 


\subsection{Lung cancer type analysis}

To further determine the capability of identifying and characterizing lung cancer using these identified carbonyl VOC markers, the subjects were grouped into squamous cell NSCLS and adenocarcinoma NSCLC. After conducting ANOVA test, 4-HNE was found significant difference between squamous cell NSCLC and adenocarcinoma NSCLC $(\mathrm{p}=0.03)$. (As shown in Figure 5.9)

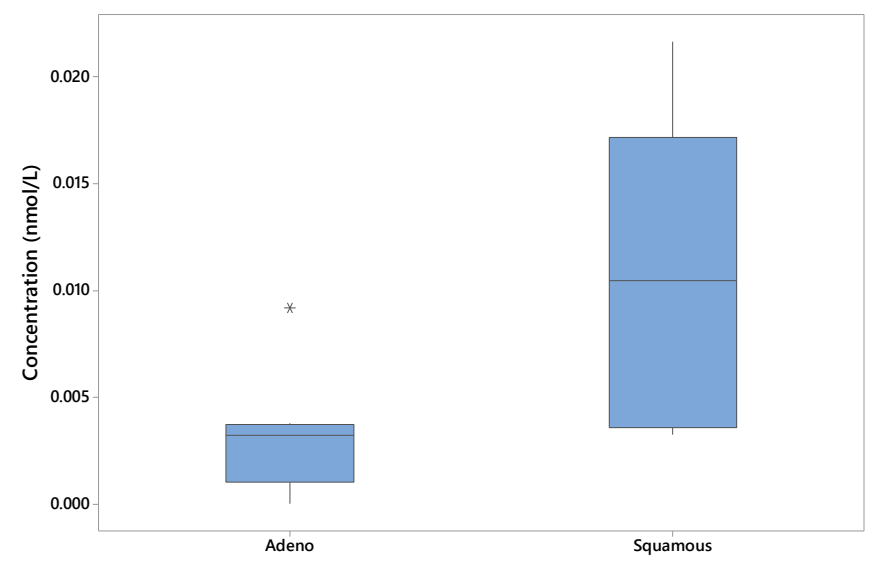

Figure 5.9 Comparisons of 4-HNE with adenocarcinoma NSCLC $(n=9)$ and squamous cell $\operatorname{NSCLC}(n=6)$.

\section{Conclusion}

This study demonstrates the potential of MEMS based microreactors combined with UHPLC-MS system to identify lung cancer breath markers for the distinction of subjects with lung cancer from subjects with healthy controls. The results show that UHPLC-MS has advantages of separation and sensitivity on carbonyl VOCs compared to FT-ICR-MS. The results also show that breath markers can discriminate between lung cancer of different types. The significant differences in concentrations of these identified 
markers in exhaled breath are related to metabolic differences of different types of lung cancers. This research demonstrated a fabricated silicon microreactor chip of $21 \mathrm{~mm}$ length with triangular micropillars for preconcentration and analysis of carbonyls compounds in exhaled breath. We have found three VOCs (2-butanone, 3-hydroxy-2-butanone and 4HNE) to distinguish LC from patients with benign pulmonary nodules and healthy controls, particularly 4-HNE can also be used to distinguish squamous cell carcinoma from adenocarcinoma LC. The 4-HHE and Hydroxyacetaldehyde do not considered as markers for lung cancer here since $\mathrm{p}>0.05$, but they are very promising since $\mathrm{p}<0.1$.

However, the test population in this study is relatively small, since this is an ongoing project, we are still collecting more patients subjects from Brown Cancer Center. Once we get enough subjects, for examples, different stages and types of lung cancer patients, benign pulmonary nodule patients and healthy controls. We will do statistical analysis can potentially find more biomarkers (especially for 4-HHE and Hydroxyacetaldehyde) that can be used to distinguish different stages of lung cancer patients. 


\section{CHAPTER VI}

\section{SUMMARY AND FUTURE WORK}

This research demonstrated MEMS based microreactors coated with aminooxy compounds combined with UHPLC-MS for chemoselective capture and analysis of trace level aldehydes and ketones. Sample sources include human exhaled breath and ambient air.

\section{Summary}

We have successfully designed a novel silicon-based microreactor with thousands of micropillars. The fabrication procedure follows the MEMS microfabrication techniques and fabricated at Micro/Nano Technology Center in University of Louisville.

The silicon-based microreactor coated with the aminooxy reagent ATM as a derivatization reagent (coating) to capture trace level carbonyl compounds was comprehensively characterized. Different designs of the microreactor were generated by L-edit software. For example, 3 different pillar distance $(10 \mu \mathrm{m}, 25 \mu \mathrm{m}$ and $50 \mu \mathrm{m})$, four different micropillar shapes (cylindrical, square, triangle and diamond) and five different 
microreactor length $(7 \mathrm{~mm}, 14 \mathrm{~mm}, 21 \mathrm{~mm}, 28 \mathrm{~mm}$ and $42 \mathrm{~mm})$. The study shows that when under the same microreactor length, the design with $10 \mu \mathrm{m}$ micropillar distance and triangle pillar shape has the best performance in capture trace aldehydes and ketones. The capture efficiency can achieve $95 \%$ at a gaseous flow rate less than $8 \mathrm{ml} / \mathrm{min}$.

The microreactors with different length were then intensively studied in this research. $7 \mathrm{~mm}, 14 \mathrm{~mm}, 21 \mathrm{~mm}, 28 \mathrm{~mm}$ and $42 \mathrm{~mm}$ length microreactors were all loaded same amount of ATM since the loading effect study in chapter 2 shows the different amount of ATM has almost no effect on capture efficiencies. The experimental results show that the microreactor capture efficiencies of trace carbonyls decrease with the increasing of flow rate. For a certain flow rate range $(<10 \mathrm{ml} / \mathrm{min})$, there is no significant capture efficiency difference between the $21 \mathrm{~mm}, 28 \mathrm{~mm}$ and $42 \mathrm{~mm}$ microrractors. Considering the practical application and economical thought, $21 \mathrm{~mm}$ length microreactor with $10 \mu \mathrm{m}$ and triangle shape micropillars is the optimal microreactor for capture of trace levels carbonyls in human exhaled breath. A theoretical model was then developed for modeling the microreactor gas reactions. Both mass transfer limiting aspect and reaction rate limiting aspect were discussed. The comparison between the experimental data and model data show that the model fit the reaction very well.

This method was used for investigating the stability of human exhaled breath including smokers and nonsmokers. The results show that the recovery percentages of carbonyl VOCs in breath samples stored at cold temperature $\left(4{ }^{\circ} \mathrm{C}\right)$ are higher than that stored at room temperature. Unsaturated aldehydes degrade much faster than saturated carbonyl compounds. The recovery percentages of saturated carbonyl compounds in the 
breath samples of smokers are obviously lower than that in the breath samples of nonsmokers.

This microreactor technology can be applied for analyzing any gas phase samples and also for environmental monitoring of volatile organic compounds whose concentrations are at ppb levels.

This method was also used to identify breath markers for the distinction of subjects with pulmonary nodules from healthy controls and the patients with COPD and asthma from healthy controls for pilot lung cancer screening project. $\mathrm{C}_{3} \mathrm{H}_{6} \mathrm{O}, \mathrm{C}_{2} \mathrm{H}_{4} \mathrm{O}_{2}$ and $\mathrm{C}_{4} \mathrm{H}_{8} \mathrm{O}_{2}$ was found can serve as biomarkers to distinguish the patients with pulmonary nodules from healthy people. Smokers and nonsmokers also were found to have significant different in acetaldehyde, formaldehyde and acetone ranges. In the clinical study with lung cancer patients, we found three VOCs (2-butanone, 3-hydroxy-2butanone and 4-HNE) to distinguish LC from healthy controls. One VOC (4-HNE) to distinguish squamous cell carcinoma from adenocarcinoma LC.

\section{Future Directions}

There are several areas or directions in the near future, which we could further enhance the work presented in this dissertation.

1. A study with a larger study population is necessary to validate the biomarkers of lung cancer patients and patients with pulmonary nodules that we found in this work. For examples, different stages of lung cancer patients, follow up study with lung cancer patients. Also, more patients with benign pulmonary nodules need to be collected. 
2. In this study, only aminooxy salt was used as the coating materials in microreactors to capture specific carbonyl VOCs. Other compounds may also be used to coat on the micropillar to capture these compounds. Also, specific catalyst may also load into the surface on the micropillars or inside the microreactor to help trigger and accelerate the selected reaction in order to get more effective analysis, especially to reduce the analysis time to several minutes.

3. The metabolism mechanism of VOCs in lung cancer patients' breath is still not known in this study. One effective way is that to analyze the VOCs released by lung cancer cells which are cultured in clinical stations. For example, the headspace air in lung cancer cell line and culture solution.

4. One limitation od this study is that an aminooxy coated microreactor can only identify or detect the carbonyl compounds components of analytical samples with accurate chemical formula, it can not identify other components of the sample like dienes, furans, alcohols, ether etc. Other method need to be developed to analyze more compounds. 


\section{REFERENCES}

1. Morisco, F.; Aprea, E.; Lembo, V.; Fogliano, V.; Vitaglione, P.; Mazzone, G.; Cappellin, L.; Gasperi, F.; Masone, S.; De Palma, G.D.; Marmo, R.; Caporaso, N.; Biasioli, F. Rapid "breathprint" of liver cirrhosis by proton transfer reaction time-offlight mass spectrometry. A pilot study. PLoS One 2013; 8, e59658.

2. Arasaradnam, R.P.; Covington, J.A.; Harmston, C.; Nwokolo, C.U.; Review article: Next generation diagnostic modalities in gastroenterology--gas phase volatile compound biomarker detection. Aliment. Pharmacol. Ther 2014, 39; 780-789.

3. Horvath, I.; Lazar, Z.; Gyulai, N.; Kollai, M.; Losonczy, G.; Exhaled biomarkers in lung cancer. European Respiratory Journal 2009; 34(1),261-275.

4. Fens, N.; van der Schee, M.P.; Brinkman, P.; Sterk, P.J. Exhaled breath analysis by electronic nose in airways disease. Established issues and key questions. Clin. Exp. Allergy 2013; 43, 705-715.

5. Patel, K. Noninvasive tools to assess liver disease. Curr. Opin. Gastroenterol 2010; 26, 227-233.

6. Probert, C.S.; Ahmed, I.; Khalid, T.; Johnson, E.; Smith, S.; Ratcliffe, N. Volatile organic compounds as diagnostic biomarkers in gastrointestinal and liver diseases. $J$. Gastrointestin. Liver Dis 2009; 18, 337-343.

7. Agnieszka U.; M. L.; Anton Amann and Boguslaw Buszewski, Determination of volatile organic compounds in exhaled breath by ion mobility spectrometry. Chem. Anal. 2008;53, 953.

8. Miekisch W., Schubert JK and Noeldge-Schomburg GFE. Diagnostic potential of breath analysis - focus on volatile organic compounds. Clinica Chimica Acta 2004; 347: 25-39.

9. Zolotov Yu A. Breath Analysis. Journal of Analytical Chemistry 2005; 6(60): 497.

10. Pleil,J.D., Toxicol, J. Environ. Health, 2008; B 11,613.

11. Bajtarevic A., Ager C., Pienz M., Klieber M., Schwarz K., Ligor M., Ligor T., Filipiak W., Denz H., Fiegl M., et al. Noninvasive detection of lung cancer by analysis of exhaled breath. BMC Cancer. 2009; 9:348.

12. Beauchamp J. Current sampling and analysis techniques in breath research-results of a task force poll. Journal of Breath Research. 2015; 9:047107.

13. Grosjean, E.; Grosjean, D.; Fraser, M.P.; Cass, G.R.; Air quality model evaluation data for organics. 2. C1-C14 Carbonyls in Los Angeles Air. Environmental Science \& Technology 1996;30(9), 2687-2703.

14. Corradi M., Rubinstein I., Andreoli R., Manini P., Caglieri A., Poli D., Alinovi R., Mutti A., Aldehydes in Exhaled Breath Condensate of Patients with Chronic Obstructive Pulmonary Disease. Am J Respir Crit Care Med. 2003; 167: 1380 -1386. 
15. Delen F.M., Sippel J.M., Osborne M.L., Law S., Thukkani N., Holden W.E. Increased exhaled nitric oxide in chronic bronchitis - Comparison with asthma and COPD. Chest, 2000; 117: 695 - 701. Montuschi P., Kharitonov S.A., Barnes P.J.; Exhaled carbon monoxide and nitric oxide in COPD. Chest 2001; 120: 496-501.

16. Antus B., Barta I., Horvath I., Csiszer E.; Relationship between exhaled nitric oxide and treatment response in COPD patients with exacerbations. Respirology. 2010; 15 : 472-477.

17. Risby T.H. and Solga S.F.; Current status of clinical breath analysis. Appl Phys B. 2006; 85: 421-426.

18. Rocco G., Pennazza G., Santonico M., Longo F., Rocco R., Crucitti P., Antonelli Incalzi R.; Breathprinting and Early Diagnosis of Lung Cancer. Journal of thoracic oncology. 2018; 13(7):883-894

19. Beauchamp J., Herbig J., Gutmann R., Hansel A. J Breath Res. 2008; 2:046001.

20. Peng G., Tisch U., Adams U., Hakim M., Shehada N., Broza Y.Y, Billan S., AbdahBortnyak R., Kuten A., Haick H.; Diagnosing lung cancer in exhaled breath using gold nanoparticles. Nature Nanotechnol. 2009; 4: 669 - 673.

21. Paweł Mochalski, Julian King, Karl Unterkofler, and Anton Amann. Analyst. 2013; 138(5): 1405-1418

22. Sethi, S.; Nanda, R.; Chakraborty, T. Clinical application of volatile organic compound analysis for detecting infectious diseases. Clin. Microbiol. Rev. 2013; 26, 462-475.

23. Phillips, M.; Cataneo, R.N.; Condos, R.; Ring Erickson, G.A.; Greenberg, J.; La Bombardi, V.; Munawar, M.I.; Tietje, O. Volatile biomarkers of pulmonary tuberculosis in the breath. Tuberculosis. 2007; 87, 44-52.

24. Ghilarducci, D. P.; Tjeerdema, R. S., Fate and effects of acrolein. Reviews of environmental contamination and toxicology 1995; 144, 95-146

25. Pleil, J.D., Lindstrom, A.B., Measurement of volatile organic compounds in exhaled breath as collected in evacuated electropolished canisters, J. Chromatogr. B: Biomed. Sci. Appl. 1995; 665 (2),271-279.

26. Pleil, J.D., Smith, L.B., Zelnick, S.D., Personal exposure to JP-8 jet fuel vapors and exhaust at air force bases, Environ. Health Perspect. 2000; 108 (3) 183.

27. Preti G.LJ, Kostelc J.G, Aldinger S., Daniele R.; Analysis of lung air from patients with bronchogenic carcinoma and controls using gas chromatography-mass spectrometry. J Chromatogr, 1988; 432: 1-11.

28. Machado, R.F.; Laskowski, D.; Deffenderfer, O.; Burch, T.; Zheng, S.; Mazzone, P.J.; Mekhail, T.; Jennings, C.; Stoller, J.K.; Pyle, J., et al. Detection of lung cancer by sensor array analyses of exhaled breath. Am. J. Respir. Crit. Care. Med. 2005; 171, 1286-1291.

29. Dyne D., Cocker J., Wilson H.K. A novel device for capturing breath samples for solvent analysis. Sci. Total Environ. 1997; 199:83-89.

30. Poli D., Carbognani P., Corradi M., Goldoni M., Acampa O., Balbi B., Bianchi L., Rusca M., Mutti A. Exhaled volatile organic compounds in patients with non-small cell lung cancer: Cross sectional and nested short-term follow-up study. Respir. Res. 2005; 6:71. 
31. Kusano M., Mendez E., Furton K.G. Development of headspace SPME method for analysis of volatile organic compounds present in human biological specimens. Anal. Bioanal. Chem. 2011; 400:1817-1826.

32. Caro J., Gallego M.; Environmental and biological monitoring of volatile organic compounds in the workplace. Chemosphere. 2009; 77:426-433.

33. Scheepers P.T., Konings J., Demirel G., Gaga E.O., Anzion R., Peer P.G., Dogeroglu T., Ornektekin S., van Doorn W. Determination of exposure to benzene, toluene and xylenes in Turkish primary school children by analysis of breath and by environmental passive sampling. Sci. Total Environ. 2010; 408:4863-4870.

34. Dyne, D., Cocker,J., Wilson, H., A novel device for capturing breath samples for solvent analysis, Sci. Total Environ. 1997; 199 (1); 83-89.

35. Jones, K., Meldrum, M., Baird, E., et al., Biological monitoring for trimethylbenzene exposure: a human volunteer study and a practical example in the workplace, Ann. Occup. Hyg. 2006; 50 (6): 593-598.

36. Hunt J. Exhaled breath condensate: An evolving tool for noninvasive evaluation of lung disease. J Allergy Clin Immunol. 2002;110(1):28-34.

37. Hunt J.F., Byrns R.E., Ignarro L.J., et al. Condensed expirate nitrite as a home marker for acute asthma. Lancet.1995; 346:1235-6.

38. Corradi M., Folesani G., Andreoli R., et al. Aldehydes and glutathione in exhaled breath condensate of children with asthma exacerbation. Am J Respir Crit Care Med 2003; 167:395-9.

39. Ho L.P., Faccenda I., Innes J.A., et al. Expired hydrogen peroxide in breath condensate of cystic fibrosis patients. Eur Respir J 2000; 16:95-100.

40. Ho L.P., Innes J.A., Greening A.P. Nitrite level in breath condensate of patients with cystic fibrosis is elevated in contrast to exhaled nitric oxide. Thorax 1998; 53:680-4.

41. Dekhuijzen P.N., Abben K.K., Dekker I., et al. Increased exhalation of hydrogen peroxide in patients with stable and unstable chronic obstructive pulmonary disease. Am J Respir Crit Care Med 1996; 154:813-6.

42. Montuschi P., Collins JV, Ciabattoni G., et al. Exhaled 8-isoprostane as an in-vivo biomarker of lung oxidative stress in patients with COPD and healthy smokers. Am J Respir Crit Care Med 2000; 162:1175-7.

43. Pereira, J.; Silva, C.L.; Perestrelo, R.; Goncalves, J.; Alves, V.; Camara, J.S. Reexploring the high-throughput potential of microextraction techniques, spme and meps, as powerful strategies for medical diagnostic purposes. Innovative approaches, recent applications and future trends. Anal. Bioanal. Chem. 2014; 406, 2101-2122.

44. Arasaradnam, R.P.; Covington, J.A.; Harmston, C.; Nwokolo, C.U. Review article: Next generation diagnostic modalities in gastroenterology--gas phase volatile compound biomarker detection. Aliment. Pharmacol. Ther. 2014;39, 780-789.

45. Haick, H.; Broza, Y.Y.; Mochalski, P.; Ruzsanyi, V.; Amann, A. Assessment, origin, and implementation of breath volatile cancer markers. Chem. Soc. Rev. 2014; 43, $1423-1449$.

46. Dettmer, K., \& Engewald, W., Adsorbent materials commonly used in air analysis for adsorptive enrichment and thermal desorption of volatile organic compounds. Analytical and Bioanalytical Chemistry,2002; 373, 490-500. 
47. Raymer, J.H.; Pellizzari, E.D.; Thomas, K.W.; Lipid-peroxidation in the newborn rat influence of fasting and hyperoxia on ethane and pentane in expired air. Journal of exposure analysis and environmental epidemiology. 1991; 4, 439-51

48. Grote, C., Pawliszyn, J., Solid phse microextraction for the analysis of human breath. Analytical Chemistry. 1997;4,587-596.

49. Lambertus, G., A. Elstro, K. Sensenig, J. Potkay, M. Agah, S. Scheuering, K. Wise, F. Dorman, and R. Sacks, "Design, fabrication, and evaluation of microfabricated columns for gas chromatography," Analytical Chemistry. 2004; 76, 2629.

50. Lewis,P.R., Manginell,R.P., Adkins,D.R., Kottenstette R.J., Wheeler D.R., Sokolowski S.S., Trudell D.E., Byrnes J.E., Okandan M., Bauer J.M., Manley R.G. and Frye-Mason G.C., Recent Advancements in the Gas-Phase Microchemlab, IEEE Sensors Journal 2006; 6 (3), 784-795.

51. Tian, W.C., Chan H.K.L., C.J. Lu, Pang S.W. and Zellers E.T., Multiple-stage microfabricated preconcentrator-focuser for micro gas chromatography system, Journal of Microelectromechanical Systems 2005; 14 (3), 498-507.

52. Lu, C.J., C.G. Jin and E.T. Zellers, Chamber evaluation of a portable GC with tunable retention and microsensor-array detection for indoor air quality monitoring, Journal of Environmental Monitoring 2006; 8 (2), 270-278.

53. Bae, B., R.I. Masel, and M.A. Shannon, A touch mode capacitance microvalve equipped with high speed and pressure microsecond switching performance, IEEE MEMS 2006, Istanbul, Jan 22-26, 2006; 766-769.

54. Bae, B., J. Yeom, B.R. Flachsbart, Y. Tang, R.I. Masel, and M.A. Shannon, A multipurpose temperature control method for MEMS microheaters without a separate temperature sensor," 2006 ASME IMECE Chicago, Nov 5-10, 2006.

55. Tang, Y., J. Yeom, J. Han, B. Bae, R.I. Masel, and M.A. Shannon, A micro-post preconcentrator for a microscale gas chromatography system, Ninth International Conference on Miniaturized Systems for Chemistry and Life Sciences ( $\mu T A S)$, Boston, Oct. $9^{\text {th }}-13^{\text {th }}, 2005$.

56. Byunghoon Bae ; Junghoon Yeom ; Adarsh D. Radadia ; Richard I. Masel ; Mark A. Shannon. A Fully-Integrated MEMS Preconcentrator for Rapid Gas Sampling. SolidState Sensors Actuators and Microsystems Conference 2009. TRANSDUCERS 2009.

57. Voiculescu I., Zaghloul M., Harasimhan N., Microfabricated chemical preconcentrators for gas-phase microanalytical detection systems. Trends Anal Chem, 2008; $27: 327-343$.

58. Pijolat C., Camara M., Courbat J., Viricelle J.-P., Briand D., De Rooij N.F. Application of carbon nano-powders for a gas micro-preconcentrator. Sensors \& Actuators B, 2007; 127, 179-185

59. Camara M., Breuil P., Briand D., De Rooij N.F., Pijolat C. A micro gas preconcentrator with improved performance for pollution monitoring and explosives detection. Analytica Chimica Acta, 2001; 688(2),175-182

60. Wang, C.; Sahay, P. Breath analysis using laser spectroscopic techniques: Breath biomarkers, spectral fingerprints, and detection limits. Sensors 2009; 9, 8230-8262.

61. Amann, A.; Miekisch, W.; Pleil, J.; Risby, T.; Schubert, J. Methodological issues of sample collection and analysis of exhaled breath. In Methodological issues for breath analysis, Maney Publishing: Leeds, UK, 2010; Volume 49, 96-114. 
62. Schubert, J.K.; Miekisch, W. Chapter 9 - breath analysis in critically ill patientspotential and limitations. In Volatile biomarkers, Amann, A.; Smith, D., Eds. Elsevier: Boston, 2013; 155-176.

63. Buszewski, B.; Kesy, M.; Ligor, T.; Amann, A. Human exhaled air analytics: Biomarkers of diseases. Biomed. Chromatogr. 2007; 21, 553-566.

64. Wang, C.; Ke, C.; Wang, X.; Chi, C.; Guo, L.; Luo, S.; Guo, Z.; Xu, G.; Zhang, F.; $\mathrm{Li}, \mathrm{E}$. Noninvasive detection of colorectal cancer by analysis of exhaled breath. Anal. Bioanal. Chem. 2014; 406, 4757-4763.

65. Phillips M., Gleeson K., Hughes J.M.B, Greenberg J., Cataneo R.N,. Baker L., McVay P. Volatile organic compounds in breath as markers of lung cancer: A crosssectional study, The Lancet 1999; 353: 1930 - 1933.

66. Smith, D.; Spaněl, P.; Herbig, J.; Beauchamp, J. Mass spectrometry for real-time quantitative breath analysis. J. Breath Res. 2014; 8, 27101.

67. Zhan, X.; Duan, J.; Duan, Y. Recent developments of proton-transfer reaction mass spectrometry (PTR-MS) and its applications in medical research. Mass Spectrom. Rev. 2013; 32, 143-165.

68. Badjagbo K., Moore S., Sauv é S. Real-time continuous monitoring methods for airborne VOCs. Trends Analyt Chem. 2007; 26:931 - 40.

69. Herbig, J.; Muller, M.; Schallhart, S.; Titzmann, T.; Graus, M.; Hansel, A. On-line breath analysis with ptr-tof. J. Breath Res. 2009; doi:10.1088/1752-7155/3/2/027004.

70. Marom O., Nakhoul F., Tisch U., Shiban A., Abassi Z., Haick H., Gold nanoparticle sensors for detecting chronic kidney disease and disease progression, Nanomedicine 2012; 7, 639-650.

71. Kischkel, S.; Miekisch, W.; Sawacki, A.; Straker, E.M.; Trefz, P.; Amann, A.; Schubert, J.K. Breath biomarkers for lung cancer detection and assessment of smoking related effects confounding variables, influence of normalization and statistical algorithms. Clin. Chim. Acta 2010; 411, 1637-1644.

72. Fuchs P., Loeseken C., Schubert J.K and Miekisch W. Breath gas aldehydes as biomarkers of lung cancer. International journal of cancer Journal international du cancer. 2010; 126:2663-2670.

73. Caldeira, M.; Barros, A.S.; Bilelo, M.J.; Parada, A.; Câmara, J.S.; Rocha, S.M. Profiling allergic asthma volatile metabolic patterns using a headspace-solid phase microextraction/gas chromatography based methodology. J. Chromatogr. A 2011; 1218, 3771-3780.

74. Phillips, M.; Basa-Dalay, V.; Blais, J.; Bothamley, G.; Chaturvedi, A.; Modi, K.D.; Pandya, M.; Natividad, M.P.; Patel, U.; Ramraje, N.N., et al. Point-of-care breath test for biomarkers of active pulmonary tuberculosis. Tuberculosis (Edinb.) 2012; 92, 314-320.

75. Broza, Y.Y.; Kremer, R.; Tisch, U.; Gevorkyan, A.; Shiban, A.; Best, L.A.; Haick, H. A nanomaterial-based breath test for short-term follow-up after lung tumor resection. Nanomed. 2013; 9, 15-21.

76. Fu, X.-A.; Li, M.; Knipp, R. J.; Nantz, M. H.; Bousamra, M., Noninvasive detection of lung cancer using exhaled breath. Cancer Medicine 2014; 3 (1), 174-181.

77. Zou Y, Zhang X, Chen X, Hu Y, Ying K and Wang P. Optimization of volatile markers of lung cancer to exclude interferences of non-malignant disease. Cancer biomarkers: section A of Disease markers. 2014; 14:371-379. 
78. Handa H, Usuba A, Maddula S, Baumbach JI, Mineshita M and Miyazawa T. Exhaled breath analysis for lung cancer detection using ion mobility spectrometry. PloS one. 2014; 9: e114555.

79. Li, M.X.et al., Breath carbonyl compounds as biomarkers of lung cancer, Lung Cancer 2015; 90(1), 92-97.

80. Fernandes M.P., Venkatesh S. and Sudarshan B.G., Early detection of lung cancer using nano-nose - A review, The Open Biomedical Engineering Journal 2015; 9, 228 233.

81. Bouza M., Gonzalez-Soto J., Pereiro R., de Vicente J.C., Sanz-Medel A. Exhaled breath and oral cavity VOCs as potential biomarkers in oral cancer patients. J Breath Res. 2017; Mar 1;11(1):016015.

82. Horvath I., Z. Lazar N., Gyulai, M., Kollai and Losonczy G.. Exhaled biomarkers in lung cancer. Eur. Respir. J. 2009; 34:261-275.

83. Phillips, M., N. Altorki, J. H. M. Austin, R. B. Cameron, R. N. Cataneo, R. Kloss, et al. Detection of lung cancer using weighted digital analysis of breath biomarkers. Clin. Chim. Acta 2008; 393:76-84.

84. Phillips M, Cataneo RN, Cummin AR, et al. Detection of lung cancer with volatile markers in the breath. Chest 2003; 123:2115-23.

85. Chen $\mathrm{X}, \mathrm{Xu} \mathrm{F}$, Wang Y, et al. A study of the volatile organic compounds exhaled by lung cancer cells in vitro for breath diagnosis. Cancer 2007; 110:835-44.

86. Wang Y, Hu Y, Wang D, et al. The analysis of volatile organic compounds biomarkers for lung cancer in exhaled breath, tissues and cell lines. Cancer Biomark 2012; 11:12937.

87. Phillips M, Altorki N, Austin JH, et al. Prediction of lung cancer using volatile biomarkers in breath. Cancer Biomark 2007; 3:95-109.

88. Spanel, P., and D. Smith. Volatile compounds in health and disease. Curr. Opin. Clin. Nutr. Metab. Care 2011; 14:455-460.

89. Song, G., T. Qin, H. Liu, G. B. Xu, Y. Y. Pan, F. X. Xiong, et al. Quantitative breath analysis of volatile organic compounds of lung cancer patients. Lung Cancer 2010; 67:227-231.

90. Schwarz, K., W. Filipiak, and A. Amann. Determining concentration patterns of volatile compounds in exhaled breath by PTR-MS. J. Breath Res. 2009; 3:027002.

91. Fu, X. A., M. Li, S. Biswas, M. H. Nantz, and R. M. Higashi. A novel microreactor approach for analysis of ketones and aldehydes in breath. Analyst 2011;136:46624666.

92. Li, M., S. Biswas, M. H. Nantz, R. M. Higashi, and X. A. Fu. Preconcentration and analysis of trace volatile carbonyl compounds. Anal. Chem. 2012; 84:1288-1293.

93. Badjagbo K., Moore S., Sauv é S. Real-time continuous monitoring methods for airborn VOCs. Trends Analyt Chem 2007; 26:931 - 40.

94. Pfeifer G.P., Denissenko M.F., Olivier M., Tretyakova N., Hecht S.S., Hainaut P. Tobacco smoke carcinogens. DNA damage and p53 mutations in smoking associated cancers. Oncogene 2002; 21:7435-51.

95. Scott Fogler H. etc. Elements of Chemical Reaction Engineering Third Edition.

96. Li L., Huang Weiqiu, Zhou Ning. Measured values and analysis of molecular diffusion coefficient of organic vapor-air. Chinese Journal of Environmental Engineering. Vol 11, NO.5; 2017. 
97. Miekisch W., Schubert J. K. and Noeldge-Schomburg G. F. E, Diagnostic potential of breath analysis-focus on volatile organic compounds Clin. Chim. Acta 2004; 347 $25-39$.

98. Aberle D.R., Adams A.M., Berg C.D., Black W.C., Clapp J.D., Fagerstrom R.M., Gareen I.F, Gatsonis C., Marcus P.M. and Sicks J.D., Reduced lung-cancer mortality with low-dose computed tomographic screening N. Engl. J. Med., 2011; 365 395409.

99. Yousaf-Khan U., Horeweg N., van der Aalst C., Ten Haaf K., Oudkerk M. and de Koning H., Baseline characteristics and mortality outcomes of control group participants and eligible non-responders in the NELSON lung cancer screening study J. Thorac. Oncol. 2015; 10 747-753.

100. Chan H.P., Lewis C. and Thomas P.S., Exhaled breath analysis: novel approach for early detection of lung cancer Lung Cancer 2009; 63 164-168.

101. Dragonieri S., Annema J.T, Schot R., van der Schee M.P., Spanevello A., Carratu P., Resta O., Rabe K.F. and Sterk P.J,An electronic nose in the discrimination of patients with non-small cell lung cancer and COPD Lung Cancer 2009; 64 166-170.

102. Phillips M., Altorki N., Austin J.H., Cameron R.B., Cataneo R.N., Greenberg J., Kloss R., Maxfield R.A, Munawar M.I and Pass H.I, Prediction of lung cancer using volatile biomarkers in breath Cancer Biomarker 2007; 3 95-109.

103. Phillips M., Altorki N., Austin J.H., Cameron R.B, Cataneo R.N, Kloss R., Maxfield R.A, Munawar M.I, Pass H.I, Rashid A., Rom W.N., Schmitt P. and Wai J., Detection of lung cancer using weighted digital analysis of breath biomarkers Clin. Chim. Acta 2008; 393 76-84.

104. Wehinger A., Schmid A., Mechtcheriakov S., Ledochowski M., Grabmer C., Gastl G. and Amann A. Lung cancer detection by proton transfer reaction mass spectrometric analysis of human breath gas Int. J. Mass Spec. 2007; 265 49-59.

105. Buszewski B., Kesy M., Ligor T. and Amann, A Human exhaled air analytics: biomarkers of diseases Biomed. Chromatogr. 2007; 21 553-566.

106. Pauling L., Quantitative analysis of urine vapor and breath by gas-liquid partition chromatography Proc. Natl. Acad. Sci. USA 1971; 68 2374-2376.

107. Phillips M., Breath tests in medicine Sci. Am. 1992; 267 74-79.

108. Gordon S.M and O'Neill H.J, Volatile organic compounds in exhaled air from patients with lung cancer Clin. Chem. 1985; 31 1278-1282.

109. Amann A., Costello Bde L., Miekisch W., Schubert J., Buszewski B., Pleil J., Ratcliffe N. and Risby T., The human volatile: volatile organic compounds (VOCs) in exhaled breath, skin emanantions, urine, feces and saliva J. Breath Res. 2014; 8 034001 .

110. Hakim M., Broza Y.Y, Barash O., Peled N., Phillips M., Amann A. and Haick H., Volatile organic compounds of lung cancer and possible biochemical pathways Chem. Rev. 2012; 112 5949-5966.

111. Dent A., Sutedja T.G, Zimmerman P.V, Exhaled breath analysis for lung cancer. $J$. Thorac Dis. 2013; 5 ,540-550.

112. Amann A., Corradi M., Mazzone P., Mutti. A Lung cancer biomarkers in exhaled breath. Expert Rev. Mol. Diag. 2011; 11 201-217;

113. Arthur C.L and Pawliszyn J., Solid-phase microextraction with thermal desorption using fused-silica optical fibers. Anal. Chem. 1990; 62 2145-8. 
114. Grote C. and Pawliszyn J., Solid-phase microextraction for the analysis of human breath Anal. Chem. 1997; 69 587-596.

115. Poli D., Goldoni M., Corradi M., Acampa O., Carbognani P., Internullo E., Casalini A. and Mutti. A Determination of aldehydes in exhaled breath of patients with lung cancer by means of on-fiber-derivatisation SPME-GC/MS J. Chromatogr. 2010; B $8782643-51$.

116. Fuchs P., Loeseken C., Schubert J.K and Miekisch W. Breath gas aldehydes as biomarkers of lung cancer Int. J. Cancer 2010;126 2663-70.

117. Liu H., Wang H., Li C., Wang L., Pan Z., Wang L. Investigation of volatile organic metabolites in lung cancer pleural effusions by solid-phase microextraction and gas chromatography/mass spectrometry J Chromatogr B 2014; 945 53-59.

118. Phillips M. Method for the collection and assay of volatile organic compounds in breath Anal. Biochem. 1996; 247 272-8.

119. Phillips M., Boehmer J.P., Cataneo R.N., Cheema T., Eisen H.J, Fallon J.T, Fisher P.E, Gass A., Greenberg .J, Kobashigawa J., Mancini D., Rayburn B. and Zucker M. Prediction of heart transplant rejection with a breath test for markers of oxidative stress Am. J. Cardiol. 2004 ;94 1593-4 .

120. Wehinger A., Schmid A., Mechtcheriakov S., Ledochowski M., Grabmer C., Gastl G.A, Amman A. Lung cancer detection by proton transfer reaction mass-spectrometric analysis of human breath gas Int. J. Mass Spectrom. 2007; 26549 - 59.

121. Wahl H.G, Hoffmann A., Haring H.U and Liebich H.M. Identification of plasticizers in medical products by a combined direct thermodesorption-cooled injection system and chromatography-mass spectrometry J. Chromatogr. A 1999; 847 $1-7$.

122. Spanel P., Smith D. Progress in SIFT-MS: breath analysis and other applications, Mass Spectrom. Rev. $2011 ; 30$ 236-267.

123. Biasioli F., Yeretzian C., Märk T.D, Dewulf J. and Van Langenhove H. Directinjection mass spectrometry adds the time dimension to VOC analysis Trends Anal. Chem. 2011; $301003-17$.

124. Peng G., Tisch U., Adams O., Hakim M., Shehada N., Broza Y.Y, Billan S., AbdahBortnyak R., Kuten A. and Haick H. Diagnosing lung cancer in exhaled breath using gold nanoparticles Nature Nanotech 2009 ;4 669-673.

125. Sulyok M., Haberhauer-Troyer C., Rosenberg E. and Grasserbauer M. Investigation of the storage stability of selected volatile sulfur compounds in different sampling containers J. Chromatogr. A 2001 ;917 367-74.

126. Groves W.A and Zellers E.T, Investigation of organic vapor losses to condensed water vapor in Tedlar bags used for exhaled-breath sampling Am. Ind. Hyg. Assoc. J. $1996 ; 57$ 257-63.

127. Mochalski P., King J., Unterkofler K. and Amann A. Stability of selected volatile breath constituents in Tedlar, Kynar and Flexfilm sampling bags Analyst 2013 ;138 $1405-18$.

128. Van Harreveld A.P, Odor concentration decay and stability in gas sampling bags $J$. Air Waste Manag. Assoc. 2003 ;53 51-60.

129. Steeghs M.M, Cristescu S.M and Harren F.J. The suitability of Tedlar bags for breath sampling in medical diagnostic research Physiol. Meas. 2007 ;28 73-84. 
130. Beauchamp J., Herbig J., Gutmann R. and Hansel A. On the use of Tedlar bags for breath-gas sampling and analysis J. Breath Res. 2008 ;2 046001.

131. Harshman S.W, Mani N., Geier B.A, Kwak J., Shepard P., Fan M., Sudberry G., Mayes R.S, Ott D.K, Martin J.A and Grigsby C.C, Storage stability of exhaled breath on Tenax A J. Breath Res. 2016 ;10 046008.

132. Kang S., Thomas C. L, How long may a breath sample be stored for at $-80{ }^{\circ} \mathrm{C}$ a study of the stability of volatile organic compounds trapped on a mixed Tenax: carbograph trap adsorbent bed from exhaled breath J. Breath Res. $2016 ; 10026011$.

133. Bajtarevic A., Ager C., Pienz M., Klieber M., Schwarz K., Ligor M., Ligor T., Filipiak W., Denz H., Fiegl M., Hilbe W., Weiss W., Lukas P., Jamnig H., Hackl M., Haidenberger A., Buszewski B., Miekisch W., Schubert J. and Amann A. Noninvasive detection of lung cancer by analysis of exhaled breath BMC Cancer 2009 ;9 348-363.

134. Turner C., Spanel P. and SmithD., A longitudinal study of methanol in the exhaled breath of 30 healthy volunteers using selected ion flow tube mass spectrometry, SIFTMS Physiol. Meas. 2006 ;27 637-48.

135. Bousamra M., Schumer E., Li M., Knipp R.J, Nantz M.H, Van Berkel V. and Fu X A. Quantitative analysis of exhaled carbonyl compounds distinguishes benign from malignant pulmonary disease, J. Thorac. Cardiovasc. Surg. $2014 ; 148$ 1074-1081 .

136. Li M., Yang D.K, Brock G., Nantz M., Bousamra M. and Fu X.A. Breath Carbonyl Compounds as Biomarkers of Lung Cancer Lung Cancer 2015 ;90 92-97.

137. Biswas S., Huang X., Badger W., Nantz M.H. Nucleophilic cationization reagents Tetrahedron Lett. $2010 ; 51$ 1727-1729.

138. Davies S., Spanel P. and Smith D. A new 'online' method to measure increased exhaled isoprene in end-stage renal failure Nephrol. Dial. Transpl. 2001 ; 16 836-9.

139. Li M., Biswas S., Nantz M.H, Higashi R.M, Fu X.A. A Microfabricated Preconcentration Device for Breath Analysis Sens Actu. 2013 ;180 130-136.

140. Basanta M. et al. Non-invasive metabolomic analysis of breath using differential mobility spectrometry in patients with chronic obstructive pulmonary disease and healthy smokers Analyst $2010 ; 135$ 315-20.

141. Beasley MB, Brambilla E, Travis WD. The 2004 World Health Organization classification of lung tumors. Semin Roentgenol. Apr 2005;40(2):90-97.

142. Jemal A, Siegel R, Xu J, Ward E. Cancer statistics, 2010. CA Cancer J Clin. SepOct 2010;60(5):277-300.

143. Aberle D.R, Adams A.M, Berg C.D, Black W.C, Clapp J.D, Fagerstrom R.M, Gareen I.F, Gatsonis C., Marcus P.M and Sicks J.D. Reduced lung-cancer mortality with low-dose computed tomographic screening N. Engl. J. Med. 2010 ;365 395-409.

144. Church T.R et al. Results of initial low-dose computed tomographic screening for lung cancer N. Engl. J. Med. 2013; 368 1980-91.

145. Van't Westeinde S.C and van Klaveren R.J. Screening and early detection of lung cancer Cancer J. 2011; 17 3-10.

146. Field J.K, van Klaveren R., Pedersen J.H, Pastorino U., Paci E., Becker N., Infante M., Oudkerk M. and de Koning H.J. European randomized lung cancer screening trials: post NLST J. Surg. Oncol. 2013; 108 280-6.

147. Van Klaveren R.J et al. Management of lung nodules detected by volume CT scanning N. Engl. J. Med. 2009; 361 2221-9. 
148. Xiang D., Zhang B., Doll D., Shen K., Kloecker G. and Freter C. Lung cancer screening: from imaging to biomarker Biomark. 2013; Res. 14.

149. Ferlay J., Steliarova-Foucher E., Lortet-Tieulent J., Rosso S., Coebergh J.W, Comber H., Forman D. and Bray F. Cancer incidence and mortality patterns in Europe: estimates for 40 countries in 2012 Eur. J. Cancer 2013; 49 1374-403.

150. Swensen S.J, Jett J.R, Hartman T.E, Midthun D.E, Mandrekar S.J, Hillman S.L, Sykes A.M, Aughenbaugh G.L, Bungum A.O and Allen K.L. CT screening for lung cancer: five-year prospective experience Radiology 2005; 235 259-65.

151. Lechner M., Moser B., Niederseer D., et al. Gender and age specific differences in exhaled 2-methyl-1, 3-butadiene levels. Respir Physiol Neurobiol 2006;154:478-83

152. Zayasu KKS, Okinage S, Yamaya M, Ohrui T, Sasaki H. Increased carbon monoxide in exhaled air of asthmatic patients. Am J Respir Crit Care Med. 1997; 156:1140-1143.

153. Louhelainen N., Myllärniemi M., Rahman I., Kinnula V.L. Airway biomarkers of the oxidant burden in asthma and chronic obstructive pulmonary disease: Current and future perspectives. International Journal of COPD. 2008;3(4):585.

154. Tonini, G.; D'Onofrio, L.; Dell'Aquila, E.; Pezzuto, A. New molecular insights in tobacco-induced lung cancer. Future Oncol. 2013; 9, 649-655.

155. Cornfield, J.; Haenszel,W.; Hammond, E.C.; Lilienfeld, A.M.; Shimkin,M.B.;Wynder, E.L. Smoking and lung cancer: Recent evidence and a discussion of some questions. Int. J. Epidemiol. 2009;38, 1175-1191.

156. Hecht, S.S. Cigarette smoking and lung cancer: Chemical mechanisms and approaches to prevention. Lancet Oncol. 2002;3, 461-469.

157. Beane, J.; Sebastiani, P.; Liu, G.; Brody, J.S.; Lenburg,M.E.; Spira, A. Reversible and permanent effects of tobacco smoke exposure on airway epithelial gene expression. Genome Biol. 2007; 8, R201.

158. Wedzicha J.A. and Seemungal T.A. COPDexacerbations: defining their cause and prevention Lancet 2007; 370 786-96.

159. Vogelmeier C.F. et al 2017 Global strategy for the diagnosis, management, and prevention of chronic obstructive lung disease Report.GOLDexecutive summary Am. J. Respir. Crit. Care Med. 2017; 195 557-82.

160. Hurst J.R et al. Susceptibility to exacerbation in chronic obstructive pulmonary disease N. Engl. J. Med. 2010; 363 1128-38.

161. Wood L.G, Gibson P.G, Garg M.L. Biomarkers of lipid peroxidation, airway inflammation and asthma. Eur Respir J. 2003; 21:177-186.

162. Puckett J.L, George S.C. Partitioned exhaled nitric oxide to non-invasively assess asthma. Respiratory Physiology \& Neurobiology. 2008; 163:166-177.

163. Dragonieri S., Annema J.T, Schot R., Schee M.P van der, Spanevello A., Carratu P., Resta O., Rabe K.F, Sterk P.J: An electronic nose in the discrimination of patients with non-small cell lung cancer and COPD. Lung Cancer 2009; 64(2):166-170. 
164. Di Natale C., Macagnano A., Martinelli E., Paolesse R., D'Arcangelo G., Roscioni C., Finazzi-Agro A., D'Amico A.: Lung cancer identification by the analysis of breath by means of an array of nonselective gas sensors. Biosens Bioelectron 2003; 18(10):1209-1218.

165. Wehinger A., Schmid A., Mechtcheriakov S., Ledochowski M., Grabmer C., Gastl G., Amann A: Lung cancer detection by proton transfer reaction mass spectrometric analysis of human breath gas. Int J Mass Spec 2007; 265:49-59.

166. Ligor T, Ligor M, Amann A, Ager C, Bachler M, Dzien A, Buszewski B: The analysis of healthy volunteers' exhaled breath by the use of solid-phase microextraction and GC-MS. J Breath Research 2008; 2:046006.

167. Ligor M, Ligor T, Bajtarevic A, Ager C, Pienz M, Klieber M, Denz H, Fiegl M, Hilbe W, Weiss W, et al.: Determination of volatile organic compounds appearing in exhaled breath of lung cancer patients by solid phase microextraction and gas chromatography mass spectrometry. Clin Chem Lab Med 2009; 47:550-560.

168. Erhart S, Amann A, Karall D, Edlinger G, Haberlandt E, Schmid A, Filipiak W, Mochalski P, Rostasy K, Scholl-Bürgi S: 3-Heptanone as a potential new marker for valproic acid therapy. J Breath Res 2009; 3:016004.

169. Pabst F, Miekisch W, Fuchs P, Kischkel S, Schubert JK: Monitoring of oxidative and metabolic stress during cardiac surgery by means of breath biomarkers: an observational study. J Cardiothorac Surg 2007; 2:37.

170. Karl T, Prazeller P, Mayr D, Jordan A, Rieder J, Fall R, Lindinger W: Human breath isoprene and its relation to blood cholesterol levels: new measurements and modeling. J Appl Physiol 2001; 91(2):762-770.

171. King J, Kupferthaler A, Unterkofler K, Koc H, Teschl S, Miekisch W, Schubert J, Hitnerhuber H, Amann A: Isoprene and acetone concentration profiles during exercise at an ergometer. J Breath Res 2009; s3:027006.

172. Chen X, Xu F, Wang Y, Pan Y, Lu D, Wang P, Ying K, Chen E, Zhang W: A study of the volatile organic compounds exhaled by lung cancer cells in vitro for breath diagnosis. Cancer 2007; 110(4):835-844.

173. Horvath I., Lazar Z., Gyulai N., Kollai M., Losonczy G., Exhaled biomarkers inlung cancer, Eur. Respir. 2009; J. 34: 261-275.

174. Wang C., Dong R., Wang X., Lian A., Chi C., Ke C., et al., Exhaled volatile organiccompounds as lung cancer biomarkers during one-lung ventilation, Sci. Rep.2014; 4, 7312.

175. Phillips M., Gleeson K., Hughes J.M.B., Greenberg J., Cataneo R.N., L. Baker,et al., Volatile organic compounds in breath as markers of lung cancer: across-sectional study, Lancet 1999; 353,1930-1933.

176. Mazzone P.J., Exhaled breath volatile organic compound biomarkers in lungcancer, J. Breath Res. 2012; 6, 027106.

177. Hatfield J., Neaves P., Hicks P., Persaud K., Travers P., towards an integratedelectronic nose using conducting polymer sensors, Sens. Actuators B 1994; $18,221-228$. 


\section{CURRICULUM VITAE}

NAME: $\quad$ Qi Li

ADDRESS: $\quad 1936$ Goldsmith Ln. Apt. 6

Louisville, KY, 40218

EDUCATION: $\quad$ University of Louisville, Louisville, KY

Doctor of Philosophy in Chemical Engineering 2013-2018

Tianjin University of Science \& Technology, Tianjin, China Bachelor of Science in Chemical Engineering 2009-2013

EXPERIMENTAL

SKIILS:

Microfabrication: Mask design and write, Photolithography, Front and back optical alignment, Wet etching, RIE, DRIE, Ebeam evaporator, PECVD, ALD, Sputtering, Oxidation, Diffusion, Anodic bonding.

Metrology: XRD, AFM, STM, Dektak surface profilermeter, Thin film stress measurement, Raman spectrum, SEM.

Chemical Analysis Techniques: GC-MS, FTICR-MS, DSC, UHPLC-MS.

Statistics Software: Matlab, MathCAD, Maple, Minitab.

Modeling \& Design Software: CoventorWare, L-edit.

PUBLICATIONS: $\quad$ Mingxiao Li, Qi Li, Michael H. Nantz and Xiao-An Fu. "Analysis of carbonyl Compounds in Ambient Air by a Microreactor Approach", ACS Omega, 2018, 3(6), 6764-6769.

Qi Li, Zhenzhen Xie and Xiao-An Fu, "Stability of Breath Volatile Organic Compounds in Tedlar Bags”, Journal of Breath Research. (Revision) 
Yizheng Chen, Qi Li, Zhenzhen Xie and Xaio-An Fu, "Characterization of DNPH-coated microreactor chip for analysis of trace carbonyls with application for breath analysis", Journal of Chromatography B. (Submitted)

Qi Li, Zhenzhen Xie and Xiao-An Fu, "Characterization and Optimization of Fabricated Microreactor Device Applied in Breath Analysis”. (In Preparation) 